NBSIR 81-2374

\title{
Investigation of Construction Failure of Harbour Cay Condominium in Cocoa Beach, Florida
}

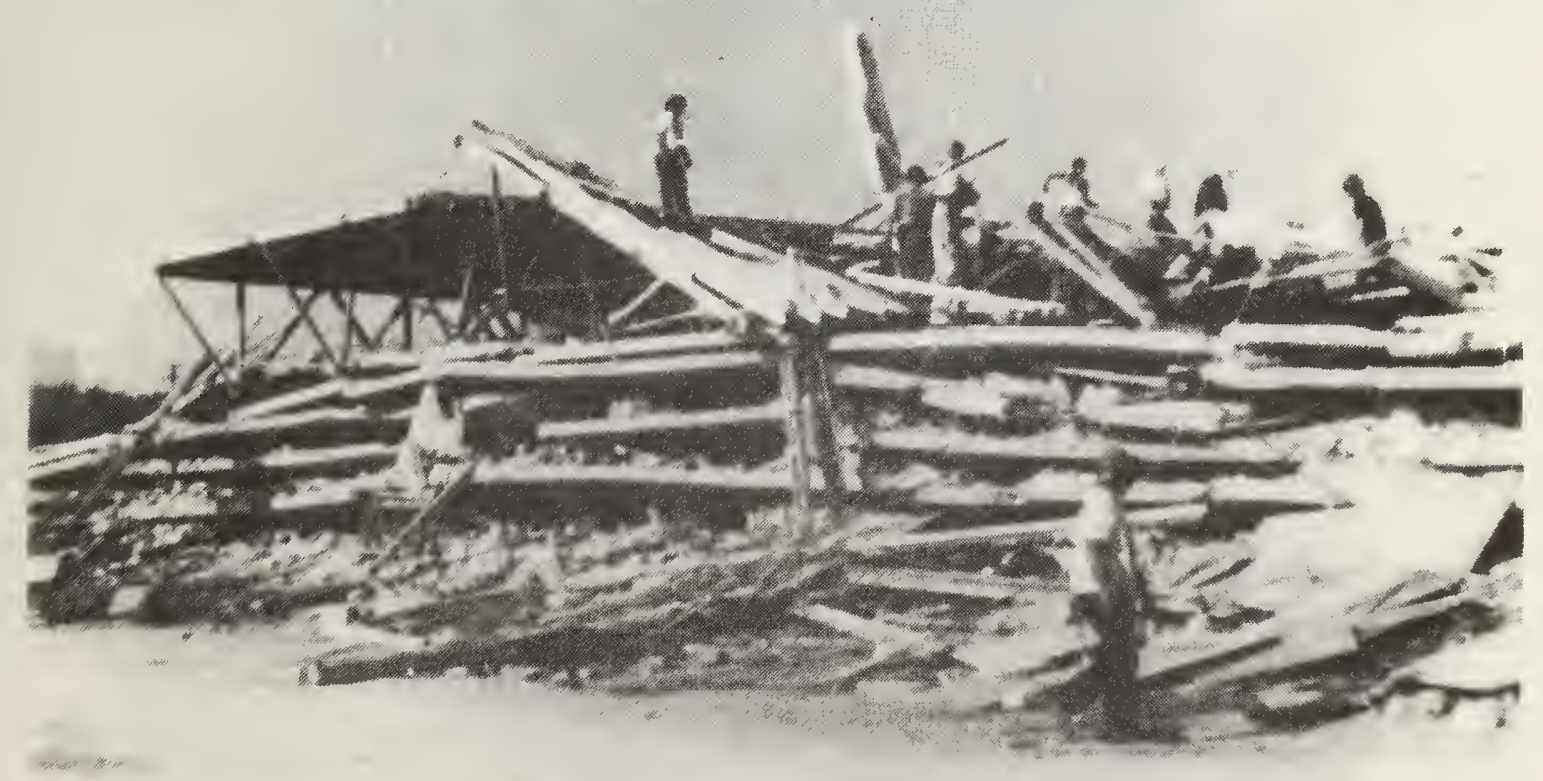

U.S. DEPARTMENT OF COMMERCE

National Bureau of Standards

National Engineering Laboratory

Center for Building Technology

Washington, DC 20234

September 1981

Sponsored by

:upational Safety and Health Administration

Q QC Department of Labor

100 shington, DC 20001

.456

$81-2374$

1981

c. 2 



\section{INVESTIGATION OF CONSTRUCTION FAILURE OF HARBOUR CAY CONDOMINIUM IN COCOA BEACH, FLORIDA}
$S$.
H. W. Lew
N. J. Carino
S. G. Fattal
M. E. Batts

U.S. DEPARTMENT OF COMMERCE

National Bureau of Standards

National Engineering Laboratory

Center for Building Technology

Washington, DC 20234

September 1981

Sponsored by

Occupational Safety and Health Administration

U.S. Department of Labor

Washington, DC 20001

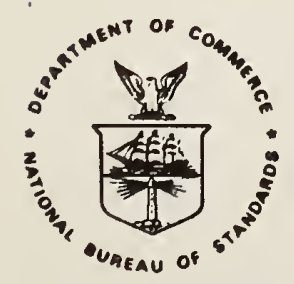

U.S. DEPARTMENT OF COMMERCE, Malcolm Baldrige, Secretary NATIONAL BUREAU OF STANDARDS, Ernest Ambler, Director 



\section{ABSTRACT}

The investigation of the collapse of a five-story reinforced concrete flatplate structure under construction at Cocoa Beach, Florida is presented in this report. The investigation included onsite inspection, laboratory tests and analytical studies.

Based on the results of this investigation, it is concluded that the most probable cause of the failure was insufficient punching shear capacity in the fifth-floor slab to resist the applied construction loads.

Two factors contributed to the low punching shear capacity: one in the design and the other in the construction of the building. In the design, the omission of a check for punching shear resulted in a smaller slab thickness than needed to satisfy the code requirements. In construction, the use of specified chairs having insufficient height to support the top reinforcing steel resulted in more than the cover specifled in the structural drawings. Both factors contributed to reducing the effective depth of the slab such that it had insufficient strength to resist the construction loads.

The analysis showed that shear stresses in the slab at many column locations on the fifth floor exceeded the nominal shear strength. Thus, punching shear failure at one of the columns precipitated a progressive fallure of the slab throughout the entire fifth floor. Collapse of the fifth floor, in turn, caused the successive collapse of the lower floor slabs. The analysis of the structure indicated that the failure of the fifth floor slab most likely initiated at column G-2, an interior column which supported the last bay of freshly placed concrete prior to the collapse.

Key Words: Building; collapse; concrete; concrete strength; construction; fallure; flat plate; shear; strength. 


\section{PREFACE}

An investigation of the construction fallure of a five-story reinforced concrete building (Harbour Cay Condominium) at Cocoa Beach, Florida on March 27, 1981 was carried out by the National Bureau of Standards (NBS) at the request of the Occupational Safety and Health Administration (OSHA), Department of Labor. This investigation was conducted pursuant to an interagency agreement between OSHA and NBS.

The NBS investigation team consisted of H. S. Lew, S. G. Fattal, N. J. Carino, and M. E. Batts. Throughout the course of this investigation, the team received full cooperation from the OSHA regional and area officers. Assistance provided by Mr. William P. Demery, Tampa Area Director and his staff is gratefully acknowledged by the NBS team. Without their help, it would not have been possible to obtain the data needed to carry out this investigation. 
The Harbour Cay Condominium, a five-story flat-plate reinforced concrete building, was under construction at Cocoa Beach, Florida. Shortly after 3:00 p.m., March 27, 1981, during the placement of concrete for the roof slab, the entire structure collapsed. As a result, 11 workers died, and another 23 were injured.

The structure had an overall length of $242 \mathrm{ft}(74 \mathrm{~m})$ and a width of $58 \mathrm{ft}(18 \mathrm{~m})$. The slab concrete was placed on flying forms, consisting of preassembled plywood decks supported by aluminum trusses. Except for the roof, which was planned to be cast in one day, the floor slabs were cast in two separate operations, each covering one-half of the total floor area. At the time of the collapse, concrete had been placed on seven of the nine flying forms comprising the entire roof area.

During the course of the investigation two site visits were made. The first site visit was made on March 28-30, 1981, one day after the collapse, and the second visit was made on April 7-8, 1981. During the visits, structural components were examined visually and photographic documents were made as the components were removed for rescue operations, selected key components were identified and marked with paint for testing laboratory personnel to secure test samples, and measurements of member dimensions were made. In addition, construction and other documents were obtained through the OSHA area office in Tampa.

At the time of collapse, the flying forms were placed on the fifth floor to receive concrete for the entire roof slab. The exact number and locations of reshores at various floors are not certain. The first story appears to have had only a few exterior reshores in place, and the fourth story probably had the full number of reshores according to the reshoring plan supplied by the general contractor after the collapse. Conflicting statements were given by workers as to the number and locations of reshores on the second and third stories. For the purpose of analysis, it was assumed that both the second and third stories had the full number of reshores.

The concrete used for the structure was supplied by both the onsite batch plant and a ready-mix plant. Approximately $1 / 3$ of the concrete used for the floor slabs was supplied by the ready-mix plant. The remainder was supplied by the onsite batch plant. The concrete produced by the onsite batch plant was reported to have been nonuniform in consistency and finishability.

Core samples were taken from slab and column sections which were identified during the first field visit to the site. Tests of these cores were made by an independent testing laboratory which was retained by OSHA. The compressive strengths of cores taken from slab sections satisfied the American Concrete Institute 318 Standard (ACI Code) strength criteria for the specified strength of 4000 psi (27.6 MPa). The compressive strength of cores taken from column sections were lower than the strengths of slab cores, and the average strength of the cores from the fifth floor columns did not satisfy the ACI criteria for the specified strength. 
Samples of ingredients used for the concretes produced by the onsite batch plant and the ready-mix plant were obtained from the site. They were subjected to chemical and physical analyses and used by NBS to make concrete mixtures representative of what was used in the structure. The purpose of the NBS laboratory investigation was to establish the strength of the concrete at the time of collapse. Based on the laboratory mixes and local temperature data at the site, the estimated compressive strengths of concrete at the time of collapse were 4000 psi (276 MPa) for the south half and $3700 \mathrm{psi}(255 \mathrm{MPa}$ ) for the north half of the fifth floor slab.

The analysis of the structure subjected to the construction loads was made with the ICES-STRUDL-II* finite element program. The finite element model analyzed incorporated both the structure, which is discretized by rectangular plate bending elements, and the formwork system. In determining the loading conditions for analysis, the effect of construction load distribution between the structure and the formwork was considered along with the effects of sequential removal of flying forms. The results of the analysis show that maximum moments and shears in the slab occur on the fifth floor. Combinations of shears and moments which would produce critical conditions occurred at columns B-2 and G-2. Description of the collapse by workers on the site indicate that the most probable origin of the collapse was the fifth floor slab in the vicinity just below where the roof concrete was being placed, which supports the critical nature of column G2.

The construction documents and field measurements revealed that the top layers of reinforcing bars in the column strips were supported by individual high chairs which produced concrete cover of $13 / 4$ in $(44 \mathrm{~mm}$ ) instead of $3 / 4$ in (19 $\mathrm{mm}$ ) as specified in the structural drawings. This discrepancy resulted in the reduction of the effective depth of the slab which had direct effect on the shear resisting capacity of the slab.

The chair heights were in conformance with the steel supplier's shop drawings, which specified the number and sizes of individual high chairs required for each floor. The record copies of these drawings show numerous check marks. One of the six pages bore the handwritten words "approved as noted" and the signature of the design engineer of record.

Using the moments and shears obtained from the finite element analysis, punching shear stresses resulting from direct shear forces and unbalanced moments were computed at slab-column connections. These shear stress values are compared with the shear capacity of the slab based on the predicted inplace strength of concrete at the time of collapse. The computed beam-type shear stress under construction loading is considerably less than the beam shear strength of the slab. On the other hand, the computed punching shear stresses at many column locations in the fifth floor exceeded the nominal punching shear capacity of the slab. Based on the probablistic nature of the shear strength, it is reasoned that the collapse was most likely initiated due to punching shear failure at column $\mathrm{G}-2$.

* A general purpose structural analysis program, see chapter 5 and ref. 5.5 for further details. 
It is shown that high punching shear stresses resulted from use of reduced height Individual high chairs to support the top reinforcing bars in the column strip, thereby reducing the effective depth of the slab. The omission of a check for punching shear capacity in the design calculations resulted in a slab thickness of 8 in $(203 \mathrm{~mm})$. The ACI Code would have required a thickness of 11 in $(279 \mathrm{~mm})$ to provide adequate safety against punching shear under design loads. It is shown that this design deficiency resulted in a reduction of the margin of safety such that the slab had insufficient reserve strength to accommodate construction errors.

It is concluded that two factors contributed to the collapse: one in the design and the other in the construction of the building. In design, a check for punching shear was omitted. In construction, the specified chairs used to support the top reinforcing steel provided more than the cover called for in the structural drawings. The analysis showed that the shear stresses at many column locations in the fifth floor exceeded the nominal shear strength. Once punching shear failure had initiated at column G-2, it propagated throughout the slab causing the total collapse of the fifth floor, which, in turn, caused the successive collapse of the lower floor slabs. 


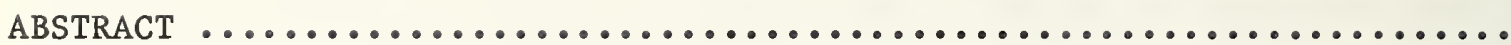

PREFACE .................................................

1. INTRODUCTION $\ldots \ldots \ldots \ldots \ldots \ldots \ldots \ldots \ldots \ldots \ldots \ldots \ldots \ldots \ldots \ldots \ldots \ldots \ldots \ldots \ldots \ldots \ldots$

1.1 Background $\ldots \ldots \ldots \ldots \ldots \ldots \ldots \ldots \ldots \ldots \ldots \ldots \ldots \ldots \ldots \ldots \ldots \ldots \ldots \ldots \ldots$

1.2 objective and Scope of the Investigation $\ldots \ldots \ldots \ldots \ldots \ldots \ldots \ldots \ldots$

1.3 Organization of the Report ........................... I

2. DESCRIPTION OF THE STRUCTURE AND THE COLLAPSE ................ 3

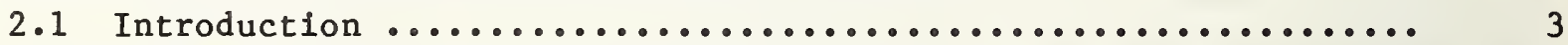

2.2 Documents Supplied by OSHA Field Office $\ldots \ldots \ldots \ldots \ldots \ldots \ldots \ldots \ldots$

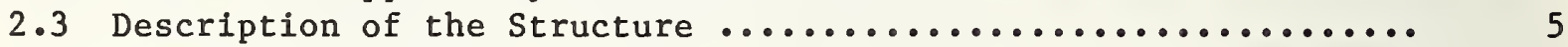

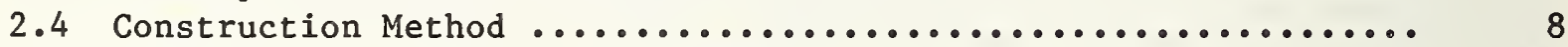

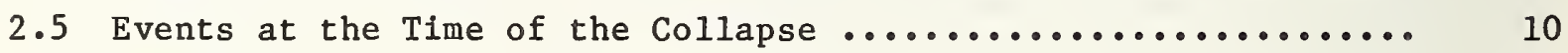

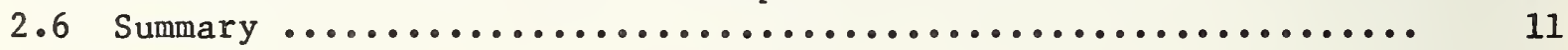

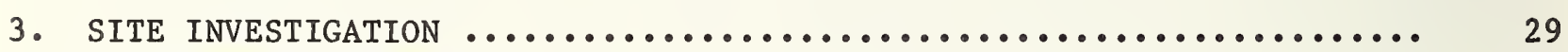

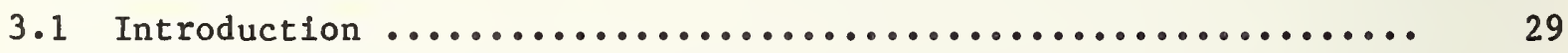

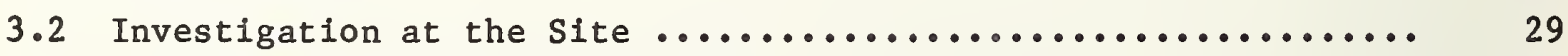

3.3 Interview Statements of Workers $\ldots \ldots \ldots \ldots \ldots \ldots \ldots \ldots \ldots \ldots \ldots \ldots \ldots . \ldots \ldots$

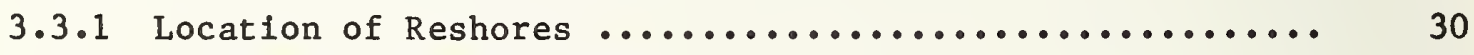

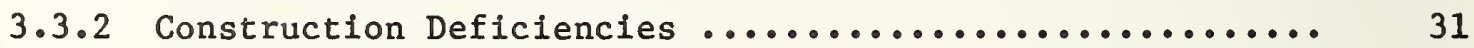

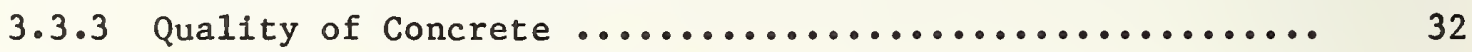

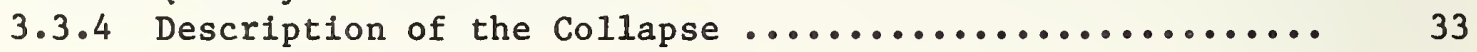

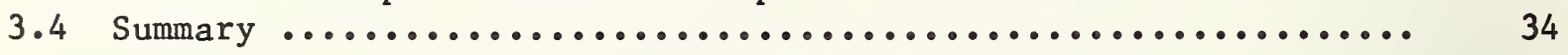

4. LABORATORY INVESTIGATIONS ............................. 39

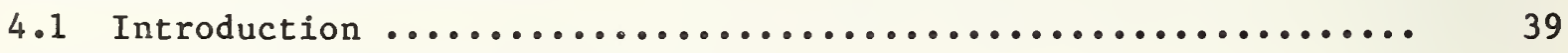

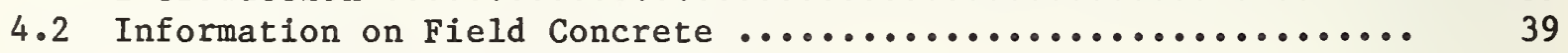

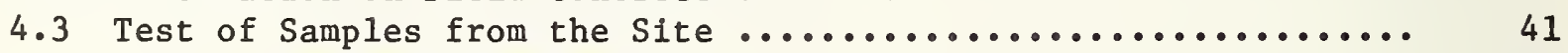

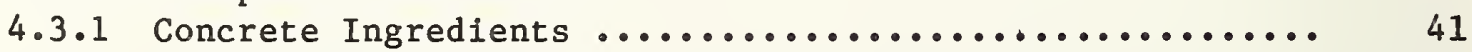

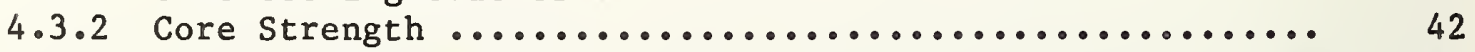

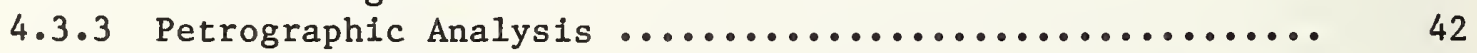

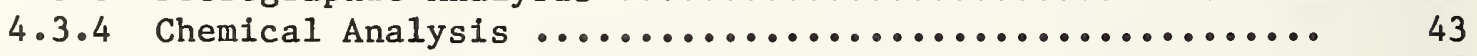

4.4 NBS Laboratory Investigation $\ldots \ldots \ldots \ldots \ldots \ldots \ldots \ldots \ldots \ldots \ldots \ldots \ldots \ldots \ldots . \ldots \ldots \ldots$

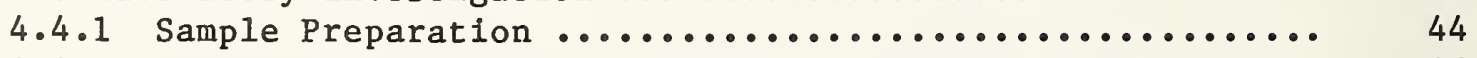

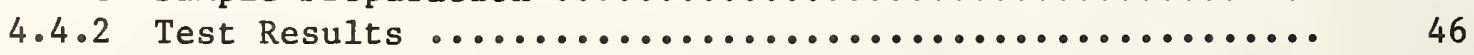

4.4.3 Estimated Strength of Concrete at Time of the Collapse - 47

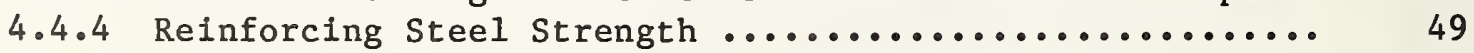

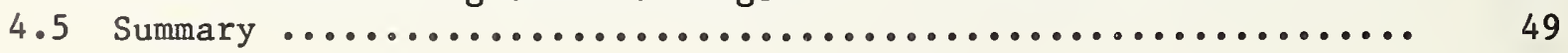

5. STRUCTURAL ANALYSIS ................................ 71

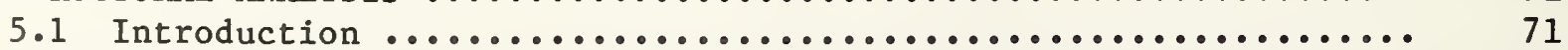

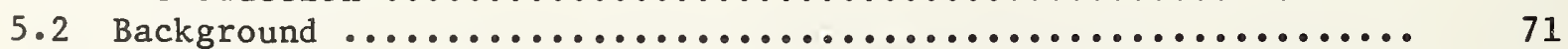

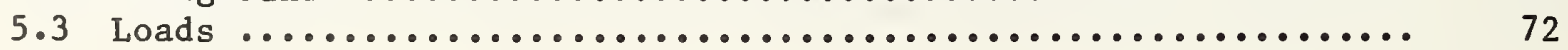




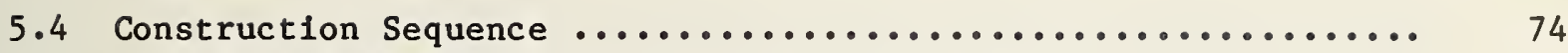

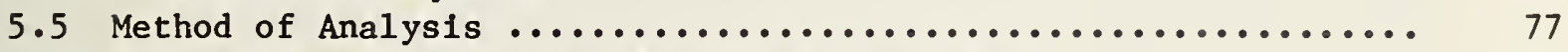

5.6 Finite Element Analysis of Entire Structure .............. 79

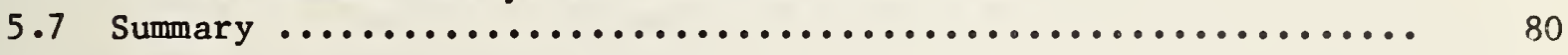

6. INTERPRETATION OF ANALYSIS $\ldots \ldots \ldots \ldots \ldots \ldots \ldots \ldots \ldots \ldots \ldots \ldots \ldots \ldots \ldots \ldots \ldots . \ldots \ldots$

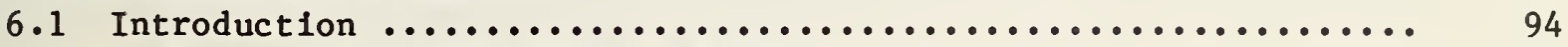

6.2 Analysis of Shear Fallure of $s l a b \ldots \ldots \ldots \ldots \ldots \ldots \ldots \ldots \ldots \ldots . \ldots \ldots$

6.3 Influence of Effective Depth of Slab on Shear Capacity ...... 96

6.4 Probable Mode of Failure .......................... 98

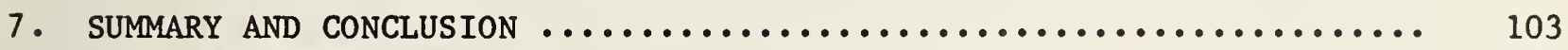

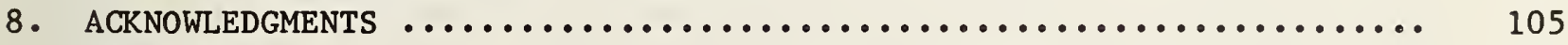

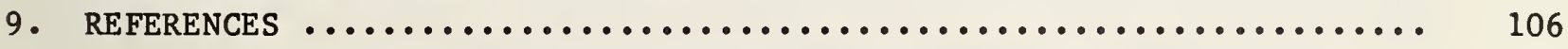

APPENDIX A. RESULTS OF TESTS ON SAMPLES FROM THE SITE ............ A-1 



\section{INTRODUCTION}

\subsection{BACKGROUND}

The Harbour Cay Condominium, a five-story flat-plate reinforced concrete building, was under construction at Cocoa Beach, Florida. Shortly after 3:00 p.m., March 27, 1981, during the placement of concrete for the roof slab, the entire structure collapsed vertically with each floor slab breaking away from the columns and landing on the ground floor. As a result, 11 workers who were performing duties at various levels of the building died, and another 23 were injured.

The structure had an overall length of $242 \mathrm{ft}(74 \mathrm{~m})$, a width of $58 \mathrm{ft}(18 \mathrm{~m})$ and contained nine bays. The slab concrete was placed on flying forms, consisting of preassembled plywood decks supported by aluminum trusses. The construction system is described in detail in chapter 2. Except for the roof, which was planned to be cast in one day, the floor slabs were cast in two separate operations, each covering one-half of the total floor area. At the time of the collapse, concrete had been placed on seven of the nine flying forms comprising the entire roof area.

Within one hour of the collapse, an inspection team from the Occupational Safety and Health Administration (OSHA), Department of Labor, arrived at the site and began an investigation of the collapse. A team from the National Bureau of Standards (NBS) joined the OSHA team one day later on March 28, 1981.

\subsection{OBJECTIVE AND SCOPE OF THE INVESTIGATION}

The National Bureau of Standards was requested to assist with the field investigation being conducted by the Occupational Safety and Health Administration at the site of the collapse and to carry out a detailed study to determine the most probable cause of the collapse.

In response to this request, NBS carried out field, laboratory, and analytical studies. The NBS investigators used data obtained from onsite inspections, OSHA case records, and other related documents such as the engineering calculations, specifications, and drawings showing details of the building construction.

\subsection{ORGANIZATION OF THE REPORT}

This report is organized in nine chapters:

Chapter 2 presents the description of the structure based on the contract drawings and the specifications and lists the various documents furnished by OSHA. In addition, it describes the method and sequence of construction of the structure, its appearance, and conditions before and after the collapse. 
Chapter 3 presents observations made and information obtained from the field investigations. It summarizes the statements made by those interviewed by OSHA officials.

Chapter 4 presents the results of concrete tests which were used to determine the strength and stiffness of the structure at the time of failure. The test results of the reinforcing steel obtained from the site are also presented.

Chapter 5 describes the rationale for defining the loads which were acting on the structure at the time of the collapse. It also presents the analytical approach used in the investigation of the structure and the results of the analysis.

Chapter 6 examines the results of the analysis of the structure, compares them with the capacity of the structure, and presents the most probable cause and mode of failure.

Chapter 7 summarizes the findings of the investigation and presents its conclusions.

Chapter 8 acknowledges those individuals, who made contributions to the various phases of the investigation and to the preparation of this report.

Chapter 9 lists the references cited in the text. 


\subsection{INTRODUCTION}

This chapter describes the structural features of the Harbour Cay condominium and the method used in its construction. The emphasis is on structural aspects that are pertinent to the investigation of the collapse. The principal sources of information were construction documents supplied by OSHA, site investigations of the collapse, and photographs of the structure taken before and after the collapse.

Section 2.2 identifies the various construction and other documents supplied by OSHA and describes briefly their uses in this investigation. The appropriate sections under which the specific contents of these documents are discussed are identified by reference.

Section 2.3 presents selected structural data for use in subsequent analytical investigations. It begins with a brief description of the layout of the building, the sectional configuration of its columns and floor slabs, reinforcing plans and schedules, materials specifications, design loads and the scope of design calculations. The latter part of,this section establishes the actual effective depth of the slab at the columns. The effective depth is a critical parameter in calculations of the shear and moment capacity of the slab.

Section 2.4 describes the falsework system and the procedure used in the construction of the building. The principal topics of discussion are the configuration and layout of the flying form system, the construction sequence, the state of construction at the time of the collapse, and the location of reshores in the lower stories.

A brief description of events at the time of the collapse is given in section 2.5. Section 2.6 provides a summary of the findings reported in this chapter.

\subsection{DOCUMENTS SUPPLIED BY OSHA FIELD OFFICE}

NBS requested certain documents in order to carry out its investigation, which were subsequent1y provided by the OSHA area office in Tampa. The documents provided information on the structural aspects of the building, the construction schedule, and the results of tests conducted by testing laboratories. OSHA also provided copies of personal interview statements of workers, many of whom were eyewitnesses to the collapse. In addition, OSHA supplied NBS with photographs taken prior to and after the collapse.

\section{Construction Documents}

The following construction documents were supplied by OSHA: (1) architectural, structural and steel supplier's drawings and job specifications, (2) a flying form plan, (3) a reshoring layout (prepared after the collapse), and

(4) structural design calculations. 
The first three documents were used extensively to develop an understanding of the structure and the construction scheme (sections 2.3 and 2.4), and to formulate the analytical models (chapter 5) employed in subsequent investigations of the collapse (chapters 5 and 6 ). The flying form plan, supplemented with information from the manufacturer (section 2.4), were the principal documents used in the evaluation of construction loads (section 5.3).

Section 2.3 includes a commentary on the structural design calculations mainly with regard to content and certain omissions. As discussed in that section, the question of adequacy of the design calculations for service loads is not addressed because it is outside the scope of this investigation.

\section{Daily Logs}

Several sources were used to reconstruct the construction history. These included the daily notes of the construction manager and of the general contractor's field superintendent, and the engineer's dally inspection reports. Copies of the daily reports of the onsite batch plant provided information which resolved some discrepancies in the above sources with respect to the construction sequence. The schedule presented in section 2.4 is based primarily on these documents.

Along with the batch plant reports, there were copies of mix design sheets for concrete that the general contractor had used on a previous project. These mix design sheets were supplemented with charts to be used by the batch plant operator to determine the quantities of concrete for different size batches and types of concrete. These documents are further discussed in chapter 4 . In addition, OSHA obtained copies of invoices and delivery tickets from various materials and service suppliers to the general contractor.

Copies of daily weather reports obtained from Patrick Air Force Base contained hourly temperature data that were used with NBS laboratory tests to predict the inplace strength of concrete at the time of the collapse (section 4.4.3).

\section{Testing Laboratory Reports}

The general contractor employed a testing laboratory to perform quality control testing of the concrete. The information contained in these reports is presented in section 4.2 .

OSHA retained a testing laboratory to test samples taken from the site after the collapse. A copy of this laboratory's report was provided to NBS and the results are summarized in section 4.3 .

\section{Interview Statements}

OSHA provided copies of the statement made by workers interviewed by OSHA Compliance officers. These statements provided very useful information on the construction of the building as discussed in section 2.4. In addition, they provided eyewitness accounts of the collapse. Section 3.3 summarizes some of the pertinent information gathered from the personal interview statements. 
Copies of the investigation reports of the Florida Department of Professional Regulation provided statements made by engineers, regulatory personnel, and construction managers involved in the Harbour Cay project.

\subsection{DESCRIPTION OF THE STRUCTURE}

The building was a five-story flat plate structure intended for residential use. A typical framing plan for the second through fifth floors is shown in figure 2.1. The columns were $10 \times 18$ in $(254 \times 457 \mathrm{~mm})$ in cross section with the following exceptions: the columns on lines $A$ and $K$ were $10 \times 12$ in (254 x $305 \mathrm{~mm}$ ) and those at the exterior ends of the stairwells were $8 \times 12$ in (203 $\mathrm{x}$ $305 \mathrm{~mm}$ ) in cross section. The thickness of the floor slabs was 8 in (203 mm). The thickness of the balcony slab along the west side varied from 7-1/4 in (184 $\mathrm{mm})$ at the column line to $6-1 / 2$ in $(165 \mathrm{~mm})$ at the edge. The thickness of the walkway slab along the east side (as scaled from the structural plans) was 7-1/2 in $(191 \mathrm{~mm})$. The first story floor slab was cast on grade. The elevator tower was structurally detached from the building. Top of slab story heights were $8^{\prime}-8^{\prime \prime}(2.64 \mathrm{~m})$. At the foundation level, the columns were supported by pile caps containing two to nine piles each. The exterior caps were connected by continuous wall footings.

Reinforcing steel for the slabs and columns was specified as deformed bars ASTM Grade 60. The framing plans in figures 2.1 and 2.2 show the top and bottom reinforcement in the slab, respectively. Table 2.1 shows the reinforcing schedule for the columns. The structural drawings called for 4000 psi (27.60 MPa) strength for concrete in the above-grade portion of the structure. The specified live loads were $20,40,60$ and 100 psf $(960,1920,2870$ and $4790 \mathrm{~Pa}$ ) for the roof, floor, public balcony and stairways, respectively. The wind design was specified to conform with the SBCC Standard Building code, $110 \mathrm{mph}(49 \mathrm{~m} / \mathrm{s})$ wind with a 100-yeapr return period [2.2]. Concrete block masonry strength was specified as $\mathrm{f}_{\mathrm{m}}=1500 \mathrm{psi}(10.35 \mathrm{MPa})$. Non-load bearing concrete masonry construction was used for the exterior walls of the building.

The structural design calculations consisted of 79 consecutively numbered pages. The first page specified the material strengths and loads assumed for the design. Pages 3 through 9 showed the axial loads in columns, computed on the basis of tributary areas. Pages 9 through 16 contained wind load calculations and the moments they produced in the assumed structure. Page 17 specified the preliminary column sizes based on the computed axial loads and assumed end moments. Pages 18 through 77 contained the slab moment calculations and sizing of the flexural reinforcement. Page 78 contained the pile cap designs and page 79 showed the final column schedule.

The design calculations were not examined in detail, but the following omissions were noted with regard to compliance with the provisions of the American Concrete Institute 318 standard (hereafter referred to as the ACI Code) [2.1], which is part of the applicable local Code [2.2] for this structure.

(1) There were no calculations to indicate whether the deflection or minimum thickness provisions of the code were met. 
(2) There were no calculations to indicate whether the punching shear and beam shear provisions of the Code were met.

(3) There were no checks to determine if the column reinforcement would satisfy the necessary spacing requirements specified by the Code.

(4) The steel area calculations for the flexural reinforcement in the slabs were based on ASTM Grade 40 steel. This is at variance with the Grade 60 steel specified in the structural drawings.

(5) The effective depth of the slab in flexural reinforcement calculations was not defined explicitly but appeared as part of a constant multiplier of computed moments. Back calculations showed that the designer used the value of "around" 6.3 in $(160 \mathrm{~mm})$ for the effective depth in steel area calculations (effective depth varies somewhat with the amount and size of steel bars; hence the use of the word "around"). For the 8-in (203-mm) slab, the effective depth used is consistent with the $3 / 4-1$ in (19-mm) minimum cover specified by the ACI Code (sec. 7.5 of ref.2.1). Explanations of "effective depth" and "cover" appear later on in this section.

The above statements are cited for information purposes only. Insofar as this investigation is concerned, the structural drawings and specifications supersede the design calculations, and therefore, are the documents referenced in subsequent comments about the "design" of the structure. Thus, questions related to consistency of the design calculations with the contract documents are not discussed any further.

According to the contract specifications, "protection for reinforcing steel shall be 1 in for slabs." However, a "typical balcony section" in the structural drawings shows 3/4-in (19-m) clear cover for top and bottom bars in the floor slab and bottom bars in the balcony slab, and 1 in (25 mm) clear cover for top bars in the balcony slab. According to the steel supplier's drawings and delivery tickets, a sufficient number of 3/4-in (19-mm) slab bolsters were supplied to obtain a 3/4-in (19-m) clear cover for the bottom bars in the slabs regardless of bar size.

From the same sources, the quantities and sizes of individual high chairs (IHC) supplied for the top steel in a floor slab were identified as follows: $500-5-3 / 4$ " IHC, 470 - 4-1/4" IHC, $70-5$ " IHC, $50-4$ " IHC and 70-3-1/4" IHC. In addition, 非 support bars were supplied for use with the high chairs in the middle strip to support the one-way top reinforcement in these strips (fig. 2.1). The specified spacing of high chairs was $4 \mathrm{ft}(1.2 \mathrm{~m})$ on center. With the aid of the framing plan for top bars in the slab (fig. 2.1), and quantities of chairs of various specified sizes supplied, it was determined that the 5-3/4-in (146-mm) high chairs were used for the one-way top reinforcement in the middle strips and the 4-1/4-in (108-mm) high chairs were used for the two-way top reinforcement in the column strips. Figure 2.3 shows the top reinforcement layout in a column strip assuming bars in both directions have the same diameter $D$. The relationship between chair height, bar diameter, effective depth, cover, and slab thickness are illustrated in the same figure. 
Chairs having specified sizes other than these two were supplied in much smaller quantities for use with the top reinforcement of the thinner slabs in the balcony and walkway, and those in the elevator tower and stairwells.

Noting that 非 to 非 bars sizes were used at the top of middle strips, the use

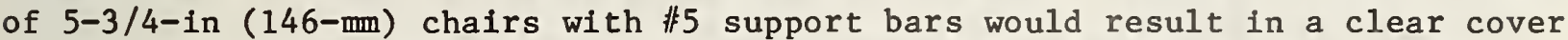
of $7 / 8$ to $1-1 / 8$ in $(22-29 \mathrm{~mm})$ for the top bars in the middle strips. This exceeds the $3 / 4-i n(19-\mathrm{mm})$ cover specified in the structural drawings but is within the $3 / 8-$ in $(9.5-\mathrm{mm})$ tolerance limit specified in section 7.5 of the ACI Code [2.1]. According to the steel supplier's drawings, in areas of two-way top steel, such as the column strips, main reinforcement in one direction is used as support bars for main reinforcement in the other direction. The use of 4-1/4-in (108-mm) chairs in these areas where the slab is 8 in (203 mm) thick would result in a net cover ranging from a minimum of $1-5 / 8$ in (41 mm) for the combination of maximum bar sizes (e.g., 非 8 and 非 9 at column C2) to a maximum of 2-1/8 in (54 mm) for the combination of minimum bar sizes (e.g., 非 and $\mathbb{N}_{8}$ at column $\mathrm{A} 3$ ). The possibility of 5-3/4-in (146-mm) chairs having been used in the column strips is ruled out because this would have resulted in virtually no top cover at most locations.

There is, therefore, an inconsistency in the construction documents. The structural drawings indicated a 3/4-in (19-mm) cover for the top slab bars, whereas the chair height indicated on the steel supplier's shop drawings would result in more than 3/4-in cover for the top bars in the column strips of the slabs. The record copies of the shop drawings contained numerous check marks. One of the six pages bore the handwritten words "approved as noted" and the signature of the design engineer of record.

For further verification, actual field measurements were carried out. Measurements of top bar cover and recovery of 4-1/4-in (108-mm) chairs from slab segments salvaged from the debris of the collapsed building, (figures 2.4 and 2.5 , respectively), confirmed the use of 4-1/4-in (108-mm) chairs for the two-way top reinforcement in the column strips.

The importance placed on actual chair heights and their location is due to the fact that the effective depth of the slab is a critical parameter governing its punching shear and bending capacity. Figure 2.6 defines the critical shear area used in calculations of punching shear stresses in the slab at the periphery of a column. The punching shear area depends on the sectional dimensions $c_{1}$ and $c_{2}$ of the column and the effective depth, $d$, which appears in all three dimensions defining this area.

The calculated effective depth at a column where the top reinforcement in the slab consists of $\# 8$ and 非 9 bars is 5.3 in $(135 \mathrm{~mm})$. This is obtained by adding to the 4-1/4-in (108-mm) chair height the average diameter of the two bars. If the effective depth is taken to the centroid of the bars, as defined in section 2.1 of the ACI Code [2.1], its value would be 5.28 in (134 mm) or 5.35 in (136 $\mathrm{mm}$ ) depending on which size bar is assumed to be at the top. Considering all the columns and using both methods of calculation, the effective depth is found to fall in the range of 4.97 to 5.35 in (126 to $136 \mathrm{~mm}$ ). These figures will be somewhat less along the sides of columns at the edges of balcony and walkway 
slabs which are less than 8 in $(203 \mathrm{~mm}$ ) thick. The value of $\mathrm{d}=5.3$ in (135 $\mathrm{mm}$ ) is assumed in the subsequent calculations of stresses in the structure (chapter 5). Generally, these stresses are somewhat on the low side because the assumed

d for the slab is high at most of the columns.

\subsection{CONSTRUCTION METHOD}

The falsework system consisted of flying forms in the top story to support freshly cast concrete in the floor directly above, and wood reshores in the lower stories.

Figure 2.7 identifies the basic components of the flying forms. The assembled form consisted of two or three parallel trusses having a specified length obtained by bolting together standard 30-ft $(9.2-\mathrm{m})$ long truss panels and, where necessary, $5 \mathrm{ft}(1.5 \mathrm{~m})$ and/or $10 \mathrm{ft}(3.1 \mathrm{~m})$ spacer panels, as indicated in the figure. The assembled configuration can be seen in figure 2.8 which shows two relatively undamaged forms that were recovered from the debris after the collapse. The trusses were spaced at $10 \mathrm{ft}(3.1 \mathrm{~m})$ on center and were crossbraced at vertical chord panel points. The supports were swivel type screw jacks with 4-in $(102-\mathrm{mm})$ square base plates attached to the bottom chords at the junctions of vertical and diagonal chords. These were spaced at $9^{\prime}-10^{\prime \prime}$ $(3.0 \mathrm{~m})$ on center, or at $5^{\prime}-5^{\prime \prime}(1.7 \mathrm{~m})$ on center where a spacer panel of that size was used. Standard size Aluma beams ( $\mathrm{fig} .2 .7$ ) were connected to the trusses across the top chords at $1.6 \mathrm{ft}(0.49 \mathrm{~m})$ intervals. The Aluma beams projected beyond the exterior trusses by various amounts, depending on the width of bay in which they were used. The plywood forms were nailed to nailer strips within the U-shaped top flanges of the Aluma beams (fig. 2.7).

Figure 2.9 shows the overall layout of the shoring system. Circled letters and numbers designate transverse and longitudinal column lines, respectively. The columns are located at the junctions of these lines and are shown as solid rectangles. To form a floor required the use of nine flying forms, all of which were laid out in the transverse (east-west) direction. The flying form assemblies consisted of three parallel trusses each, except in the case of bay $\mathrm{DE}$, where only two trusses were used. The flying forms had four different configurations. These are identified by the letters A, B, C and D, enclosed in hexagons. The location of the screw jacks are designated by solid circles. The hollow squares designate reshores used in the lower stories. These were

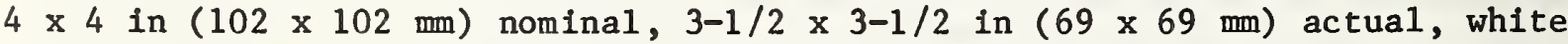
pine single posts. They were installed using wooden wedges at the bottom. E1lis type wood shores were used to support narrow filler form strips along the transverse column lines between the edges of adjacent flying forms.

Unless otherwise noted, the following sequence of construction is based on construction schedules supplied by the general contractor and on worker statements.

Figure 2.10 shows a typical forming schedule for the upper stories. Construction progressed at the rate of one story per week, according to the following cycle. The south half of a particular floor slab was cast on a Tuesday. The placement of steel bars in the north half of the slab and casting of the columns 
over the south half were carried out the next day, or Wednesday. On Thursday, the columns in the south half were stripped, the north half of the slab was cast and the forms below the south half of the slab were lowered. On Friday, the forms in the south half were replaced by reshores and flown to the same location in the story directly above, and the columns over the north half were cast. The following Monday, the columns in the north half were stripped, the steel bars in the south half of the slab above were placed, and the flying forms below the north half were lowered, replaced by reshores, and flown to the story directly above.

Figure 2.11 shows the various casting and stripping dates and the ages of the columns and floor slabs relative to the time of the collapse. In the case of incomplete information or conflicting witness statements regarding the date of a particular event, a question mark appears next to the specified date in the figure. Note that, unlike the lower story slabs, the roof slab was scheduled to be cast in one day. At the time of the collapse, all but the two north bays of the roof slab had been cast.

The flying forms were flown out of the west side of the building where the mobile crane was located. The forms under the fifth floor slab were all flown the same day proceeding consecutively from south toward north. The procedure for removing forms is reconstructed on the basis of worker statements and verified against that recommended by the supplier. It consists of four steps as follows: (1) the form is lifted hydraulically at the four corners, (2) the screw jacks are then loosened and folded, (3) the form is lowered on rollers and moved out gradually, and (4) the portion vacated by the form is reshored.

Figure 2.11 shows full reshores in the second through fourth stories. A fully reshored story conforms with the reshoring layout shown in figure 2.9. There is sufficient indication from worker statements to assume that the fourth story was fully reshored at the time of the collapse. Likewise, it is known that there were no rehores in the first story with the exception of some peripheral reshores under the balconies and walkways (see sec. 3.3 and fig. 2.11). Although there is a question as to when the first story reshores were removed, they would have been recovered for reuse when the fourth story forms were flown. Note that the removal of reshores from the first story marks the first time when the forces in the total shoring system will no longer have a direct path independent of the columns to the foundation (slab on grade, in this case).

Based on worker statements (see section 3.3) and photographic evidence, there is some doubt as to whether the third and second stories were fully reshored at the time of the collapse. According to one worker account, only two lines of reshores were used in each bay of the second story. This would make the number of reshores in that bay about two-thirds that of a fully reshored story. other accounts mention cracked reshores in the fourth story being replaced by reshores removed from the lower stories, or reshores being taken out to allow masonry work to proceed, etc.

Figure 2.12 is a partial view of the east facade of the building between the south stairwell and the elevator tower. Because the building was viewed from the northeast side, it is possible to identify all the columns on column lines C 
and $D$, as indicated in the figure. Within the third story, it is shown, by means of the superimposed graphics in the figure, that the projected space between columns $\mathrm{C} 1$ and D3 (the distance between $\mathrm{Cl}$ and D3 in the figure) should be occupied only by eight reshores within bay $C D$, assuming that story is fully reshored. From figure 2.12 and the closer view shown in figure 2.13, the third story appears to be fully reshored at the time these photographs were taken. It also appears that the number of second story reshores is comparable to that in the third story, although their locations appear to be different. Noting that the flying forms within the south four bays of the fourth story are in place, the date of the photographs is placed between March 12 to March 15, or 12 to 15 days before the collapse (see figs. 2.10 and 2.11 ). It is not known whether or not any of these reshores were removed in the interim.

Figure 2.14 is an aerial photograph of the building viewed from the southeast side. The direction of the shadows and the presence of the steel reinforcement for the roof slab indicate the photograph to have been taken on the morning of March 26, or the day before the collapse. The steep angle of the photograph conceals the view of interior reshores in the fourth story and below. It is noted that at the south end only one exterior reshore is in place in each bay of the fourth story while no reshores are in place at the same location in the third story. This contradicts the reshoring plans supplied by the general contractor where two reshores are shown in each bay along the exterior edges of the slabs. It is possible that some of the original reshores were removed to place masonry units in the third floor, as indicated by worker statements.

Because of the uncertainties noted above, for the purpose of analysis, all three stories below the fifth floor were assumed to be fully reshored, while no reshores were assumed within the first story (see fig. 2.11). The effect of this assumption would make the calculated stresses less critical than if partial reshoring were assumed in the second and third stories.

\subsection{EVENTS AT THE TIME OF THE COLLAPSE}

The collapse occurred at approximately 3:00 p.m., on March 27. Based on worker statements, it appears to have been triggered by a failure in the fifth story slab somewhere in the center portion of the bullding, and propagated straight down to the ground. This topic is discussed further in section 3.3.

Figure 2.14 provides a fairly close indication of the stage of construction at the time of the collapse. In the south end, the exterior walls for the first two stories were in place and stacks of masonry units were on the third floor. In the north end, construction of masonry walls was completed in the first three stories and masonry units were stacked on the fourth floor. Masonry loads are taken into consideration in the analysis of the building (sec. 5.3).

Figure 2.15 shows the location of the workers in the building at the time of the collapse. Hollow and solid circles designate respectively survivors and workers killed in the crash. The two workers in the first story were installing the framing for the window units. The workers in the third story were mostly masons finishing up the masonry walls in that story. The two survivors in the fourth story were making leveling adjustments in the formwork, while the 
third worker near the south bay was cleaning up the debris in that area. The workers on the roof were engaged in concreting operations for the roof slab. They were mostly within the two north bays where concrete had not yet been placed. According to worker statements, no concrete was being delivered to the roof at the time of the collapse.

Figures 2.16 and 2.17 are photographs of the debris taken in the wake of the collapse. Figure 2.16 gives a full view of seven bays of the collapsed building. The bays can be identified by referring to the superimposed letters corresponding to the column lines shown in figure 2.1. Note that many of the columns, three and four stories high, are still standing, indicating that the second to fourth floor slabs had been punctured at the columns on their way down. A partial view of the flying form in the second bay from the north end can be seen in the figure. This is one of the two flying forms at the north end (fig. 2.8) that remained relatively undamaged in the collapse because it was not supporting freshly cast concrete. A partial side view of the same flying form appears in figure 2.17 which was taken from the west side of the building after the flying form in the north bay had been removed.

\subsection{SUMMARY}

The following summarizes the information about the design and construction of the building which were used in subsequent analysis of the collapse. The documents on the collapse were supplied by the OSHA area office in Tampa.

1. Based on construction docunents and the superintendent's daily log, the construction schedule, from the casting of the first floor slab up until the day of collapse, was established.

2. Flying forms were used to cast the slabs for the second through fifth floors at a rate of one per week.

3. Omissions were noted in the structural design calculations. There were no calculations to indicate that the structure would satisfy the deflection and punching shear requirements of the ACI Code. The value of effective depth of the floor slabs used in the design was not defined explicity.

4. The top reinforcement within the column strips of the slab was supported by 4-1/4-in (108-mm) individual high chairs, and this resulted in an effective depth about 1 in $(25 \mathrm{~mm})$ less than if $3 / 4$ in $(19 \mathrm{~mm})$ cover were provided, as indicated in the structural drawings. The lower effective depth reduced the structural strength of the slab.

5. At the time of collapse, the three stories below the flying forms were reshored. However, it could not be firmly established how many reshores were in the second, third and fourth stories. Consequently, for the purpose of subsequent analysis, full reshoring was assumed in the three stories below the flying forms. 


\begin{tabular}{|c|c|c|c|c|c|c|c|}
\hline 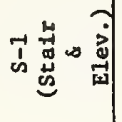 & $\begin{array}{l}\Sigma \\
\infty \\
e \\
\stackrel{y}{y}\end{array}$ & $\stackrel{n}{2}$ & $\stackrel{n}{a}$ & $\begin{array}{l}n \\
\vdots \\
\vdots\end{array}$ & 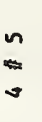 & $\begin{array}{l}n \\
s\end{array}$ & $\begin{array}{l}\underset{7}{\sim} \\
x \\
\infty\end{array}$ \\
\hline$\stackrel{n}{2}$ & 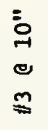 & $\begin{array}{l}n \\
0\end{array}$ & $\because$ & $\begin{array}{l}n \\
0\end{array}$ & $\begin{array}{l}n \\
0 \\
0\end{array}$ & $\begin{array}{l}0 \\
0 \\
0\end{array}$ & \begin{tabular}{l}
$\infty$ \\
\multirow{1}{*}{} \\
$x$ \\
0 \\
0
\end{tabular} \\
\hline 劾 & $\begin{array}{l}\bar{y} \\
\overline{0} \\
0 \\
0 \\
0\end{array}$ & $\begin{array}{l}n \\
\infty\end{array}$ & $\begin{array}{l}n \\
0 \\
0\end{array}$ & $\begin{array}{l}n \\
0\end{array}$ & $\begin{array}{l}n \\
0 \\
0\end{array}$ & $=$ & 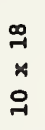 \\
\hline 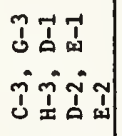 & $\begin{array}{l}\vdots \\
\overline{1} \\
0 \\
m \\
\text { m }\end{array}$ & $\frac{n}{6}$ & $\begin{array}{l}n \\
\infty\end{array}$ & $\begin{array}{l}n \\
0 \\
0\end{array}$ & $\begin{array}{l}5 \\
5 \\
0\end{array}$ & $\begin{array}{l}9 \\
0 \\
0\end{array}$ & 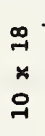 \\
\hline 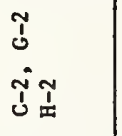 & $\begin{array}{l}\vdots \\
0 \\
0 \\
0 \\
m\end{array}$ & 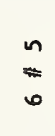 & 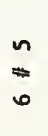 & $\begin{array}{l}\infty \\
= \\
0\end{array}$ & $\begin{array}{l}9 \\
\infty \\
\infty\end{array}$ & $\begin{array}{l}9 \\
\infty \\
\infty\end{array}$ & $\begin{array}{l}\infty \\
\overrightarrow{1} \\
x \\
0 \\
-1\end{array}$ \\
\hline $\begin{array}{l}1 \\
1 \\
1 \\
1 \\
1\end{array}$ & $\begin{array}{l}\overline{0} \\
\overline{0} \\
0 \\
0 \\
0\end{array}$ & $\begin{array}{l}n \\
\infty \\
0\end{array}$ & $\begin{array}{l}n \\
0 \\
0\end{array}$ & $\begin{array}{l}n \\
0\end{array}$ & $\begin{array}{l}n \\
0\end{array}$ & $\begin{array}{l}n \\
0\end{array}$ & 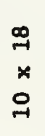 \\
\hline í & $\begin{array}{l}\overline{0} \\
\stackrel{0}{0} \\
\cong\end{array}$ & $\begin{array}{l}n \\
\infty\end{array}$ & $\begin{array}{l}n \\
0\end{array}$ & $\begin{array}{l}n \\
0\end{array}$ & $\begin{array}{l}n \\
\Rightarrow \\
0\end{array}$ & $\begin{array}{l}\infty \\
0\end{array}$ & 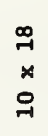 \\
\hline 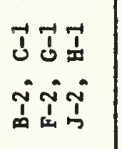 & $\begin{array}{l}\bar{a} \\
\stackrel{1}{0} \\
0 \\
m\end{array}$ & $\begin{array}{l}0 \\
n \\
0\end{array}$ & $\begin{array}{l}n \\
\infty\end{array}$ & $\begin{array}{l}n \\
0\end{array}$ & $\infty$ & $\begin{array}{l}7 \\
0 \\
0\end{array}$ & $\begin{array}{l}\infty \\
\rightarrow \\
* \\
0 \\
-\end{array}$ \\
\hline $\begin{array}{l}\overrightarrow{1} \\
\dot{1} \\
\dot{1} \\
\dot{n}\end{array}$ & $\begin{array}{l}\bar{y} \\
\stackrel{1}{0} \\
0 \\
0\end{array}$ & 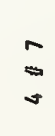 & 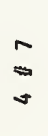 & 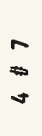 & $\underset{\infty}{\infty}$ & $\begin{array}{l}\Rightarrow \\
\infty \\
\infty\end{array}$ & $\begin{array}{l}\stackrel{\infty}{*} \\
\stackrel{x}{-} \\
\stackrel{-}{7}\end{array}$ \\
\hline ì & $\begin{array}{l}\vdots \\
\vdots \\
0 \\
m \\
=\end{array}$ & $\stackrel{n}{a}$ & 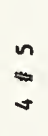 & 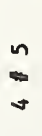 & $\approx$ & $n$ & 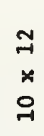 \\
\hline $\begin{array}{l}\tilde{m} \\
\dot{m} \\
\dot{m}\end{array}$ & 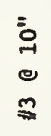 & $\stackrel{n}{\infty}$ & n & 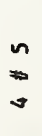 & $\begin{array}{l}n \\
\vdots\end{array}$ & $\stackrel{0}{\circ}$ & $\begin{array}{l}\approx \\
\stackrel{x}{9} \\
\stackrel{9}{*}\end{array}$ \\
\hline 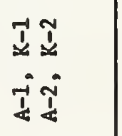 & $\begin{array}{l}\bar{y} \\
\stackrel{1}{0} \\
0 \\
m\end{array}$ & 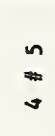 & $n$ & $\approx$ & $\stackrel{n}{*}$ & $=$ & $\begin{array}{l}7 \\
* \\
0 \\
0\end{array}$ \\
\hline $\begin{array}{l}\frac{1}{3} \\
\stackrel{3}{8}\end{array}$ & $\stackrel{\mathbb{Z}}{\mathbb{E}}$ & 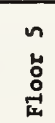 & 芒 & m & 岁 & 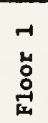 & 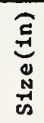 \\
\hline
\end{tabular}




\section{INDIVIDUAL HIGH CHAIR (41/4")}

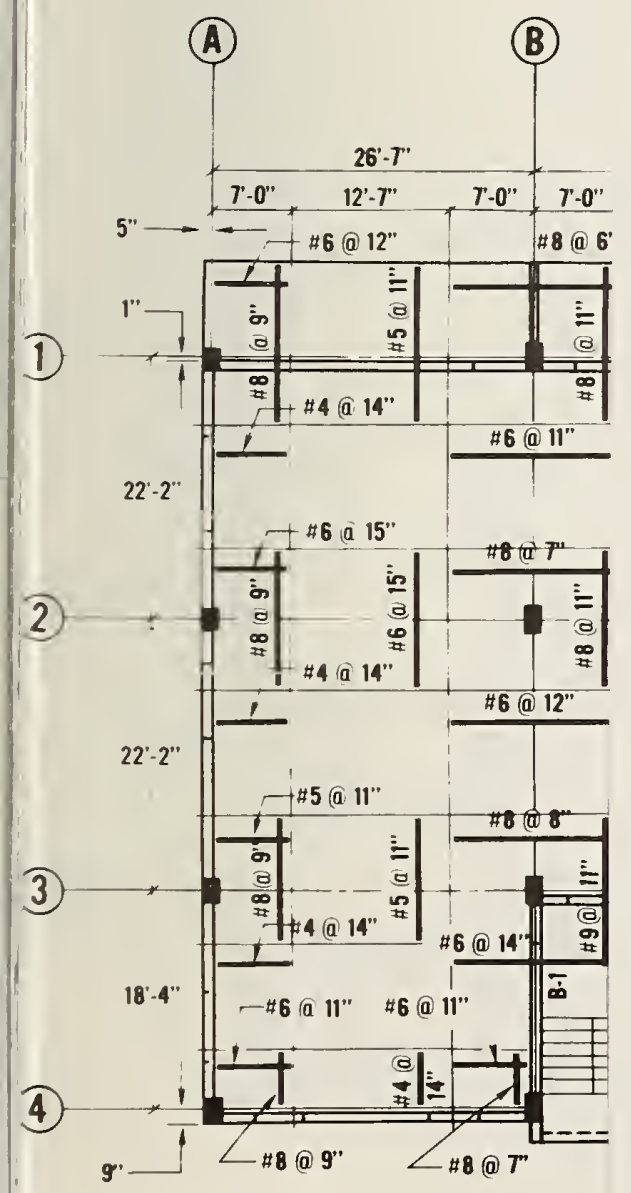




\begin{tabular}{|c|c|c|c|c|c|c|c|}
\hline 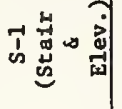 & $\begin{array}{l}\overline{1} \\
0 \\
\cong\end{array}$ & $\begin{array}{l}n \\
\text { s }\end{array}$ & $\begin{array}{l}n \\
s\end{array}$ & 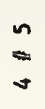 & $\approx$ & $\stackrel{n}{a}$ & $\begin{array}{l}7 \\
x \\
\infty\end{array}$ \\
\hline a & $\begin{array}{l}\overline{0} \\
\stackrel{0}{0} \\
0 \\
m\end{array}$ & $\begin{array}{l}n \\
0 \\
0\end{array}$ & 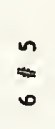 & $\approx$ & $\stackrel{n}{0}$ & $\frac{0}{0}$ & \begin{tabular}{l}
$\infty$ \\
\multirow{2}{*}{} \\
$\stackrel{-}{9}$
\end{tabular} \\
\hline 婄 & $\begin{array}{l}\bar{z} \\
\stackrel{9}{0} \\
\cong\end{array}$ & $\begin{array}{l}n \\
0\end{array}$ & $\begin{array}{l}n \\
0 \\
0\end{array}$ & 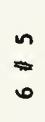 & 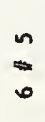 & 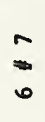 & \begin{tabular}{l}
$\infty$ \\
\multirow{-}{*}{} \\
$\stackrel{-}{\gamma}$ \\
0
\end{tabular} \\
\hline 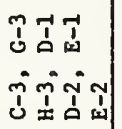 & $\begin{array}{l}\bar{y} \\
\overline{0} \\
0 \\
\text { \% }\end{array}$ & $\begin{array}{l}n \\
0 \\
0\end{array}$ & $\begin{array}{l}n \\
0 \\
0\end{array}$ & $\begin{array}{l}n \\
0\end{array}$ & $\begin{array}{l}n \\
0\end{array}$ & $\begin{array}{l}\text { ㅇ } \\
5 \\
0\end{array}$ & 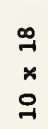 \\
\hline 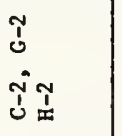 & $\begin{array}{l}\vdots \\
0 \\
0 \\
m\end{array}$ & $\begin{array}{l}n \\
0\end{array}$ & $\begin{array}{l}n \\
\infty\end{array}$ & $\begin{array}{l}\infty \\
\infty \\
\infty\end{array}$ & $\begin{array}{l}\text { 9 } \\
\text { - } \\
\text { - }\end{array}$ & 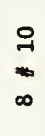 & $\begin{array}{l}\stackrel{\infty}{-1} \\
\stackrel{0}{*} \\
\stackrel{9}{\mid c}\end{array}$ \\
\hline $\begin{array}{l}1 \\
1 \\
1 \\
1 \\
1\end{array}$ & $\begin{array}{l}\bar{\partial} \\
\stackrel{0}{0} \\
\Sigma\end{array}$ & $\begin{array}{l}\text { n } \\
0\end{array}$ & in & in & $\begin{array}{l}n \\
0\end{array}$ & $\underset{0}{n}$ & 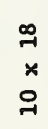 \\
\hline$\dot{m}$ & $\begin{array}{l}\overline{0} \\
\stackrel{0}{0} \\
\cong\end{array}$ & $\begin{array}{l}n \\
0\end{array}$ & $\begin{array}{l}n \\
0 \\
0\end{array}$ & n & $\stackrel{n}{\Rightarrow}$ & $\begin{array}{l}\infty \\
= \\
0\end{array}$ & $\begin{array}{l}\infty \\
\stackrel{7}{x} \\
0\end{array}$ \\
\hline 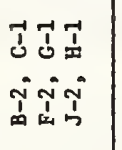 & $\begin{array}{l}\vdots \\
\stackrel{0}{0} \\
0 \\
\stackrel{m}{*}\end{array}$ & $\begin{array}{l}0 \\
n \\
0\end{array}$ & 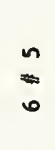 & $\approx$ & $\begin{array}{l}\infty \\
0\end{array}$ & $\begin{array}{l}7 \\
0\end{array}$ & $\begin{array}{l}\stackrel{\infty}{A} \\
* \\
\stackrel{-}{\sim}\end{array}$ \\
\hline $\begin{array}{l}i \\
\dot{1} \\
\dot{1}\end{array}$ & $\begin{array}{l}\bar{y} \\
\overline{0} \\
0 \\
0 \\
0\end{array}$ & $=$ & 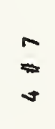 & $\infty$ & $\infty$ & $\begin{array}{l}\exists \\
\infty\end{array}$ & $\begin{array}{l}\stackrel{\infty}{*} \\
\stackrel{x}{\rho}\end{array}$ \\
\hline $\begin{array}{l}i \\
\dot{1} \\
\dot{j} \\
\dot{j}\end{array}$ & $\begin{array}{l}\vdots \\
\text { 亏 } \\
0 \\
\cong\end{array}$ & n & $\stackrel{n}{a}$ & in & 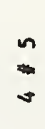 & n & 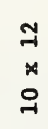 \\
\hline $\begin{array}{l}m \\
\dot{m} \\
\dot{m} \\
\dot{m}\end{array}$ & 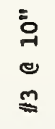 & $\begin{array}{l}n \\
\Rightarrow\end{array}$ & 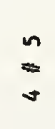 & m & $\approx$ & $\stackrel{0}{\circ}$ & $\begin{array}{l}\approx \\
x \\
\stackrel{9}{\pi}\end{array}$ \\
\hline 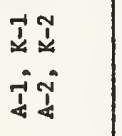 & $\begin{array}{l}\stackrel{0}{0} \\
\stackrel{0}{0}\end{array}$ & $\approx$ & 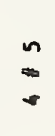 & 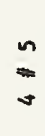 & $\approx$ & $=$ & 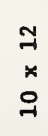 \\
\hline 臱 & 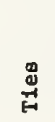 & n & 芒 & 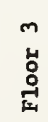 & 芒 & $\begin{array}{l}\overrightarrow{1} \\
\stackrel{5}{0} \\
\stackrel{5}{4}\end{array}$ & 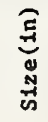 \\
\hline
\end{tabular}




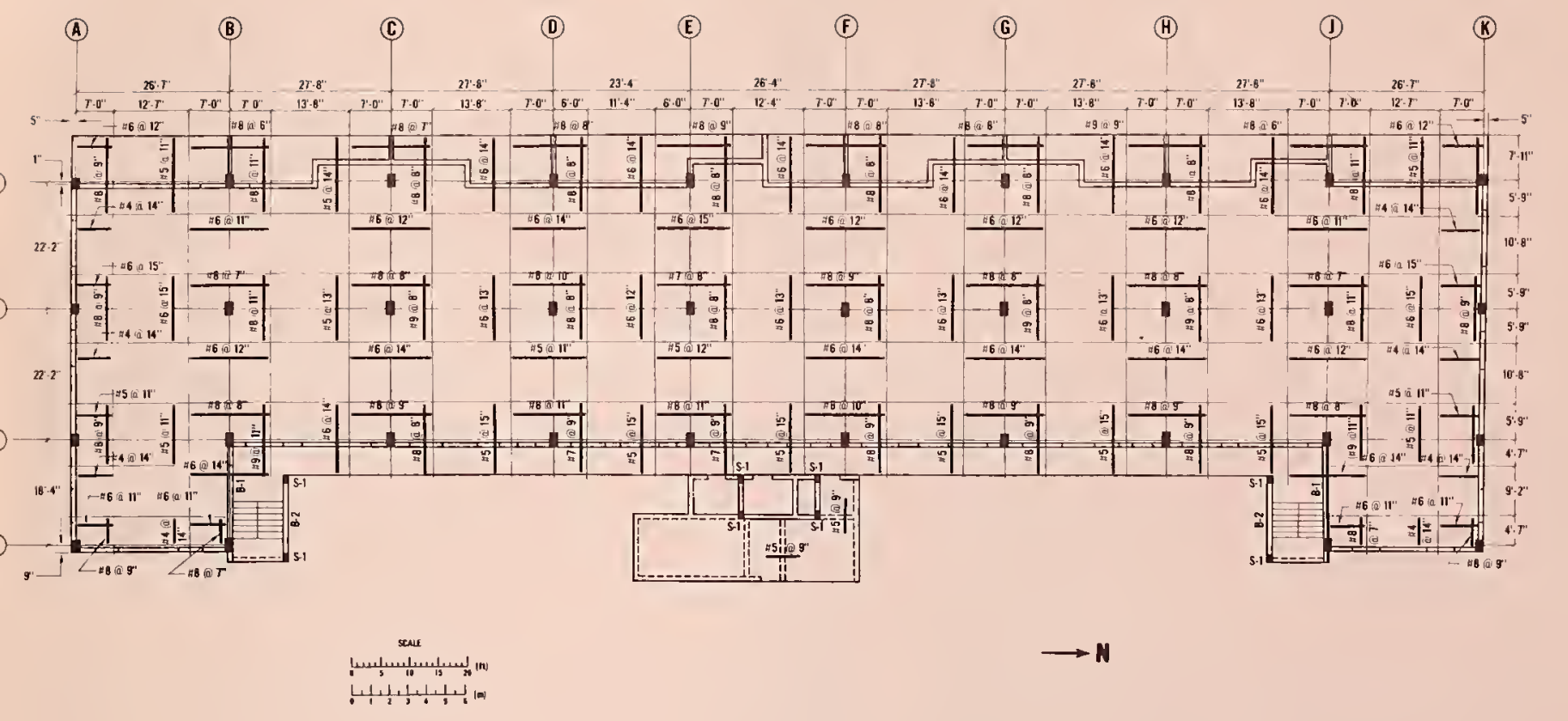

Figure 2.1 Top reinforcement layout in typical floor slab 


\begin{tabular}{|c|c|c|c|c|c|c|c|}
\hline 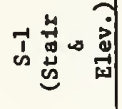 & $\begin{array}{l}5 \\
\infty \\
0 \\
\$\end{array}$ & $\begin{array}{l}n \\
\vdots\end{array}$ & $\stackrel{n}{a}$ & 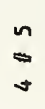 & $\stackrel{n}{a}$ & 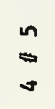 & \begin{tabular}{l}
$\underset{7}{*}$ \\
\multirow{\infty}{\infty}{}
\end{tabular} \\
\hline$\stackrel{m}{\Sigma}$ & 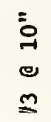 & $\begin{array}{l}n \\
0\end{array}$ & n & n & $\begin{array}{l}\text { in } \\
b \\
0\end{array}$ & $\begin{array}{l}a \\
0 \\
0\end{array}$ & $\begin{array}{l}\infty \\
\stackrel{\infty}{*} \\
\stackrel{9}{9}\end{array}$ \\
\hline
\end{tabular}


INDIVIDUAL HIGH CHAIR (41/4")

(A)

(B)

(1)

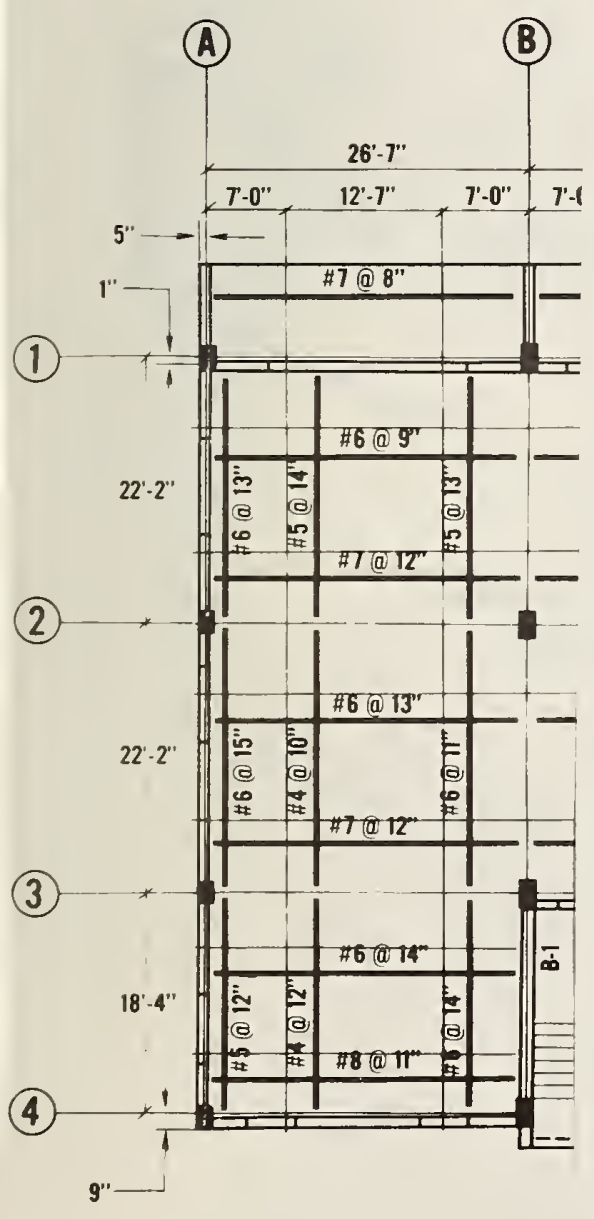




\begin{tabular}{|c|c|c|c|c|c|c|c|}
\hline 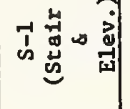 & $\begin{array}{l}\vdots \\
0 \\
0 \\
\$\end{array}$ & $\stackrel{n}{v}$ & $\stackrel{n}{a}$ & 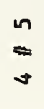 & n & 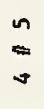 & $\underset{\infty}{\stackrel{7}{*}}$ \\
\hline 耪 & $\begin{array}{l}\overline{0} \\
0 \\
0 \\
0\end{array}$ & in & $\stackrel{n}{n}$ & $\begin{array}{l}n \\
0\end{array}$ & $\stackrel{n}{n}$ & $\begin{array}{l}\sigma \\
0 \\
0\end{array}$ & $\begin{array}{l}\stackrel{\infty}{7} \\
\not \\
0\end{array}$ \\
\hline
\end{tabular}




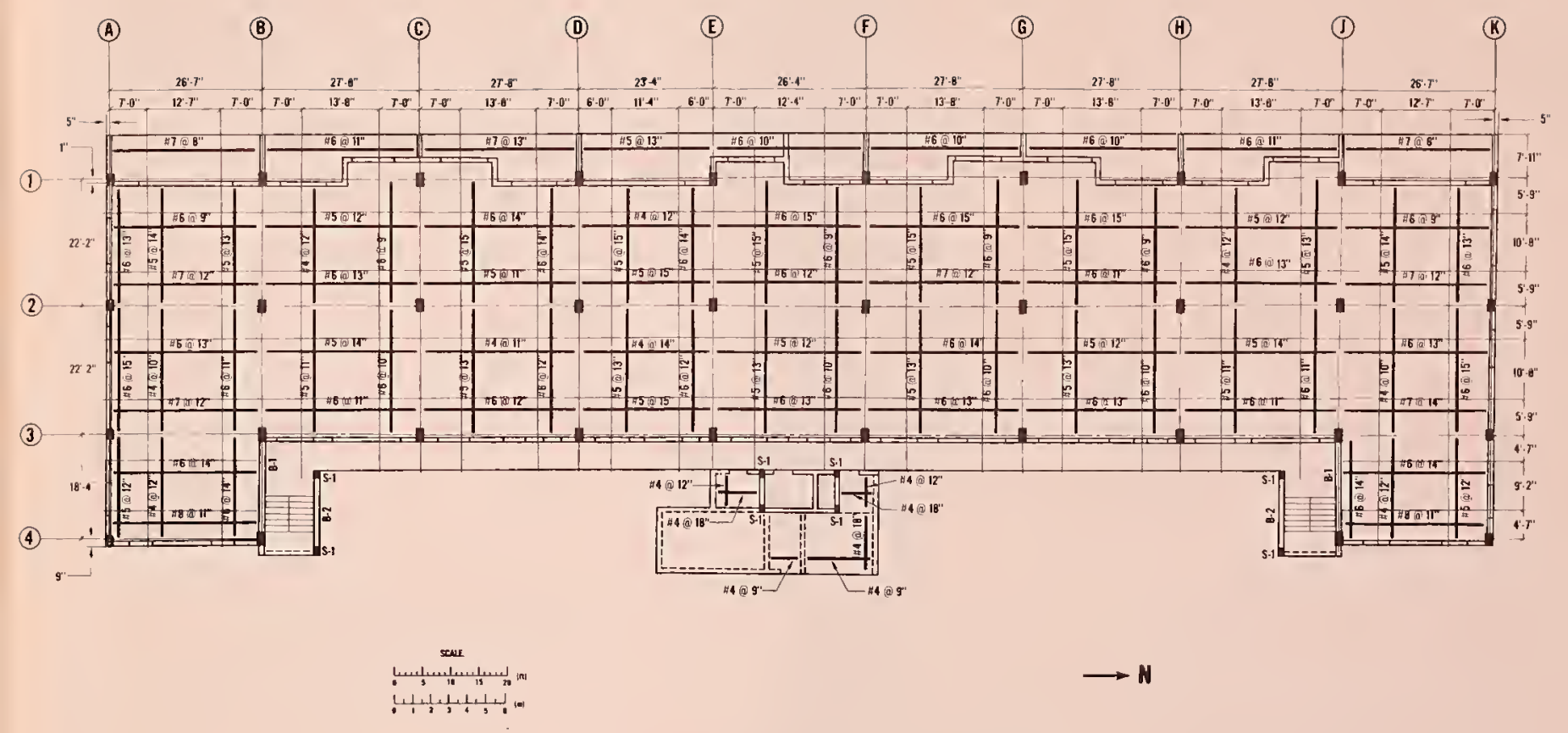

Figure 2.2 Bottom reinforcement layout in typical floor slab 


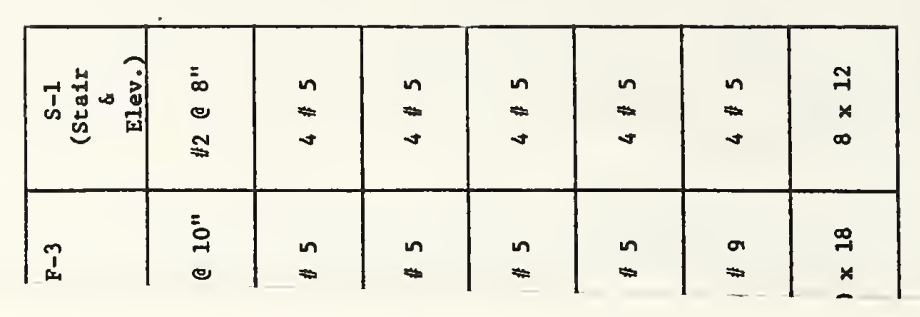




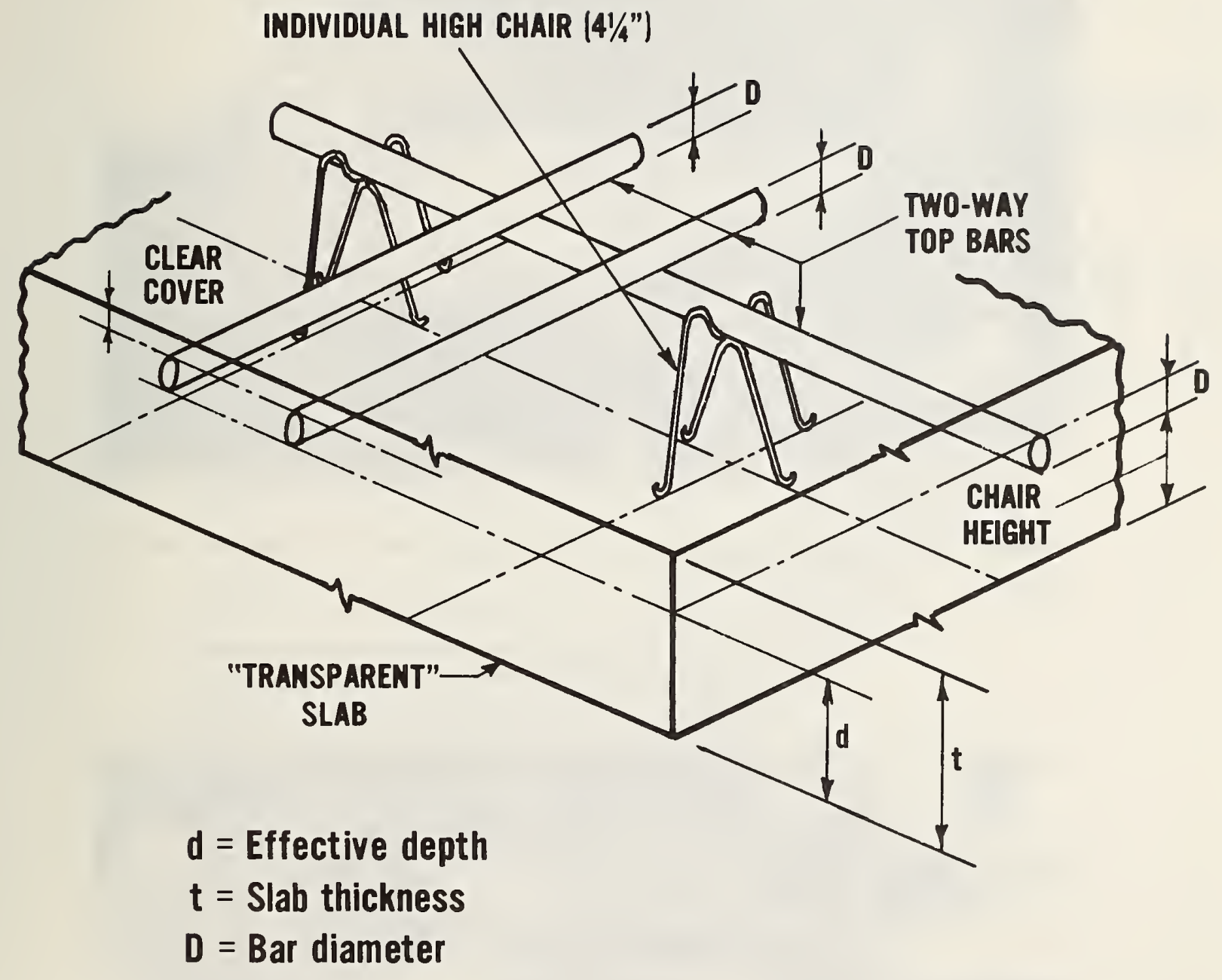

Figure 2.3 Configuration of chairs and top reinforcement in column strip 


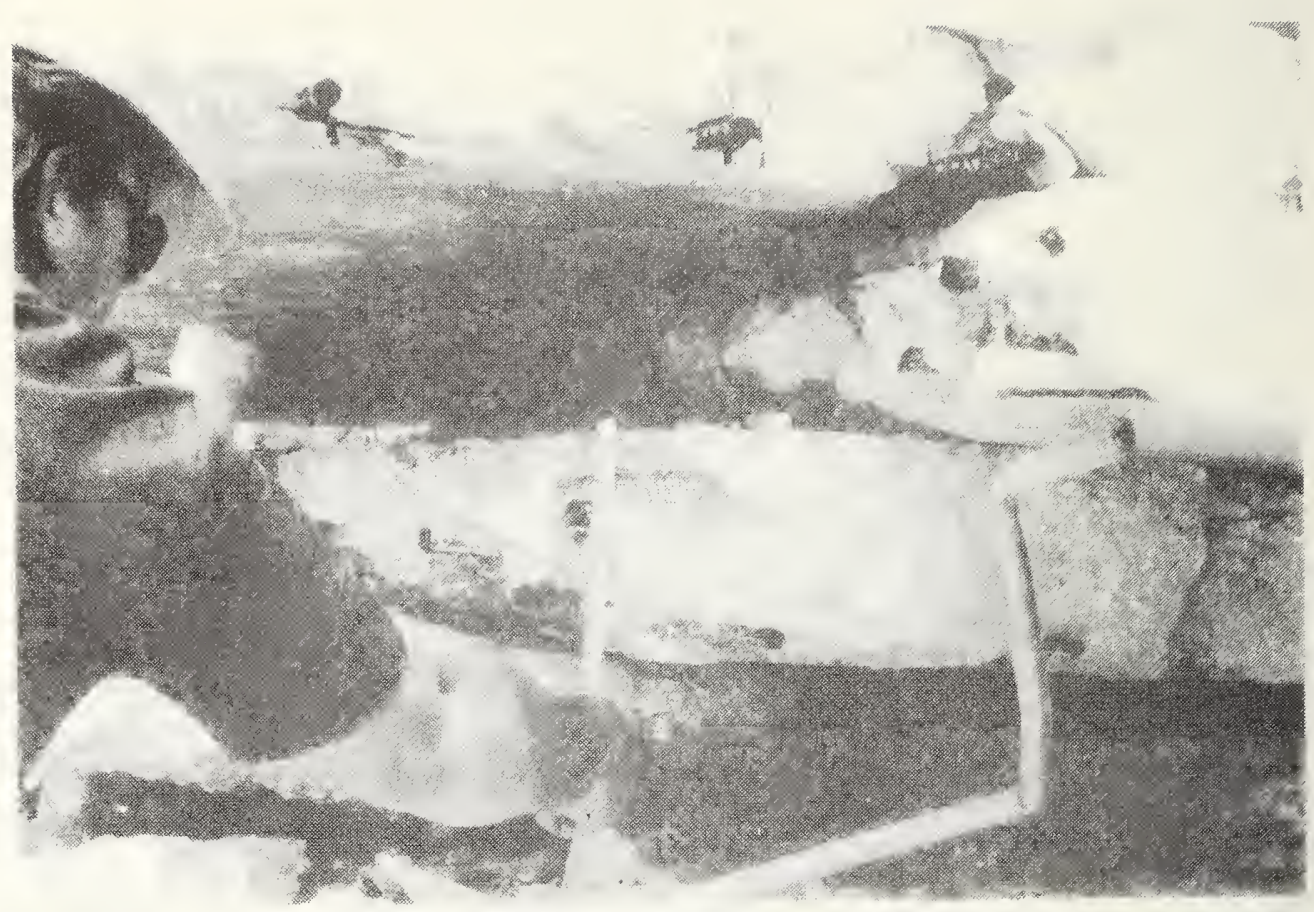

Figure 2.4 Field measurement of top bar cover in column strip

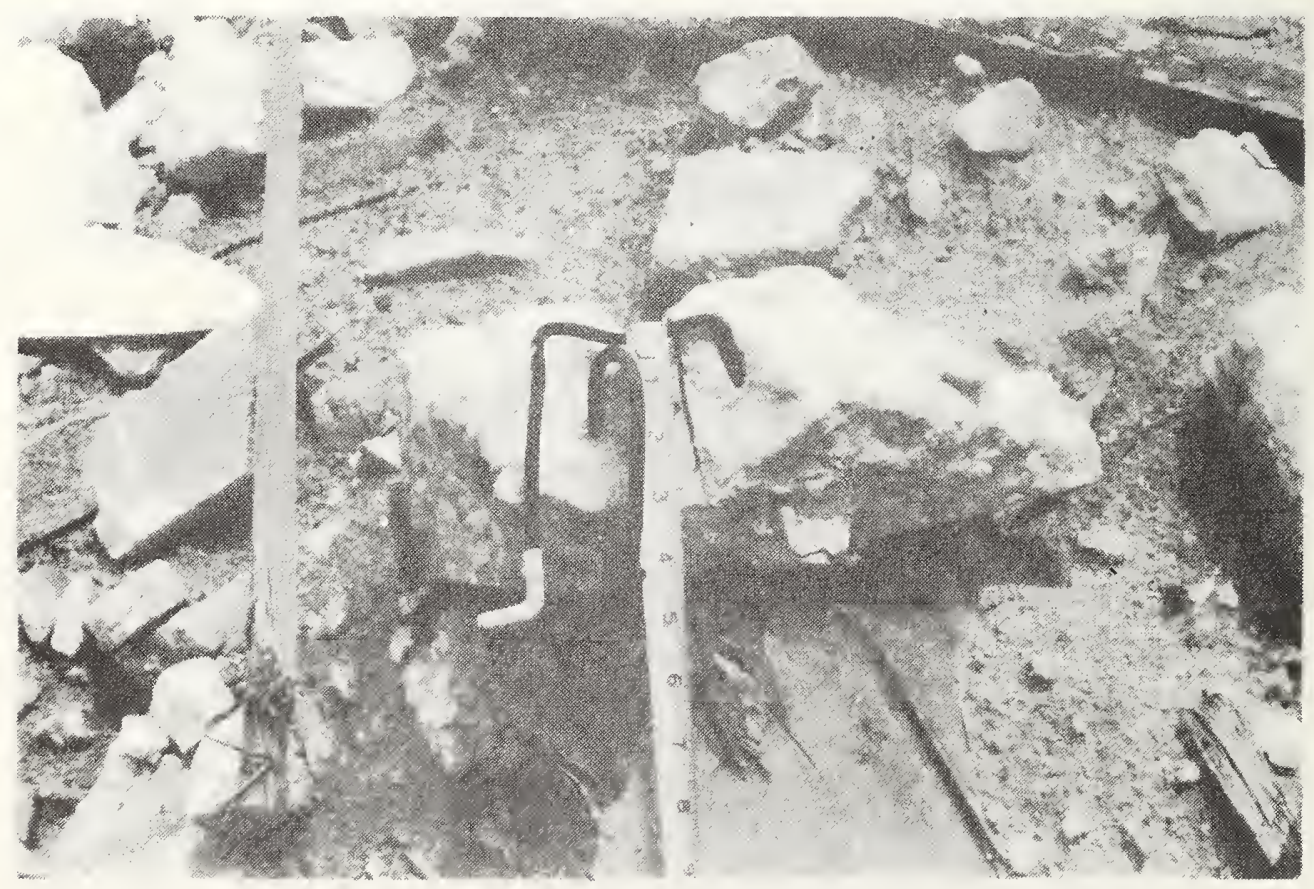

Figure 2.5 Field measurement of chair heights for top bars in column strip 


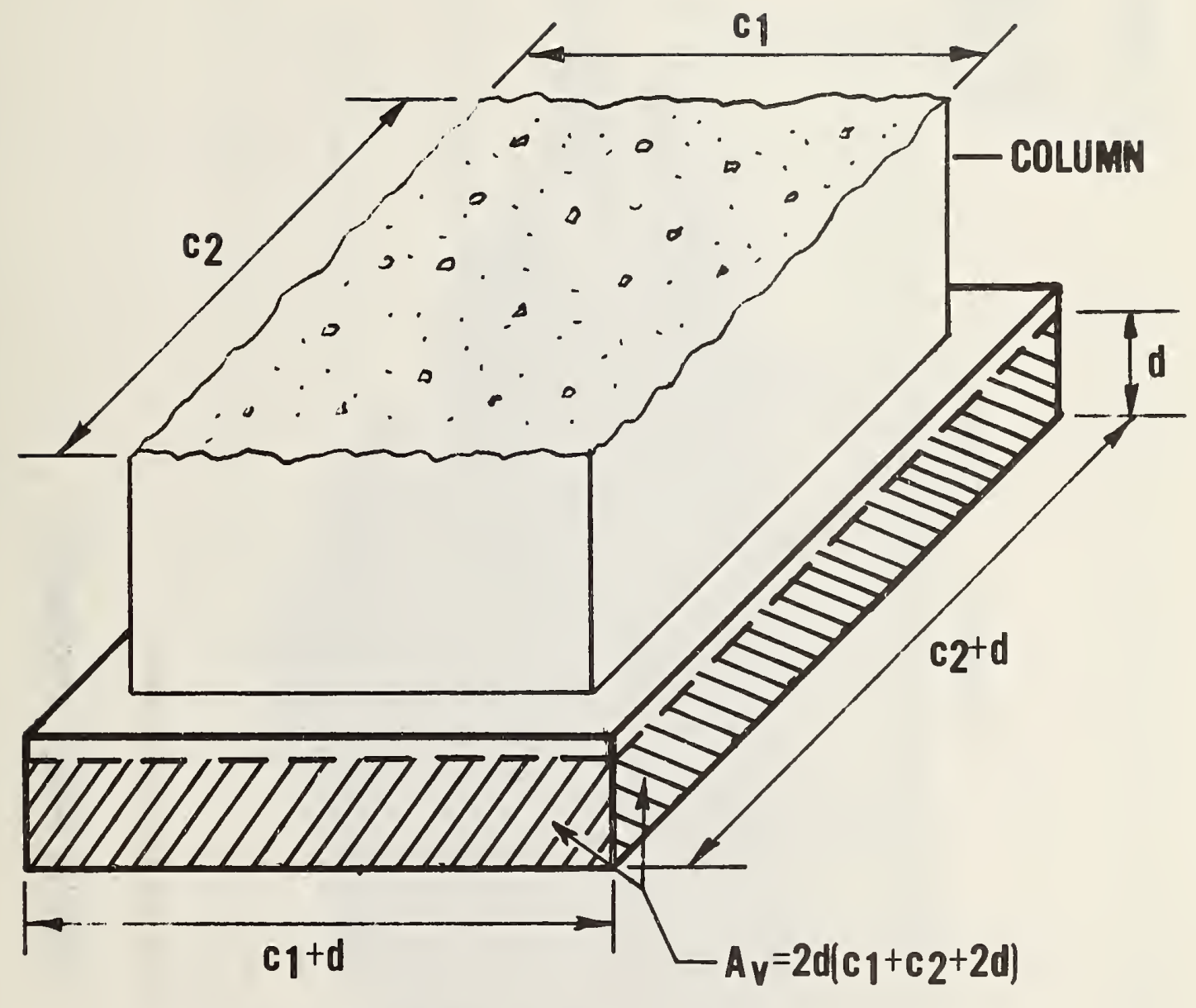

$A_{v}=$ Area of Critical Section

Figure 2.6 Area of critical section for punching shear 


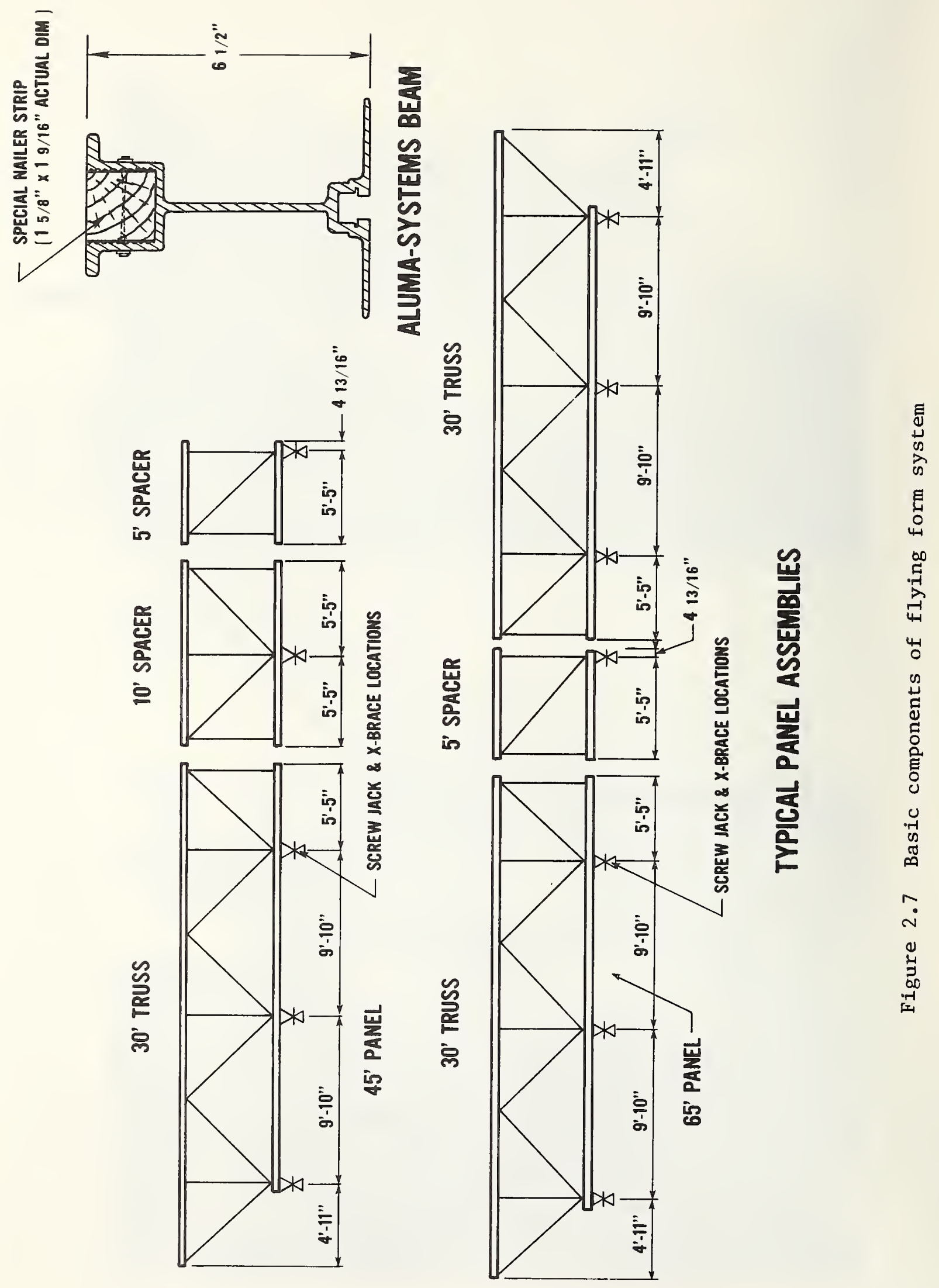




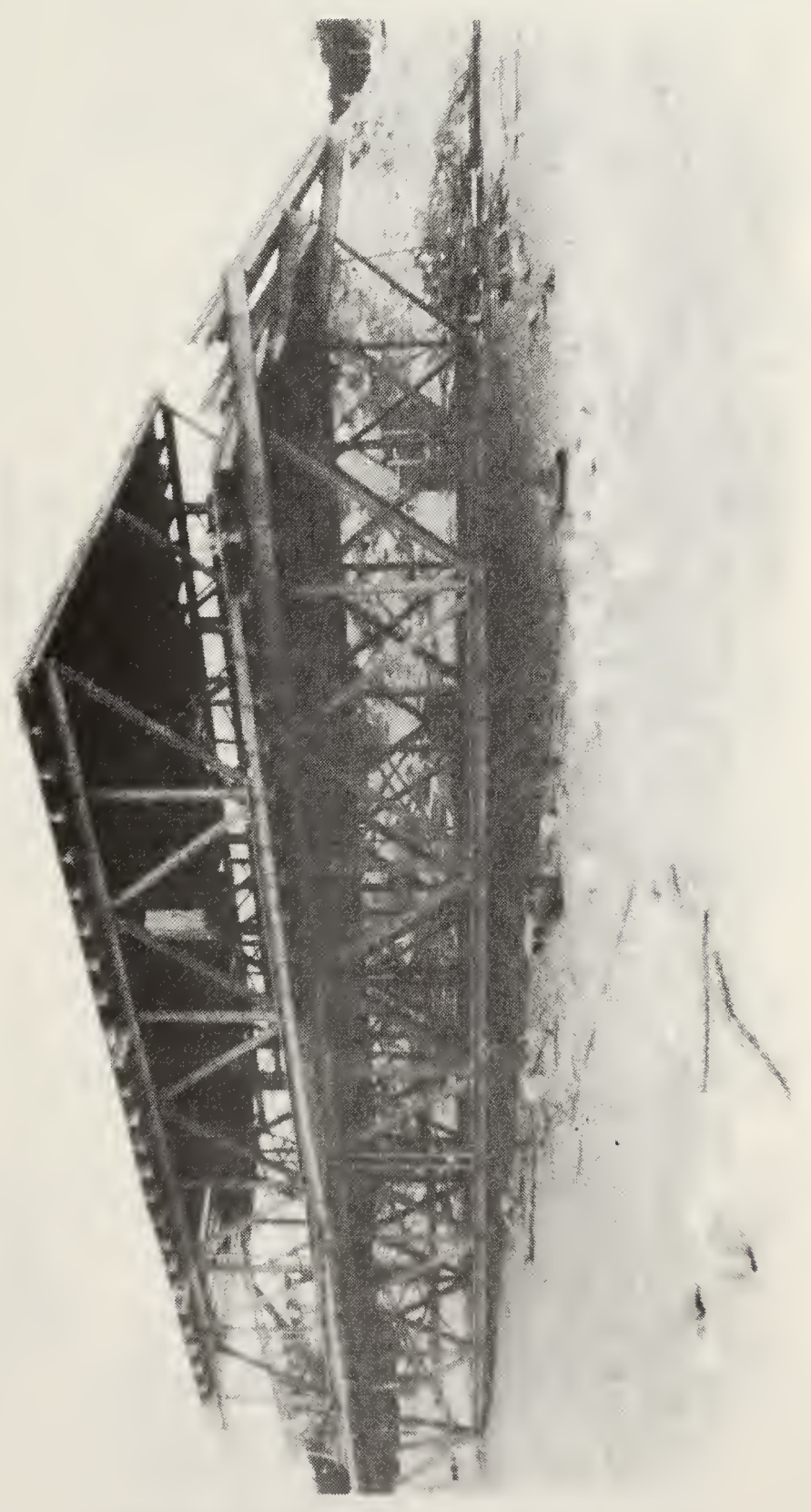

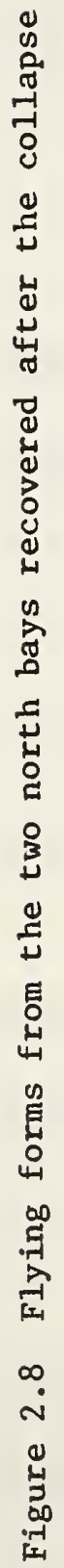




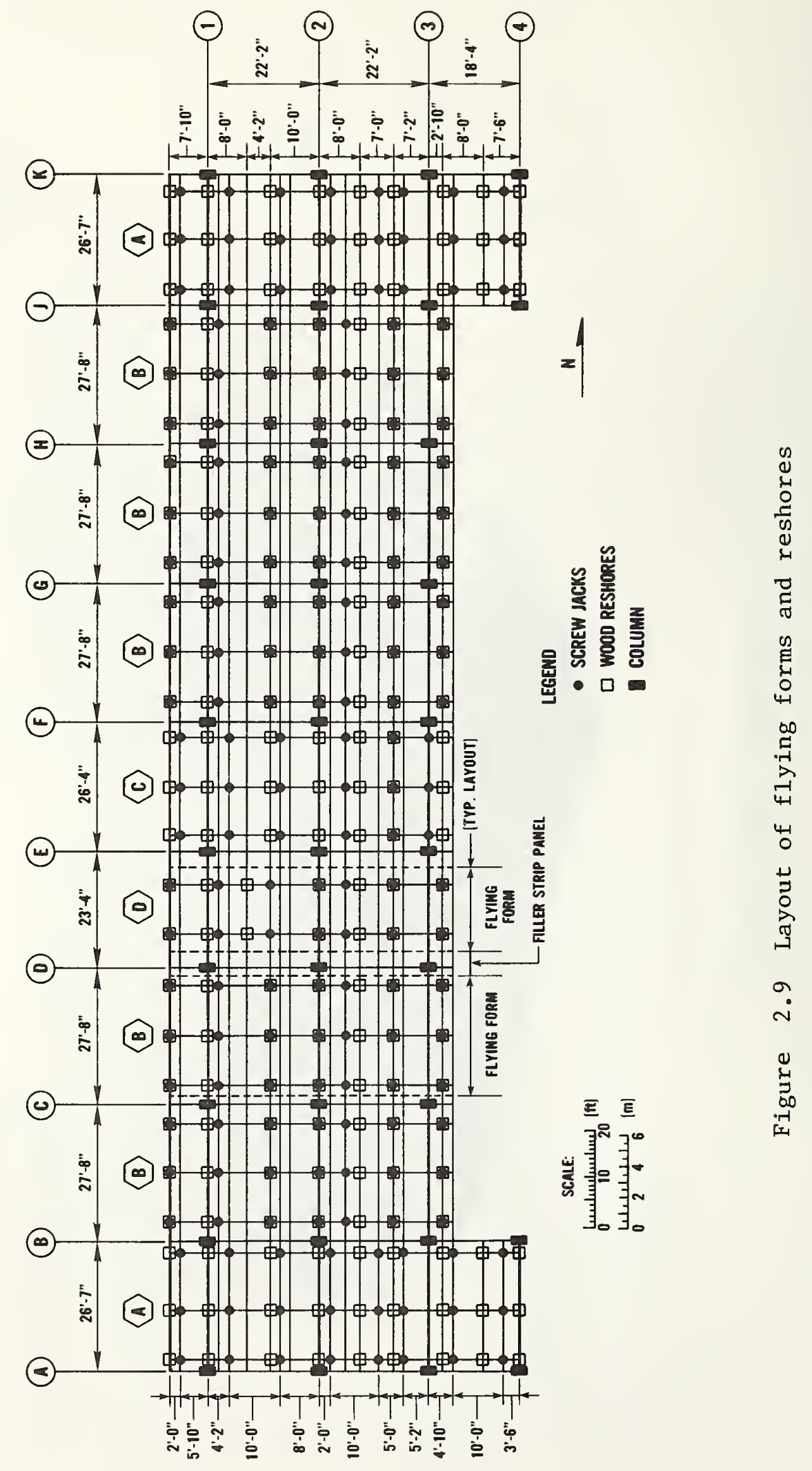


TUESDAY : Cast S(1/2) Slab

WEDNESDAY : Place Steel $N(1 / 2)$, Cast Columns $S(1 / 2)$

THURSDAY : Strip Columns $s(1 / 2)$, Cast $N(1 / 2)$ slab, Drop Forms $s(1 / 2)$

FRIDAY : Set Forms $S(1 / 2)$ Slab, Cast Columns $N(1 / 2)$

MONDAY : Strip Columns $N(1 / 2)$, Place Steel $S(1 / 2)$, Drop and Fly forms $N(1 / 2)$
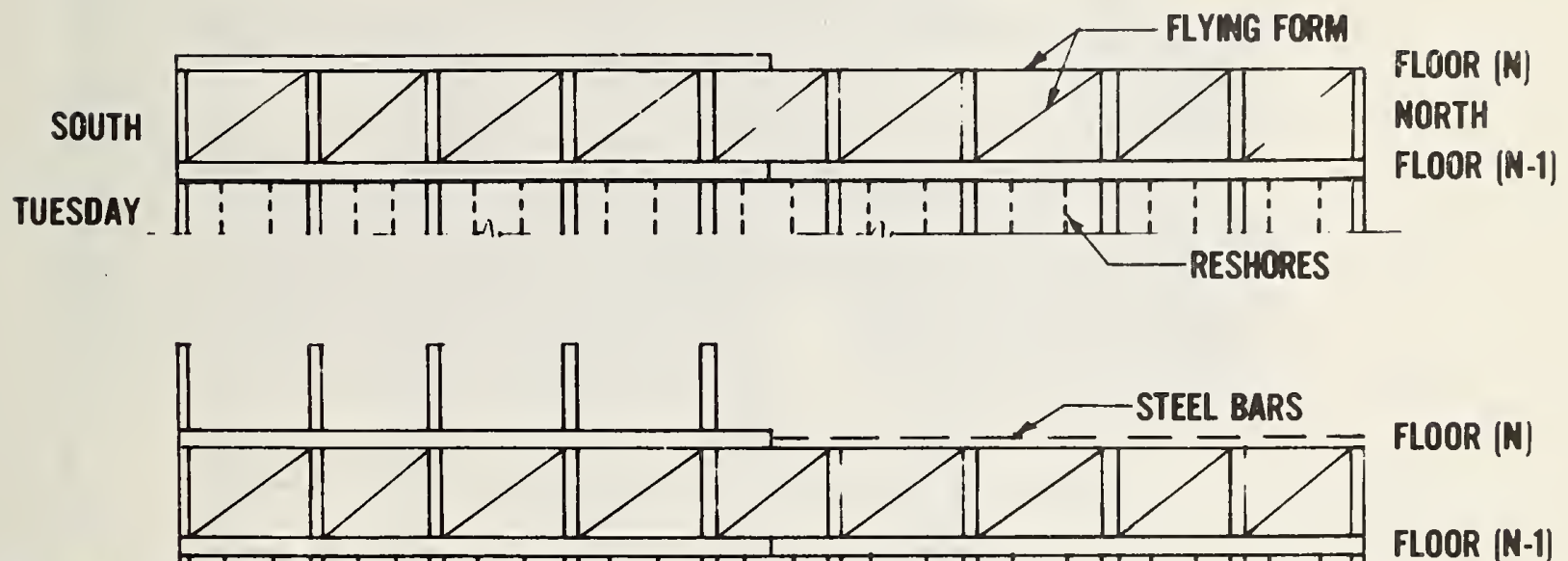

FLOOR (N)

FLOOR [ $\mathrm{N}-1)$

WEDNESDAY

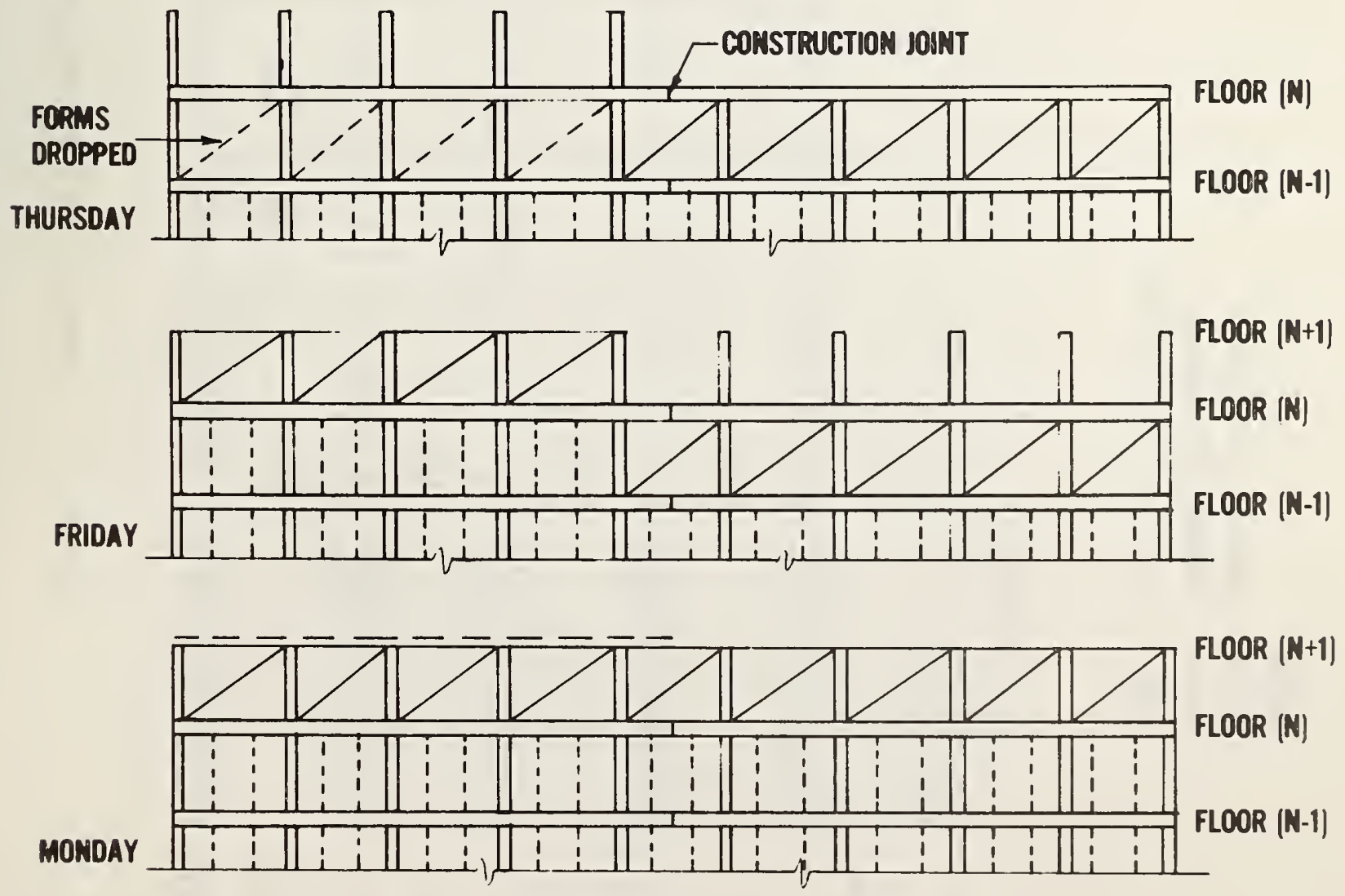

Figure 2.10 Typical forming schedule 


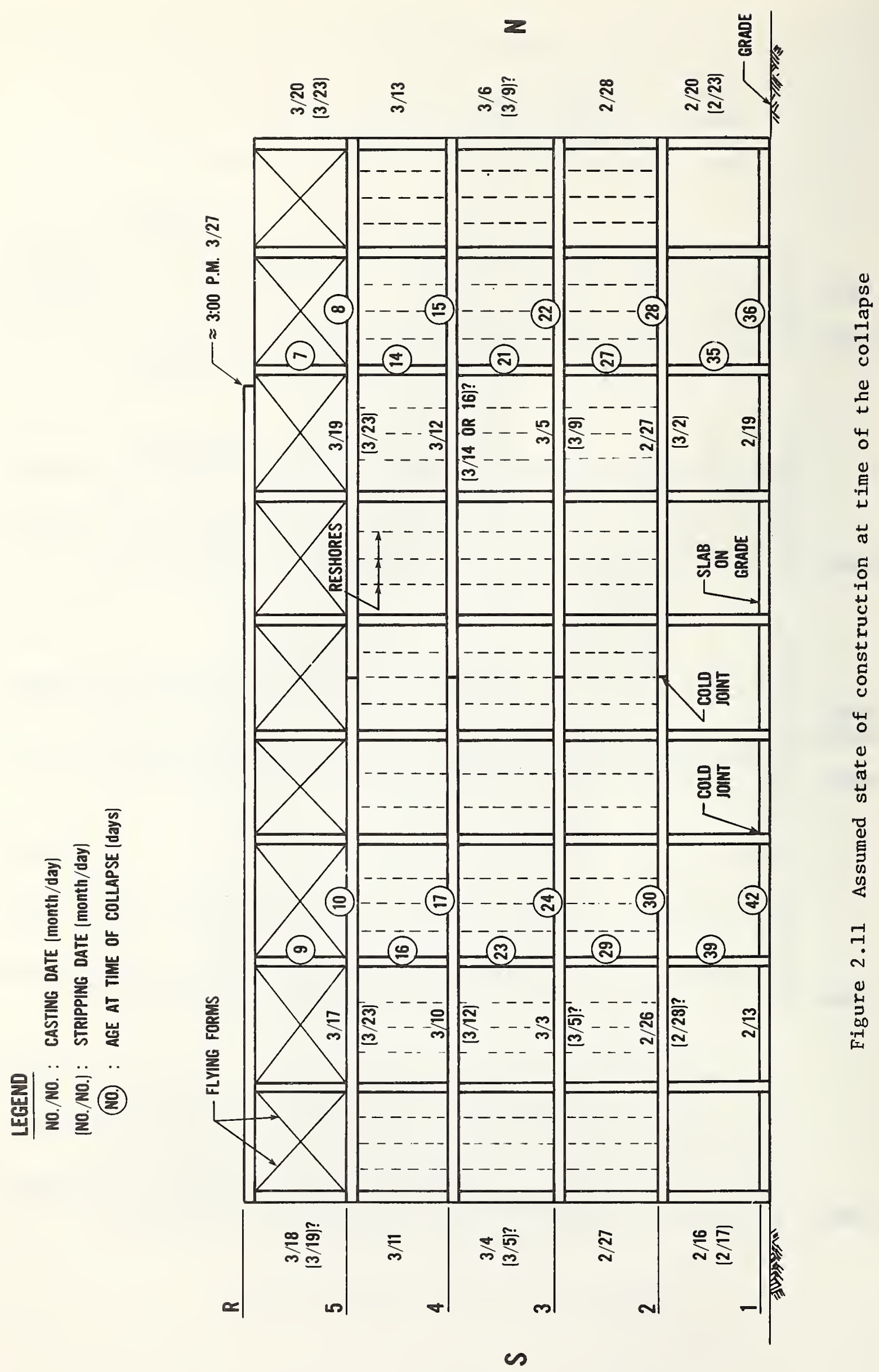




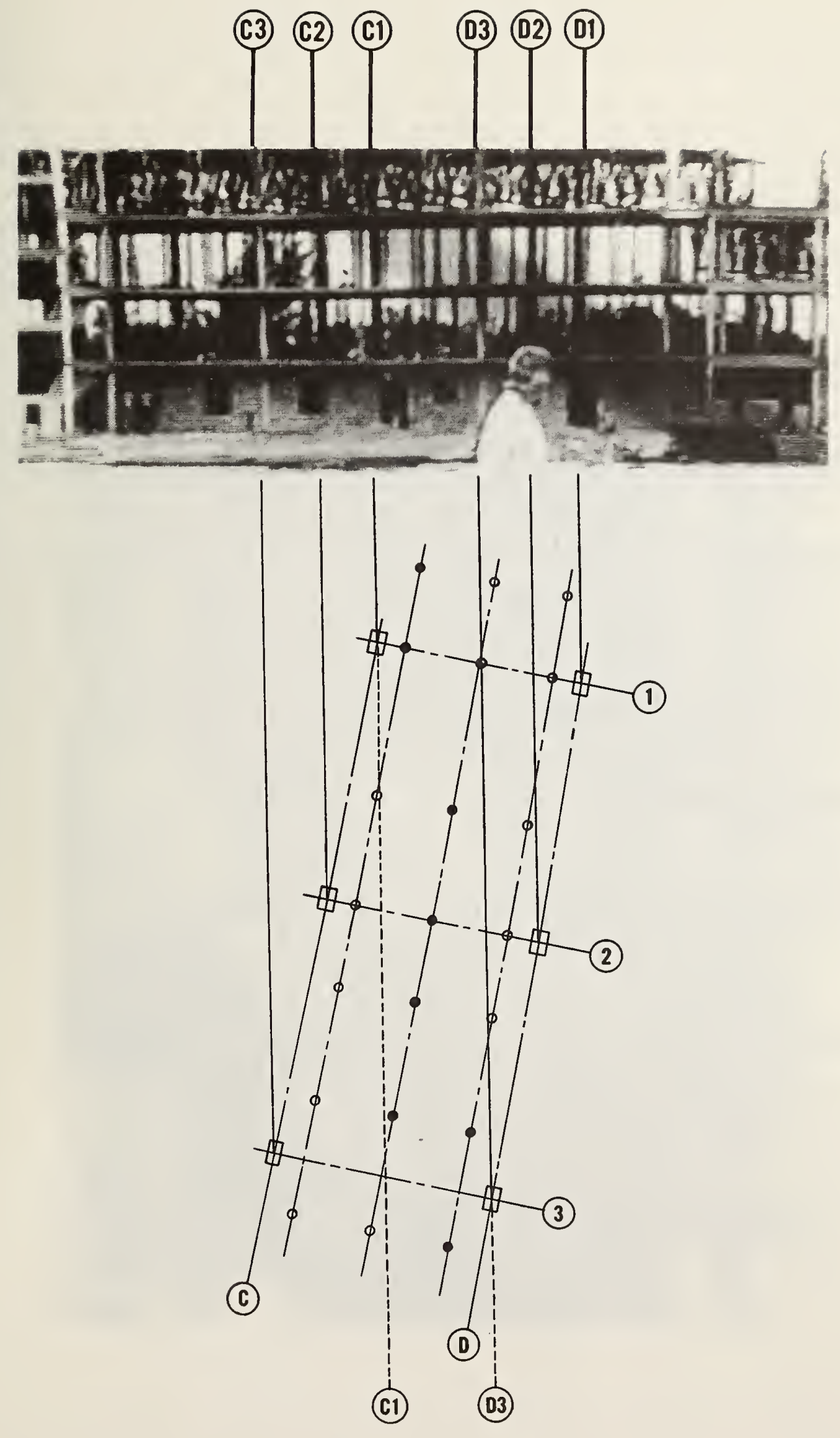

Figure 2.12 Schematics for determining amount of reshores using partial view of east side of building 


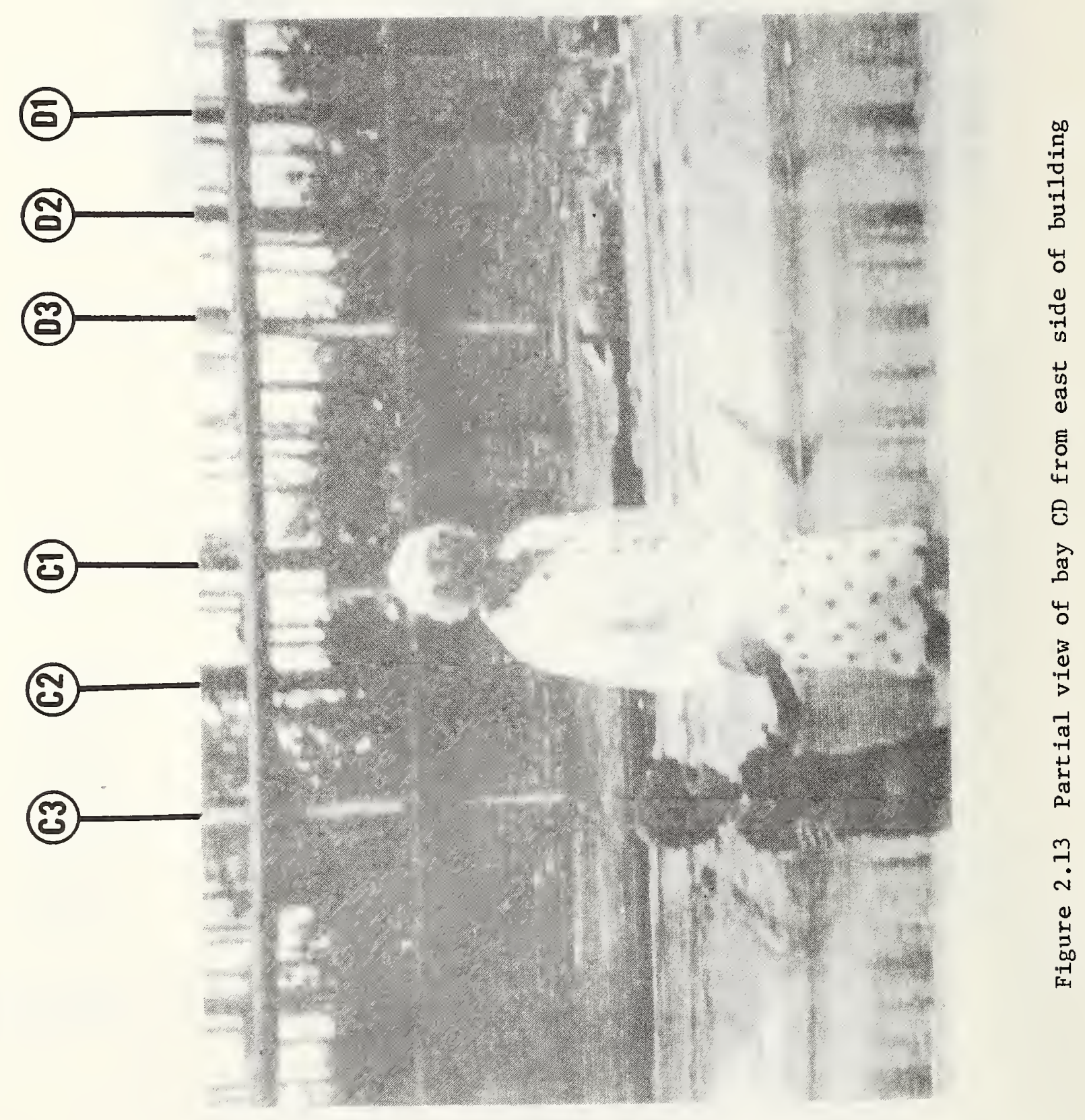




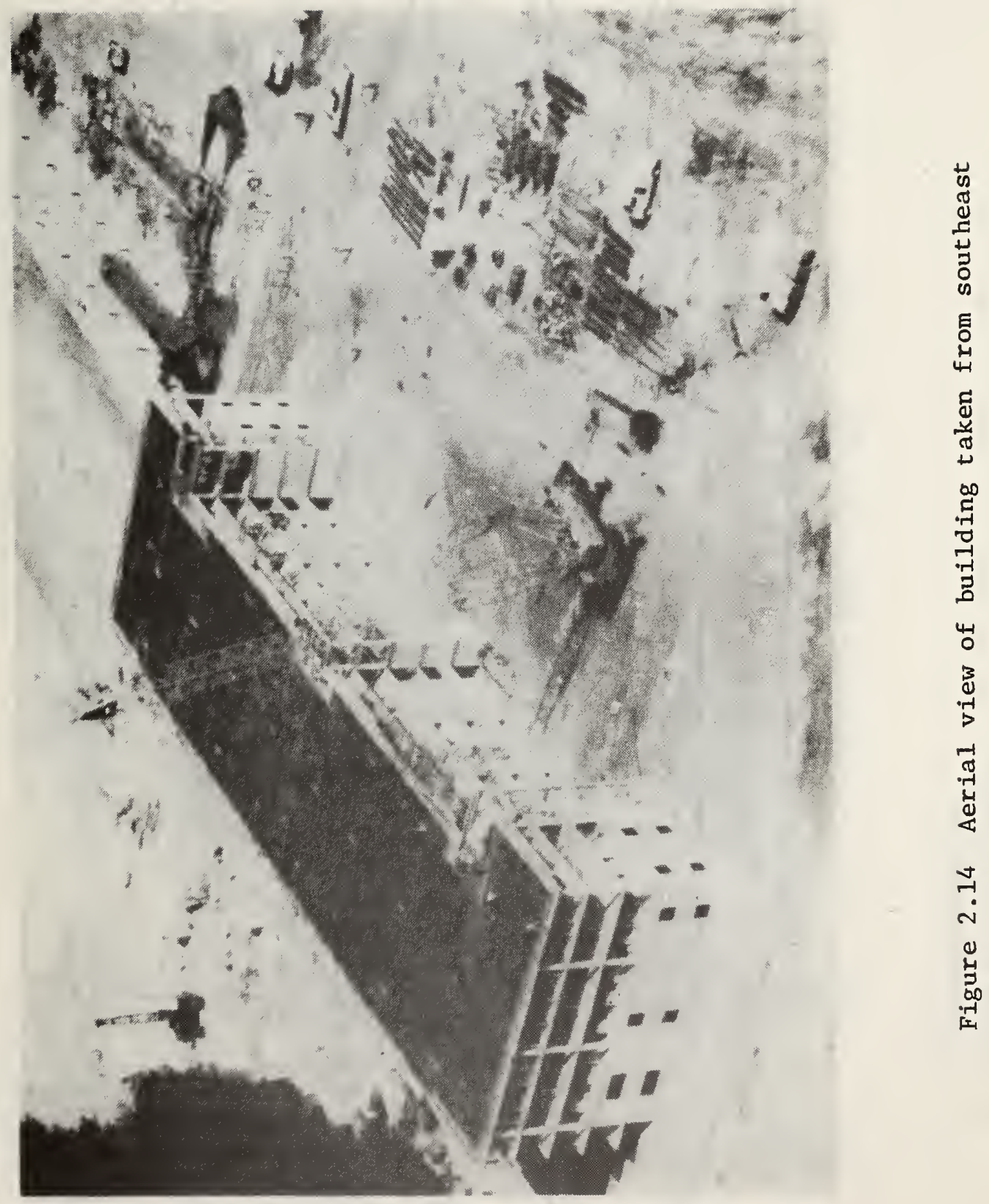



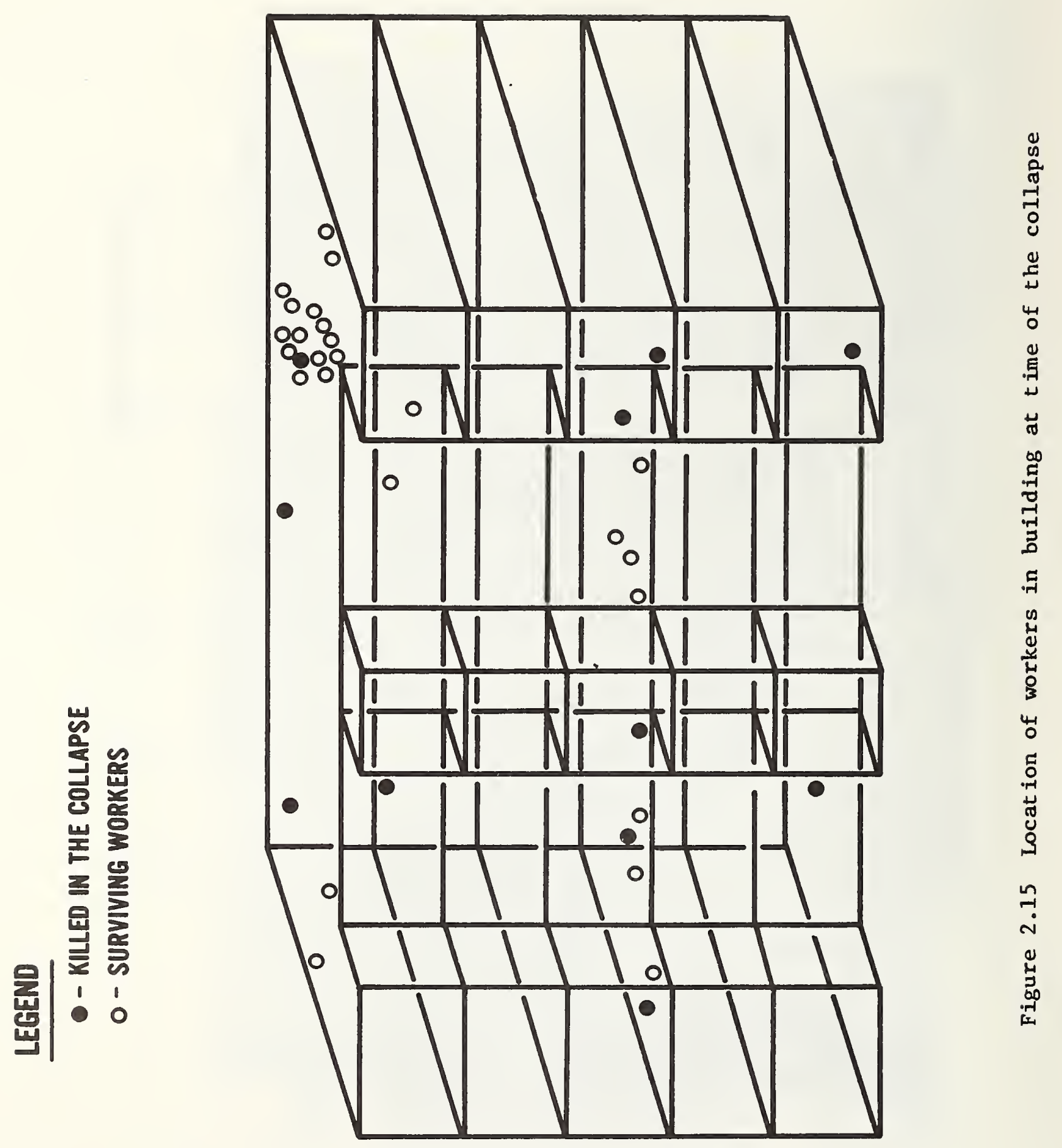


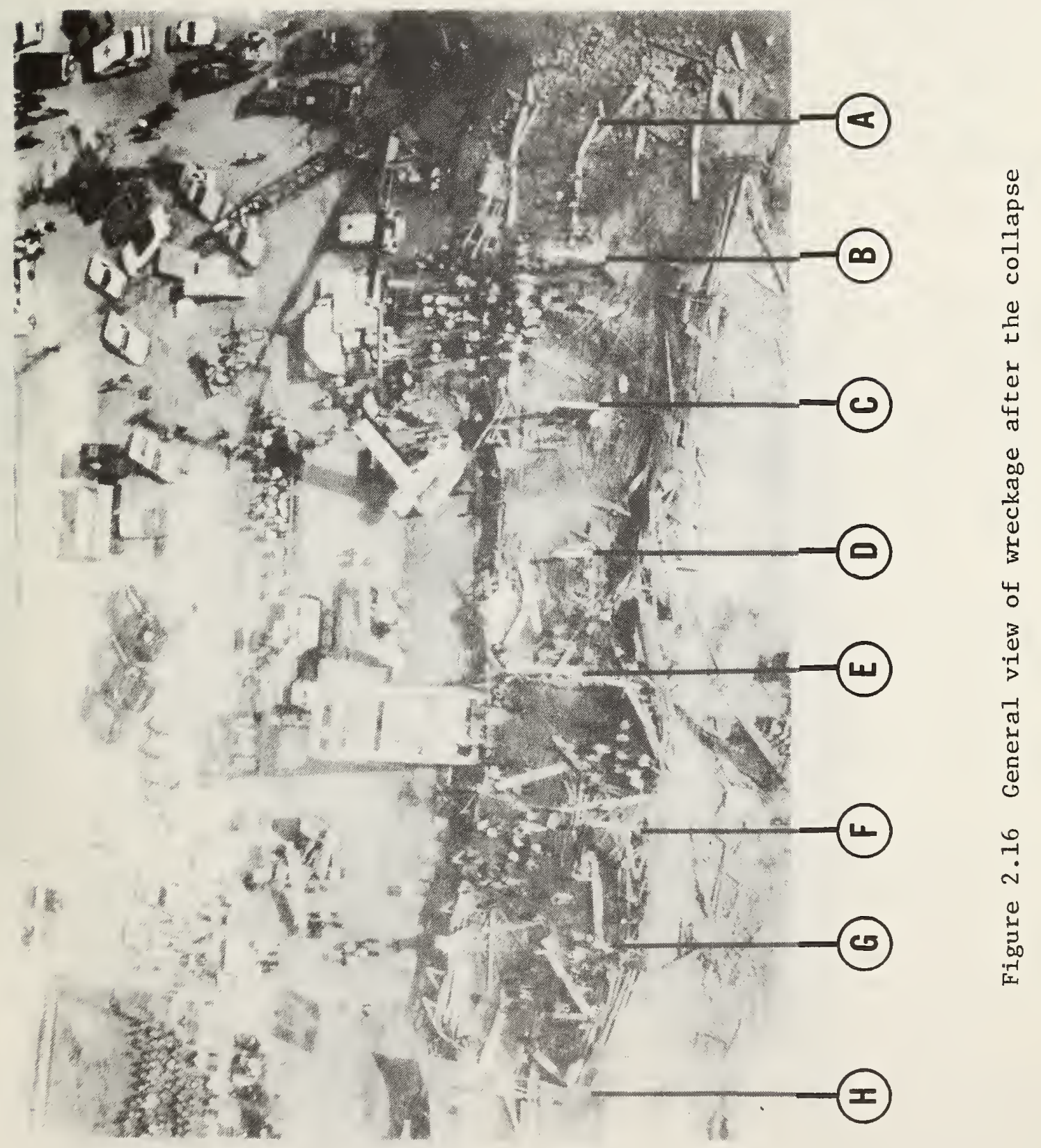




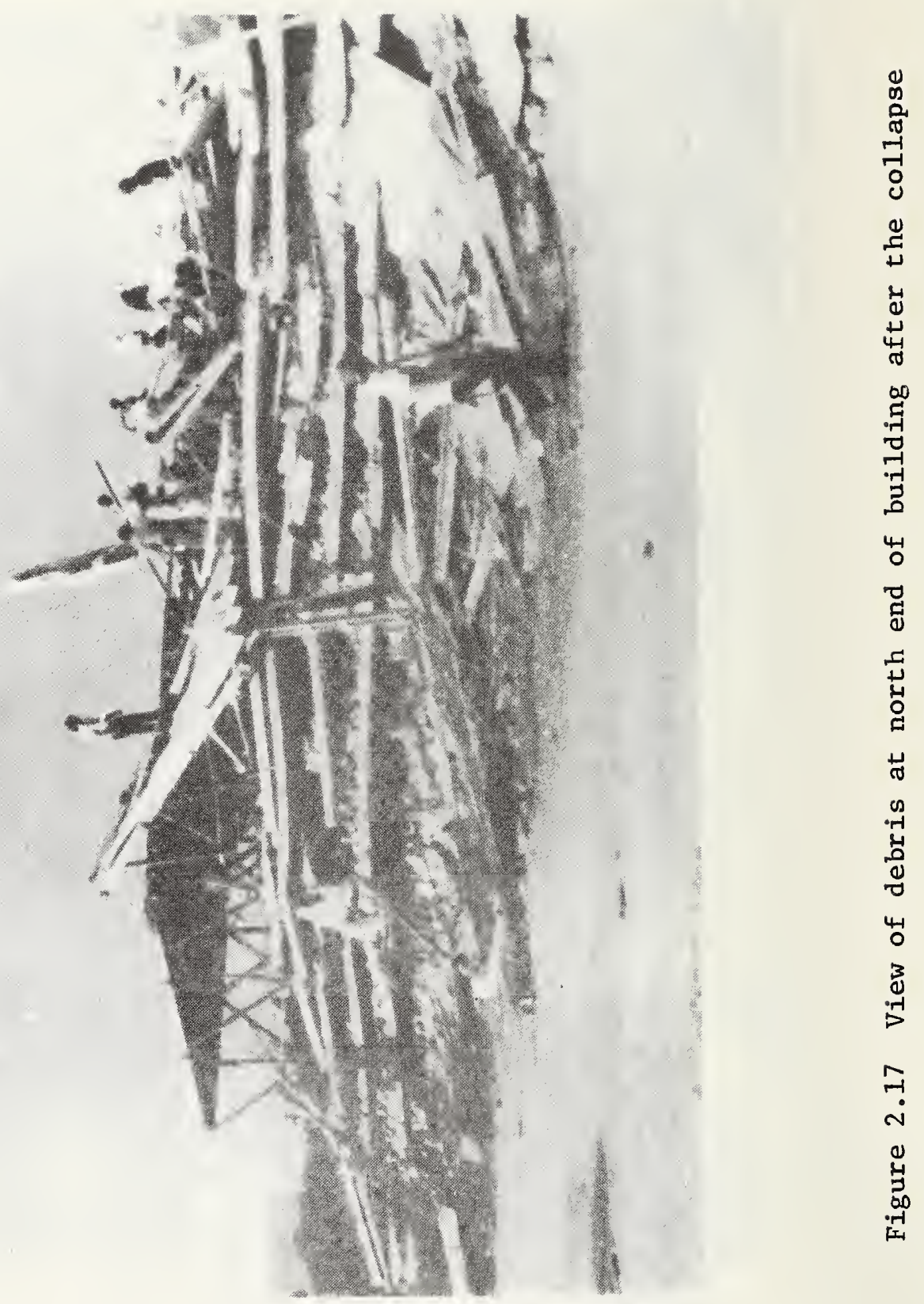




\subsection{INTRODUCTION}

Section 3.2 presents observations and measurements made by NBS during two site visits to Cocoa Beach, Florida, and sec. 3.3 summarizes the statements made by individuals who were interviewed by the OSHA officials during the course of the investigation. The first site visit was made on March 28-30, 1981, one day after the collapse, and the second visit was made on April 7-8, 1981. During the visits, the structural components were examined visually as they were removed for rescue operations, selected key components were identified and marked with paint for later removal of drilled cores, and measurements of member dimensions were made.

\subsection{INVESTIGATION AT THE SITE}

A thorough inspection of the undisturbed wreckage for possible clues as to the cause of the collapse was ruled out during the rescue operation, which involved over 200 people and was not completed until the morning of March 29. Instead, a substantial number of photographs were taken before and during the removal of debris. The stacked configuration of the second through fifth floor slabs (as seen in figure 2.17) showed no evidence of sidesways or overturning. Examination of the debris and photographs did not provide any further clues than those supplied by workers as to the exact location of the origin of the collapse.

In order to carry out rescue operations, the floor slabs were cut into approximately $20 \mathrm{ft}(6 \mathrm{~m})$ square pieces by air hammers and removed by mobile cranes. All slab layers (2nd, $3 \mathrm{rd}, 4 \mathrm{th}$, and 5 th floor) were removed in this manner. Some of the slab sections and columns were salvaged and their location in the building was identified (figure 3.1). They were the source of core samples which were subsequently tested for ingredient content and compressive strength (chapter 4). The slab sections were also used to determine size and location of reinforcing bars and support chairs (sec. 2.3).

Careful examination of a number of column pieces revealed the following:

1. The slabs broke away from the columns at the slab-column interface (figure 3.2).

2. One or two bottom slab bars were placed through some columns. In many other columns no such evidence was noted.

3. In some cases, the vertical reinforcement above the floor level was bent severely during fabrication (figure 3.2).

4. Column size measurements agreed with the structural drawings.

It was also noted from the first-story column sections still standing on the ground level that where 8- \# 10 or 8- \# 11 bars were lapped, in a $10 \times 18$ in $(250 \times 460 \mathrm{~cm})$ column section, the total steel area exceeded considerably the maximum limit of four percent of the gross area of the concrete allowed by the 
ACI Code [2.1]. As shown in figure 3.3, the vertical reinforcement was so congested that there was hardly any space left between adjacent bars to allow the flow of concrete during placement.

The slab thickness was measured at several locations where concrete cores were taken. In all cases, the thickness was within $\pm 1 / 8$ in $(3 \mathrm{~mm})$ of 8 in (200 $\mathrm{mm})$. Further data on slab thickness were obtained from measurements of the lengths of the core samples (chapter 4). These measurements confirmed the agreement of the slab thicknesses with the construction drawings.

The onsite batch plant, located southeast of the building, had a single compartment hopper into which a front-end loader deposited both coarse and fine aggregate. The cement was weighed by a separate hopper. The onsite batch plant was equipped with large tanks containing the various admixtures that were added to the concrete. Smaller admixture tanks on the west side of the building contained the superplasticizer that was added prior to discharge of the concrete truck.

The weighed materials were deposited into a 15 cubic yard $\left(11.5 \mathrm{~m}^{3}\right)$ ready-mix concrete truck for mixing and delivery to the discharge point adjacent to the building under construction. The distance of travel of the truck between the onsite plant to the discharge point was about 150 yd (137 m).

Samples of concrete-making materials were obtained from the onsite plant and from the ready-mix plant which also supplied concrete for the project. Some samples were sent to a testing laboratory for analysis, and others were sent to NBS for use in making concrete mixtures (see chapter 4).

\subsection{INTERVIEW STATEMENTS OF WORKERS}

As part of the investigation, OSHA compliance officers interviewed workers and others who were involved in the construction of the building. The statements obtained from the interviews provided valuable information which served as source documents in reconstructing the events prior to the collapse. This section summarizes their contents pertinent to the investigation. These include the location of reshores on the day of the collapse; deficiencies encountered in the performance of the building as it was being constructed; quality of the concrete; and eyewitness descriptions of the collapse. In the following sections, the numbers in parentheses refer to numbers assigned to the interview statements.

\subsubsection{Location of Reshores}

One of the critical elements in the determination of the cause of the collapse is the location and number of reshores in the building at the time of the collapse. The interview statements contained conflicting testimony. Four employees ( 1 7, $\$ 50, \# 53, \ldots 65)$ stated that reshores were in position on the second, third, and fourth floors. On the other hand, others (\#8, 1 9, \#12, \#22, \#25, 非0) indicated that there may not have been the full amount of reshores on the second and third floors. One of the workers (非) claimed that reshores were removed from the lower floors for use on upper stories, but it was also 
stated (\#39) that enough posts were put into the building to fully reshore three floors. Other workers (非 1 , 非, 非7, 非) said they saw masons remove some posts or saw posts fall down which were not replaced. These statements were contradicted by others who said the masons did not touch the posts while placing concrete block walls (非63) or that posts were periodically replaced (非).

Several workers (非7, 非10, 非18，非2，非4，非2, 非4, 非5) stated that they saw bowed reshores and two workers ( 32 , 非4) saw two reshores on the fourth floor break or fall while concrete was being placed on the roof.

According to a supervisory worker (非) there was no reshoring plan to follow, and one of the superintendents directed him to change from two to three rows of reshores per bay for the third floor and above. There were only two workers who described how the reshores were installed (非5, 非3); the reshores were held in position by wedges inserted between the floor slab and the reshores. There is no indication that the wedges were driven in so as to lift the slab and relieve its self weight.

In summary, based on the personal interview statements, it is not possible to determine firmly the reshoring layout at the time of collapse. The fourth floor probably contained the full number of reshores as indicated on the reshore drawing supplied by the general contractor after the collapse. The first floor probably contained no interior reshores (some shores were probably present along the balcony and walkway beneath the block walls placed on the second floor). The precise number and locations of reshores which existed on the second and third floors is unknown.

\subsubsection{Construction Deficiencies}

There were many statements by workers of different trades concerning the existence of cracks in all the slabs. The testimonies indicate that the cracks were noticed shortly after the flying forms were removed and that they were located around the columns and near the midspans. These cracks were marked with crayon by one of the superintendents. On March 10, 1981 the structural engineer inspected the building; the second and third floors were in place by that time. According to one of the superintendents, the engineer suggested that additional reinforcing bars be added in the midspan of the walkways. Similar cracks subsequently developed in the fourth and fifth floor slabs. A worker (\#34) described them as "spider cracks," and reported that upon removing plumbing sleeves from floor slabs, the cracks could be seen extending to a depth of 4 to 5 in (102 to $127 \mathrm{~mm}$ ) into the slabs.

In addition to the cracks, it was reported that noticeable deflections occurred in the slabs after the forms were removed. According to one of the superintendents, the deflections were most evident in the north and south end apartment units; on the second floor, a deflection of $1-3 / 4$ in (45 mm) was noted in the end apartment on the north side of the building.

Four employees (非, 非, 非8, 非3) mentioned another significant problem which occurred during construction. During placement of the roof, a water puddle 
formed on the east side near the elevator tower, indicating that a low point existed. Additional concrete (an unspecified quantity) was added to the depressed area but it was reported (非, 非) that the water puddle reappeared after refinishing the area. Apparently (according to 338 and 非3), the same problem occurred at the same location during placement of the fourth floor.

Three workers (非0, 非5, 非3) mentioned that the construction joints at the middle of the building were not of good quality. They were described as "ragged", "cracked", and "honeycombed". Two workers (\#45, \#14) mentioned that they saw rebars showing on the faces of some columns. The incomplete filling of the column forms was probably due to congestion of steel (see figure 3.3), which, according to a supervisor ( 1 (12) was so severe in some of the second and third floor columns that the top reinforcing steel in the slabs could not pass through. In order to pass slab bars through some columns, the protruding column reinforcement was "bunched together" and the slab bars were placed alongside the column bars (figure 3.2 ).

\subsubsection{Quality of Concrete}

The concrete for the building was supplied by an onsite batch plant operated by the general contractor and by a ready-mix company. According to the onsite batch plant operator (非7), the ready-mix company supplied about one-third of the concrete used in the floor slabs. All of the concrete for the columns came from the onsite batch plant. Chapter 4 will contain more details of the mix proportions and the results of strength tests by the testing laboratory. In this section, workers' impressions of the concrete quality is presented.

Based on the Department of Professional Regulation's report and the diaries of the construction manager and the general contractor's superintendent, it was determined that the developer's superintendent, who usually oversaw the batch plant operation, was absent from February 2, 1981 until March 9, 1981. During the week of March 2, 1981, the general contractor's superintendent was also on vacation. A worker (非) stated that during the placement of the second and third floors, the concrete appeared to have erratic slump; he estimated that the slump varied from three to nine inches. Referring back to the construction schedule (section 2.4), it is seen that the third floor was placed while both job superintendents were absent. The same concrete finisher stated that the texture and slump became more consistent after the developer's superintendent returned to the job site.

Severa1 workers ( $\$ 37$, \#74, 非2, \#34, \#63) who talked to masons mentioned that some of the concrete was difficult to finish and tended to set up quickly. This may be attributed to the slump loss [3.1] associated with the use of superplasticizers (which was added to the concrete in the trucks prior to placement). Apparently on some batches with lower than normal water contents, it was necessary to add more than the usual quantity of superplastercizer to produce the proper consistency for placement (see section 4.2). By the time finishing operations were performed, the workability was reduced due to slump loss; during finishing the concrete reflected its low water content. According to the statements of two workers (非34, 非4), this problem occurred only with the concrete prepared on site. 


\subsubsection{Description of the Collapse}

Descriptions of the collapse were provided by 28 persons, 13 of whom were located in the building. Ten of those in the building who described the collapse were on the roof, one was on the fifth floor, another on the fourth, and one on the third floor. The remainder were on the ground at various locations with respect to the building.

According to those on the roof at the time of the collapse, concrete was being placed at approximately column line $\mathrm{H}$ (see figure 2.1). Thus, the two flying forms at the north end of the building did not have concrete on them. One worker (非) said he had felt the building tremble two or three times during the day without any apparent reason. He was on the form between column lines $H$ and $J$ and near the west side when the collapse occurred, and he described the plywood as tilting toward the south and east. He described the fall as "one long slide with one thump." Another worker (非), who was also on a dry form, stated that his "feet were suddenly knocked out from under" him and noticed that the finishing crew had fallen to a lower level. An employee (非18) working 50 to $60 \mathrm{ft}$ ( 15 to $18 \mathrm{~m}$ ) south of the finishers heard a rumble and saw the roof caving in at the position of the pour; the "wave" moved toward him as he turned away toward the south. Other witnesses (非, 非, 非6, 非38) a1so indicated that the apparent origin of the roof collapse was in the vicinity of the boundary of freshly placed concrete, 1.e., column line H. A worker (非6) who rode down on the dry form near the north end stated that he "could see that the middle of each floor gave way as each floor was collapsing."

A person working on the fifth floor (非) said he heard a "pop" about 5 to 10 minutes prior to the collapse. He was standing near the center of the building near column line $H$ when "the fifth floor fell out from under" him. He further stated that "the floor fell straight down with slight hesitation at the fourth and third floors."

A worker on the fourth floor (非4) also believed the collapse originated in the middle of the building but could not say which floor fell first. However, he stated that he didn't think it was the top floor otherwise he would have been "hit on the head." A person (非) on the third floor who was working on a block wall near column line F stated that he "heard a crack overhead, looked to the southeast and saw a big hole and it was coming towards him." He further stated that he tried to run but the floor fell out from under him.

A person (非2) who was working at the garage northeast of the building offered this account of the collapse: "I heard a crack and the center of the fifth floor started down followed by the rest of the floor, and then the fourth, third, and second floors right on top of each other with the roof of wet concrete following. The floors appeared to slide right down around and over the columns." The same general description was also supplied by others on the ground (非5, 非5, \#27, 非29, 非0). An employee (非29) who was at the northwest corner of the building stated that "the fifth floor, about the second set of columns from north end of floor gave out and the building came down." A worker (非40) who was north of the building also described hearing a crack and seeing 
the fourth and fifth floors coming down to meet the third floor; he also saw the middle of the building "go in" first.

Different descriptions were provided by persons at other vantage points. A worker (\#39) who was on the northwest side near the second bay from the north end he stated: "I saw the extreme northwest corner of the fourth floor near the columns starting to fall, tilting eastward, then the rest of the fourth floor fell, then the fifth floor and the flying forms caught up with the fourth floor and the whole building collapsed."

A person (非2) working north of the building said he heard a loud crack like wood splitting, looked up and saw the flying form going down while the fifth floor was still in place. Another laborer (非43) who was $50 \mathrm{ft}$ (15 m) away and walking toward the northeast corner, heard cracking noises and witnessed the south end of the building at the top falling first toward the north followed by the collapse of all the columns.

\subsection{SUMMARY}

Based on the site visits, the following conclusions were drawn:

1) The failure mode appeared to be of the punching-shear type, because the slabs had broken away from the columns at the slab-column interfaces.

2) There was no evidence that sidesway or overturning of the building had occurred.

3) Measurements of the outside dimensions of selected column and slab sections indicated conformity with the structural drawings.

4) The reinforcing steel in some first-story columns did not meet the clear spacing requirements of the ACI code.

The worker interview statements gave valuable information on the circumstances prior and up to the collapse, and provided eyewitness accounts of the failure. The following were some of the significant findings from these statements:

1) It was not possible to establish the exact layout of reshores at the time of collapse. The first floor appears to have had only a few exterior reshores in place, and the fourth floor probably had the full amount of reshores. Conflicting statements were given as to the number of reshores on the second and third floors.

2) Extensive cracking occurred in floor slabs when supporting formwork was removed. The structural engineer was made aware of this problem.

3) The concrete produced by the onsite batch plant was non-uniform in terms of consistency and finishability. The greatest problems were reported during the absence of both job superintendents. 
4) Descriptions of the collapse by workers on the site indicate that the most probable origin of the collapse was in the fifth floor slab in the vicinity beneath where the roof concrete was being placed. 


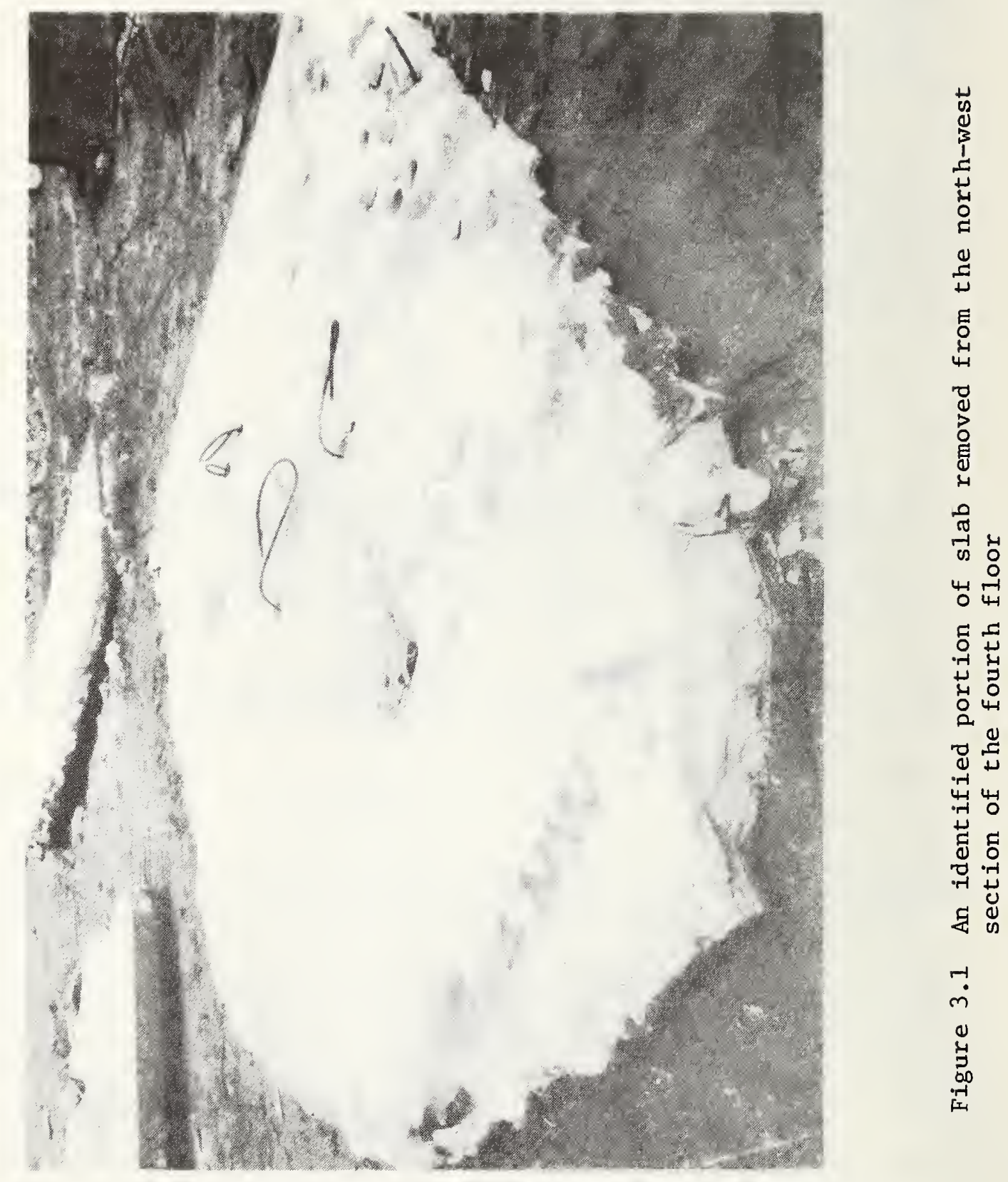




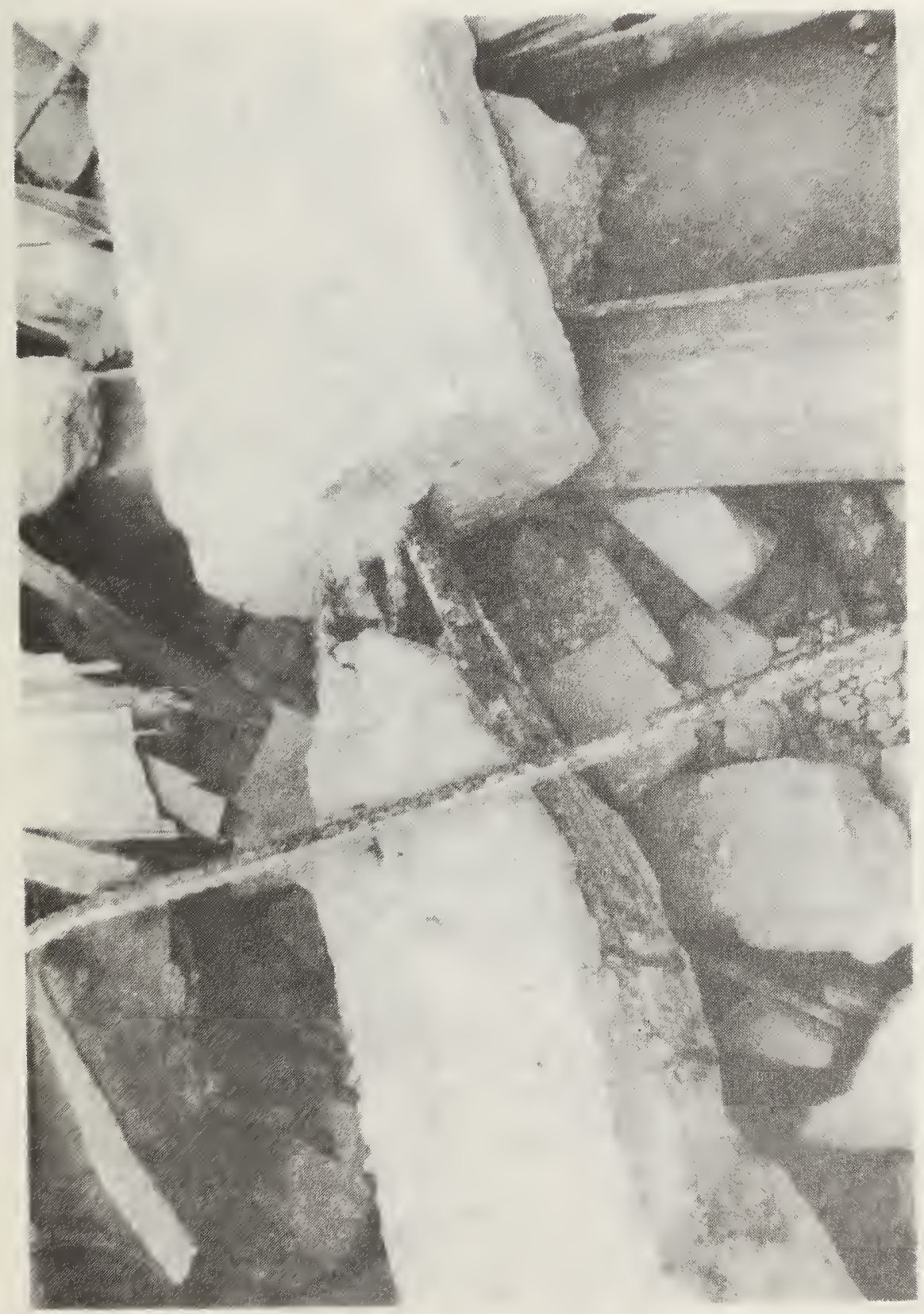

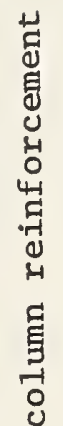

芩

崩

พ

m

苟 


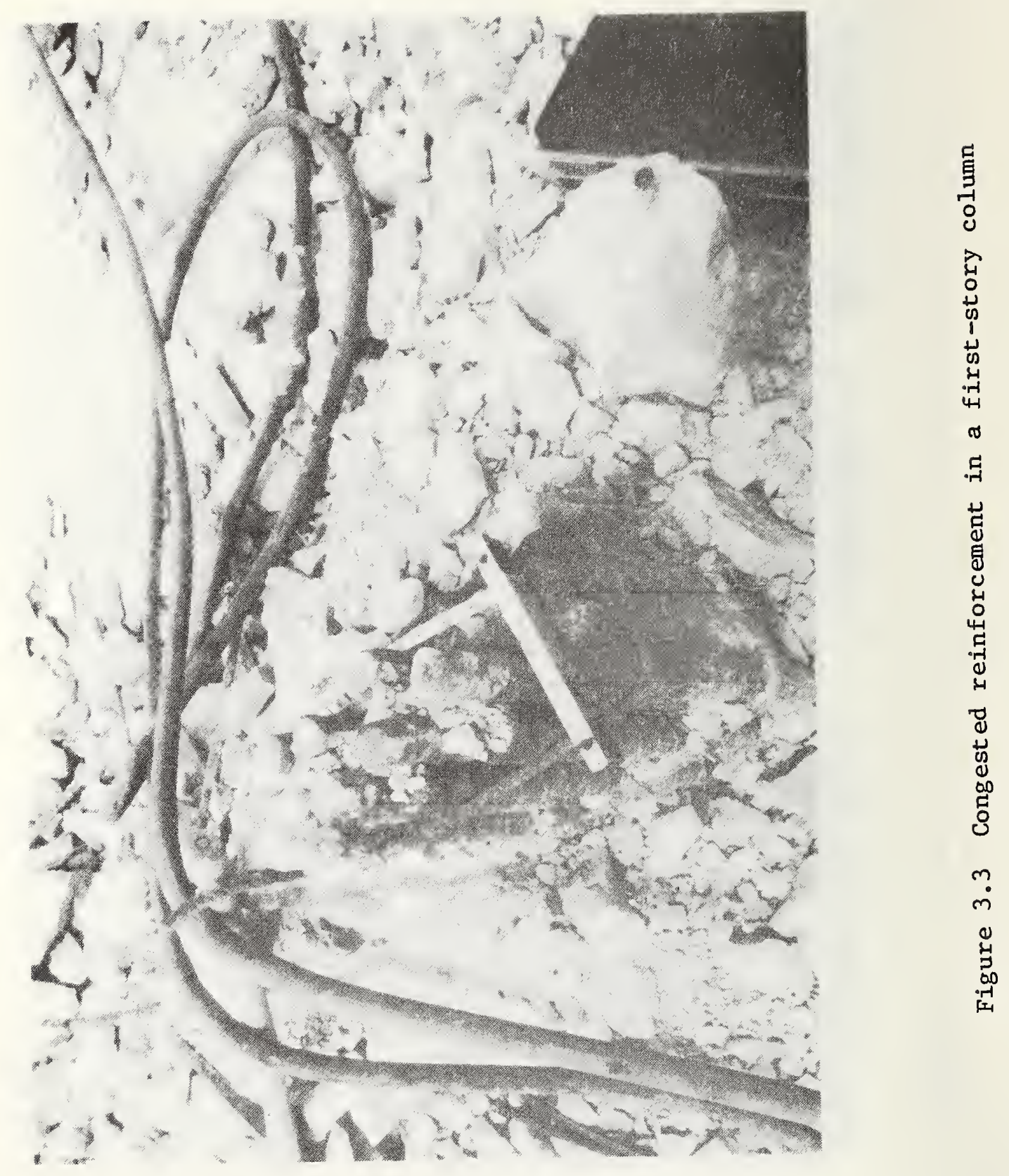




\subsection{INTRODUCTION}

The objective of the laboratory investigations was to establish the strength of concrete in the structure at the time of the collapse. The approach used involved gathering data from the site and preparing concrete mixtures representative of the inplace concrete. A commercial testing laboratory was contracted by OSHA to carry out tests on concrete cores from the site. This laboratory took drilled core samples from identified portions of the structure as directed by NBS. The cores were used for compressive strength tests, petrographic examination, and chemical analysis. In addition, samples of the ingredients used in the concrete were taken and subjected to physical and chemical analyses.

Based on the available mix design information, three concrete mixtures were prepared at NBS from which specimens were cast for strength testing at specified ages. The results of these tests were compared with the core strength data.

Section 4.2 discusses the information provided by OSHA dealing with the prescribed concrete mix proportions and the results of quality control tests performed on the concrete.

Section 4.3 summarizes the results of tests conducted on samples of concrete ingredients and drilled cores taken from the site after the collapse.

Section 4.4 presents the results of the NBS laboratory investigation. This includes the strength-gaining characteristics of the concrete mixes, and the predicted strengths of various portions of the structure at the time of collapse.

\subsection{INFORMATION ON FIELD CONCRETE}

OSHA interviewed the onsite batch plant operator (Univel) and the president of the ready-mix company (Dixie) to determine the mix designs that were being followed. Table 4.1 shows the stated mix proportions (saturated surface dry basis) for one cubic yard of $4000 \mathrm{psi}(27.6 \mathrm{MPa})$ concrete. The onsite batch plant used the same proportions for the floor slab and column concrete, except that $3 / 8$ in $(10 \mathrm{~mm})$ maximum size aggregate was used for the columns, whereas $3 / 4$ in $(20 \mathrm{~mm})$ maximum size was used for the slabs. The ready-mix plant only provided concrete for the slabs and used 1 in (25 mm) maximum size aggregate. All mixtures contained an air entraining agent (AEA) and a water reducer/set retarder (WR/SR). In addition, a high range water reducer (HRWR), or superplasticizer, was added by the general contractor prior to discharge from the concrete truck mixers. According to the onsite batch plant operator, 2 gal* of superplasticizer were added to 10 or 11 cubic yard* trucks and $1-1 / 2$ gal were added to 9 cubic yard trucks. A waterproofing admixture was added along with

\footnotetext{
* 1 gallon $=3.785 \times 10^{-3} \mathrm{~m}^{3}$

1 cubic yard $=0.7645 \mathrm{~m}^{3}$

1 ounce $=2.457 \times 10^{-5} \mathrm{~m}^{3}$

100 pounds $=45.36 \mathrm{~kg}$
} 
superplasticizer to concrete placed for balconies and walkways. The dosage reported by the batch plant operator was $4-1 / 2$ to $5 \mathrm{gals}$ per truck. The manufacturer's recommended dosage for these admixtures were as follows: AEA, $3 / 4$ to 3 oz per hundred pounds of cement; WR/SR, 5 to $8 \mathrm{oz}$ per hundred pounds of cement; HRWR, 15 to $20 \mathrm{oz}$ per hundred pounds of cement.

The ready-mix company had a computer-controlled batch plant and employed a moisture meter in the sand bin. The onsite plant did not make moisture content determinations, and based aggregate weights on assumed moisture contents of 1 percent and 3 percent for the coarse aggregate and sand, respectively.

Based on the available testimony, it appears that water was added until the concrete reached a slump in the range of 3 to 5 in (76 to $127 \mathrm{~mm}$ ). The batch plant operator stated that he performed slump tests on the first two trucks each day, but made no record of these values. Additional water had to be added to mixes that "tightened up" in the mixer, possibly due to absorption of water by the highly absorptive stone when it was mixed in a dry condition.

Daily reports of the onsite batch plant indicated: the size of the batches; the type of concrete; the truck number; the batch weights of cement, sand, coarse aggregate, water reducer and air entraining agent. The quantities of ingredients shown on the reports agreed with the quantities called for in the 4000 psi (27.6 MPa) mix design. However, in most of the reports, the column labeled "Gals. Water" contained no entry of the quantity of water added. When the quantity of water was reported, it was observed that widely different quantities were reported for batches of the same size. This may reflect changes in the moisture content of the aggregates, or that dissimilar concrete mixtures were being produced. There were no copies of the delivery tickets of the ready-mix concrete.

The general contractor employed a testing laboratory to inspect samples of concrete prior to placement and prepare standard $6 \times 12$ in (152 x $305 \mathrm{~mm}$ ) cylinders for quality control testing. On the days of floor slab placement, samples were taken from one truck from the ready-mix plant and one truck from the onsite plant. Concrete used for the columns which was supplied by the onsite plant was not sampled. Table 4.2 summarizes the information contained in the test reports: the first column indicates the date and time of sampling; the second and third columns indicate the supplier and where the concrete was placed, respectively; the fourth column is the slump, which was measured after the addition of the superplasticizer; the fifth and sixth columns give the test age and compressive strength of the cylinders; and the last column indicates the quantity of superplasticizer added. Note that only one cylinder was tested at early ages, while two were tested at 28 days. Some 28-day strengths apparently exceeded the capacity of the testing machine and may account for the $"+$ " after some strength values.

A study of table 4.2 reveals several significant facts. The typical slump was in the range of 8 to 10 in (203 to $254 \mathrm{~mm}$ ) except for samples of the onsite plant concrete taken during the placement of the north half of the second floor and both halves of the third floor. One might infer that these samples had lower than normal water content, and this is borne out by the very high 
early strengths of the corresponding cylinders. Both job superintendents testified that the early age strength results were used to determine if sufficient strength had been reached for form removal. They testified that forms were removed only if the cylinder strength exceeded $2 / 3$ to $3 / 4$ of $4000 \mathrm{psi}$ $(27.6 \mathrm{MPa})$. In general, the reported test ages agree with the formwork removal schedule. However, it appears that the fifth floor samples were not tested

at ages corresponding to the formwork removal times. The practice of using laboratory-cured cylinders intended for quality control testing for the purposes of scheduling formwork removal may be an unsafe approach if the inplace maturity (see section 4.4.3) at test age is less than the maturity of the control cylinder. Finally, only three test reports give the quantity of plasticizer added to the mixes, and in each case it exceeded the quantity specified by the batch plant operator. This may indicate that these mixes had lower than average initial slumps and that more admixture was required to produce the typical 8 to 10 in (203 to $254 \mathrm{~mm}$ ) slump.

The strength and age data in table 4.2 are shown in figures 4.1 and 4.2 for the onsite plant and ready-mix concretes, respectively. Also shown are the bestfit curves to represent the data. In figure 4.1 two curves are shown, the solid curve includes all the data, while the dashed curve excludes those data of the low slump samples for the north half of the second floor and both halves of the third floor. In general, these data indicate that the 28-day strengths are consistent with the specified strength of $4000 \mathrm{psi}(27.6 \mathrm{MPa})$. However, samples of concrete from the fifth floor are weaker than samples from other floors.

\subsection{TESTS OF SAMPLES FROM THE SITE}

A commercial testing laboratory was retained by OSHA to secure samples from the site and carry out the pertinent tests. This section summarizes the information obtained from the report of the testing labortory

\subsubsection{Concrete Ingredients}

Samples of cement, aggregates, water, and admixtures were secured from the onsite plant and from the ready-mix plant. Appendix A contains the reported results of physical and chemical tests on the samples. Table A.1 shows the physical characteristics of sand and coarse aggregate samples. The coarse aggregates had higher than typical absorption capacities for normal weight aggregates. The sands were finer than typical concrete sands, and the coarse aggregates did not, in general, have uniform particle size distributions which may explain some of the finishing difficulties mentioned in section 3.4 .3 .

The results of chemical analyses of cement samples are presented in table A.2. Except for differences in setting times, there were no significant differences between the samples from the two batch plants. The samples meet the requirements of ASTM C150 [4.1] for Type I cement. Because samples were taken only after the collapse, it is not known whether all cement in the structure agreed with the results in table A.2. 
Tables A.3 and A.4 show the results of tests on water and admixture samples. Although a pond water sample was chemically analyzed, there were no indications from the available data that pond water was used in the concrete.

\subsubsection{Core Strength}

Core samples were drilled from column and slab sections from April 1 to April 3, 1981. Some cores were used for compressive strength determinations and others for petrographic and chemical analyses. Table 4.3 indicates the identification numbers and locations in the structure, as identified by NBS, of six column sections and 14 slab sections from which cores were drilled. Also shown are the number of cores tested in compression from each section. An attempt was made to obtain at least six strength values from each floor level in the structure.

The cores from each part of the structure were tested at three ages: soon after core samples were obtained and at seven and 14 days subsequent to the first test. The samples were stored in plastic bags to preserve the inplace moisture conditions until tested. Table A.5 gives the dimensions, ages and strengths of the tested cores. The cores had nominal 2, 3, and 4 in ( 51,76 , and $102 \mathrm{~mm}$ ) diameters. The reported compressive strengths include the standard (ASTM C 42 Standard Method of Obtaining and Testing Drilled Cores and Sawed Beams of Concrete) correction factors for cores with an aspect ratio less than two [4.1]. Figure 4.3 shows the floor slab core strengths as a function of their test ages. Cores from the south half are identified by a shaded symbol. Except for two 23-days old cores from the south half of the fifth floor (and a severely damaged core from slab section 13), the strengths were greater than the specified strength of $4000 \mathrm{psi}(27.6 \mathrm{MPa}$ ). However, all cores (except the damaged one), satisfy the " 85 percent of specified strength" criterion in section 4.8 .4 .4 of the ACI Code [2.1]

Figure 4.4 shows the compressive strengths of cores drilled from columns. Since it was not known whether the column sections were from the north or south halves of the building, the age shown in Figure 4.4 is the average age of the north and south columns on each floor. It is evident that the concrete in the columns was weaker than that in the floor slabs. The average strength of the fifth story cores does not satisfy the ACI Code strength criterion mentioned above.

The lengths of unbroken cores from the slab sections had an average value of $8-1 / 16$ in $(205 \mathrm{~mm}$ ) with a standard deviation of about $3 / 16$ in $(5 \mathrm{~mm})$. Four cores were about 6-1/2 in (165 mm) long which indicates cores from the walkway or balcony areas.

\subsubsection{Petrographic Analysis}

Nineteen 6 in $(152 \mathrm{~mm})$ diameter cores were used for subsequent petrographic and chemical analyses. Eleven cores were from column sections and eight from slab sections as indicated in table 4.3. Polished sections were examined with a stereo-microscope according to ASTM C 856 (Standard Practice for Petrographic Examination of Hardened Concrete [4.1] . The polished sections were also examined according to ASTM C 457 (Standard Practice for Microscopical Determination 
of Air-Void Content and Parameters of the Air-Void System in Hardened Concrete) [4.1], from which the volume fractions of paste, sand, coarse aggregate and air were measured. In addition, specific gravity, percent absorption and percent voids were measured according to ASTM C 642 (Standard Test Method for Specific Gravity, Absorption and Voids in Hardened Concrete) [4.1].

Table A.6 in appendix A gives the results of the above analyses for each core; these results are summarized in table 4.4. For quantitative determinations the numbers in table 4.4 represent the average values and the numbers within parentheses are the standard deviations of the averages. The similarity of the slab and column cores in terms of percent volumes of the ingredients confirms the statements that the same mix proportions were used in the columns and in the slabs. An unexplained finding is the color of the cement paste: most of the fifth floor cores were gray, while the cores from the other floors were buff colored. The columns had slightly higher air content than the slabs, but in each case the air bubbles were characteristic of entrapped air (large size, large spacing) rather than entrained air. This phenomenon is consistent with a reported effect of superplasticizers [3.1].

\subsubsection{Chemical Analysis}

In addition to petrographic analysis, the core samples were used for chemical analyses to determine cement and admixture content. Analysis for cement was carried out in accordance with ASTM C 85 (Standard Test Method for Cement Content of Hardened Portland Cement Concrete) [4.1]. However, it is recognized that the method is imprecise when the concrete contains significant amounts of calcareous aggregates, which is the situation in this case since the coarse aggregate was calcareous and the sands also contained shell fragments. Separate tests were performed on samples of fine and coarse aggregates so that an allowance for the lime in the aggregates could be made when computing the cement content. Cement analyses were performed on seven column cores and six slab cores. The calculated cement contents, expressed as percentages of the unit dry weights of the concrete samples, are given on the last line of table A.6. Using the weight percent of cement and the corresponding dry specific gravity of each sample, the cement content was expressed in pounds per cubic yard of concrete. These quantitites are given in table A.7 of appendix A, and the average values are given in table 4.5. Using the volume percentage of paste (table A.6) and cement content, the approximate water content was calculated and the values are shown in table A.7, while the average values are given in table 4.5. Likewise, using the percentage volumes of sand and coarse aggregate, and their corresponding specific gravities (saturated surface dry), the weights of sand and coarse aggregate per cubic yard of concrete were calculated. Table 4.5 also shows the average aggregate contents for the column and slab cores.

Study of table 4.5 revealed the following points: (1) The calculated weights of sand and coarse aggregate are in excellent agreement with the quantities of the mix designs shown in table 4.1. (2) The calculated cement contents are significantly lower than the mix design values. (3) The calculated average water cement ratios are 0.65 and 0.72 for the columns and slabs, respectively. The low cement contents and corresponding high water-cement ratios are inconsistent with the core strengths. It is highly improbable that these high water 
cement ratios would result in the strengths shown in figures 4.3 and 4.4. This leads one to suspect that the calculated cement contents are not precise.

In addition to cement content analyses, the cores were examined for their admixture contents. The general procedure involved making reference samples of concretes with different admixture combinations; then, a solution of calcium carbonate was used to extract the admixtures from the samples; finally, the extractions were analyzed by infrared spectrometry and a comparison was made between the reference samples and samples from the cores. The procedure is best suited for sulfonated admixtures which include the water reducer/set retarder and superplasticizer that were used on the job. Table 4.6 summarizes the results of the analyses. The cores are identified in terms of their location as described in table 4.3. The quantities of admixture are expressed as a percent of the weight of concrete. According to the infrared analyses, the core samples had signature spectra that corresponded with reference samples made with the water reducer/set retarder or with a combination of superplasticizers (HRWR) and accelerating admixture. At the bottom of the table are shown the quantities of the admixtures used in the laboratory mixes (to be discussed in the next section) representing the ideal mix designs, and the manufacturer's recommended dosages for a cement content of $530 \mathrm{lbs}$ per cubic yard ( $315 \mathrm{~kg}$ per $\left.\mathrm{m}^{3}\right)$.

There are several contradictions between table 4.6 and the information obtained from the site. First is the appearance of the accelerating admixture, which according to the onsite batch plant operator was not used in the columns or floor slabs. For the column, the measured quantities of water reducer/set retarder are greater than the mix design values for the onsite plant. For the floor slabs, the measured quantities of superplasticizer and accelerator are in general lower than the mix design values. Some cores from the fifth and fourth floors had higher than expected quantities of water reducer/set retarder.

In summary, some of the chemical analysis results contradict or are inconsistent with other information. It is difficult to conclude whether such differences are real, or whether they are due to the difficult nature of the chemical analyses and the inherent uncertainties in the results.

\subsection{NBS LABORATORY INVESTIGATION}

The purpose of the NBS laboratory investigation was to establish the strength of the concrete in the structure at the time of the collapse. This was to be accomplished by developing the strength-maturity relations of the column and slab concretes. In addition, it was necessary to determine the elastic moduli of the concretes for inclusion in the structural analyses of the structure. Finally, it had to be established whether the concretes had typical tensile strength properties.

\subsubsection{Sample Preparation}

Samples of aggregate, cement, and admixtures were obtained from the onsite batch plant and from the ready-mix plant. These materials were used to prepare 
the concrete mixtures to be discussed. The original plan called for the preparation of concrete batches according to the stated mix designs as indicated in table 4.1 , and if necessary, for the preparation of mixes according to the results of the petrographic and chemical analyses of the core samples. Thus, three mixes were initially prepared: Mix I represented the concrete supplied by the ready-mix plant; Mix II, the onsite batch plant concrete for the floor slabs; and Mix III, the onsite plant concrete for the columns. It was assumed that the column concrete contained superplasticizer in the same proportion as the slab mixes.

In order to minimize the quantity of concrete that had to be mixed, $4 \times 8$ in $(102 \times 203 \mathrm{~mm})$ cylindrical specimens were used. However, some $6 \times 12$ in $(152 \times 305 \mathrm{~mm}$ ) cylinders were made for checking the results of the smaller specimens. Forty-five, $4 \times 8$ in (102 × $203 \mathrm{~mm})$ cylinders and seven $6 \times 12$ in $(152 \times 305 \mathrm{~mm})$ cylinders were molded from a 4-1/2 cu ft $\left(0.13 \mathrm{~m}^{3}\right)$ batch of each mix. A 9 cu ft $\left(0.25 \mathrm{~m}^{3}\right)$ capacity, revolving drum mixer was used.

Table 4.7 shows the batch quantities used for each mix. Coarse aggregate, sand and cement were placed in the mixer in that order. Water was added in two portions, one portion contained the air entraining agent, the other contained the water reducer/set retarder. The initial quantity of water was less than shown in table 4.7. After a period of initial mixing, a slump test was performed and additional water was added as needed to achieve a slump of three to five inches. When the desired slump was attained, superplasticizer was mixed into the concrete and slump, air content and unit weight determinations were made. As shown in table 4.7 , addition of superplasticizer at the dosage rate of 2 gal per 10 cubic yards $\left(9.9 \times 10^{-4} \mathrm{~m}^{3}\right.$ per $\left.\mathrm{m}^{3}\right)$ of concrete produced an increase in slump of about 3 in $(76 \mathrm{~mm}$ ) Referring back to table 4.2 , which shows the slump values for samples from the job, it may be concluded that in most cases either more than the above dosage of superplasticizer was used or the initial slumps were greater than about 5 in $(127 \mathrm{~mm})$

The air contents of the three mixes are in good agreement with the results of the petrographic analyses of core samples (table 4.4). Note that Mix I (representing the ready-mix concrete) contained more air than Mix II (the onsite plant concrete), which is consistent with the higher quantity of air entraining agent in Mix I. Mix III (containing small aggregate) had the highest air content, which is consistent with the known effect of aggregate size on air content: small aggregates tend to entrap more air in the mix than large aggregates.

When the aggregates were being weighed, samples were taken for moisture content determination. The moisture content values along with the batch weights and specific gravities, were used to calculate the volume percentages of paste and aggregates in each mix. Table 4.8 shows the results of these calculations, and for comparison the values from the petrographic analyses of the cores are also shown. There is good agreement between the laboratory mixes and the concrete in the structure. Thus, it was concluded that concrete used in the building agreed fairly well with the stated mix designs in terms of the relative volumes of paste, air and aggregates. 
After completing the fresh concrete tests, the cylinder molds were filled as follows: the $6 \times 12$ in $(152 \times 305 \mathrm{~mm})$ molds were filled in the standard manner using three layers and 25 strokes of the tamping rod; the $4 \times 8$ in $(102 \times$ $203 \mathrm{~mm}$ ) plastic molds were filled in two layers, and each layer was compacted by striking the outside of the mold 25 times with a rubber mallet. It was felt that rodding the small specimens would tend to cause segregation of the coarse aggregate toward the bottom of the molds. Specimen preparation was completed about two hours after mixing was begun.

Since the available information suggests that no special curing procedures were employed during construction, the molded specimens were kept in their molds with the top surfaces uncovered and allowed to cure in the laboratory at an ambient temperature of about $70^{\circ} \mathrm{F}\left(21^{\circ} \mathrm{C}\right)$. For comparison, seven $4 \times 8$ in (102 × $203 \mathrm{~mm})$ specimens and the seven $6 \times 12$ in (152 $\times 305 \mathrm{~mm}$ ) specimens were covered with plastic and subsequently cured under water at $70^{\circ} \mathrm{F}\left(21^{\circ} \mathrm{C}\right)$. For each batch, thermocouples were placed in two uncovered small cylinders, in one covered small cylinder and in one $6 \times 12$ in (152 × $305 \mathrm{~mm})$ cylinder. Temperatures were monitored by a data logger at regular time intervals, and the resulting data was used to calculate maturity of the specimens when they were tested.

\subsubsection{Test Results}

The cylinders were used for compression tests according to ASTM C 39 (Standard Test for Compressive Strength of Cylindrical Concrete Specimens) and for splitting tensile tests according to ASTM C 496 (Standard Test for Splitting Tensile Strength of Cylindrical Concrete Specimens) [4.1]. In addition stressstrain curves were recorded during the compression tests of all $4 \times 8$ in (102 $\times$ $203 \mathrm{~mm}$ ) cylinders. The moist-cured cylinders were not tested for splitting tensile strength. Specimens were tested at the following ages: 0.5 days, 1.3 days, 3 days, 7 days, 14 days, and 28 days. Figure 4.5 shows the compressive strength as a function of age. Each point represents the average of three cylinders. The shaded data points represent the average strengths of the moistcured specimens which were tested at 7 and 28 days. It appears that the method of curing plays a more significant role on strength development in the weaker concrete. The results of Mix III were significant. Apparently, the increased air content and increased water demand of the small aggregate mix resulted in significantly lower compressive strength than the other mixes.

Table 4.9 compares the average strengths and standard deviations of moist-cured $4 \times 8$ in $(102 \times 203 \mathrm{~mm})$ and $6 \times 12$ in $(152 \times 305 \mathrm{~mm})$ cylinders. The results indicate that there were no statistically significant differences between the two sizes, and confirm that using the smaller specimens is an acceptable alternative.

In order to check whether the strength-gaining properties of the laboratory mixes were consistent with the core strengths, the best-fit curves in figure 4.5 were superimposed on the core strength versus age data. Figure 4.6 shows the curves for Mixes I and II compared with the core strengths of the slab concretes. The agreement is reasonable. The third floor core strengths agree with the strength development curve of Mix I. The generally greater strength for the third floor cores is consistent with the results of the inspection 
laboratory reports (table 4.2), which showed that the slumps for the onsite plant concrete used on the third floor were lower than normal. Mix II has a strength development curve consistent with the core strengths of the second, fourth and fifth floor slabs.

Figure 4.7 compares Mix III with the column core strengths. The laboratory $\mathrm{mix}$ is consistent with these core tests.

The overall agreements noted above led to the conclusions that, in general, the laboratory mixes were representative of the concrete in the structure. Thus, the strength development characteristics of these mixes were used for estimating the inplace strength of various parts of the structure at the time of the collapse.

Figure 4.8 shows the increase with age of the secant modulus of elasticity at 50 percent of the ultimate strength for the laboratory mixes. Mixes I and II gave nearly identical results, while the weaker Mix III was significantly less stiff. Note that the development of stiffness occurs at a faster rate than strength, and the stiffness reaches its limiting value sooner than strength.

The results of the splitting tensile tests were used to determine whether the tensile strength characteristic of concrete made with the job-site materials was similar to typical normal weight concrete. Figure 4.9 shows the indirect tensile strength (average of three specimens) as a function of the compressive strength of companion specimens tested at the same age. Also shown is the function

$$
\mathrm{f}_{\mathrm{t}}=\left(\mathrm{f}_{\mathrm{c}}\right)^{0.73}
$$

which is known to be a good representation of the relation between splitting tensile strength $\left(f_{t}\right)$ and compressive strength $\left(f_{c}\right)$. The data indicate that concrete made with the materials from the job site would have tensile strength properties that are typical of normal weight concrete.

In summary, the three mixes prepared and tested by NBS are in agreement with the strength of cores from the structure, and it may be concluded that they are representative of concrete in the structure. As a result, it became unnecessary to make additional mixes to correspond with the results of the chemical analyses of the cores.

The next section describes the development of the strength-maturity functions for the laboratory mixes, which were used in making in place strength predictions at the time of collapse.

\subsubsection{Estimated Strength of Concrete at Time of the Collapse}

In order to make the best possible estimate of the strength of concrete in the structure at the time of collapse, the maturity concept was employed [4.2]. The maturity concept attempts to represent the combined effects of temperature and time on the strength development of concrete by means of a single quantity 
called "maturity", which is calculated from the temperature-time history of the concrete.

The premise of the maturity concept is that strength of concrete is a singlevalued function of maturity, independent of the actual temperature-time history. Thus, a given concrete possesses a unique strength-maturity relation; and once this relation is established under any particular (but measured) curing history, it can be used to predict strength due to any other curing condition. For this investigation, the strength-maturity functions of the laboratory mixes were developed and used to predict the inplace strength. Reference [4.3] provides additional information on the nature of the strengthmaturity function of concrete.

As discussed in section 4.4.1, thermocouples were installed in two $4 \times 8$ in $(102 \times 203 \mathrm{~mm})$ cylinders of each laboratory mix. Temperatures were recorded automatically every hour, from the filling of the molds until the last cylinder was tested. The average temperature of the two cylinders was used to represent the thermal history of each mix. Maturity was calculated for each test age, and the resulting compressive strength versus maturity data are shown in figure 4.10. For each mix, least squares curve fitting was used to determine the curves shown in figure 4.10. Each curve is an hyperbola with the general equation

$$
S=\frac{S u K\left(M-M_{0}\right)}{1+K\left(M-M_{0}\right)}
$$

where, $S$ = compressive strength for maturity $M$

$\mathrm{Su}=1$ imiting strength as maturity approaches infinity

$\mathrm{M}_{0}$ = maturity when strength development is assumed to begin

$\mathrm{K}$ = slope of curve at $\mathrm{M}_{0}$ divided by $\mathrm{Su}$

The results of the least-squares fit gave 6125,4870 and 3870 psi (42.2, 33.6, and $26.7 \mathrm{MPa}$ ) as the best fit values of the limiting strengths for Mixes $\mathrm{I}$, II, and III, respectively. The strengths for each mix were divided by their corresponding limiting strengths, and the normalized strengths were plotted as function of maturity as shown in figure 4.11. The equation of the best-fit function was found to be as follows:

$$
\frac{\mathrm{S}}{\mathrm{Su}}=\frac{0.0209(M-11.4)}{1+(M-11.4)}
$$

where maturity is expressed in ${ }^{\circ} \mathrm{F}$-days. Equation (4.3) was used to estimate the fraction of ultimate strength in various portions of the structure at the time of the collapse.

In order to use eq. (4.3), the maturity of the concrete in the structure had to be established from the inplace temperature history. Since such a history was not available, an approximation was used. It was assumed that the thermal history of the structure was equal to the air-temperature history obtained from Patrick Air Force Base, located about five miles south of the structure. 
Maturity at the time of the collapse was calculated for each portion of the structure and the results are given in table 4.10 .

Based on the computed maturities, the corresponding values of concrete strength as a fraction of ultimate strength were calculated according to eq. (4.3). These values are also given in table 4.10. Finally, using the NBS 1aboratory data and the core strength information, the relative strengths were converted to absolute values. The limiting strength of Mix III was assumed to be representative of the column concrete. While for the slab concrete, the limiting strength of Mix I was assumed to be representative of the third floor, and the limiting strength of Mix II was used for the remaining floor slabs. The last three columns in table 4.10, give the estimated strengths, rounded off to the nearest $100 \mathrm{psi}(0.7 \mathrm{MPa})$, for the various components of the structure at the time of the collapse.

\subsubsection{Reinforcing Steel Strength}

Samples of reinforcing steel were obtained from the site and had the identification markings of Grade 60 bars. One bar of each size (非 to 非11) was tested in uniaxial tension and the measured yield strengths varied from 61 to $67.5 \mathrm{ksi}$ ( 420 to $465 \mathrm{MPa}$ ). Thus, tests confirmed that Grade 60 steel was used in the structure as required by the contract documents.

\subsection{SUMMARY}

Based on the information supplied by OSHA and the results of the NBS laboratory study, the following conclusions were drawn relative to the construction materials used on the project:

1) There was insufficient documentation of the quantities of ingredients used in each batch of concrete.

2) The compressive strength of cores taken from slab sections satisfied the ACI Code strength criteria for a specified strength of 4000 psi (27.6 MPa).

3) The compressive strength of cores taken from column sections were lower than the strength of slab cores, and the average strength of the cores from the fifth floor columns did not satisfy the ACI Code criteria for the specified strength.

4) Core strength values had high variability.

5) Petrographic analyses of core samples revealed that the volumetric proportions of paste and aggregate were in agreement with the stated mix designs. The proportions, however, did show high variability.

6) The computed cement contents based on the chemical analysis of core samples were lower than stated in the mix designs. Since the low values are inconsistent with the core strengths, it was concluded that the calculated cement content values were imprecise. 
7) The strength development curves of the three mixes prepared by NBS were consistent with the average value of the core strengths.

8) The tensile strength characteristics of the NBS mixes were typical of normal weight concrete.

9) The reinforcing steel was Grade 60.

In summary, there are no indications that a gross error was committed in concrete proportioning that would have resulted in seriously deficlent concrete. The high variability of the concrete, as indicated by core strengths and other data, is significant and its importance is discussed in chapter 6 . 
Table 4.1. Mix Designs (S.S.D. Bas1s) Quantities Per Cubic Yard

\begin{tabular}{|c|c|c|}
\hline Ingredient & UNIVEL* & DIXIE* \\
\hline Cement* & 526 & 545 \\
\hline (1bs) & 1178 & 1230 \\
\hline $\begin{array}{l}\text { Coarse } \\
\text { Aggregate (1bs) }\end{array}$ & 1772 & 1600 \\
\hline Water & -- & 250 \\
\hline WR/SR & 5.3 & 28 \\
\hline AEA $\quad(o z)$ & 1.6 & 4 \\
\hline
\end{tabular}

* Type I

Univel = Onstte batch plant

DIxIe $=$ Ready-mix plant

$11 b=0.4536 \mathrm{~kg}$

$1 \mathrm{oz}=2.957 \times 10^{-5} \mathrm{~m}^{3}$ 
Table 4.2. Summary of Testing Laboratory Results

\begin{tabular}{|c|c|c|c|c|c|c|}
\hline $\begin{array}{l}\text { Sampling } \\
\text { Date (hour) }\end{array}$ & Supplier & Floor (N/S) & $\begin{array}{l}\text { S1ump } \\
\text { (1n) }\end{array}$ & $\begin{array}{c}\text { Test Age } \\
\text { (days) }\end{array}$ & $\begin{array}{l}\text { Strength } \\
\text { (ps1) }\end{array}$ & $\begin{array}{l}\text { P1asticlzer } \\
(\mathrm{gal})\end{array}$ \\
\hline $2 / 13-(800)$ & Un1ve1* & $1(\mathrm{~s})$ & 10 & $\begin{array}{r}7 \\
28 \\
\end{array}$ & $\begin{array}{l}5260(1)^{\star} \\
5660+\end{array}$ & 一 \\
\hline $2 / 13-(930)$ & $D 1 \times f e^{\hbar}$ & $1(\mathrm{~s})$ & $91 / 2$ & $\begin{array}{r}7 \\
28\end{array}$ & $\begin{array}{l}4500(1) \\
5650\end{array}$ & $=$ \\
\hline $2 / 19-(930)$ & Un1ve1 & I(N) & 10 & $\begin{array}{r}5 \\
28\end{array}$ & $\begin{array}{l}3940(1) \\
5380\end{array}$ & $=$ \\
\hline $2 / 19-(900)$ & D1xie & 1 (N) & 8 & $\begin{array}{r}5 \\
28\end{array}$ & $\begin{array}{l}4060(1) \\
5660+\end{array}$ & $=$ \\
\hline $2 / 26-(900)$ & Un1ve1 & $2(\mathrm{~S})$ & 9 & $\begin{array}{r}2 \\
7 \\
28\end{array}$ & $\begin{array}{l}3680(1) \\
5310(1) \\
6010+\end{array}$ & 8 \\
\hline $2 / 26-(815)$ & D1xie & $2(\mathrm{~s})$ & $71 / 2$ & $\begin{array}{r}2 \\
7 \\
28\end{array}$ & $\begin{array}{l}2020(1) \\
4240(1) \\
5860\end{array}$ & $31 / 2$ \\
\hline $2 / 27-(920)$ & Un1ve1 & $2(\mathrm{~N})$ & 4 & $\begin{array}{r}3 \\
7 \\
28 \\
\end{array}$ & $\begin{array}{l}4560(1) \\
5250(1) \\
5850\end{array}$ & $=$ \\
\hline $2 / 27-(945)$ & Dixie & $2(\mathrm{~N})$ & 9 & $\begin{array}{r}3 \\
7 \\
28\end{array}$ & $\begin{array}{l}3250(1) \\
4360 \text { (1) } \\
4780\end{array}$ & $=$ \\
\hline $3 / 3-(830)$ & Unive1 & $3(\mathrm{~s})$ & $33 / 4$ & $\begin{array}{r}2 \\
7 \\
28\end{array}$ & $\begin{array}{l}4300 \\
5060 \\
6260\end{array}$ & $=$ \\
\hline $3 / 3-(840)$ & D1xie & $3(\mathrm{~s})$ & $91 / 4$ & $\begin{array}{r}20 \\
7 \\
28\end{array}$ & $\begin{array}{l}3050 \\
3580 \\
5870\end{array}$ & $=$ \\
\hline $3 / 5-(1025)$ & UnIve1 & 3 (N) & $51 / 2$ & $\begin{array}{r}1 \\
7 \\
28 \\
\end{array}$ & $\begin{array}{l}4190(1) \\
5660+(1) \\
5840+\end{array}$ & $=$ \\
\hline $3 / 5-(1000)$ & D1xie & $3(\mathrm{~N})$ & .9 & $\begin{array}{r}1 \\
7 \\
28\end{array}$ & $\begin{array}{l}1450(1) \\
3760(1) \\
5200\end{array}$ & \\
\hline $3 / 10-(1035)$ & Unive1 & $4(S)$ & $91 / 2$ & $\begin{array}{r}2 \\
7 \\
28\end{array}$ & $\begin{array}{l}2940(1) \\
4040 \text { (1) } \\
5050\end{array}$ & 5 \\
\hline $3 / 12-(900)$ & Unive1 & $4(\mathrm{~N})$ & $81 / 2$ & $\begin{array}{r}4 \\
7 \\
28\end{array}$ & $\begin{array}{l}4000 \text { (1) } \\
4780 \text { (1) } \\
5360\end{array}$ & $\begin{array}{l}- \\
1\end{array}$ \\
\hline $3 / 12-(845)$ & D1xie & 4(N) & $81 / 2$ & $\begin{array}{r}4 \\
7 \\
28\end{array}$ & $\begin{array}{l}3470(1) \\
4260 \text { (1) } \\
5290\end{array}$ & $=$ \\
\hline $3 / 17-(900)$ & UnIvel & $5(\mathrm{~S})$ & $91 / 2$ & $\begin{array}{r}2 \\
7 \\
28\end{array}$ & $\begin{array}{l}2790(1) \\
3650(1) \\
4710\end{array}$ & $=$ \\
\hline $3 / 17-(945)$ & Dixie & $5(5)$ & 10 & $\begin{array}{r}2 \\
7 \\
28\end{array}$ & $\begin{array}{l}2640(1) \\
4260(1) \\
5510\end{array}$ & - \\
\hline $3 / 19-(850)$ & Unfvel & $5(\mathrm{~N})$ & $81 / 2$ & $\begin{array}{r}2 \\
7 \\
28 \\
\end{array}$ & $\begin{array}{l}2310(1) \\
3750(1) \\
4740\end{array}$ & - \\
\hline $3 / 19-(840)$ & Dirie & $5(\mathrm{~N})$ & 8 & $\begin{array}{r}2 \\
7 \\
28\end{array}$ & $\begin{array}{l}1490(1) \\
3180(1) \\
4320\end{array}$ & $=$ \\
\hline $3 / 27-(230)$ & Dixie & $\overline{\mathbf{R}}$ & 6 & $\begin{array}{r}4 \\
7 \\
28\end{array}$ & $\begin{array}{l}3360(1) \\
4390 \\
5050\end{array}$ & Bydrocel ${ }^{k}$ \\
\hline $3 / 27-(215)$ & Univel & $\overline{\mathbf{R}}$ & 8 & $\begin{array}{r}4 \\
7 \\
28\end{array}$ & $\begin{array}{l}2940(1) \\
3710 \\
4600\end{array}$ & Hydrocel \\
\hline
\end{tabular}

* (1) Indicates one cylinder tested

-- Indicates quantity not given in the report

Hydrocel is a waterproofing admixture

Univel is the onsite batch plant

Dixle is the ready-mix plant

$1 \mathrm{in}=25.4 \mathrm{~mm}$

$100 \mathrm{ps1}=0.69 \mathrm{MPa}$

$1 \mathrm{gal}=3.785 \times 10-3 \mathrm{~m} 3$ 
Table 4.3. Location and Number of Cores Tested

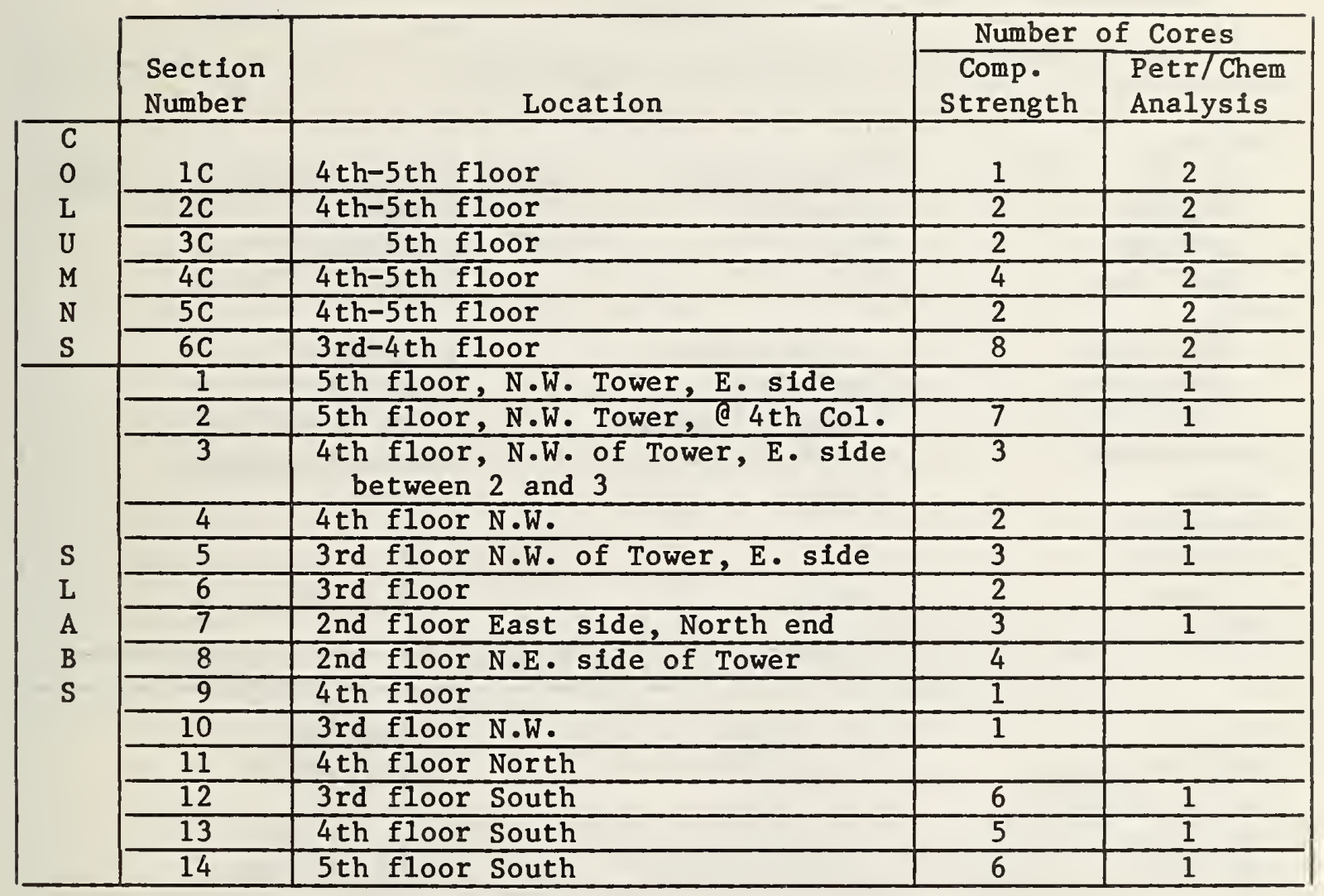


Table 4.4. Petrographic Analysis Average Results

\begin{tabular}{|c|c|c|}
\hline & Columns & Slabs \\
\hline \multicolumn{3}{|c|}{ ASTM C856 (Comments) } \\
\hline $\begin{array}{l}\text { Paste } \\
\text { color } \\
\text { texture } \\
\text { uniform } \\
\text { hydration } \\
\text { Voids } \\
\text { entrained } \\
\text { entrapped } \\
\text { water gain } \\
\text { Retempering } \\
\text { Cracks } \\
\text { Aggregate } \\
\text { fine } \\
\text { coarse } \\
\text { Other }\end{array}$ & $\begin{array}{l}\text { buff ( } 4 \text { gray }-7 \text { buff) } \\
\text { medium } \\
\text { ok } \\
\text { ok } \\
\text { slight-some } \\
\text { mostly } \\
\text { some instances } \\
\text { some instances } \\
\text { none } \\
\text { ok } \\
\text { ok } \\
\text { - }\end{array}$ & $\begin{array}{l}\text { buff ( } 2 \text { gray }-6 \text { buff) } \\
\text { medium } \\
\text { variable } \\
\text { ok } \\
\text { slight } \\
\text { mostly } \\
\text { few instances } \\
\text { some instances } \\
\text { none } \\
\text { ok } \\
\text { ok } \\
\text { - }\end{array}$ \\
\hline \multicolumn{3}{|c|}{ ASTM C457 (percent by volume) } \\
\hline $\begin{array}{l}\text { Paste } \\
\text { Fine Aggregate } \\
\text { Coarse Aggregate } \\
\text { Air Voids } \\
\text { Spacing Factor, in. }\end{array}$ & $\begin{array}{l}27(1.9) \\
27(2.3) \\
41(2.9) \\
4.2(1.1) \\
0.025(0.006)\end{array}$ & $\begin{array}{l}28(2.5) \\
27(1.9) \\
41(3.6) \\
3.2(1.6) \\
0.024(0.007)\end{array}$ \\
\hline \multicolumn{3}{|c|}{$\begin{array}{c}\text { ASTM C642 (after immersion } \\
\text { and boiling) }\end{array}$} \\
\hline $\begin{array}{l}\text { Absorption, } \% \\
\text { Specific Gravity, dry } \\
\text { Specific Gravity, SSD } \\
\text { Voids, permeable, } \%\end{array}$ & $\begin{array}{l}9.1(0.6) \\
2.02(0.02) \\
2.20(0.02) \\
18.4(1.0) \\
\end{array}$ & $\begin{array}{l}8.6(0.7) \\
2.07(0.04) \\
2.25(0.03) \\
17.8(1.2) \\
\end{array}$ \\
\hline
\end{tabular}

1 in $=25.4 \mathrm{~mm}$ 
Table 4.5. Average of Approximate Material Proportions in Concrete

\begin{tabular}{|c|c|c|c|}
\hline & \\
\hline & Column & \multicolumn{2}{|c|}{ Slab } \\
\hline Cement* $\left(1 \mathrm{bs} / \mathrm{yd}^{3}\right)$ & $(29)+$ & 442 & (41) \\
\hline Fine Aggregate (1bs/yd $\left.\mathrm{y}^{3}\right)$ & $(103)$ & 1213 & (83) \\
\hline Coarse Aggregate (1bs/yd ${ }^{3}$ ) & 1750 (123) & 1743 & (149) \\
\hline Water $\left(1 \mathrm{bs} / \mathrm{yd}^{3}\right)$ & $315 \quad(38)$ & 320 & $(42)$ \\
\hline $\begin{array}{l}\text { Unit Weight, SSD, } \\
\text { lbs/ft }\end{array}$ & 137.5 & 139.6 & $(1.4)$ \\
\hline Air Voids, \% & $4.2(1.1)$ & 3.2 & $(1.6)$ \\
\hline Water Cement Ratio & $0.65(0.11)$ & 0.72 & $(0.15)$ \\
\hline
\end{tabular}

Notes:

+ Standard deviation.

* Cement content determined from ASTM C 85 , Modified ASTM C85 and dehydration to allow for calcareous coarse aggregate (limerock and calcareous material (shel1) present in fine aggregate.

** Unit weight SSD estimate by using bulk SSD specific gravity (ASTM C 642) after immersion and boiling.

$11 \mathrm{~b} / \mathrm{yd}^{3}=0.5933 \mathrm{~kg} / \mathrm{m}^{3}$

$1 \mathrm{~b} / \mathrm{ft}^{3}=16.02 \mathrm{~kg} / \mathrm{m}^{3}$ 
Table 4.6. Results of Admixture Analysis

\begin{tabular}{|c|c|c|c|c|c|c|}
\hline & Core I.D. & $\begin{array}{c}\text { Location } \\
\text { Section (Floor) }\end{array}$ & $\begin{array}{l}\text { Admixture } \\
(\% \text { concrete wt. })\end{array}$ & WR/SR & HRWR & ACC. \\
\hline \multirow{11}{*}{$\begin{array}{l}\mathrm{C} \\
0 \\
\mathrm{~L} \\
\mathrm{U} \\
\mathrm{M} \\
\mathrm{N} \\
\mathrm{S}\end{array}$} & P01 & $1 C(5)$ & 0.02 & $\mathrm{X}^{*}$ & & \\
\hline & P02 & $2 \mathrm{C}(5)$ & 0.01 & $\bar{X}$ & & \\
\hline & P03 & $3 C(5)$ & 0.02 & $\overline{\mathrm{X}}$ & & \\
\hline & P04 & $4 C(5)$ & 0.01 & & $\bar{X}$ & $\bar{X}$ \\
\hline & P05 & $5 \mathrm{C}(5)$ & 0.06 & $\bar{X}$ & & \\
\hline & P06 & IC (4) & 0.05 & & & \\
\hline & P07 & $6 C(4)$ & 0.08 & $\bar{X}$ & & \\
\hline & P08 & $2 C(4)$ & 0.06 & $\bar{X}$ & & \\
\hline & P09 & $5 C(4)$ & 0.09 & $\bar{X}$ & & \\
\hline & P10 & $4 C(4)$ & 0.02 & $\bar{X}$ & & \\
\hline & P11 & $6 C(3)$ & 0.02 & & $\overline{\mathbf{X}}$ & $\overline{\mathrm{X}}$ \\
\hline \multirow{8}{*}{$\begin{array}{l}\text { S } \\
\text { L } \\
\text { A } \\
\text { B } \\
\text { S }\end{array}$} & P12 & $1(5)$ & 0.02 & & $\bar{X}$ & $\bar{X}$ \\
\hline & P13 & $2(5)$ & 0.10 & $\mathrm{X}$ & & \\
\hline & P14 & $14(5)$ & 0.08 & $\bar{x}$ & & \\
\hline & P15 & $4(4)$ & 0.08 & $\overline{\mathrm{X}}$ & & \\
\hline & $\overline{\text { P16 }}$ & $13(4)$ & 0.09 & & $\mathrm{X}$ & $\bar{X}$ \\
\hline & P17 & $5(3)$ & 0.01 & & $\mathrm{X}$ & $\mathrm{X}$ \\
\hline & P18 & $12(3)$ & 0.01 & & $\bar{X}$ & $\bar{X}$ \\
\hline & P19 & $7(2)$ & 0.02 & $\bar{X}$ & & \\
\hline & \multirow{2}{*}{\multicolumn{3}{|c|}{ Mix Design: }} & & & \\
\hline & & & & 0.01 & 0.05 & 0 \\
\hline & \multicolumn{3}{|c|}{ Ready Mix } & 0.06 & 0.05 & 0 \\
\hline & \multicolumn{3}{|c|}{ Manufacturer ${ }^{\mp}$} & $\begin{array}{l}0.05- \\
0.09\end{array}$ & $\begin{array}{l}0.11- \\
0.27\end{array}$ & $\begin{array}{l}0.12- \\
0.37\end{array}$ \\
\hline
\end{tabular}

* An " $X$ " indicates presence of this admixture.

+ Quantities based on manufacturer's recommended dosages and assuming $5301 \mathrm{bs}$ of cement per cubic yard ( $315 \mathrm{~kg}$ per $\left.\mathrm{m}^{3}\right)$ of concrete. 
Table 4.7. Summary of Laboratory Mixes

\begin{tabular}{|c|c|c|c|}
\hline & Mix I & Mix II & Mix III \\
\hline Cement (1bs) & 93.6 & 86.5 & 86.5 \\
\hline Water (1bs) & 40.6 & 48.4 & 53.1 \\
\hline Sand (1bs) & 216 & 198 & 198 \\
\hline C. Aggregate (1bs) & 278 & 291 & 284 \\
\hline $\begin{array}{l}\text { Moisture Content (\%) } \\
\text { Sand } \\
\text { C. Aggregate }\end{array}$ & $\begin{array}{l}1.5 \\
2.1 \\
\end{array}$ & $\begin{array}{r}1.1 \\
-1.3\end{array}$ & $\begin{array}{r}1.7 \\
-1.7\end{array}$ \\
\hline $\begin{array}{l}\text { Slump (In) } \\
\text { Before HRWR } \\
\text { After HRWR }\end{array}$ & $\begin{array}{ll}4 & 1 / 2 \\
7 & \end{array}$ & $\begin{array}{ll}4 & 1 / 2 \\
7 & 1 / 2\end{array}$ & $\begin{array}{ll}4 & 3 / 4 \\
7 & 3 / 4\end{array}$ \\
\hline Air Content (\%) & 3.8 & 2.9 & 4.9 \\
\hline Unit Weight (pcf) & 140.2 & 142.9 & 136.0 \\
\hline
\end{tabular}

$11 \mathrm{~b}=0.4536 \mathrm{~kg}$

1 in $=25.4 \mathrm{~mm}$

$1 \mathrm{pcf}=16.02 \mathrm{~kg} / \mathrm{m}^{3}$

Table 4.8. Calculated Volume Percentages of Ingredients in Laboratory Mixes Compared with Measured Values from Cores

\begin{tabular}{|l|c|c|c|c|c|}
\cline { 2 - 6 } \multicolumn{1}{l|}{} & Mix I & Mix II & $\begin{array}{c}\text { Measured } \\
\text { Slab* }\end{array}$ & Mix III & $\begin{array}{l}\text { Measured } \\
\text { Column* }\end{array}$ \\
\hline Paste & 28.5 & 27.1 & $28(2.5)$ & 27.9 & $27(1.9)$ \\
\hline Sand & 28.7 & 26.9 & $27(1.9)$ & 26.1 & $27(2.3)$ \\
\hline C. Aggregate & 39.1 & 43.1 & $41(3.6)$ & 41.1 & $41(2.9)$ \\
\hline Air & 3.8 & 2.9 & $3.2(1.6)$ & 4.9 & $4.2(1.1)$ \\
\hline
\end{tabular}

* From petrographic analysis of cores from structure. Quantities in parentheses are standard deviations of average values. 
Table 4.9. Comparison of Compressive Strength of $4 \times 8$ in and $6 \times 12$ in Cylinders

\begin{tabular}{|l|c|cc|c|}
\cline { 3 - 5 } \multicolumn{2}{c|}{} & \multicolumn{4}{|c|}{ Average } \\
\hline \multirow{2}{*}{ Mix } & $\begin{array}{c}\text { Age } \\
\text { (days) }\end{array}$ & $4 \times 8$ in & $6 \times 12$ (in) \\
\hline \multirow{2}{*}{ I } & 7 & $5060(68)$ & $5125(69)$ \\
& 28 & 5815 & $(42)$ & $6010(97)$ \\
\hline \multirow{2}{*}{ II } & 7 & $4185(113)$ & $4115(144)$ \\
& 28 & $5350(124)$ & $5490(221)$ \\
\hline \multirow{2}{*}{ III } & 7 & $3270(80)$ & $3250(54)$ \\
& 28 & $4345(112)$ & $4250(84)$ \\
\hline
\end{tabular}

* Average of three specimens, number in parentheses are standard deviations.

1 in $=25.4 \mathrm{~mm}$

$1000 \mathrm{ps} 1=6.9 \mathrm{MPa}$ 
Table 4.10 Estimated Maturities and Strengths at Time of Collapse

\begin{tabular}{|c|c|c|c|c|c|c|c|}
\hline \multirow[b]{2}{*}{ Floor } & \multirow[b]{2}{*}{ Portion } & \multirow[b]{2}{*}{$\begin{array}{c}\text { Approx. } \\
\text { Age (Days) }\end{array}$} & \multirow{2}{*}{$\begin{array}{l}\text { Calculated } \\
\text { Maturity } \\
\text { (F-Days) }\end{array}$} & \multirow[b]{2}{*}{$\begin{array}{c}\text { Predicted } \\
\mathrm{S} / \mathrm{Su}\end{array}$} & \multicolumn{3}{|c|}{ Strength (psi) } \\
\hline & & & & & $\begin{array}{c}\text { Column } \\
\text { Su }=3900\end{array}$ & $\begin{array}{c}\text { Slab } \\
\text { Su }=4900\end{array}$ & $S u=6100$ \\
\hline 5 & $\begin{array}{l}\mathrm{C}-\mathrm{N}^{*} \\
\mathrm{~S}-\mathrm{N}^{*} \\
\mathrm{C}-\mathrm{S} \\
\mathrm{S}-\mathrm{S}\end{array}$ & $\begin{array}{r}7 \\
8 \\
9 \\
10 \\
\end{array}$ & $\begin{array}{l}148 \\
163 \\
192 \\
213 \\
\end{array}$ & $\begin{array}{l}0.74 \\
0.76 \\
0.79 \\
0.81 \\
\end{array}$ & $\begin{array}{l}2900 \\
3100\end{array}$ & $\begin{array}{l}3700 \\
4000 \\
\end{array}$ & \\
\hline 4 & $\begin{array}{l}\mathrm{C}-\mathrm{N} \\
\mathrm{S}-\mathrm{N} \\
\mathrm{C}-\mathrm{S} \\
\mathrm{S}-\mathrm{S} \\
\end{array}$ & $\begin{array}{l}14 \\
15 \\
16 \\
17 \\
\end{array}$ & $\begin{array}{l}305 \\
329 \\
351 \\
375 \\
\end{array}$ & $\begin{array}{l}0.86 \\
0.87 \\
0.88 \\
0.88 \\
\end{array}$ & $\begin{array}{l}3400 \\
3400\end{array}$ & $\begin{array}{l}4300 \\
4300\end{array}$ & \\
\hline 3 & $\begin{array}{l}C-N \\
S-N \\
C-S \\
S-S\end{array}$ & $\begin{array}{l}21 \\
22 \\
23 \\
24 \\
\end{array}$ & $\begin{array}{l}467 \\
492 \\
520 \\
544 \\
\end{array}$ & $\begin{array}{l}0.90 \\
0.91 \\
0.91 \\
0.92 \\
\end{array}$ & $\begin{array}{l}3500 \\
3500\end{array}$ & $\begin{array}{l}4500 \\
4500\end{array}$ & $\begin{array}{r}5600 \\
5600 \\
\end{array}$ \\
\hline 2 & $\begin{array}{l}C-N \\
S-N \\
C-S \\
S-S \\
\end{array}$ & $\begin{array}{l}27 \\
28 \\
28 \\
29 \\
\end{array}$ & $\begin{array}{l}621 \\
643 \\
643 \\
662 \\
\end{array}$ & $\begin{array}{l}0.93 \\
0.93 \\
0.93 \\
0.93 \\
\end{array}$ & $\begin{array}{l}3600 \\
3600\end{array}$ & $\begin{array}{l}4600 \\
4600 \\
\end{array}$ & \\
\hline 1 & $\begin{array}{l}C-N \\
S-N \\
C-S \\
S-S\end{array}$ & $\begin{array}{l}35 \\
36 \\
39 \\
42\end{array}$ & $\begin{array}{l}791 \\
815 \\
895 \\
969\end{array}$ & $\begin{array}{l}0.94 \\
0.94 \\
0.95 \\
0.95\end{array}$ & $\begin{array}{l}3700 \\
3700\end{array}$ & $\begin{array}{l}4600 \\
4700\end{array}$ & \\
\hline
\end{tabular}

* C-N denotes the columins in the north-half while S-N derotes the slab in the north-half; $C-S$ and $S-S$ are the columns and slab in the south half.

$\mathrm{F}$-days $=0.555 \mathrm{C}$-days

$1000 \mathrm{psi}=6.9 \mathrm{MPa}$ 


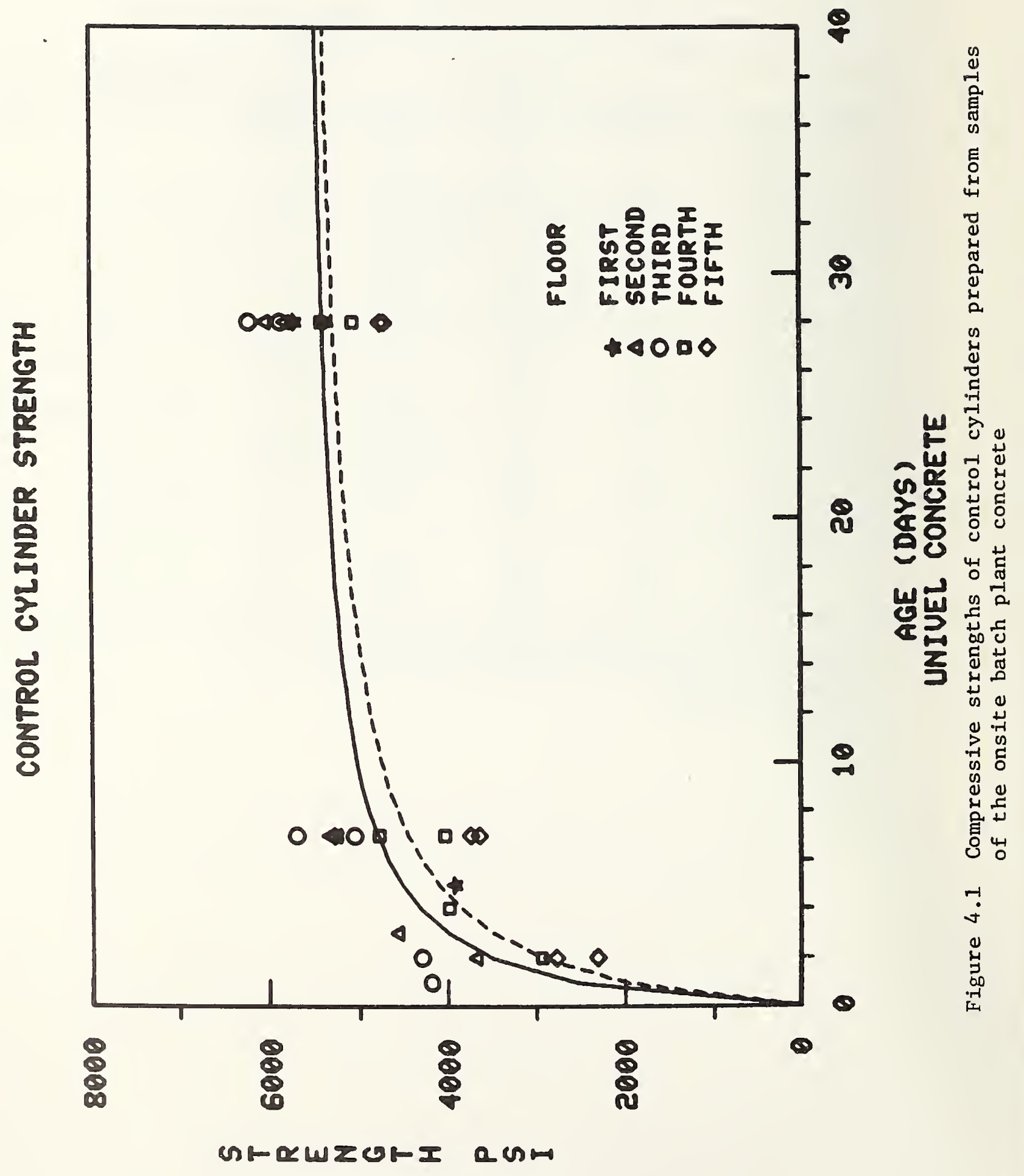




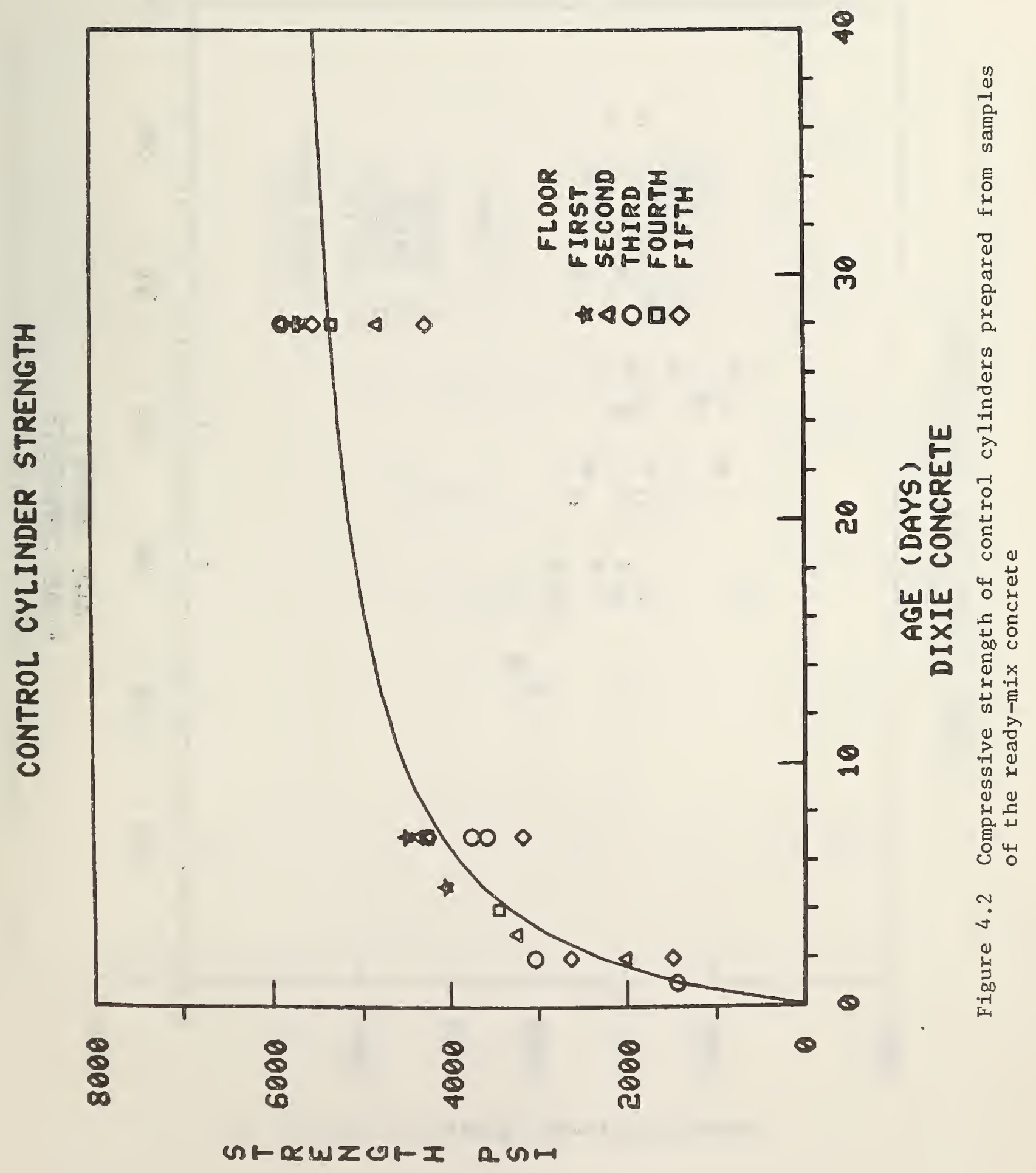




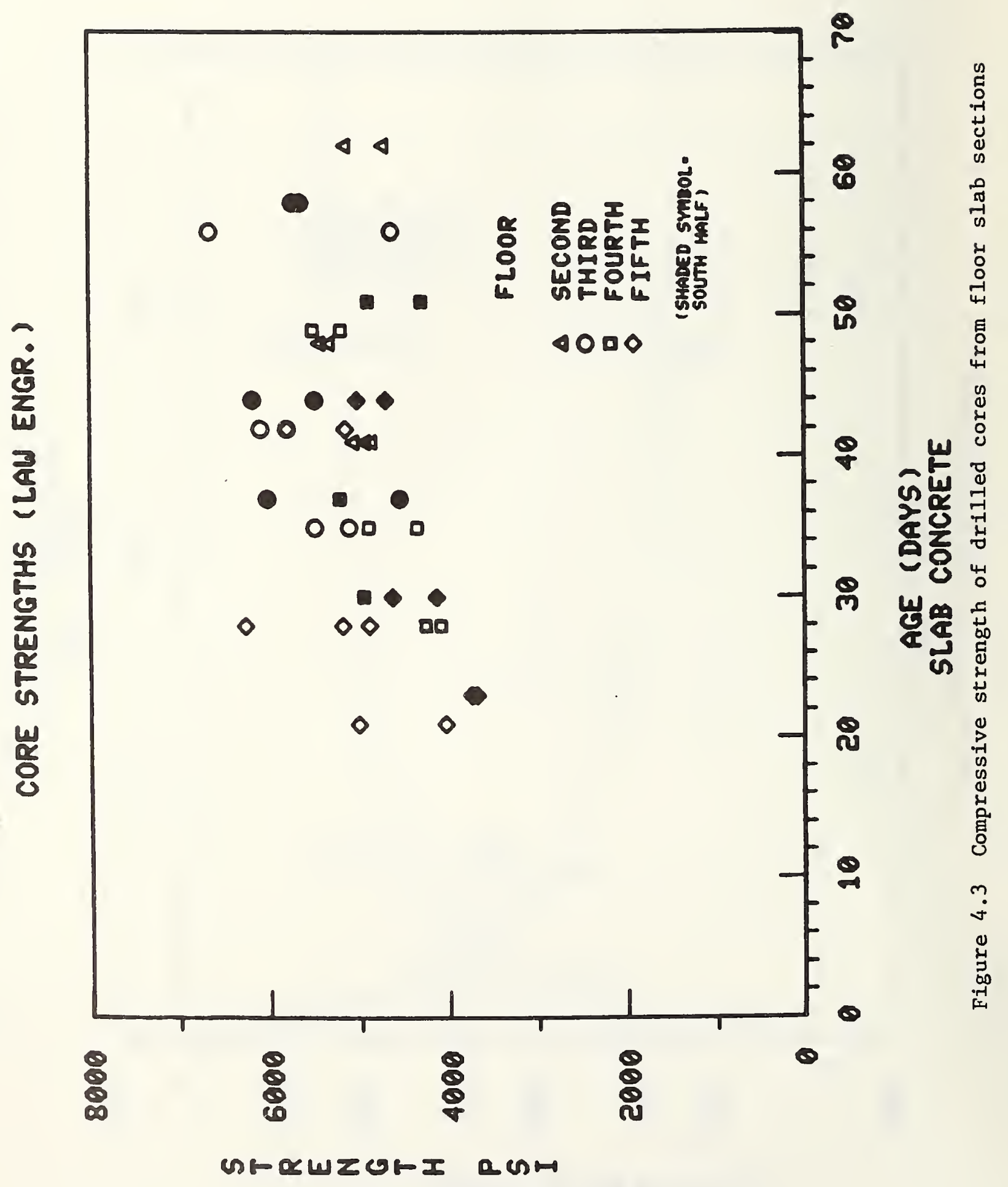




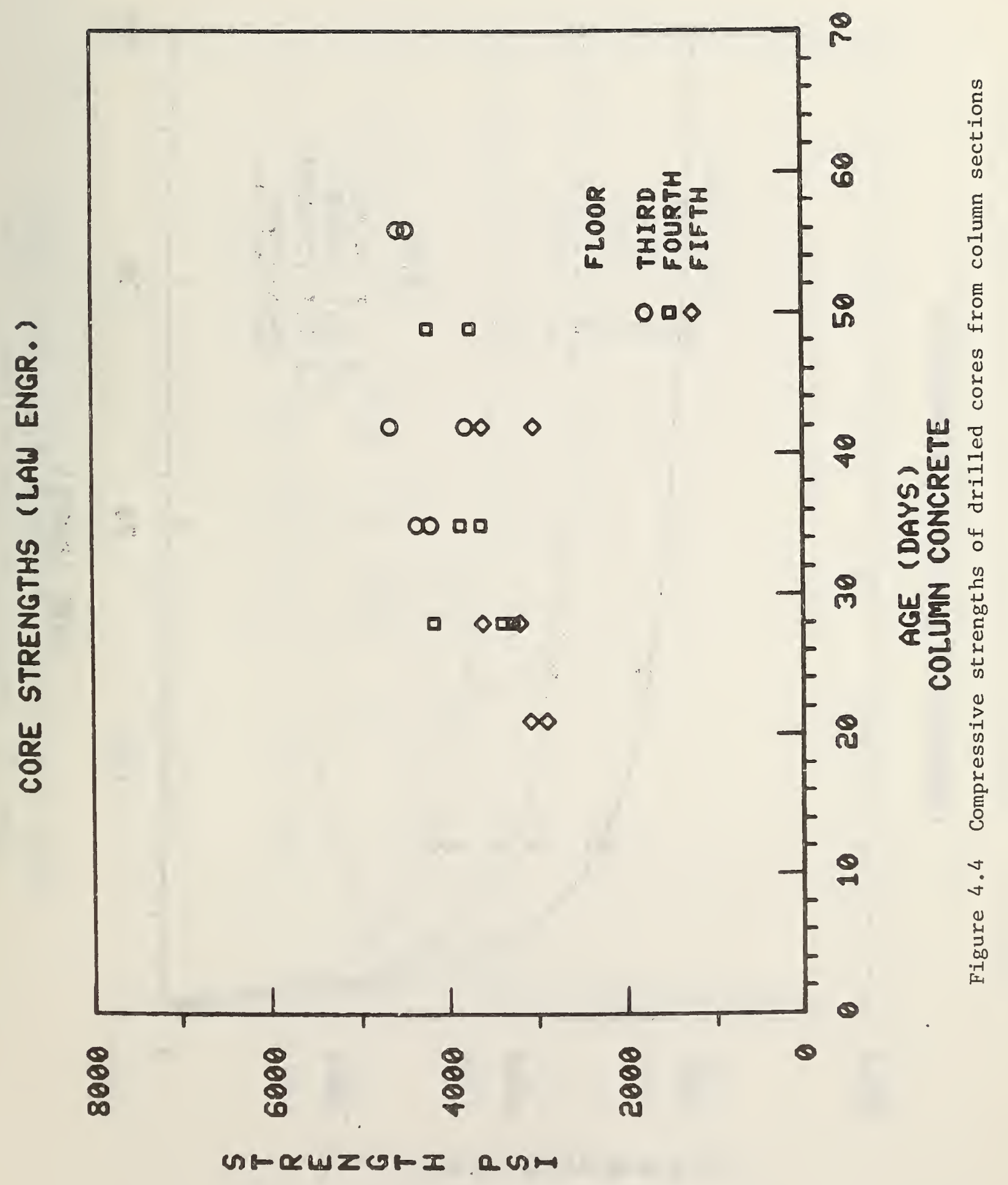




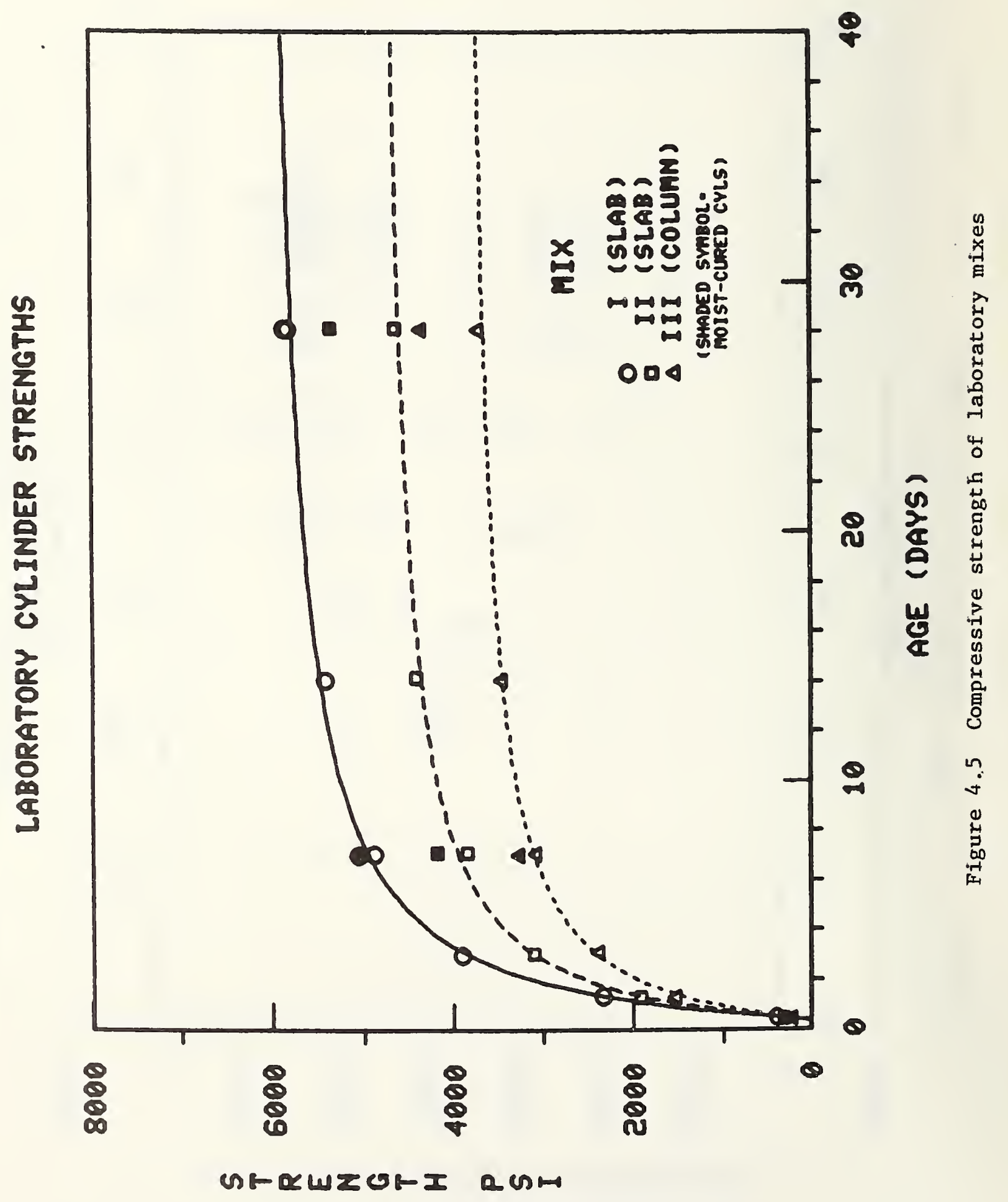




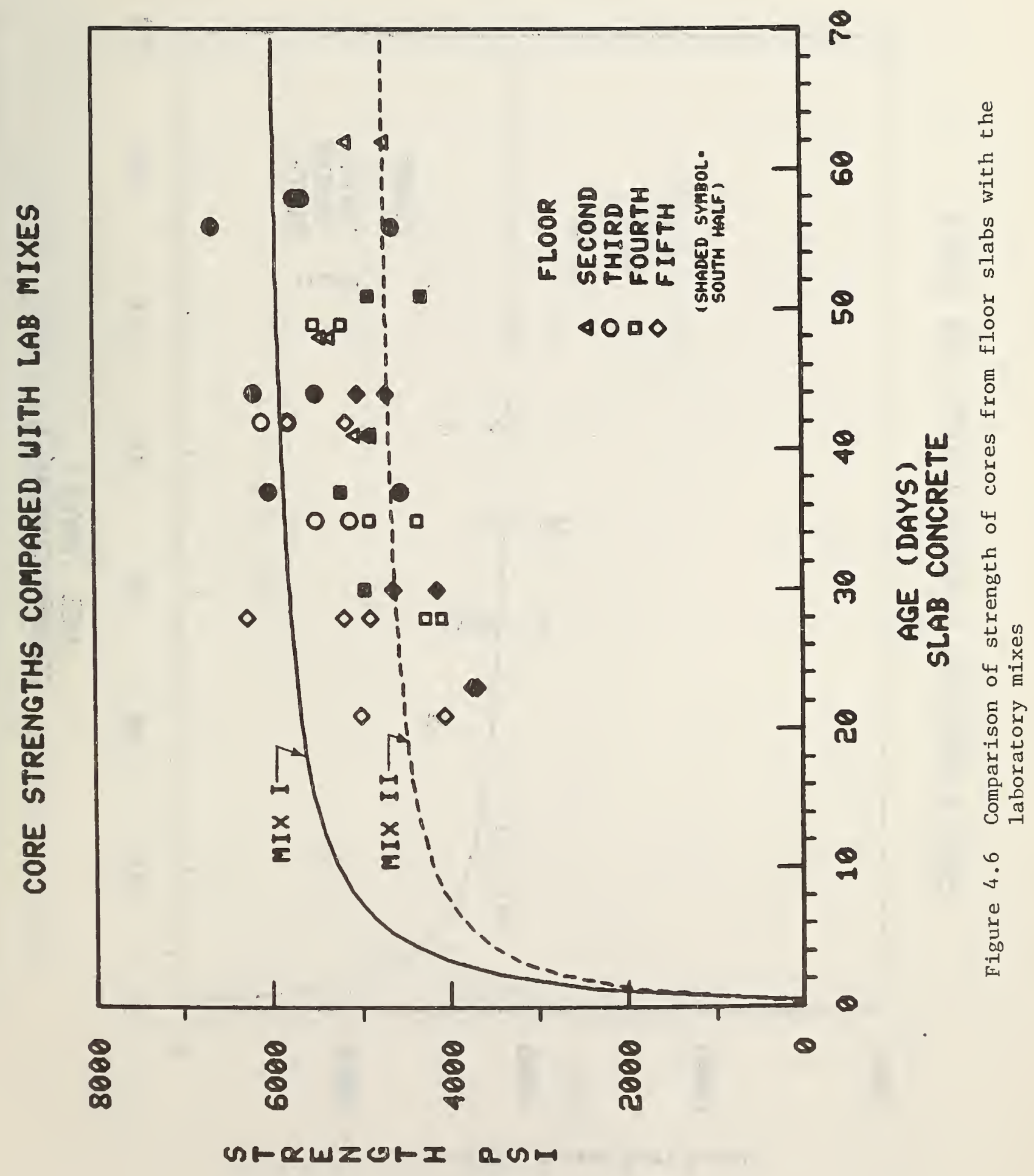




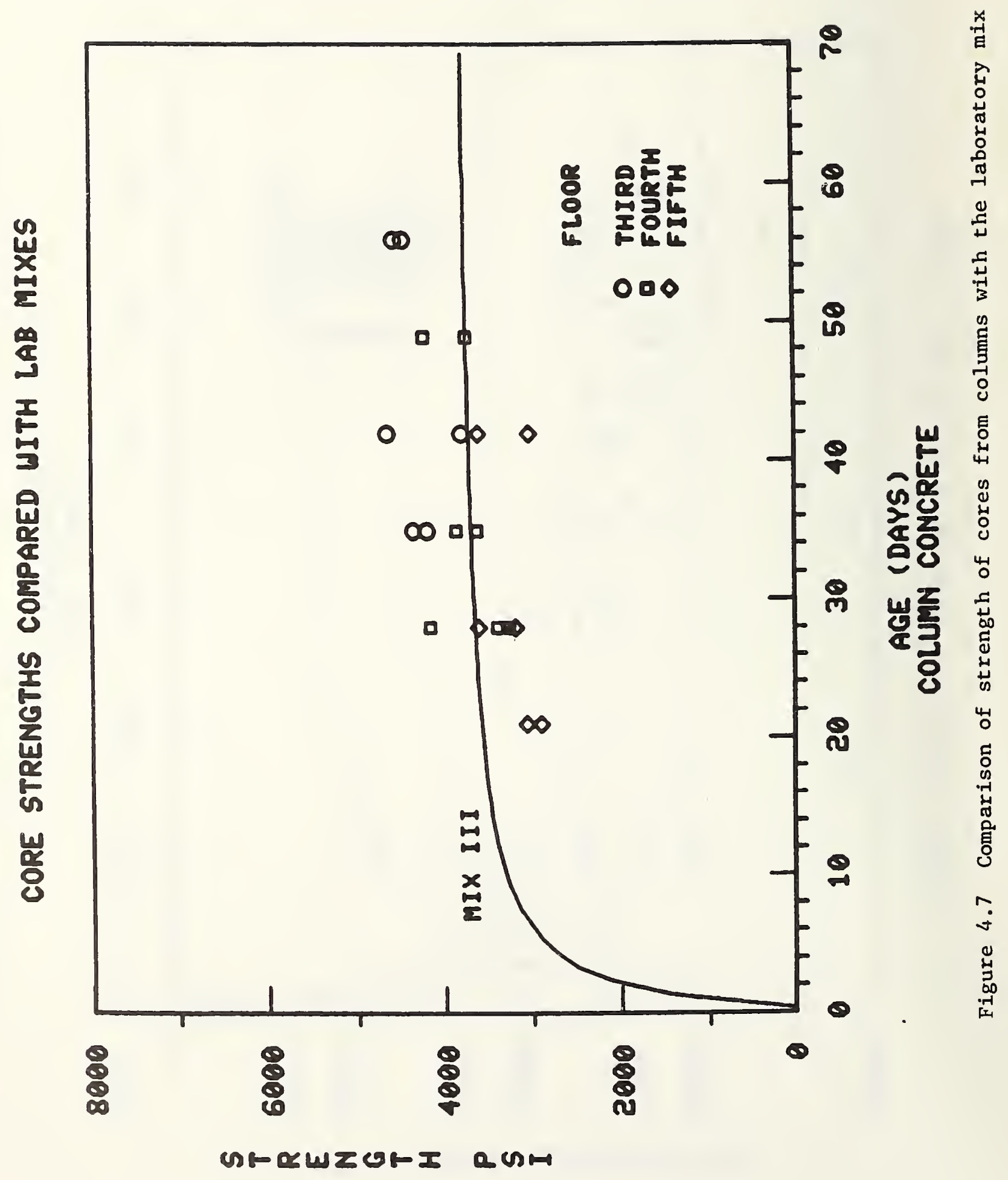




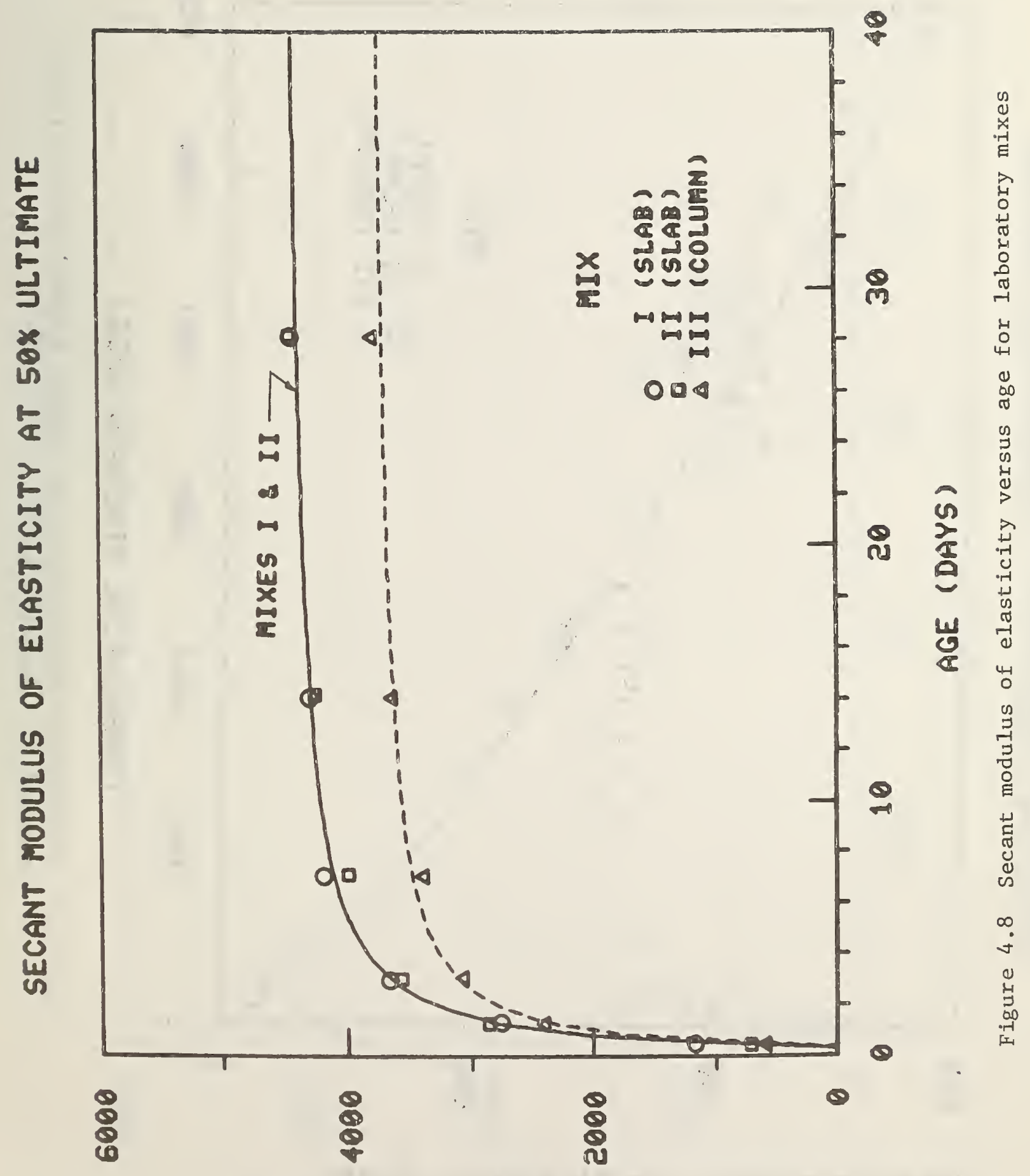

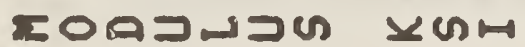




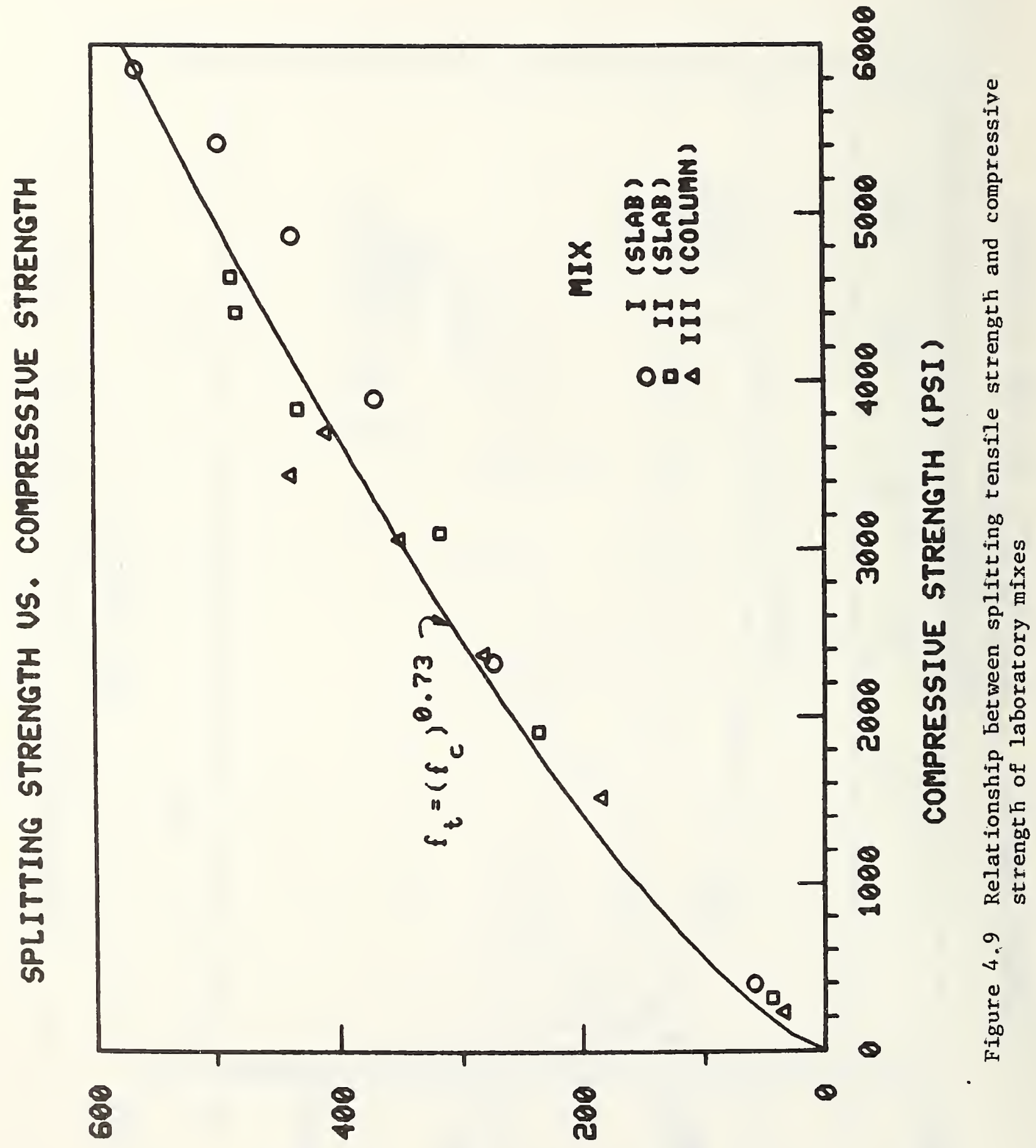

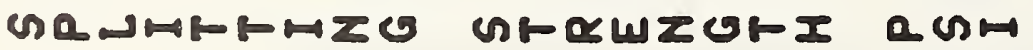




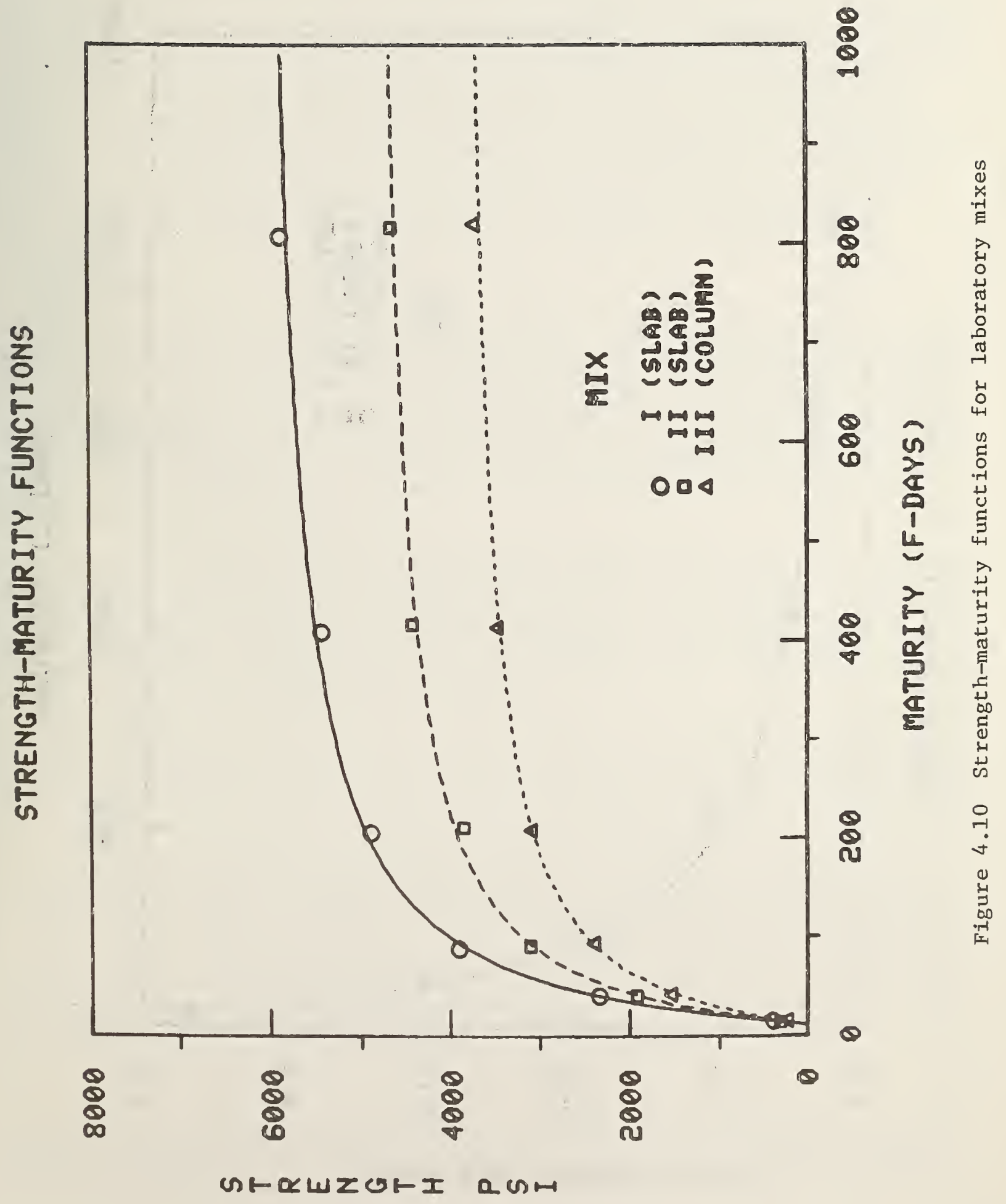




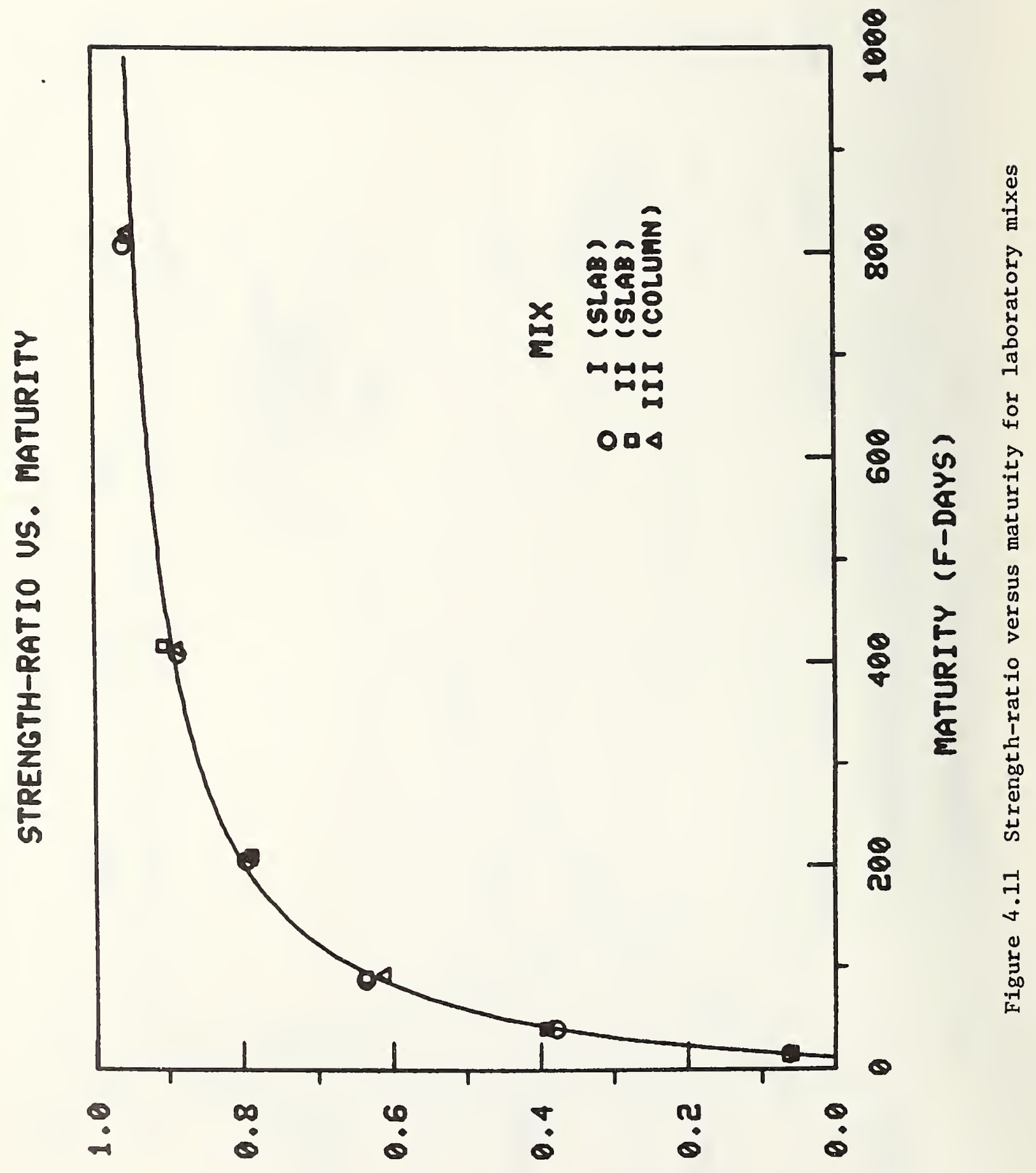

UROUZURI LARHO 


\section{STRUCTURAL ANALYSIS}

\subsection{INTRODUCTION}

This chapter presents the analytical investigation of the Harbour Cay structure under conditions existing at the time of the collapse. Section 5.2 provides background information with the intent to acquaint the reader with the complex force transfer mechanisms in shored building construction. The definition of loads and the bases used in their calculations are the topics discussed in section 5.3. The possible effect of the reshoring sequence, including the sequence of removal of flying forms from a story, is examined in section 5.4. The basis for selecting the method of analysis is discussed in section 5.5 . The results of the analysis are presented and explained in section 5.6. A summary of major findings in this chapter is presented in section 5.7 .

\subsection{BACKGROUND}

In multistory flat plate building construction, it is common practice to support the freshly cast slab by a shoring system which distributes the load to lower floors. The number of stories requiring shores* and reshores* depends primarily on the magnitude of imposed construction loads, curing characteristics of the concrete, and the rate of construction. The convention $n_{s}+n_{r}$ is sometimes used to designate the number of shored and reshored stories, respectively. Shoring combinations in which $1 \leq n_{S} \leq 3$ and $0 \leq n_{r} \leq 5$ (other than $\mathrm{n}_{\mathrm{s}}+\mathrm{n}_{\mathrm{r}}=1$ ) have been used in the past.

Shoring systems commonly utilize metal frames and/or single posts. In systems without reshores $\left(n_{r}=0\right)$, a newly placed slab remains shored until the $n_{s-1}$ floors above it have been cast. In mixed systems, an intermediate step occurs when the story under a particular floor is reshored. Depending on the method used, the forces on the reshores may vary from almost zero to levels comparable to those existing in the shores they replace.

Regardless of the shoring scheme used, as construction progresses upward, the building is subjected to unidentical cycles of loading and unloading which produce residual forces in the structure. At a certain stage of construction, when a new floor is cast, the forces introduced combine with the residual forces in the structure to produce the highest load on a particular slab, which is the maximum load any slab will experience during the construction of the building. The magnitude of this load does depend on the shoring scheme $\left(n_{s}+n_{r}\right)$ used, as well as on the stiffness properties of the partially matured concrete structure and, where $n_{r}>0$, on the amount of precompression in the reshores when they are first installed. It should be pointed out, however, that insofar as the most critical condition is governed by available capacity as well as loads, it may not necessarily occur in the slab which develops the peak load.

* Shores are vertical members which support formwork and freshly cast concrete. Reshores are vertical members used to support new structural members after shores and formwork are removed. 
In the case of the Harbour Cay building, flying forms were used in lieu of conventional shores (frames and/or posts) in one story $\left(n_{s}=1\right)$. At the time of the collapse, three stories were reshored with wood posts. This identifles the shoring scheme as $n_{s}+n_{r}=1+3$. A flying form is an integrated system which incorporates shores and formwork into a large unit capable of forming several bays at a time. The method of replacing flylng forms with reshores (described in section 2.3) results in unloading a tier of bays at a time ( 2 or 3 bays in this case), allowing the floor above that area to deflect under its own weight, before reshores are installed. Consequently, the forces on the reshores may be minimal; that is, they are installed snug enough to keep them from falling down. The supposition that reshores were not subjected to appreciable precompression is corroborated by interview statements (section 3.4) of several instances of workers restoring fallen reshores.

\subsection{LOADS}

The following list identifies possible sources of loading on the structure at the time of the collapse.

(1) The self weight of the structure

(2) The weight of fresh concrete in the roof slab

(3) The weight of the shoring system

(4) The weight of construction workers, equipment and materials

(5) Wind

(6) Impact

Impact loads due to the placement of concrete could be significant only if concrete were being discharged from the bucket at the time of the collapse. It has been established that concrete was not being discharged onto the forms at the time of the collapse (chapter 2) and no other materials were being delivered to the roof. The prevailing wind was estimated at $9 \mathrm{mph}(4 \mathrm{~m} / \mathrm{s})$ from the northwest direction based on weather reports from nearby Partick Alr Force Base. This corresponds to wind pressures which are less than one percent of the design wind pressures stipulated by the applicable Code [2]. The ratio of actual-to-design wind forces on the structure may be even smaller due to the absence of the upper story walls and roof parapet. Thus, compared to gravity loads, the effect of wind on the structure is not significant.

Figure 2.13 shows the approximate location of the workers who were in the building at the time of the collapse. Very few workers were in the stories below the roof and they appeared to be dispersed. There was a concentration of 13 workers near the edge of the completed portion of the roof. If they are all assumed to be in bay HJ ( $\mathrm{fig} .2 .1$ ), the load in that bay due to their combined weight (assuming $200 \mathrm{lb}$ or $90 \mathrm{~kg}$ per worker) would be slightly over 4 psf $(190 \mathrm{~Pa})$. No evidence was discovered of any heavy equipment (such as compressors) in the building. Miscellaneous other equipment in the building, such as hand-operated concrete finishing tools, vibrators, etc., are light and too few to make a significant contribution to existing gravity loads.

Loads attributed to the self-weight of the structure were calculated as a uniform load of 105 psf (5030 Pa) for the second through fifth floor slabs, of 
which 100 psf ( $4790 \mathrm{~Pa}$ ) represents the weight of concrete in the 8-in (203-mm) slab based on a unit weight of $150 \mathrm{pcf}\left(2400 \mathrm{~kg} / \mathrm{m}^{3}\right)$ for the concrete. The additional 5 psf ( $240 \mathrm{~Pa})$ load accounts for the weight of reinforcing bars in the slab, determined in accordance with the reinforcing plans shown in the structural drawings.

Loads attributed to the cast portion of the roof slab (between column lines A to $\mathrm{H}$, figure 2.1) were likewise calculated as 105 psf on the same basis as above. Loads attributed to the weight of flying forms were estimated as a 5 psf $(240 \mathrm{~Pa}$ ) uniform load based on information supplied by the manufacturer. For the purpose of analysis, the flying form loads were lumped with the roof loads so that a total load of $110 \mathrm{psf}(5270 \mathrm{~Pa}$ ) was assumed acting on the flying form at the roof level where concrete was in place. A load of 10 psf (480 Pa), representing the combined weight of reinforcement and flying forms, was applied to the portion of the roof which was void of concrete (the area between column lines $\mathrm{H}$ and $\mathrm{K}$, figure 2.1).

The weight of the masonry walls on the periphery of the structure plus stacked masonry pallets on the north bay of the fourth floor (bay JK, fig. 2.1) and the south bay of the third floor (fig. 2.12 and bay $A B$, fig. 2.1) were included in the analysis of the structure. The walls were in place in the first, second and most of the third stories (see figure 2.1 for the location of masonry walls in a completed story). The wall loads for the second and third stories were estimated at $0.3 \mathrm{kips}$ per lineal $\mathrm{ft}(4.4 \mathrm{kN} / \mathrm{m})$ based on $351 \mathrm{~b}(15.9 \mathrm{~kg})$ unit weight for the masonry. The pallet loads were estimated at about 2 kips ( $9 \mathrm{kN}$ ) per end bay (south or north). Both wall loads and pallet loads were converted to equivalent concentrated loads and were placed at the appropriate nodes in the finite element model of the structure.

Based on the foregoing comments, only the first three sources of loading defined above were considered in the analysis of the structure. It should be noted that according to independent laboratory investigations subsequent to the collapse (see table A.7), the unit weight of concrete was closer to $140 \mathrm{pcf}$ $\left(2240 \mathrm{~kg} / \mathrm{m}^{3}\right)$ than the $150-$ pcf $\left(2400-\mathrm{kg} / \mathrm{m}^{3}\right)$ assumed in load calculations. However, this difference is compensated by other load effects not considered in the analysis, such as items (4) and (5) cited above, the additional weight of concrete placed in the slab where ponding occurred (see section 3.3 ), and the weight of reshores in the second through fifth stories.

Figure 5.1 shows a partial drawing of flying form types A and B within the two bays at the north end of the building to assist in vizualizing the layout. Note that in the case of form type $A$, instead of a continuous beam, two shorter beams are used at each location that overlap at the middle truss.

Referring to figures 2.7 and 2.9 , it is noted that roof loads are transmitted to the fifth floor as concentrated loads through the flying form reaction points. The widths of the flying forms were $25.0,26.0,24.5$ and $21.0 \mathrm{ft}$ $(7.63,7.93,7.47,6.41 \mathrm{~m}$ ) for types A to $D$, respectively (the widths of forms $A$ and $B$ are shown in fig. 5.1). Since the widths of the transverse bays were also different, the filler panels (figures 2.9 and 5.1 ) had, in general, different widths as well. The lengths of the Aluma beams for types A, C and D 
are the same as the corresponding widths of the forms. The Aluma beams for types $B$ and $C$ are therefore continuous over the center truss. No continuity occurs in the case of type $D$ which has only two trusses.

Each flying form was assumed to support the entire load within its bay. Therefore, the portion of loads on the filler strips between the edge of the form and column centerline was assumed as a uniform line load applied to the top of the exterior truss of the form. The Aluma beam reactions at the trusses were calculated taking into consideration the effect of continuity where such was the case. These reactions were also applied at the top of the trusses as a uniform line load. The truss reactions were then determined on the basis of tributary spans for simplicity. In the case of form $B$, the tributary reactions were compared with those obtained by analysis using the sectional and material properties of the trusses supplied by the manufacturer and assuming continous top and bottom chords and pinned verticals and diagonals. This comparison showed that the differences between corresponding reactions were within 12 percent. In the analysis of the structure, forces opposite to the tributary reactions were applied to the fifth floor as point loads.

\subsection{CONSTRUCTION SEQUENCE}

The forming and reshoring sequence at various stages of construction was examined in the analysis of the Harbour Cay building because it affects the load paths in the system. An analytical approach to evaluating the effect of loading history on the interaction between slabs and falsework was first formulated by Neilsen [5.1], taking into consideration the deformation characteristics of the slabs and the shores. Grundy and Kabaila [5.2] developed a simplified method for analyzing the distribution of loads between slabs and falsework based on the assumption of rigid shores. For a single bay structure, without reshores $\left(n_{r}=0\right.$, sec. 5.1) this approach yielded a maximum load ratio of 2.36 (i.e., the maximum load on a slab divided by its dead load). This was close to the more rigorous analysis by Nielsen which yielded a maximum load ratio of 2.56 .

Both of these analyses assume a shored system (no reshores). To reduce the load ratios, Taylor [5.3] proposed a scheme which involved physically relieving reshore loads prior to the placement of a new concrete floor. This reduced the maximum load ratio to 1.44. The method of construction in the Harbour Cay building (sections 2.4 and 5.2) allows the slab to deflect under its own weight in the reshoring operation. This results in a reduction of the maximum load ratio in a manner similar to that described by Taylor.

\section{Vertical Construction Sequence}

To examine the effect of the construction history on the Harbour Cay building, an analysis was performed according to the method proposed by Grundy and Kabaila [5.1] assuming no loads are taken by the reshores when they replace the flying forms. The results of this analysis are schematically summarized in figure 5.2. The numbers on the right side of each sketch are load ratios (defined above). In this analysis, reshores are assumed to be weightless and axially rigid and the stiffness of the slabs to be equal. A step-by-step explanation 
(steps a through $\mathrm{n}$ ) of the shoring sequence and corresponding load ratios, (designated by $r$ ) follows. In the case of reshores, $r$ designates the load on reshores in a story divided by the dead load of the slab.

(a) Second floor placed. Flying form ("form," in brief) takes entire load.

(b) Form removed. First floor assumes self weight $(r=1)$.

(c) Reshores are installed snug in first story $(r=0)$. First floor still carries its own weight $(r=1)$.

(d) Flying forms are placed in the second story and the third floor is cast. Flying form carries third floor's weight $(r=1)$ which in turn is transferred directly to the first story reshores $(r=1)$. The first floor slab still carries its own weight $(r=1)$.

(e) Flying form removed causing third floor to carry its own weight $(r=1)$. - First story reshores are relieved $(r=0)$.

(f) Reshores are installed in a snug fit.

(g) to ( $j$ ). is the same as the cycle from (d) to (f).

(k) Reshores in the first story are removed. (For the Harbour Cay building, it was assumed that the reshores in the first story were removed before the flying forms in the fourth story were flown since the reshores would be needed on hand to replace the flying forms as they were removed.) The load relieved from the vacated reshores $(r=1)$ is equally shared by floors 2 to $4(\mathrm{r}=1 / 3 \mathrm{each})$. The load in the second story reshores are relieved by two-thirds $(r=-2 / 3)$ since one-third of the vacated reshore load is carried by the second floor slab. The third story reshores are unloaded by one-third $(r=-1 / 3)$ since an additional one-third of the vacated reshore load is carried by the third floor slab.

(1) Flying forms in the fourth story are removed. The fifth floor assumes its own self weight $(r=1)$. Floors 2 to 4 are unloaded equally $(r=-1 / 3$ each). The loads in the reshores in the third story are relieved by two-thirds $(r=-2 / 3)$ since one-third of the vacated flying form load is taken by the fourth floor slab. The loads in the reshores in the second story are relieved by one-third $(r=-1 / 3)$ since another one-third of the vacated flying form load is taken by the third floor slab.

(m) The result of (1), i.e., the reshores are unloaded $(r=0)$.

(n) Finally the reshores are installed snug in the fourth story.

To summarize, this analysis shows that prior to placement of the roof, all the floor slabs are supporting their own weight and the reshores are unloaded; i.e., the reshores are not involved in transmitting the slab weights of the second through fourth floors. 
The values of the load ratios would be somewhat different if actual reshore and slab stiffnesses were considered in the analysis.

It should be kept in mind that this is a simplified analysis that highlights the response of a single bay plane structure to a particular shoring scheme and sequence of construction. In a multibay space structure there are other construction effects that need to be examined. This topic is discussed below.

Effect of Lateral Form Removal

Because the Harbour Cay building was a multibay structure, the possibility exists that the sequence of form removal from a particular story will have an effect on load distribution. Specifically, the question to resolve is whether or not the replacement of flying forms with reshores in a multibay story causes the entire slab above to carry its own weight.

As explained in chapter 2, the sequence of form removal was from the south side bays to the north side bays. All indications are that the forms were removed sequentially, beginning with bay $\mathrm{AB}$ and ending with bay JK. With this sequence, an analysis of the effect of the lateral removal of the flying forms is depicted in figure 5.3. The steps of the analysis are explained below.

Figure 5.3 (a) shows a cast slab being supported by the flying forms. In (b) the flying forms are removed from the first bay. This loads the frame by an amount equal to the floor dead weight in that slab (2.35 k/ft or $34.3 \mathrm{kN} / \mathrm{m})$. A frame analysis of the structure in (b) shows that the flying form in the adjacent bay $B C$ is unloaded by $13.5 \mathrm{kips}(60.1 \mathrm{kN}), 6.5 \mathrm{kips}(29.0 \mathrm{kN})$, and 0 kips as shown in (c). The effect of unloading the first bay causes negligible forces in all bays but the adjacent bay.

Next, reshores are inserted in a snug fit in the first bay and the flying forms in the second bay are removed. This loads the frame by the slab weight of that bay. However, that load is reduced by the amount caused by the removal of the flying forms from the first bay, i.e., the $13.5 \mathrm{kips}(60.1 \mathrm{kN}), 6.5 \mathrm{kips}$ $(29.0 \mathrm{kN})$, and $0 \mathrm{kips}$. This net loading of the frame results in an unloading of the flying forms in the adjacent bays by 9.3 kips $(41.4 \mathrm{kN}), 4.4$ kips $(19.6 \mathrm{kN})$, and $0 \mathrm{kips}$. Again the effect of removing the flying forms induces negligible forces in all bays but the adjacent bays. Since in (c) the reshores in the first bay were simply inserted in a snug fit, i.e. zero load, a reduction in the load in these reshores caused by removing the flying form in the second bay would cause them to go into tension.

Since reshores cannot develop tension, it is reasonable to assume that they were installed just tight enough to keep them from falling down when forms in adjacent bays are lowered. Thus, in (d), with the removal of the flying form in the third bay, the load in the reshores in the first bay would still be zero. The removal of this flying form again loads the frame by the slab dead weight of that bay less the amount caused by the removal of the flying form in the second bay, i.e., 9.3 kips $(41.4 \mathrm{kN}), 4.4 \mathrm{kips}(19.6 \mathrm{kN})$, and 0 kips. 
This process is repeated until the north bay is reshored, at which time, the forces in the reshores are all zero or nearly so, and the slab is supporting its own dead weight as assumed in the analysis shown in figure 5.1.

\section{Definition of Analysis Models}

The above analyses indicate that when the flying form system is used, the reshores are effective in transferring only the newly placed concrete loads to the lower floors. When the flying forms are removed, the forces in the reshores revert to zero and the slabs carry their own dead weight. As a result, it is reasonable to assume that before the roof is cast the fifth, fourth, third, and second floor slabs are supporting their own weight and the reshores are unloaded (as indicated in fig. 5.2, step $\mathrm{n}$ ). When the roof is cast, the load will be shared by all the floor slabs through the action of the reshores. Thus, to determine the state of stress at the time of collapse, two separate cases should be analyzed. In the first case, the structure without reshores is loaded by the dead weight of floors 2 through 5 as shown in figure $5.4 \mathrm{a}$. In the second case, the reshored structure is loaded with the dead weight of the roof as shown in figure $5.4 \mathrm{~b}$. The final result is obtained by adding the results from the two analyses.

\subsection{METHOD OF ANALYSIS}

The design of a flat plate structure such as the Harbour Cay Condominium typically involves either a simplified "direct design" analysis in which the structure is designed for assumed upper and lower bounds of bending and shear stresses based on tributary areas, or, the structure is designed to resist moments and shears determined by analysis using the equivalent frame method (EFM). The equivalent frame method involves modeling the structure as a series of plane frames along the column lines, where the slabs between the centerlines of adjacent spans are modeled as wide beams. As specified in the ACI Code [2.1], the actual column stiffnesses in the EFM are modified after Corley and Jirsa [5.4] to better represent the transfer of bending moments at the slab-column connections (table 5.1).

The EFM is a simple method to use. However, since the Harbour Cay condominium was reshored irregularly in addition to having irregularly spaced flying form loads, the EFM analysis was compared to results of a finite element method (FEM) of analysis which can model the three-dimensional aspect of the loading.

Equivalent Frame Analysis of Fifth Floor

The comparison was made using only the fifth story of the structure and assuming the columns were fixed at the base and the reshores pinned at both ends, as shown in figure 5.5a (see section 2.4 for the number and location of reshores). The EFM analysis summarized in figure 5.5 was the frame along column line 2. The loading including the distributed dead weight of the fifth floor slab (106 psf or $5.08 \mathrm{kPa}$ ) plus the weight of the flying forms and the newly cast roof up to column line $H$ (figure 2.1), applied as joint loads. The roof loads were calculated as explained in section 5.3. The pertinent structural data for the EFM is summarized in table 5.1. The results of the analysis 
as summarized in figure 5.5(a) are for the frame with reshores and in figure $5.5(b)$ for the frame without reshores. These results were then compared to a FEM analysis of the fifth floor alone using the same loading conditions as above.

Table 5.1. Structural Data for Fifth Floor only EFM

$A_{\text {reshores }}=3(12.25)=36.75 \mathrm{in}^{2}\left(237 \mathrm{~cm}^{2}\right) \quad E_{\text {reshores }}=\begin{aligned} & 1,600,000 \mathrm{psi} \\ & (=11 \mathrm{GPa})\end{aligned}$
$\mathrm{b}_{\text {slab }}=266 \mathrm{in} .(6.76 \mathrm{~m})$
$\mathrm{I}_{\text {slab }}=11350 \mathrm{in}^{4} \quad \mathrm{I}_{\text {interior } \mathrm{col}}=56 \mathrm{in}^{4} \quad \mathrm{I}_{\text {exterior col }}=474 \mathrm{in}^{4}$
$\mathrm{E}_{\mathrm{C}}=4,280,000 \mathrm{psi}(29.5 \mathrm{GPa})$
$\mathrm{W}_{\mathrm{D}}=(0.106)\left(22.2^{\circ}\right)=2.35 \mathrm{k} 1 \mathrm{f}(34,300 \mathrm{~N} / \mathrm{m})$

Finite Element Analysis of Fifth Floor

The finite element software used in the analysis was the Sperry Univac implementation of ICES-STRUDL-II [5.5]. Rectangular plate bending elements (type BPR) were used. This element is described in reference 5.6. The finite element mesh used for the fifth floor is shown in figure 5.6. The rationale behind the fairly dense mesh can be seen upon a careful examination of a plan view of the fifth floor (figure 5.7). Nodal points were necessary at the locations of the flying form truss jacks and at the locations of the reshores underneath the slab. Nodal points were added between the flying form trusses to reduce the maximum aspect ratio of the plate bending elements from 5.0 to 2.5 .

The FEM model of the fifth floor consisted of the plate bending mesh shown in figure 5.6 supported by columns fixed at their base. As before, two different analyses were made: one for the structure with reshores and one for the structure without reshores.

The results for the column forces for the FEM fifth-floor model with reshores are shown in figure 5.8. Due to almost symmetric loading and closeness of span lengths, the column moments are all relatively small. A comparison of axial forces in columns on column line 2 with those obtained from the EFM analysis (fig. 5.5a) shows poor agreement between the two sets of results.

The results for the column forces for the FEM model without the reshores are shown in figure 5.9. The largest column force is 146 kips ( $650 \mathrm{kN}$ ) occurring in column $\mathrm{B}-2$. This value compares well with the value of $144 \mathrm{kips}$ ( $641 \mathrm{kN}$ ) for the EFM results summarized in figure 5.5(b). The other column forces also agree reasonably well.

The results for column axial forces from the EFM and FEM analyses agree fairly well for the case without reshores since the axial force is primarily due to tributary area loads. With the addition of reshores, the load transmission 
becomes three-dimensional and the EFM column axial forces do not match the FEM results even reasonably wel1; for this reason, a three-dimensional FEM analysis is required.

\subsection{FINITE ELEMENT ANALYSIS OF ENTIRE STRUCTURE}

Due to the absence of flying forms in the second through fourth floors a coarse FEM mesh, as shown in figure 5.10, could be used for modeling these levels. The fifth floor mesh (figure 5.6) was retained for this analysis. The columns were modeled as three-dimensional beam-column elements and the reshores were modeled as three-dimensional truss elements.

The structural geometry is defined in chapter 2. The values for the modulus of elasticity of concrete, $E_{C}$, (as described in chapter 4) are summarized in table 5.2. Poisson's ratio was assumed as 0.2 . The modulus of elasticity of the reshores was taken as $1,600 \mathrm{ksi}$ ( $11 \mathrm{GPa}$ ).

Table 5-2. Assumed Concrete Modulus of Elasticity

\begin{tabular}{|c|cc|}
\hline & \multicolumn{2}{|c|}{ Ec } \\
\hline 5th Floor Slab & $4,150 \mathrm{ksi}$ & $(28.6 \mathrm{GPa})$ \\
4th Story Columns & $3,590 \mathrm{ksi}$ & $(24.7 \mathrm{GPa})$ \\
4th Floor Slab & $4,270 \mathrm{ksi}$ & $(29.4 \mathrm{GPa})$ \\
3rd Story Columns & $3,630 \mathrm{ksi}$ & $(25.0 \mathrm{GPa})$ \\
3rd Floor Slab & $4,310 \mathrm{ksi}$ & $(29.7 \mathrm{GPa})$ \\
2nd Story Columns & $3,650 \mathrm{ksi}$ & $(25.2 \mathrm{GPa})$ \\
2nd Floor Slab & $4,340 \mathrm{ksi}$ & $(29.9 \mathrm{GPa})$ \\
1st Story Columns & $3,660 \mathrm{ksi}$ & $(25.7 \mathrm{GPa})$ \\
\hline
\end{tabular}

As described in section 5.4, two cases are analyzed. In the first case, the structure without reshores is loaded with the dead weight of the floors, as shown in figure 5.4(a). In the other case, the structure with reshores in the second, third, and fourth stories, as shown in figure 5.4 (b), is loaded with the flying forms and the roof slab, which was cast from column line A to column line H. Superposition of the results of these two analyses yield the final results which are discussed below.

The FEM analysis of a large structure such as this (5328 members, 2543 nodes, 12679 degrees of freedom) causes problems as to the most efficient manner of presenting the results. Since it was suspected that failure was due to punching shear, shear forces at the columns and top column moments are presented. These quantities are used to calculate punching shear stresses in the slab.

Although the typical failure mode of a flat plate structure of this type is by punching shear, in the interest of completeness, various failure modes were checked prior to the complete analysis of the structure.

Bending stresses were checked according to the ACI Code [2.1] direct design method. The steel ratios in the slabs were also checked and found to be less 
than the balanced ratio as required. Column slenderness effects were also investigated; however due to the nature of the collapse, i.e., vertical with no sidesway component, this mode of failure was not suspected. Axial stresses in the columns were checked for tributary area loads and found to be well below allowable. Initial estimates of punching shear stresses (from tributary areas) showed the degree of safety to be marginal for this mode of failure.

Figure 5.11 shows the combined results of punching shear forces (difference between column axial forces at the slab-column connections) for the slab-column connections along column line B. Figure 5.12 shows the same results for column line 2. These figures indicate that the fifth floor was the most heavily loaded floor (in punching shear) as suspected from the load path analysis in section 5.4. The punching shear and unbalanced column moments for all the fifth floor slab column connections are tabulated in figure 5.13. The most heavily loaded connections are on the fifth floor at column B-2 and G-2; 102 kips and $100 \mathrm{kips}(454 \mathrm{kN}$ and $445 \mathrm{kN}$ ), respectively. The analysis of punching shear stresses corresponding to the axial forces and moments shown in figure 5.13 is presented in the next chapter.

\subsection{SUMMARY}

The following are the major points resulting from the analysis of the structure under construction loads;

1) At the time of collapse, gravity loads were the only significant kinds of loading on the structure.

2) Using a simplified and approximate analysis of the load distribution during construction, it is shown that at the stage just before the roof loads are applied each slab carries its own weight and there are no loads in the reshores. When the roof is cast, the reshores are effective in distributing the roof load to the slabs of the reshored stories.

3) The final analysis of the construction load effects was obtained by superposition of the results of two analyses. In one case, the unshored structure was loaded by the self weight of floor slabs 2 through 5 . In the second case, the shored structure was loaded with the roof load.

4) In order to account for the three-dimensional response of the shored structure, the finite element method was used for the final analysis.

5) The results of the analysis indicate that the most heavily loaded slab-column connections are in the fifth floor at columns B-2 and G-2. 


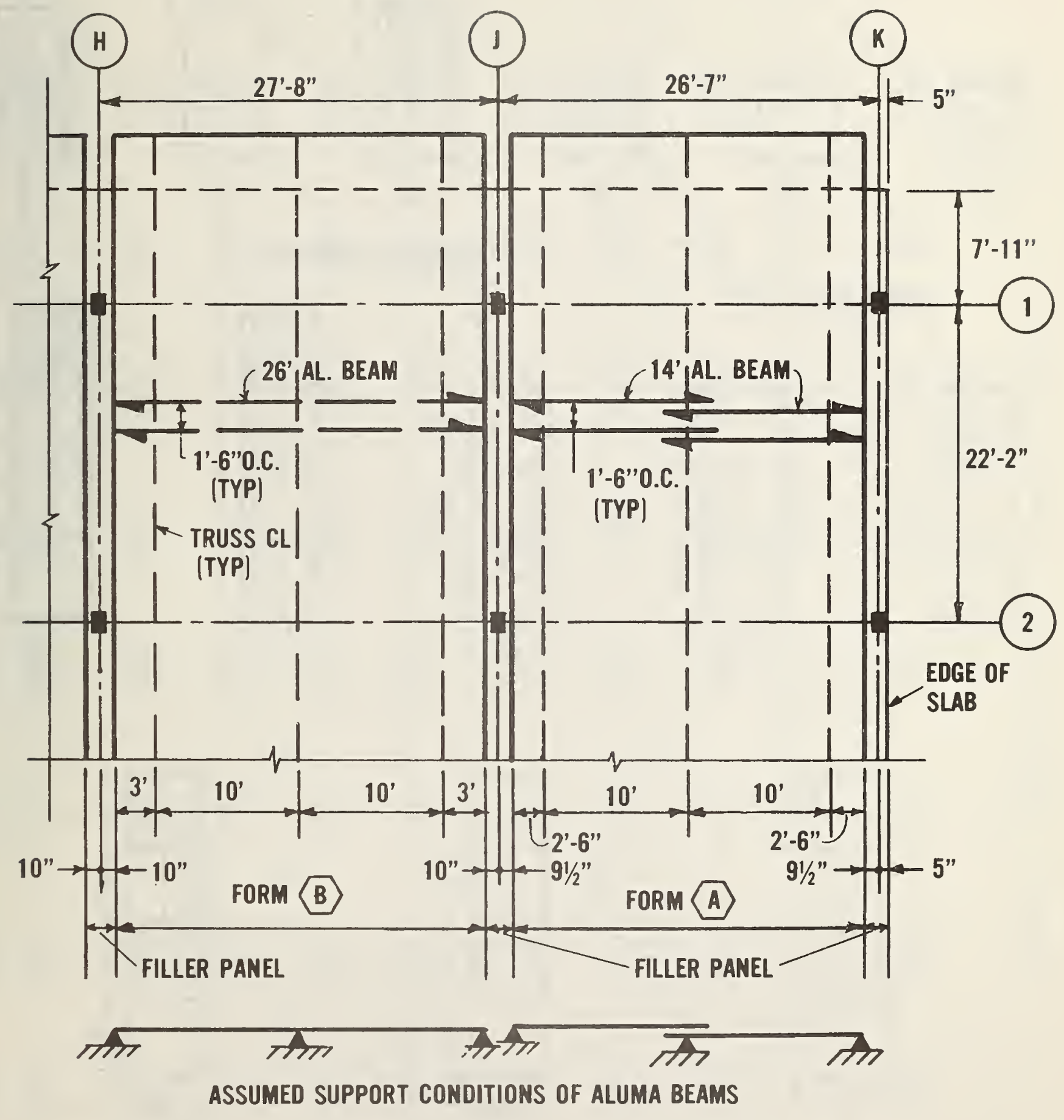

Figure 5.1 Configurations of flying forms $A$ and $B$ in north bays 


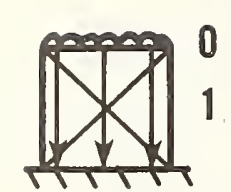

a)

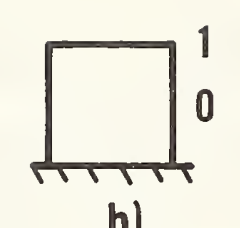

b)

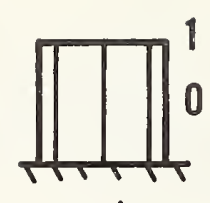

c)

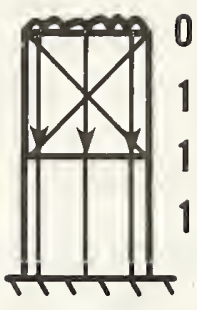

d)

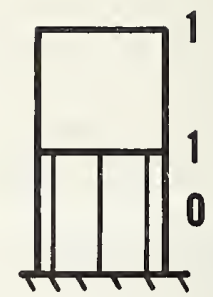

e)

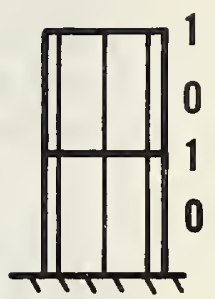

f)
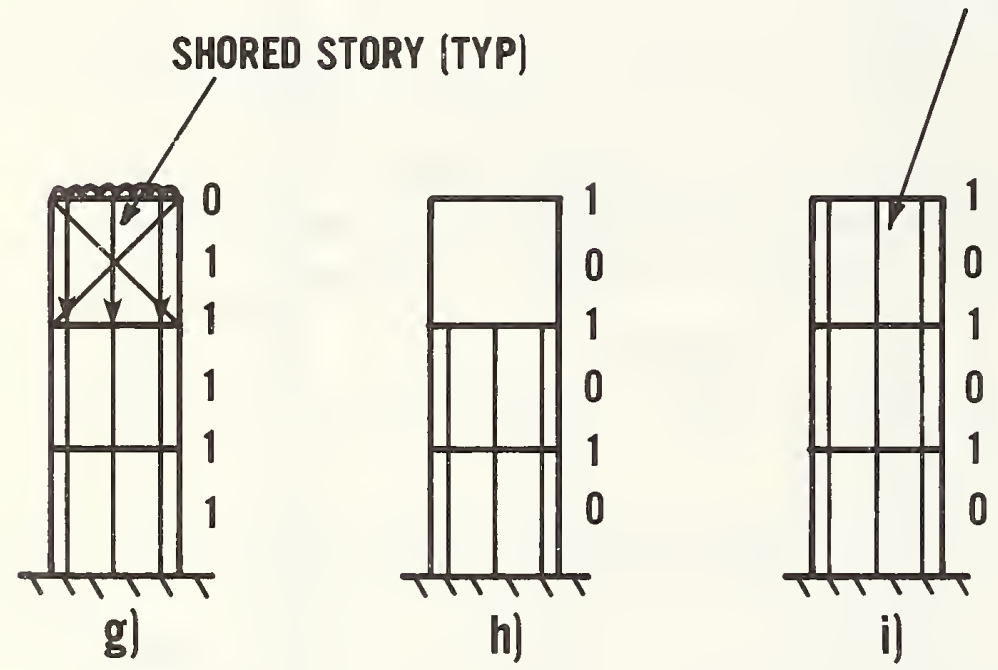

RESHORED STORY (TYP)

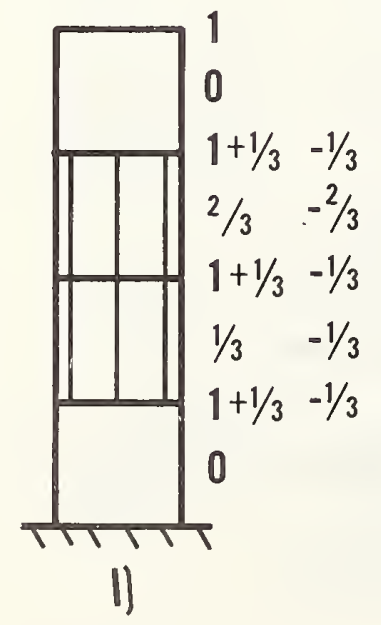

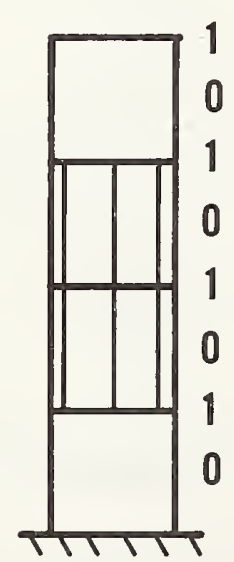

m)
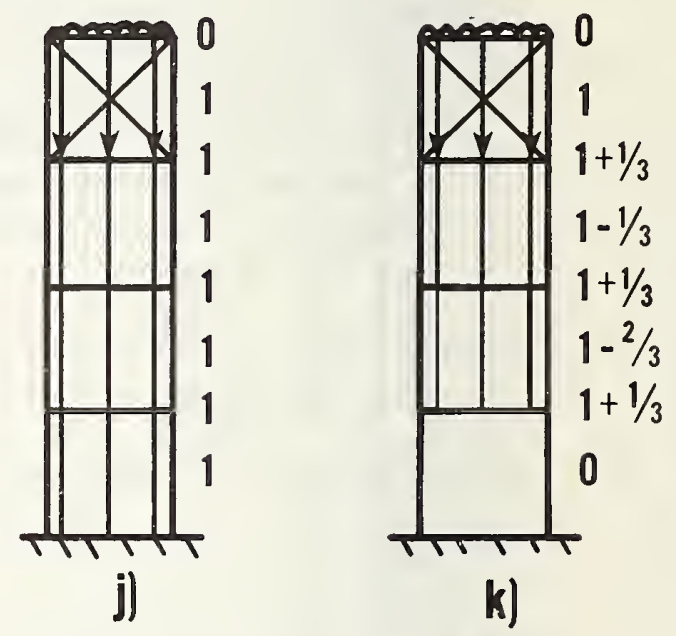

Figure 5.2 Effect of vertical construction sequence 
()

으

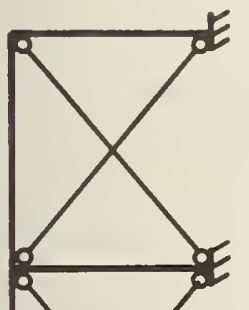

(ㄱ)

()

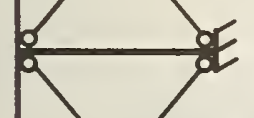

(4)

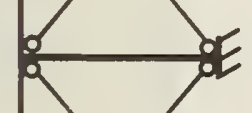

()

())

()

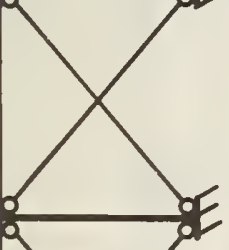

○
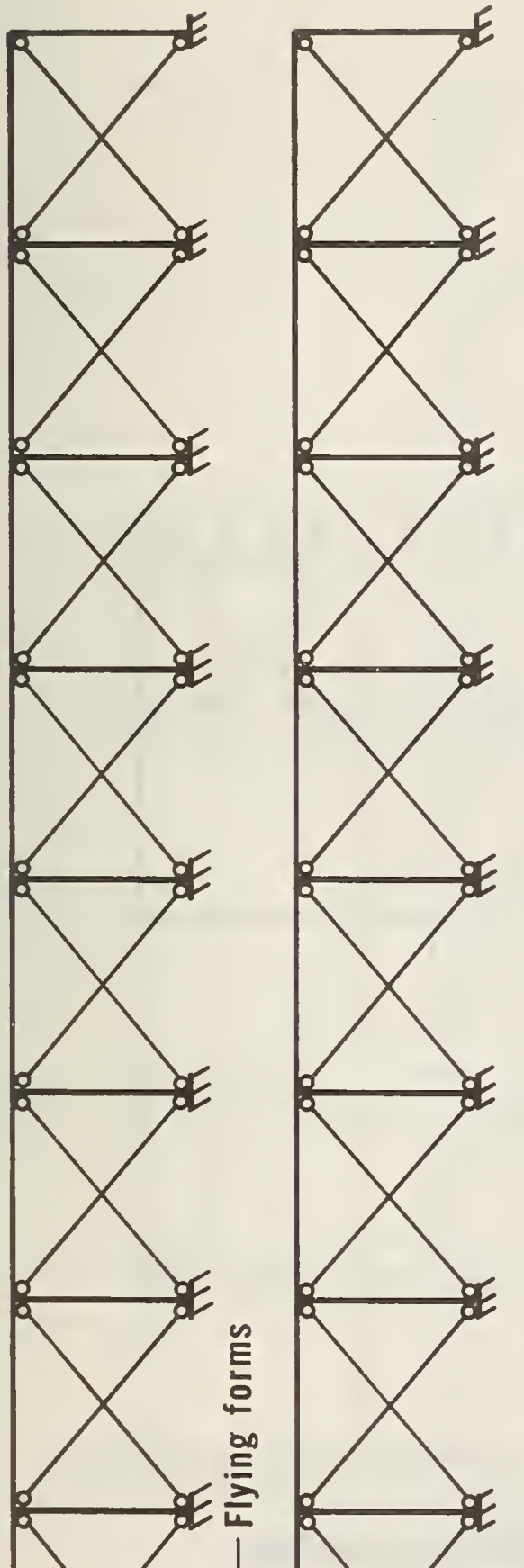

(4)
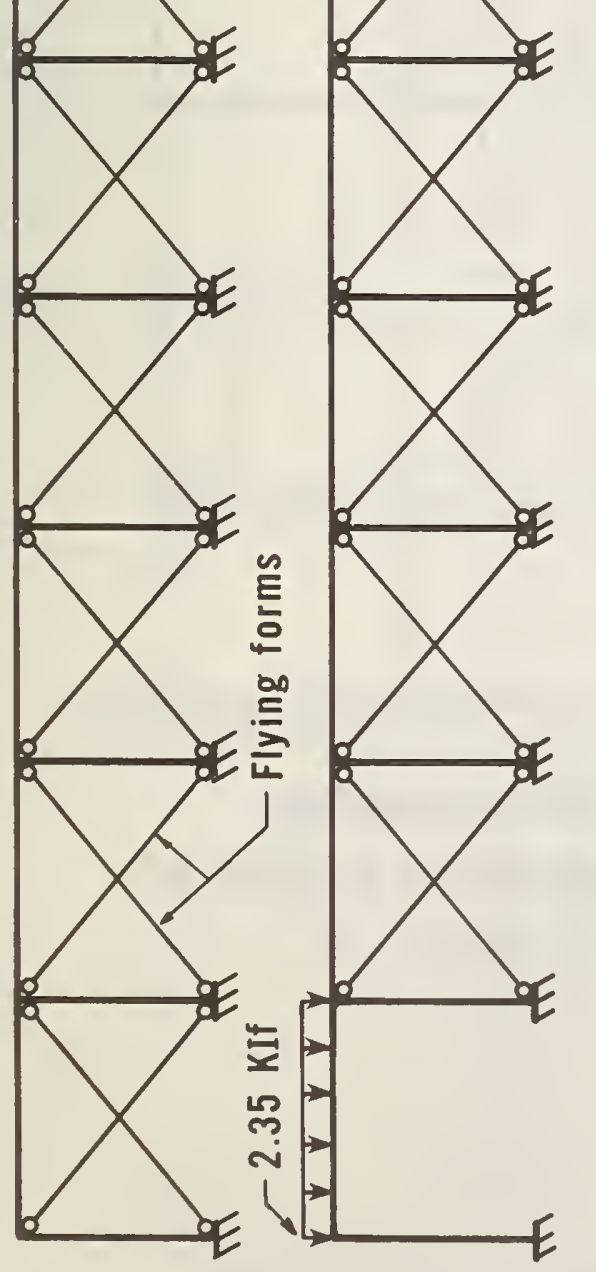

ס

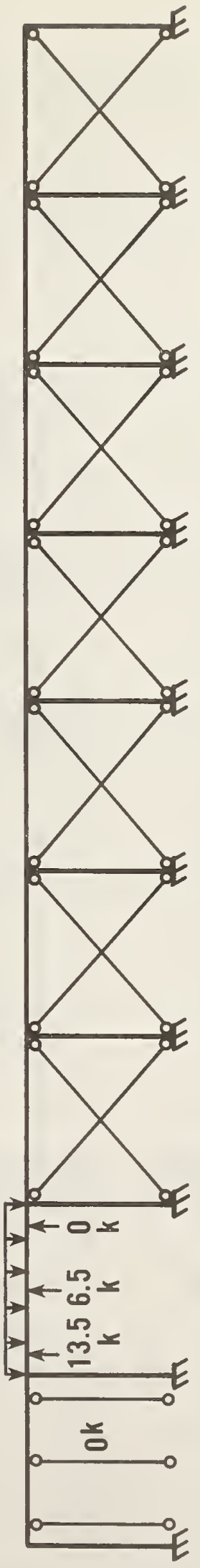

ن
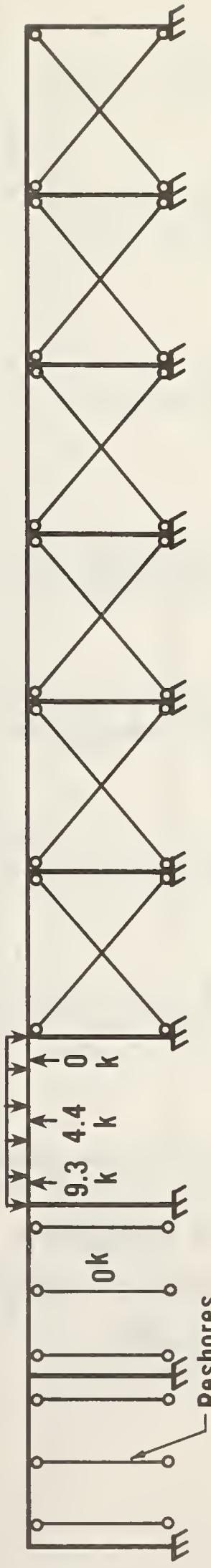

D

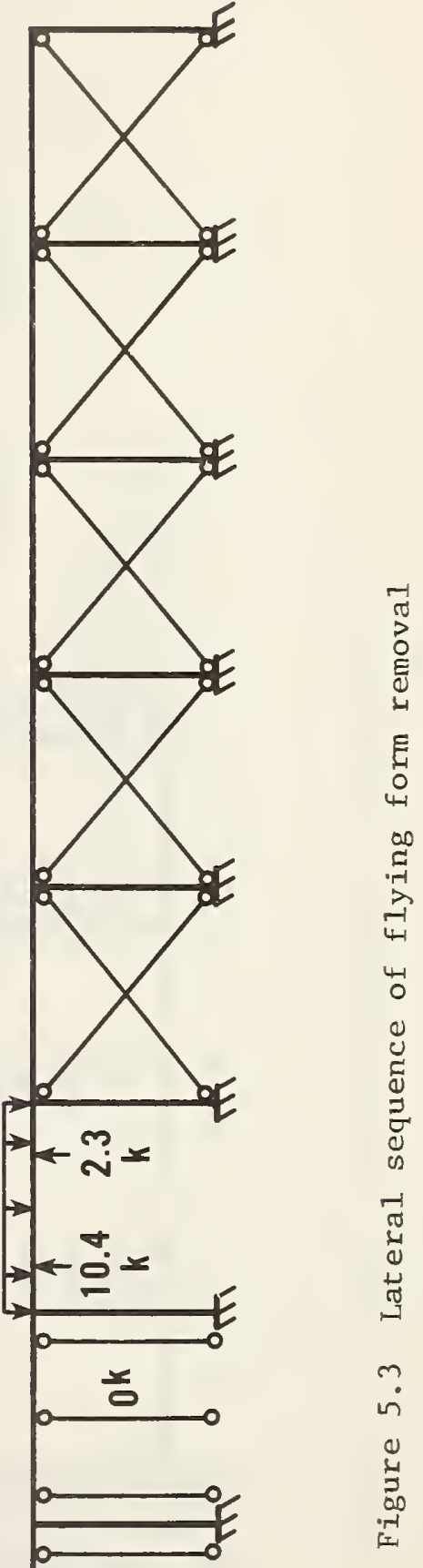

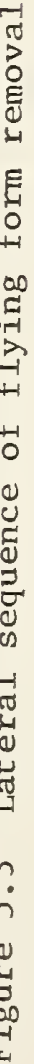

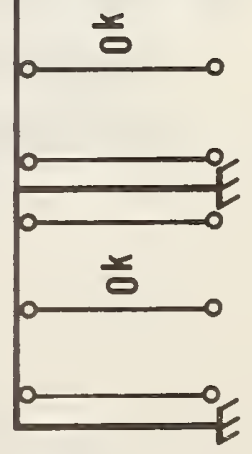

a) 


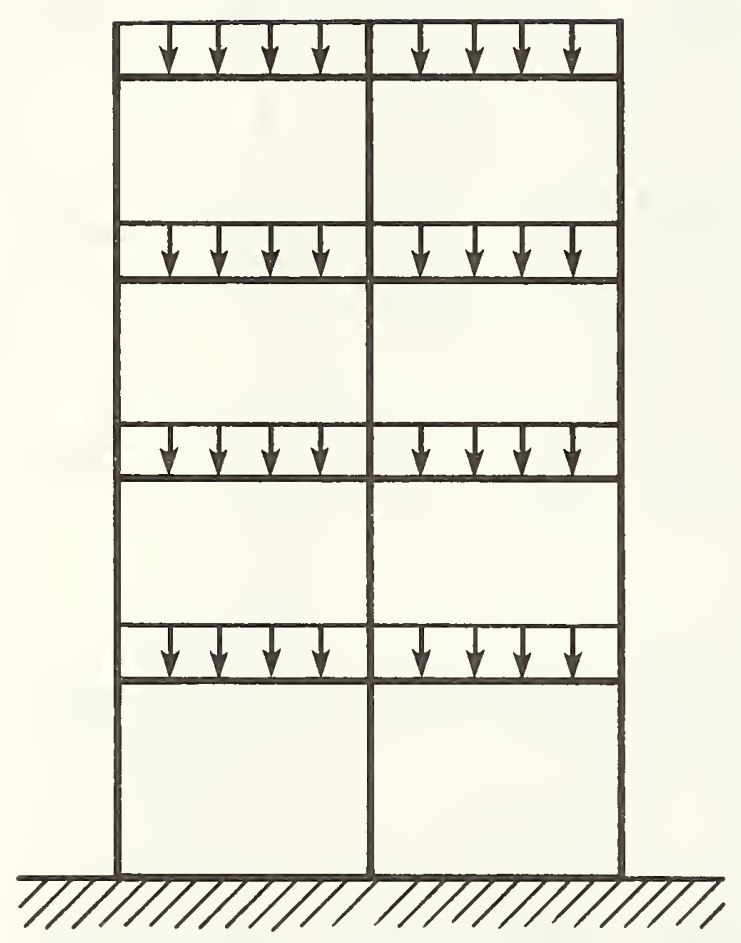

a) Unshored structure supporting self-weight of floor slabs

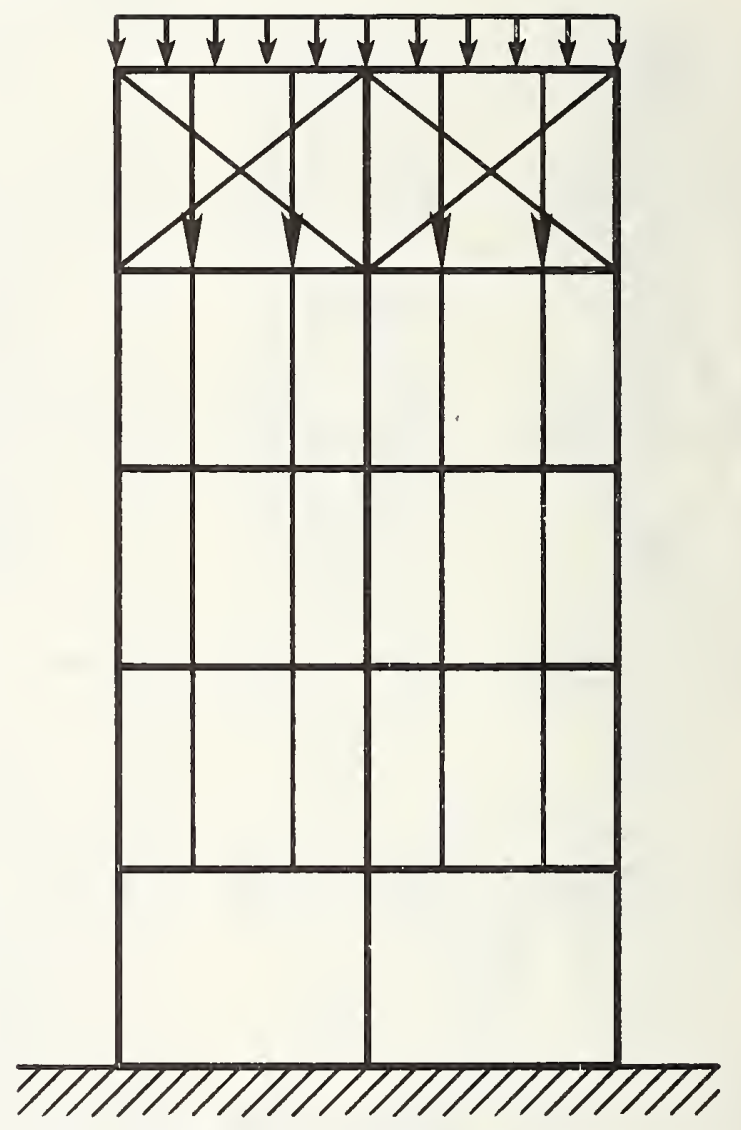

b) Shored structure supporting weight of roof slab

Figure 5.4 Two cases analyzed to obtain final solution 


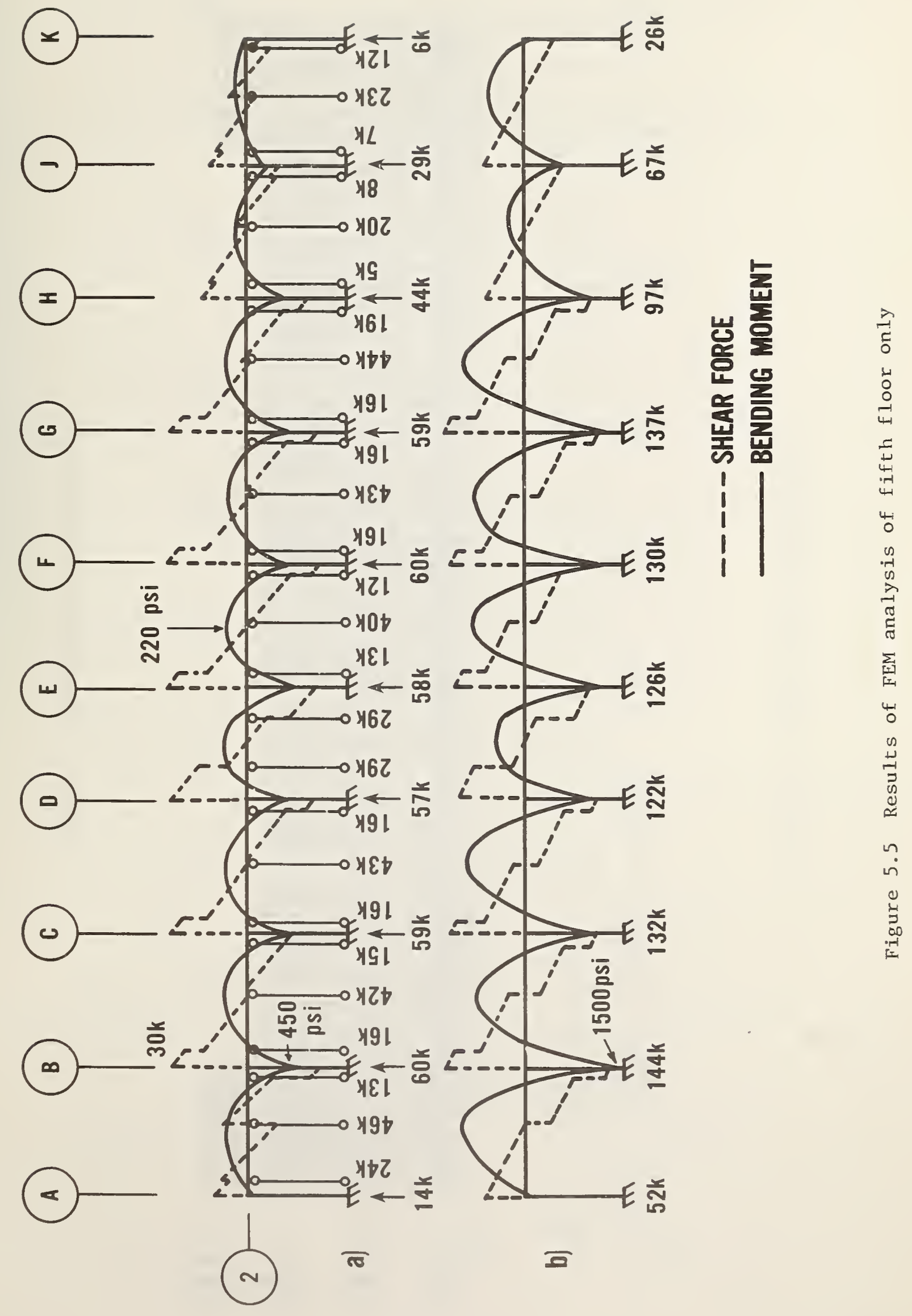




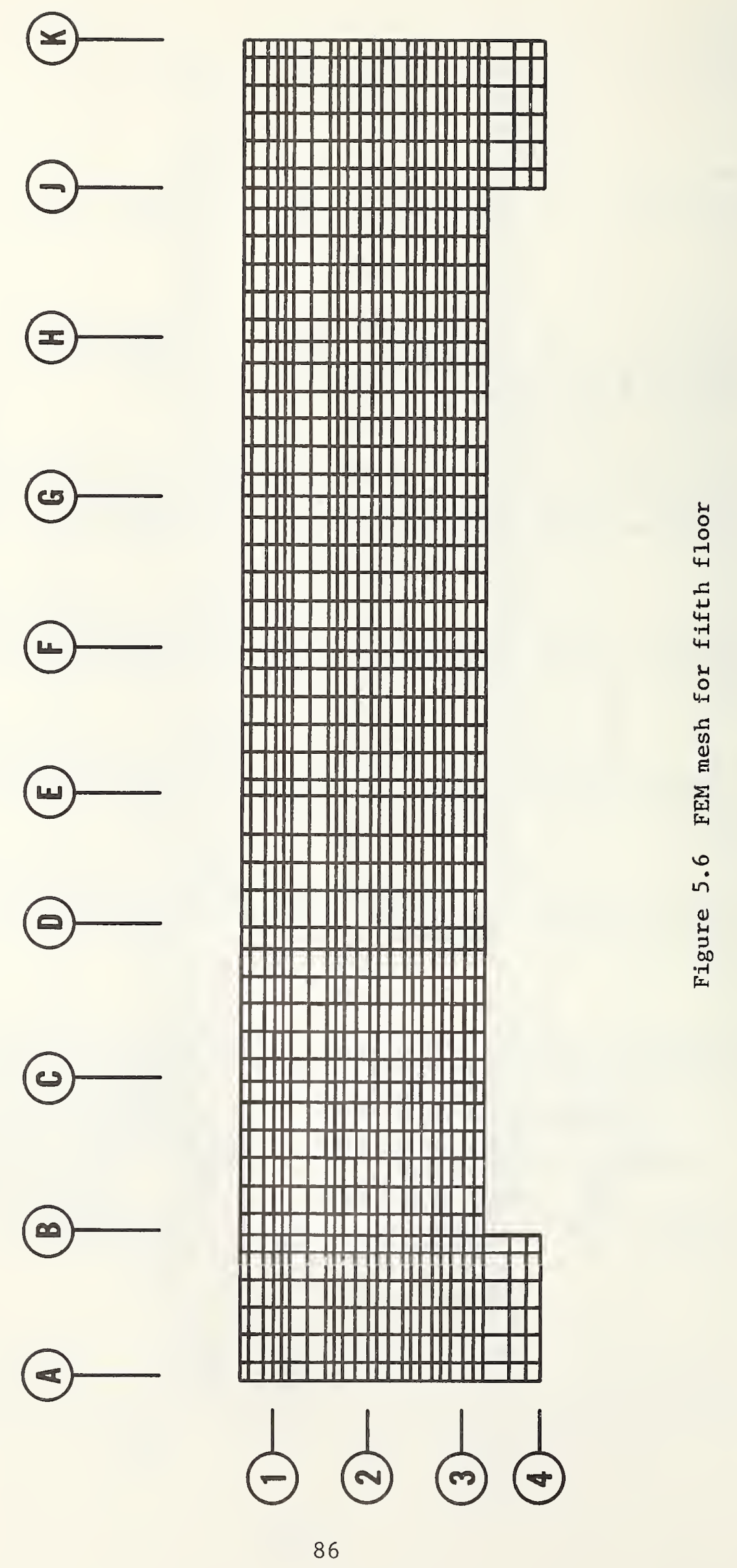




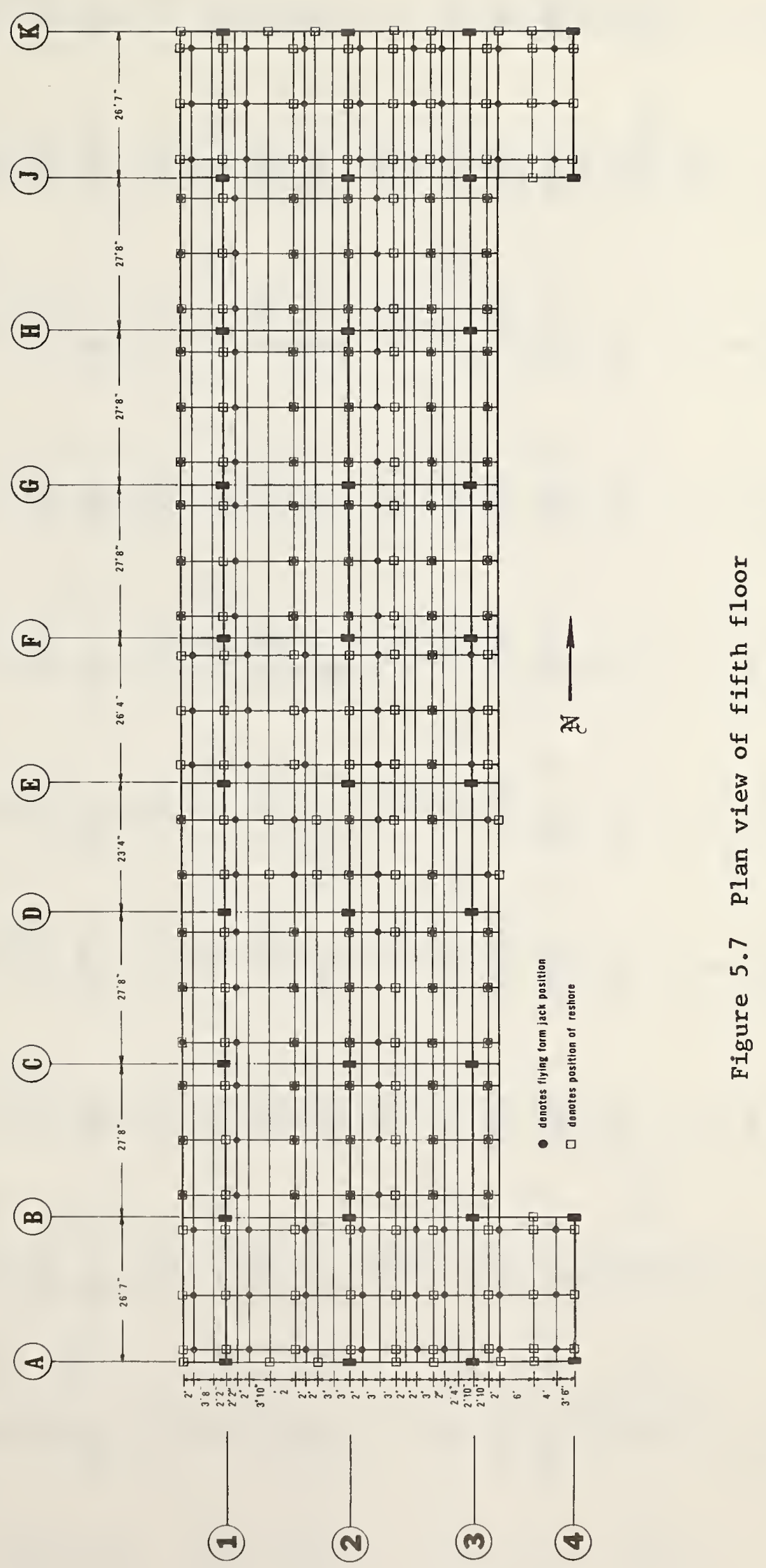



$\stackrel{0}{\dot{d}}$
0

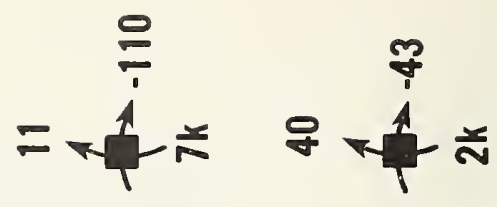

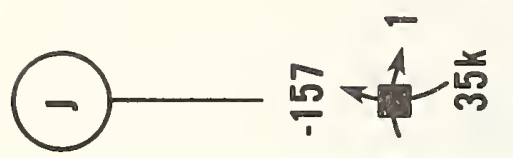

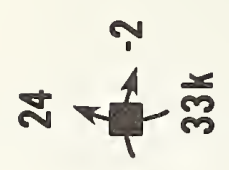

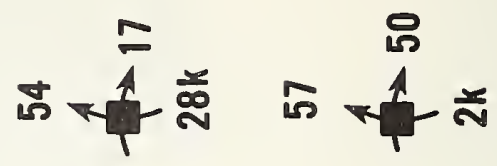

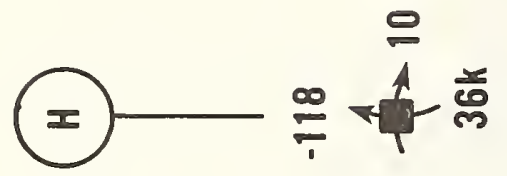
ص
$\infty \pi \frac{1}{\sqrt[1]{n}}$
(6) $\frac{3}{0} \frac{\pi}{4}=$
$+\pi \frac{4}{m}=$
\& $\pi \frac{4}{2}$
(12) $\approx \frac{1}{4}$
$\infty+\frac{1}{m}$
$=\pi \frac{1}{2}=$
(1) $\frac{\text { ป }}{\frac{1}{4}} \frac{1}{m}$
- सी 年
๕
(0) $\stackrel{\frac{2}{7}}{\frac{\pi}{1}} \frac{1}{m}$
พ
$\stackrel{m}{\stackrel{1}{\approx}} \pi \frac{1}{1}$
(0)
$\stackrel{4}{\frac{N}{m}}$
$\infty \frac{1}{4}^{\frac{1}{n}}$
先
空
号
.
出题
告

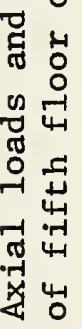

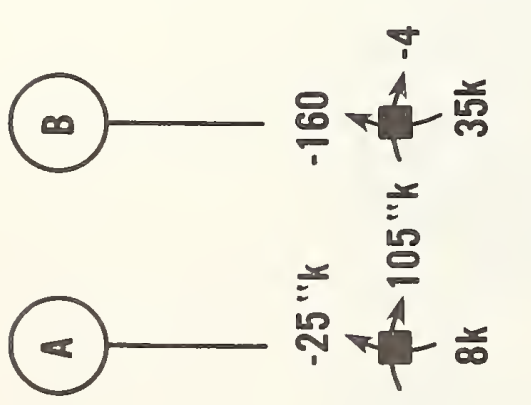

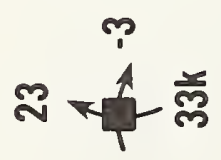
疍
मै
$\infty$<smiles>[CH]C1C(C)C(C)C(C)C1C</smiles>
$0 \frac{1}{2}=$
$\frac{2}{\frac{1}{4}}=$
1
(v)
$\infty$
$+$ 

คำ
$\approx-8 \times \frac{1}{4}$

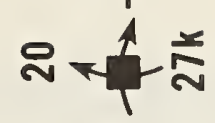

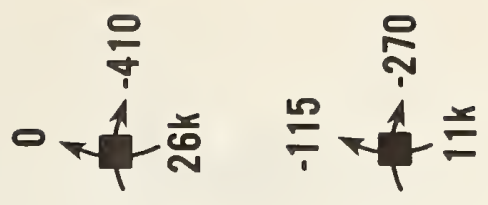

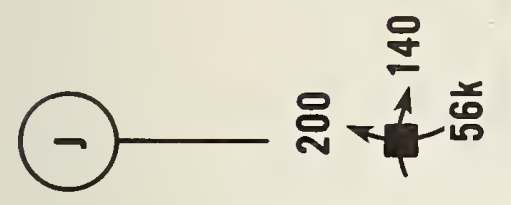
은

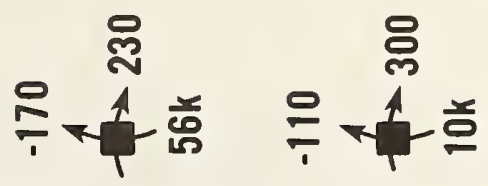
品
(工) $\stackrel{\infty}{-1}$

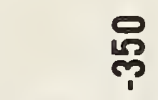
品
管
(6) -
总然亭
总总望
(4) ㅇำ
旅兽
总 售商
(4) 告兽言

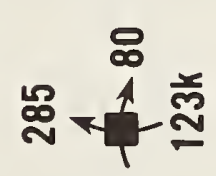

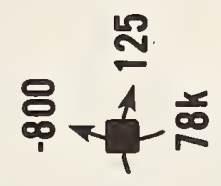
(-) 든

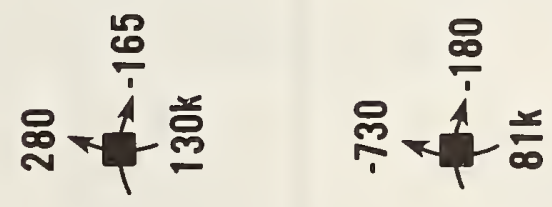
(2) 은
总点商

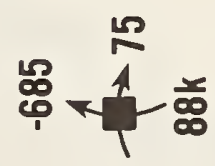
$\infty$ -
สิ-4

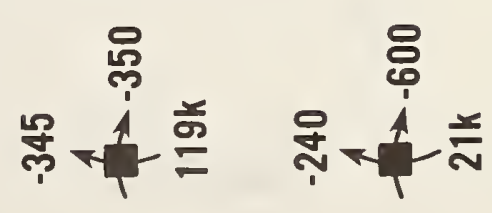

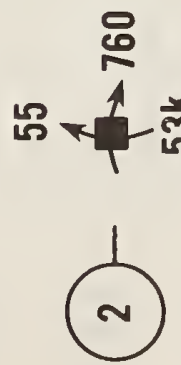

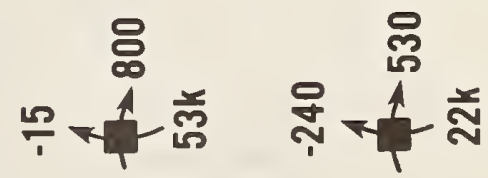

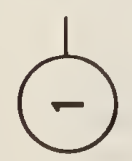
$\infty$

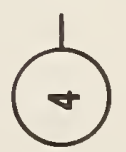




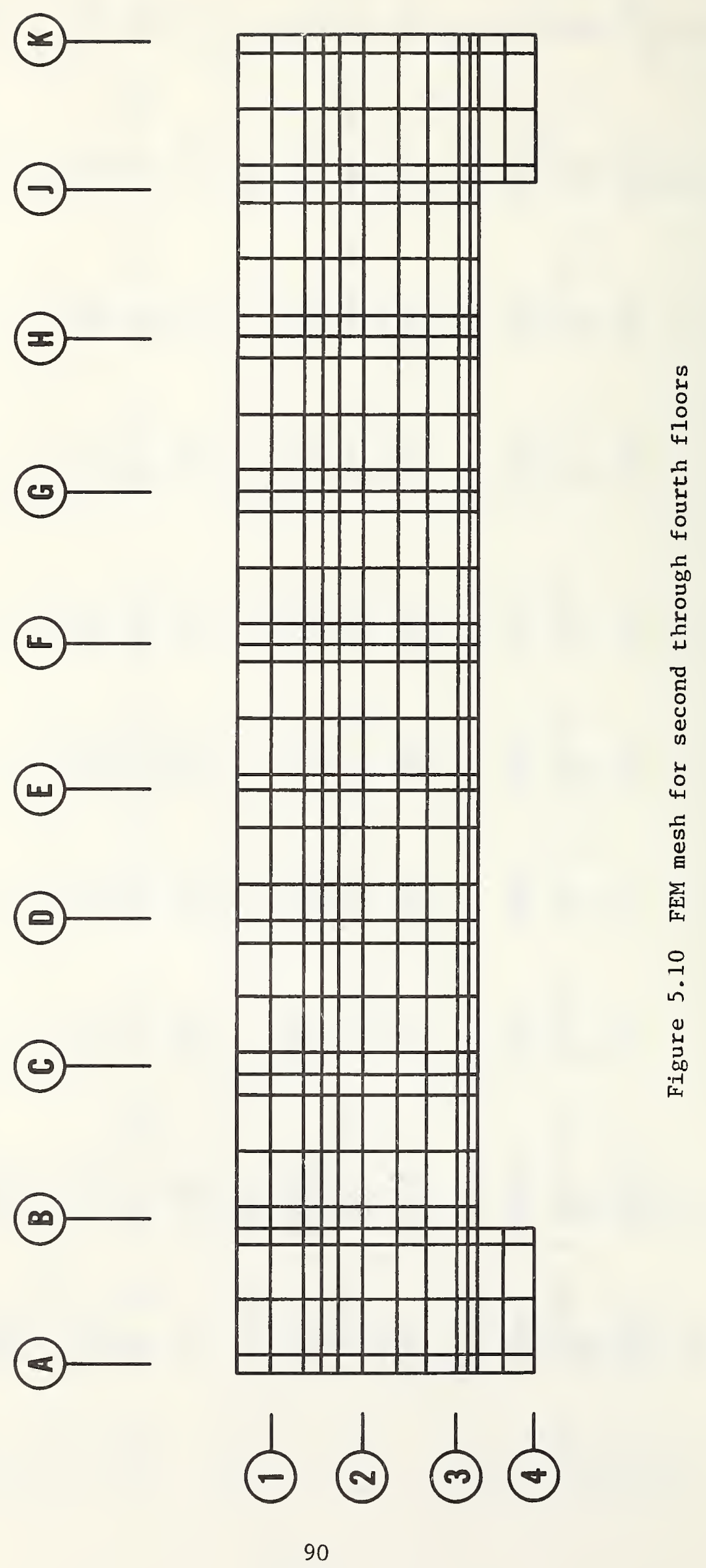




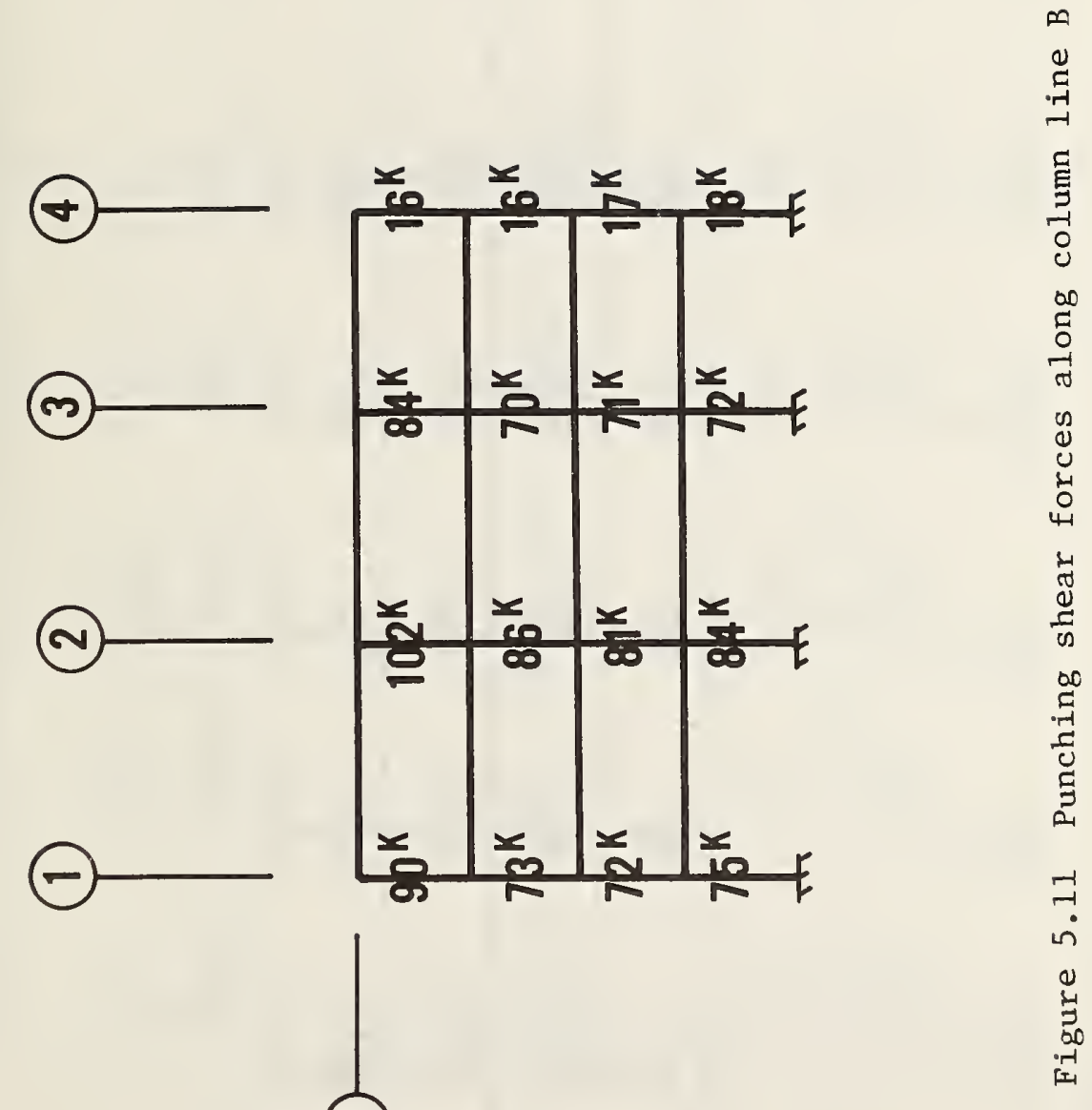

(0) 

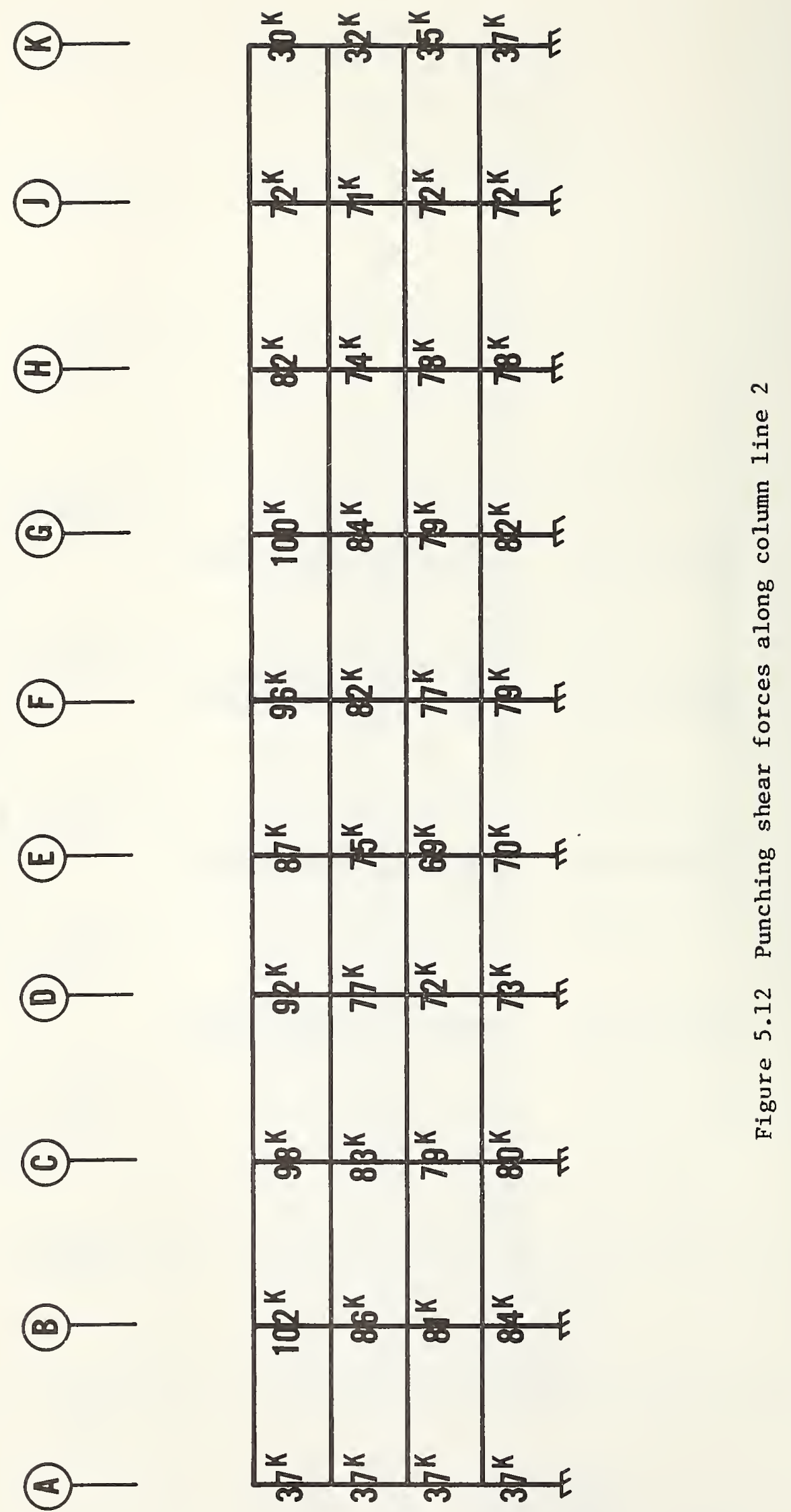

욤

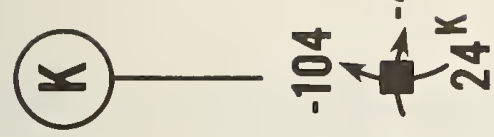

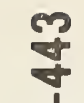
욤
임
(7) ${ }^{\infty} \frac{1}{\infty} x$
$\frac{1}{2} \stackrel{\infty}{\pi}$
$\frac{\pi}{\pi}=\frac{\pi}{\pi}$
กี

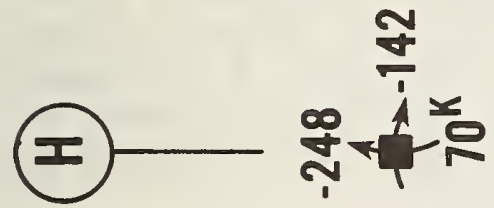
$\frac{\pi}{2 \pi}$
邹
(c) $\underset{1}{\infty}+\frac{1}{\infty}$
$\frac{\infty}{1}+\frac{1}{1}$
$\infty \pi \frac{\pi}{1}=$
(4) ${ }_{1}^{\infty} \frac{\infty}{4} \frac{\infty}{\infty}$
\%
$\frac{\pi}{4} \frac{\pi}{4}$
(1)
$\frac{m}{1} \stackrel{\infty}{\frac{1}{1}}$
ำ
(0) $\frac{1}{2} \frac{1}{2}=$
$\frac{\pi}{\pi} \frac{\pi}{2 \pi}$
$\operatorname{lin} \frac{\pi}{1}$

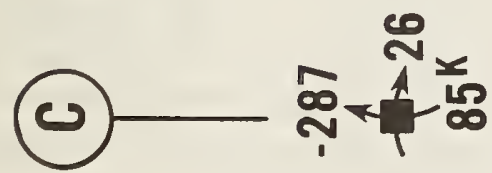

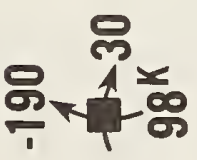

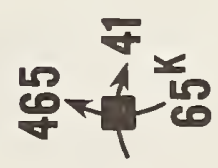
(0)
$\frac{1}{1}$

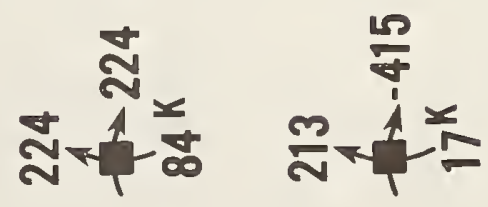
का
$\infty$ ת
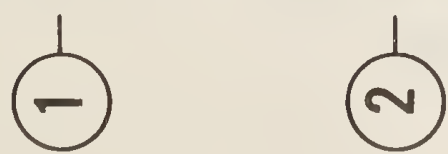
(1)

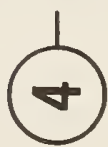




\subsection{INTRODUCTION}

This chapter evaluates the results of the analysis of the structure and draws conclusions therefrom on the most probable cause of the collapse. First, in section 6.2 shear stresses at the critical sections are computed and compared with the capacity of the structural elements. Second, in section 6.3 the thickness of the slab is examined to see whether the slab thickness of 8 in (203 $\mathrm{mm}$ ) was adequate to support the design loads and if not, to what extent the design inadequacy contributed to the collapse. In section 6.4 the cause of the collapse is established based on this analysis, and the most probable mode of failure and the reason for the occurrence of progressive collapse are given.

\subsection{ANALYSIS OF SHEAR FAILURE OF SLAB}

It has been shown in a number of studies [6.1] that flat plate structures are inherently weak in shear at the slab-column connection and, when punching shear failure occurs, the structure is highly susceptible to progressive collapse unless it is adequately designed and carefully constructed [6.2, 6.3] . Judging from the manner in which the Harbour Cay structure failed and in the absence of any evidence of ductile failure, it was suspected that the structure had experienced shear failure at slab-column connections.

To verify that such a failure had occurred, punching shear stresses resulting from direct shear forces and unbalanced moments were computed at slab-column connections using the shear and moment values for construction loads given in figure 5.13. These shear stress values were compared with the shear capacity of the slab based on the predicted inplace strength of concrete at the time of collapse. Because the punching shear stress values are maximum at the fifth floor level (see figures 5.12 and 5.13), the shear stresses are evaluated only for this level. The guidelines given in the ACI Code [2.1] are followed in computing the punching shear stress. Figure 6.1(a) shows the critical section in the slab around an interior column. The critical section where shear stresses are evaluated is taken perpendicular to the plane of the slab and a distance a half of the effective depth away from the periphery of the column. The assumed distribution of shear stresses at the critical section is shown in figure 6.1(b). The critical sections for edge and corner columns and corresponding assumed shear stress distributions at these critical sections are shown in figure $6.2(a)$ and (b) and figure $6.3(a)$ and (b), respectively.

The results of the punching shear stress calculations are 1isted in figure 6.4 . In this figure, the numbers given in parentheses are the shear stresses resulting from the direct shear only and the other numbers are the shear stresses resulting from the combined effect of the direct shear and the unbalanced biaxial bending moments. The negative values shown at the edge and corner columns are upward shear stresses resulting from the combined effect. Negative stresses occur on a side of the critical section when the absolute value of the moment-induced shear stress exceeds the absolute value of the direct shear stress. 
It is seen from figure 6.4 that maximum shear stresses resulting from direct shear occur at columns B-2 and G-2 with shear stress values of 250 psi (1.72 $\mathrm{MPa}$ ) and $244 \mathrm{psi}(1.70 \mathrm{MPa})$, respectively. Except for the edge columns in line $\mathrm{A}$ and corner column $\mathrm{B}-4$, maximum combined shear stresses occur also at columns $\mathrm{B}-2$ and $\mathrm{G}-2$. It needs to be pointed out that the large shear stresses at the edge and corner columns may not develop as a result of moment redistribution to the interior columns due to cracking of the slab in the vicinity of exterior columns caused by high moments [6.4]. If this redistribution of moments takes place, the moment-induced stress would increase at the columns in line $B$ and $J$ and would decrease at the edge columns in line $A$ and $\mathrm{K}$. Because combined shear stresses at these edge and corner columns would be limited by cracking in the slab and because shear stresses due to vertical loads are relatively small, it is less likely that punching shear failure would develop at these column locations, and they are not considered as the critical locations in the failure analysis.

For the purpose of design, the nominal shear strength specified by the ACI Code [2.1] is $2 \sqrt{f_{c}^{\prime}}$ for beam-type shear and $4 \sqrt{f_{c}^{\prime}}$ for punching shear where $f_{c}^{\prime}$ is the compressive strength of concrete.

For the south half of the fifth floor, the beam-type shear strength given by the ACI Code would be 126 psi $(0.87 \mathrm{MPa})$ while the punching shear strength would be 253 psi ( $1.74 \mathrm{MPa}$ ) for an estimated compressive strength ( $f_{c}^{\prime}$ ) of 4000 psi ( $27.6 \mathrm{MPa}$ ) at the time of collapse. The corresponding strengths for the north half would be 121 psi $(0.83 \mathrm{MPa}$ ) and $243 \mathrm{psi}$ (1.66 MPa) for an estimated $f_{c}$ of 3700 psi $(25.5 \mathrm{MPa})$. It should be recalled that the south half of the slab was two days older than the north half.

The computed beam-type shear stress under construction loading is 51 psi (352 $\mathrm{kPa})$ and $49 \mathrm{psi}(338 \mathrm{kPa})$, respectively, at the critical sections corresponding to columns $\mathrm{B}-2$ and $\mathrm{G}-2$. These values are considerably less than the beam shear strength of the slab. Therefore, it is concluded that beam-type shear failure did not precipitate the collapse.

When the ACI Code punching shear strengths are compared with the computed shear stresses, it appears that the punching shear stresses at many columns in the fifth floor exceeded the nominal punching shear capacity of the slab. This would suggest that failure should have occurred prior to the placement of concrete to column line $\mathrm{H}$. To examine why failure did not occur earlier requires a review of the ACI provision of $4 \sqrt{\mathrm{f}_{\mathrm{C}}^{\prime}}$. Figure 6.5 shows experimental punching shear strengths, normalized by bd $\sqrt{\mathrm{f}}$, versus $\mathrm{c} / \mathrm{d}$ where $\mathrm{b}$ is the perimeter of critical section, $c$ is the side length of column and $d$ is the effective depth of the slab [6.1]. It is clearly seen in this figure that the punching : shear strength is a probabilistic parameter which exhibits a high degree of variability. It is evident that $4 \sqrt{\mathrm{f}_{\mathrm{c}}^{\prime}}$ as used in the ACI Code is a lower bound strength, that would be justified for the purpose of design. For failure analysis, however, the actual shear strength should be used, and it would be greater than $4 \sqrt{f_{c}^{1}}$. According to the data shown in figure 6.5 , the mean punching shear strength could be as high as $7 \sqrt{\mathrm{f}_{\mathrm{c}}^{\mathrm{r}}}$ and the probability of a punching shear strength of $4 \sqrt{f_{C}^{r}}$ occurring at any given location in the structure is relatively low. However, the probability of failure initiating at 
some location in the entire structure increases rapidly with the number of locations where the shear stresses are in the neighborhood of $4 \sqrt{f_{c}^{\prime}}$. According to figure 6.4 , there are at least 30 such locations in the fifth floor slab.

If, for the sake of illustration, the probability of failure at any given location where a stress of $4 \sqrt{\mathrm{f}_{\mathrm{c}}^{+}}$occurs is assumed to be two percent $\left(\mathrm{P}_{1}=\right.$ $.02)$, which is quite plausible in light of the data shown in figure 6.5 , the probability of failure, $P_{2}$, of an element in a system consisting of 30 such locations would be (assuming indepdence)

$$
\mathrm{P}_{2}=1-\left(1-\mathrm{P}_{1}\right)^{30}=0.45,
$$

or 45 percent. If a value of 0.03 (or 3 percent) is assumed for $\mathrm{P}_{1}, \mathrm{P}_{2}$ would increase to 0.60 (or 60 percent), and so on. This means that even though the probability of failure at each column location is relatively low, the probability of the entire structure having a failure is relatively high.

The likelihood of failure having initiated at B2 or G2, where the shear stresses are maximum, will be somewhat greater than at other locations (except those excluded along column line A for reasons stated above). In fact, in terms of

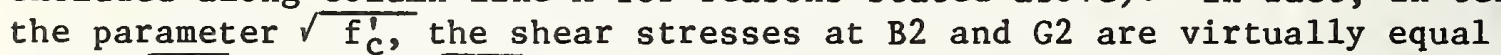
( $4.57 \sqrt{f_{c}^{1}}$ and $4.52 \sqrt{f_{c}^{\prime}}$, respectively); an indication that failure could have occurred at either location. The supposition that failure initiated at column G2 rather than B2 is borne out by witness statements (as discussed in sec. 3.3) indicating that the collapse started somewhere in the region where concrete was being cast. However, from a probabilistic view, this is not an absolute certainty (failure could have been initiated at location other than B2 and G2).

It should be pointed out that the data shown in figure 6.5 was obtained from laboratory experiments where, in general, much better quality control can be exercised than in the field. Therefore, it is reasonable to expect that if actual field conditions were simulated, the data would have shown greater scatter and a lower expected value than indicated in figure 6.5. Both factors imply a greater probability of strength below $4 \sqrt{\mathrm{f}_{\mathrm{c}}^{\prime}}$. There is evidence, as discussed in chapter 4, that the concrete used in the structure had high variability in terms of composition and strength.

\subsection{INFLUENCE OF EFFECTIVE DEPTH OF SLAB ON SHEAR CAPACITY}

Without special reinforcement at the slab-column connection, the effective depth of slab at the critical section must be sufficient to resist punching shear failure around the column. Both the thickness of slab and the location of tension reinforcement govern the effective depth. It was discussed in section 2.3 that the 4-1/4 inch (108 $\mathrm{mm}$ ) individual high chairs used to support the top reinforcing bars in the column strips produced more than the $3 / 4-i n$ (19 $\mathrm{mm}$ ) minimum coverage required by the structural drawing. This resulted in an effective depth of the slab of 5.3 in $(135 \mathrm{~mm})$. Had higher size individual high chairs been used, to just meet the $3 / 4-i n$ coverage requirements, the slab could have had a 6.3 in $(160 \mathrm{~mm})$ effective depth. 
The increase in effective depth by 1 inch $(25.4 \mathrm{~mm})$ increases the critical cross sectional area to resist the punching shear by 25 percent, which, in turn, decreases the shear stress acting on the critical section.

Because under construction loads the computed shear stresses in the slab at many of the column locations exceeded the shear strength of $4 \sqrt{f_{c}^{\prime}}$, the slab thickness of 8 inch $(203 \mathrm{~mm})$ was checked to see whether it was adequately designed to resist punching shear stresses due to the design loads. The required thickness for the slab was computed following the equivalent frame method described in the ACI Code [2.1] in accordance with the following three load combinations in the code:

$$
\begin{aligned}
& \text { (1) } U=1.4 \mathrm{D}+1.7 \mathrm{~L} \\
& \text { (2) } \mathrm{U}=0.75(1.4 \mathrm{D}+1.7 \mathrm{~L}+1.7 \mathrm{~W}) \text {, and } \\
& \text { (3) } U=0.9 \mathrm{D}+1.3 \mathrm{~W}
\end{aligned}
$$

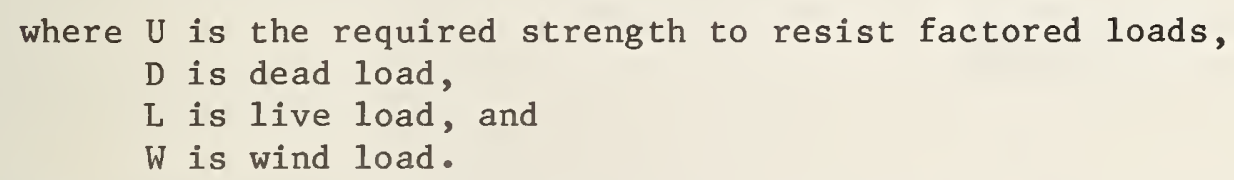

The strength reduction factor of 0.85 is applied to $4 \sqrt{\mathrm{f}_{\mathrm{c}}^{\mathrm{r}}}$ in computing the design shear strength.

It was mentioned in section 2.3 that the original design calculations were examined and that no computation was noted for checking the punching shear capacity of the slab. For the dead load of the required thickness slab, the same live loads used in the design (see section 2.3) and the wind load specified in the Southern Standard Building Code [2.2], the required slab thickness should have been 11 in $(279 \mathrm{~mm})$ instead of 8 in $(203 \mathrm{~mm})$ for the column size of $10 \times 18$ in $(254 \mathrm{~mm} \times 457 \mathrm{~mm})$. The slab thickness is governed by the load combination of $(1.4 \mathrm{D}+1.7 \mathrm{~L})$. This clearly indicates that the design of the slab was inadequate to support the design loads with the margin of safety implied by the ACI Code. Table 6.1 lists the punching shear stresses at column G-2 for the 11-in slab with a 3/4-in $(19 \mathrm{~mm})$ cover and with a $13 / 4-i n$ cover $(44 \mathrm{~mm})$ for the same construction condition which existed in the structure. In addition, the punching shear stresses at column G-2 for the 8-in slab with a 3/4-in cover and with a $13 / 4-i n$ cover are also listed.

It is seen in table 6.1 that for the 11 -in slab with the tension reinforcement placed such that it has a $3 / 4$-in cover $(d=9.3 \mathrm{in})$, the punching shear stress under the construction loads is $174 \mathrm{psi}$ (1.19 $\mathrm{MPa}$ ) which is considerably less than $4 \sqrt{\mathrm{f}_{\mathrm{c}}^{\prime}}=243 \mathrm{psi}(1.66 \mathrm{MPa})$. With $13 / 4$-in cover for the tension reinforcement $(d=8.3 \mathrm{in})$, the punching shear stress would still be lower than the nominal strength, 205 psi vs. 243 psi. It is also clear that had proper size high chairs been used for the 8-in slab such that the tension reinforcement had a $3 / 4$ in cover $(d=6.3)$, the punching shear stress would have been less than the nominal strength, 218 psi vs. 243 psi. Only when the design error (which resulted in an $8-$ in $s l a b$ ) and the use of improper size chairs (which resulted in $13 / 4$-in cover) occur simultaneously, the punching shear stress exceeds the nominal strength, 275 psi vs. 243 psi at column G-2. Thus, 
Table 6.1 Punching Shear Stresses at Column G-2 for 11 and 8 in Slab Under Actual Construction Loads

\begin{tabular}{|l|l|}
\hline \multicolumn{1}{|c|}{8 -in Slab } & \multicolumn{1}{|c|}{ l1-in Slab } \\
\hline $\begin{array}{l}\mathrm{d}=6.3 \text { in (3/4 in cover) } \\
\mathrm{v}=218 \mathrm{ps} i \\
\mathrm{v} /\left(4 \sqrt{\mathrm{f}_{\mathrm{c}}^{\prime}}\right)=0.90\end{array}$ & $\begin{array}{l}\mathrm{d}=9.3 \text { in }(3 / 4 \text { in cover }) \\
\mathrm{v}=174 \mathrm{psi} \\
\mathrm{v} /\left(4 \sqrt{\mathrm{f}_{\mathrm{c}}^{\prime}}\right)=0.72\end{array}$ \\
\hline $\begin{array}{l}\mathrm{d}=5.3 \text { in (1 3/4 in cover) } \\
\mathrm{v} /\left(4 \sqrt{\mathrm{f}_{\mathrm{c}}^{\prime}}\right)=1.13\end{array}$ & $\begin{array}{l}\mathrm{d}=8.3 \text { in }(13 / 4 \text { in cover }) \\
\mathrm{v}=205 \mathrm{psi} \\
\mathrm{v} /\left(4 \sqrt{\mathrm{f}_{\mathrm{c}}^{\prime}}\right)=0.84\end{array}$ \\
\hline
\end{tabular}

1 in $=25.4 \mathrm{~mm}$

$100 \mathrm{psi}=0.69 \mathrm{MPa}$

the lack of consideration of punching shear in the design of the slab resulted in a reduction of the margin of safety such that the slab had little reserve strength to accommodate construction errors. Based on this analysis, it is clear that both the design error and the use of chairs having insufficient height contributed to the collapse.

\subsection{PROBABLE MODE OF FAILURE}

The analysis of the structure has shown that failure of the fifth floor was most likely initiated at column G-2. This conclusion was corroborated by the witness accounts. The loss of support at column G-2 was due to punching shear failure of the slab rather than failure of the column below the slab. The computed strength of the column at the time of failure was more than three times the stress produced by the loading.

When the slab failed, the portion of loads originally resisted in shear at the four sides of column G-2 was transferred to four adjacent columns (columns $\mathrm{F}-2$, $G-1, G-3$, and $H-2$ ). This transfer action resulted in a substantial increase in the total shear in the slab-column connection at these four columns. Likewise, moments transferred to these four columns would also have increased the moment-induced shear stresses. Because shear stresses in the slab-column connection at these columns were already near the limiting shear strength of the slab, this transfer action would have precipitated punching shear failure at these four locations, which in turn would have triggered failures at other column locations. The propagation of punching shear failure continued until it swept through the entire fifth floor slab.

Once the fifth floor had failed and landed on the fourth floor, punching shear failure of that slab was inevitable. The total weight of the roof and the fifth floor slab was more than enough to produce shear stresses greater 
than the shear strength of the fourth floor slab. The third and second floor slabs failed by the same process. Thus, collapse of the entire structure was initiated by punching shear failure of the slab at the fifth floor level.

It is concluded that the most probable cause of the failure was the lack of adequate punching shear capacity in the fifth-floor slab at several of the columns to resist the applied construction loads. This deficiency was brought about by the design inadequacy which resulted in the slab thickness of 8 in instead of 11-in and by the placement of the top reinforcement at the column strips with significantly greater cover than that which would have met the cover requirement specified by the structural drawings. This resulted in an insufficient effective depth of the fifth floor slab to resist punching shear under construction loads. 


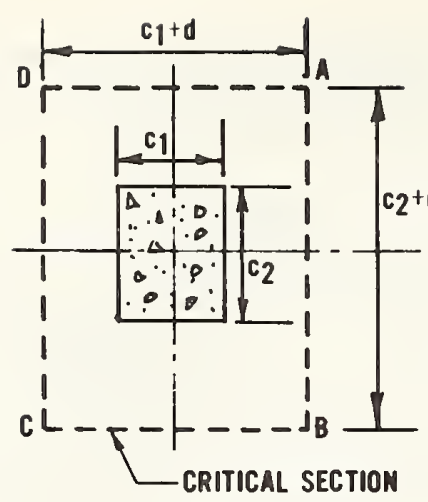

CRITICAL SECTIOM

d = EFFECTIVE SLAB DEPTH

(a)

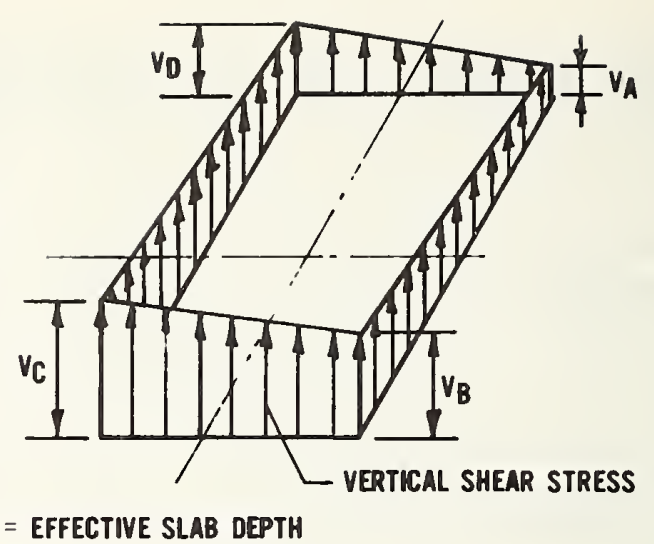

(b)

Figure 6.1- Shear stress distribution at interior column

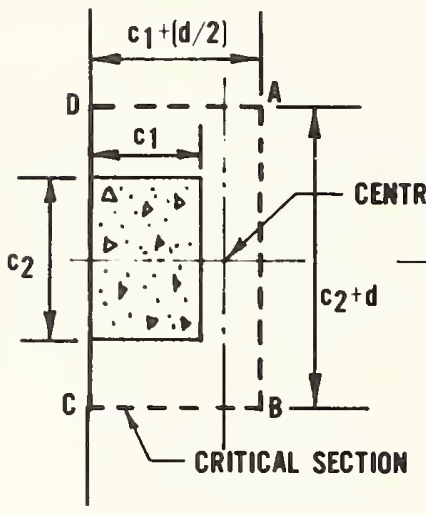

(a)

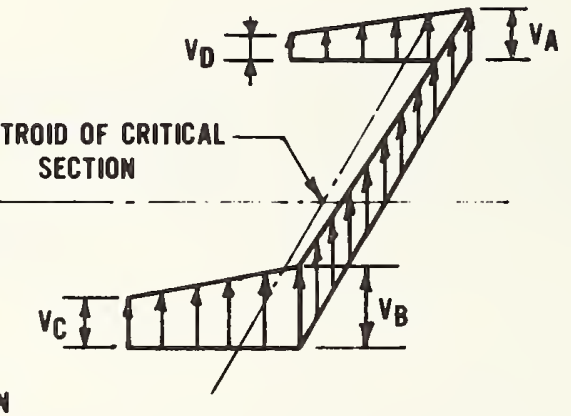

(b)

Figure 6.2 Shear stress distribution at edge column

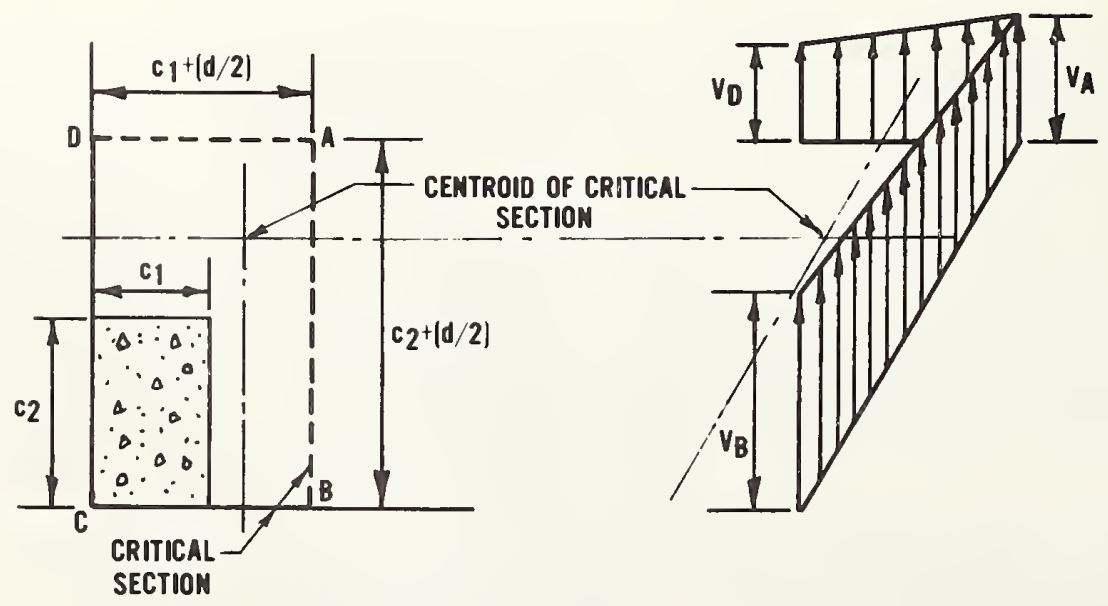

(a)

(b)

Figure 6.3 Shear stress distribution at corner column 


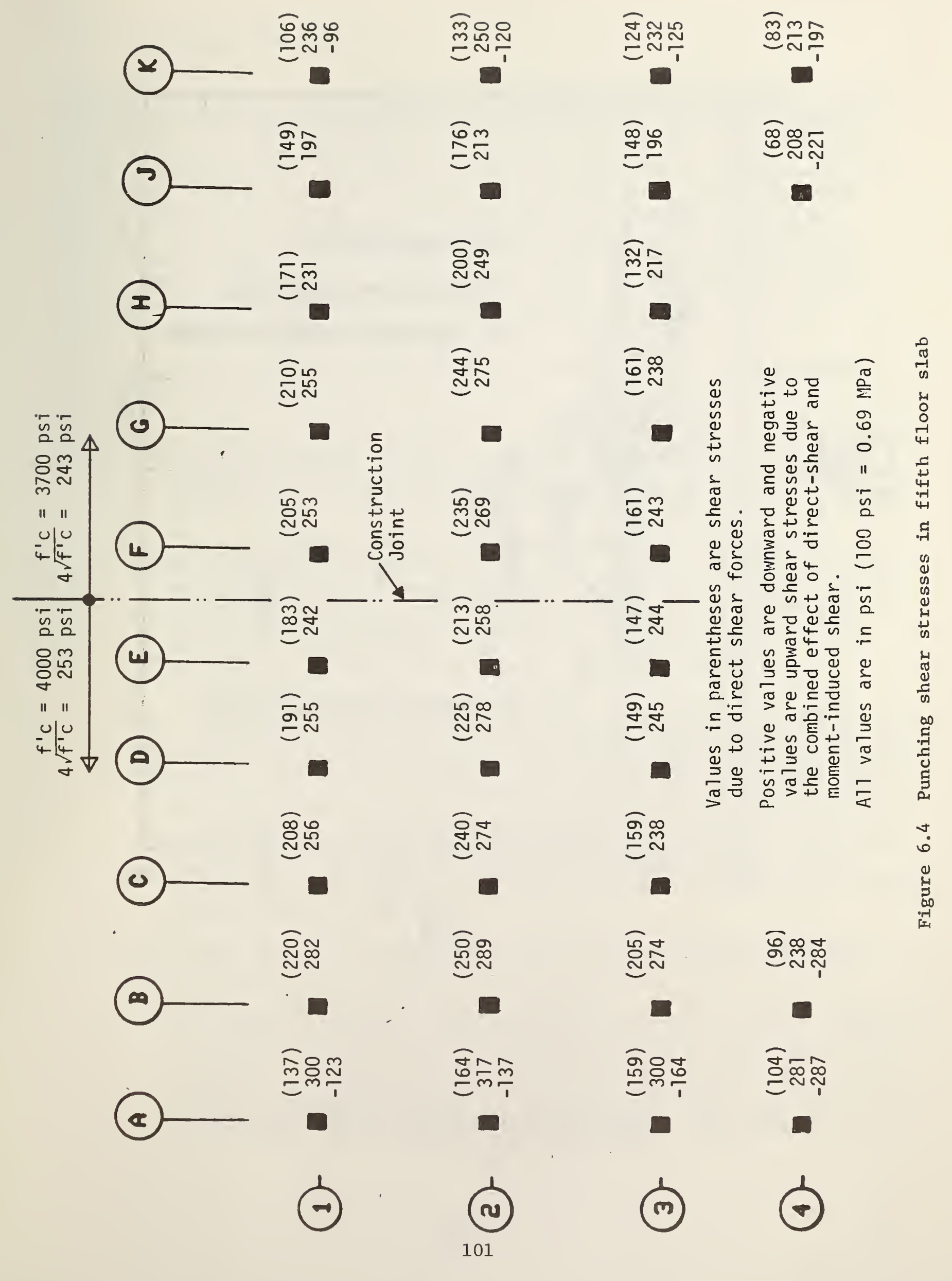




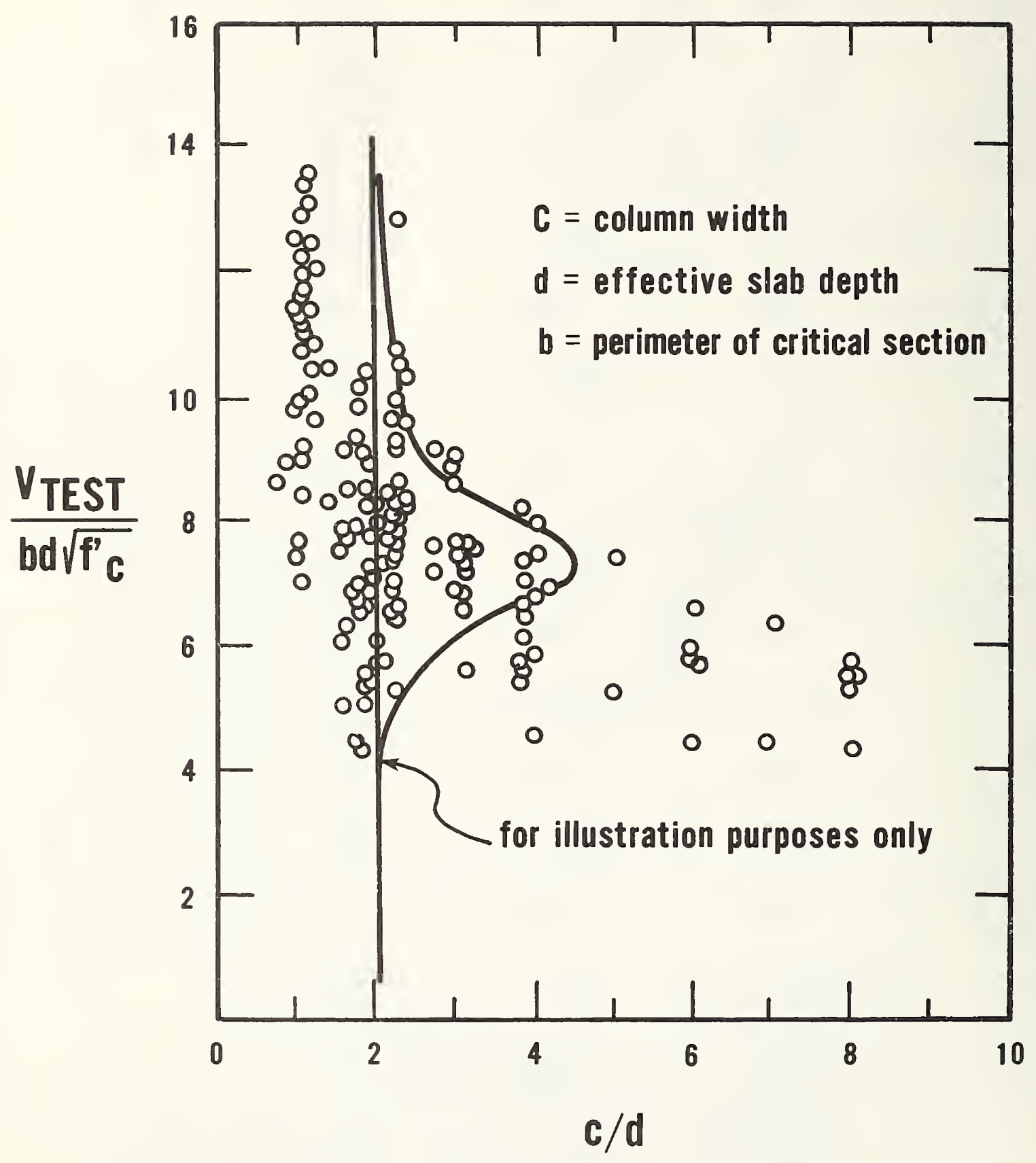

Figure 6.5 Results of punching shear tests of slab-column connections (ref. 6.1) 
As a result of the collapse of a five story reinforced concrete building during construction at Cocoa Beach, Florida, the National Bureau of Standards (NBS) was requested by the Occupational Safety and Health Administration (OSHA) to carry out an in-depth study aiming at the determination of the most probable cause of the collapse. In response to this request, NBS has carried out comprehensive field and laboratory investigations, including tests of concrete and reinforcing steel. NBS also performed analytical evaluation of the response of the structure under the loading condition which existed at the time of the collapse. The findings based on the results of the NBS study are presented in this report, together with other information such as structural drawings and calculations and OSHA case records. The conclusions drawn from this study are summarized in the following statements:

(1) The structure as built had a number of deviations from standard practice of construction.

(a) A number of columns examined disclosed that the inclined portion of offset bars above the floor level were bent more than 1 in 6 as required by the ACI Code. Furthermore, the bars were not placed parallel to the axis of the column above the offset bend.

(b) The placement of a large number of large-size reinforcing bars (12 - 非 through 16 - 非1) for lap splices in 10 in $\mathrm{x} 18$ in (254 mm x $457 \mathrm{~mm}$ ) columns created a congestion of bars which violated the ACI Code requirement for clear spacing. Examination of columns showed that such a congestion prevented flow of concrete into the space between reinforcing bars. This lack of concrete prevented the development of adequate bond between reinforcing bars.

(c) Both the reinforcing steel shop drawings and field measurements revealed that 4-1/4 in (108 $\mathrm{mm}$ ) individual high chairs were used to support the two-way top layer reinforcing steel for the slabs at the column strips. This resulted in a net concrete cover ranging from $1-5 / 8$ in $(41 \mathrm{~mm})$ to $2-1 / 8$ in $(54 \mathrm{~mm})$ with an average effective depth of the slab of 5.3 in $(135 \mathrm{~mm})$. This was about 1 in $(25 \mathrm{~mm})$ less than the effective depth corresponding to the $3 / 4$ in $(9.5 \mathrm{~mm}$ ) cover specified in the structural drawings. Excessive concrete cover reduced the effective depth of the slab, thereby reducing the punching shear capacity of the slab.

(2) The results of tests on core samples and laboratory prepared specimens were used to predict the strength of concrete at the time of failure.

(a) The results of tests on cores obtained from the floor slabs indicated that the compressive strength of the slab concrete met the specification value. That is, the compressive strength of cores exceeded 85 percent of the specified value of $4000 \mathrm{psi}(27.6 \mathrm{MPa})$. However, the average compressive strength of cores obtained from the fifth-story columns fell below the 85 percent requirement. The strengths of the 
cores obtained from the third- and fourth-story columns meet this requirement.

(b) There are no indications that a gross error was committed in concrete proportioning. However, the petrographic analysis of core samples revealed high variability in volumetric proportions of paste and aggregate. High variability was also noted in core strengths.

(c) The result of the NBS laboratory tests and the results of core tests agreed well. Based on the laboratory tests, the estimated compressive strength of concrete at the time of collapse was $3700 \mathrm{psi}(25.5 \mathrm{MPa})$ and $4000 \mathrm{psi}(27.6 \mathrm{MPa})$, respectively, for the north- and south-halves of the fifth floor slab, and $2900 \mathrm{psi}(20.0 \mathrm{MPa})$ and $3100 \mathrm{psi}$ $(21.4 \mathrm{MPa})$, respectively, for the north- and south-halves of the fifth-story columns.

(3) The analysis of the structure showed there are two major contributing factors which caused the collapse.

(a) The use of lower individual chairs for supporting the top layer reinforcing bars in the column strips than required to provide the $3 / 4$ in ( $19 \mathrm{~mm}$ ) cover called for in the structural drawings reduced the effective depth and punching shear capacity of the slab.

(b) Omission in the slab design of a check for punching shear resulted in an 8-in (203-mm) slab whih was shallower than needed to safely support the design loads for the completed structure. This reduced the margin of safety such that the slab had insufficient reserve strength to accommodate the use of 4-1/4-in (108-mm) individual high chairs within the column strips.

(4) The analysis showed that failure of the slab most likely initiated at Column G-2. The analysis also showed that the shear stresses at many column locations on the fifth floor exceeded the nominal shear strength. Once punching shear failure had initiated at column G-2, it propagated throughout the slab causing the total collapse of the fifth floor, which, in turn, caused the successive collapse of the lower floor slabs. 


\section{ACKNOWLEDGMENTS}

The authors acknowledge the contributions made by the following persons:

Dr. E. 0. Pfrang provided technical guidance and constructive criticism; Dr. E. V. Leyendecker and Dr.W. C. Stone critically reviewed the report; and the staff of the CBT Word Processing Center typed the manuscript. 


\section{REFERENCES}

2.1 ACI Standard 318-77, Building Code Requirements for Reinforced Concrete, American Concrete Institute, Detroit, Michigan, 1977.

2.2 Standard Building Code, Southern Building Code Congress International, Birmingham, Alabama, 1979.

3.1 Malhotra, V. M., Superplasticizers: Their Effect on Fresh and Hardened Concrete, Concrete Internationa1, V3, No. 5, pp. 66-81, May 1981.

4.1 Annual ASTM Standards, Part 14, American Society for Testing and Materials, Philadelphia, PA, 1981.

4.2 Plowman, J. M., Maturity and Strength of Concrete, Magazine of Concrete Research 8, No. 22, pp. 13-22, March 1956.

4.3 Carino, N. J., Temperature Effects on the Strength-Maturity Relation of Mortar, National Bureau of Standards (U.S.), NBSIR 81-224, 98 pp, March 1981.

5.1 Nielson, K. E. C., Loads on Reinforced Concrete Floor Slabs and their Deflections During Construction, Bulletin No. 15, Swedish Cement and Concrete Research Institute, Royal Institute of Technology, Stockholm, 1952.

5.2 Grundy, P., and Kabaila, A., Construction Loads on Slabs with Shored Formwork in Multistory Buildings, ACI Proceedings, V. 60, No. 12, pp. 1729-1738, December 1963.

5.3 Taylor, P. J., Effect of Formwork Stripping Time on Deflections of Flat Slabs and Plates, Australian Civil Engineering and Construction (Melbourne), V. 8, No. 2., pp. 31-35, February 1967.

5.4 Corley, W. G. and Jirsa, J., Equivalent Frame Analysis for Slab Design, J. American Concrete Institute, V. 67, No. 11, pp. 875-885, November 1970.

5.5 ICES STRUDL-II Engineering User's Manua1, MIT, Report R68-91, November 1968 .

5.6 Przemieniecki, J. J., Theory of Matrix Structural Analysis, McGrawHill, N.Y., 1968.

6.1 ACI-ASCE Committee 426, The Shear Strength of Reinforced Concrete Members - Slabs, Journal of the Structural Division, ASCE, V. 100, August 1974 .

6.2 Leyendecker, E. V. and Fattal, S. G., Investigation of the Skyline Plaza Collapse in Fairfax County, Virginia, Nat. Bur. Stand. (U.S.), Bldg. Sci. Ser. 94, June 1973. 
6.3 Litle, W. A., The Boston Collapse at 2000 Commonwealth Avenue, Boston, Mass., Symposium on Progressive Collapse, ACI Annual Convention, Boston, April 1975.

6.4 Neth, U. W., DePaiva, H. A. R., and Long, A. E., Behavior of Models of Reinforced Concrete Flat Plate Edge-Column Connection, J. American Concrete Institute, V. 78, No. 4, pp. 269-275, July-August 1981 . 

APPENDIX A

RESULTS OF TESTS ON SAMPLES FROM

THE SITE

$A-1$ 


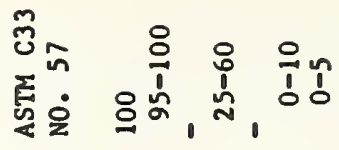

$\therefore$

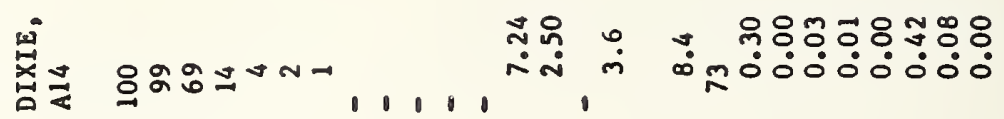

$\frac{2}{2}$

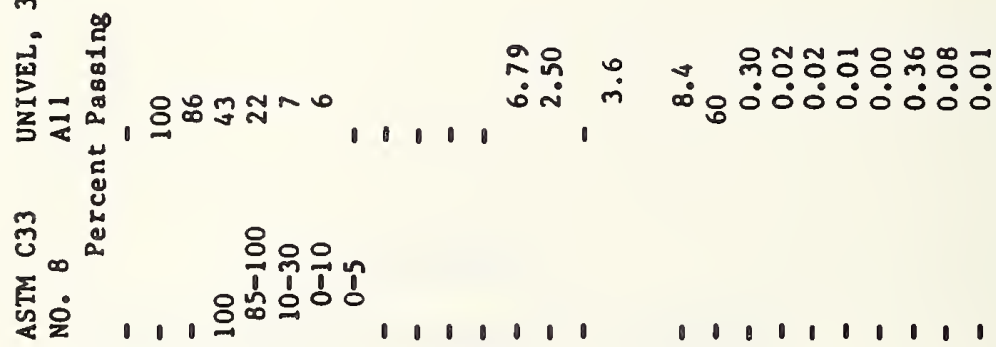

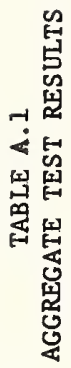

$\stackrel{\infty}{m}$

से

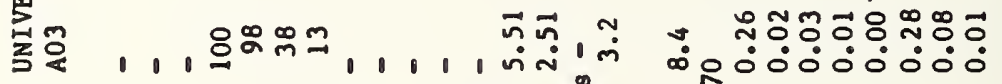

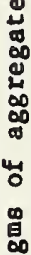

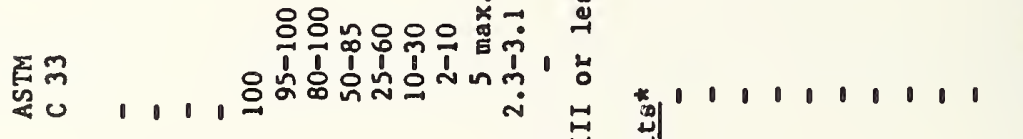

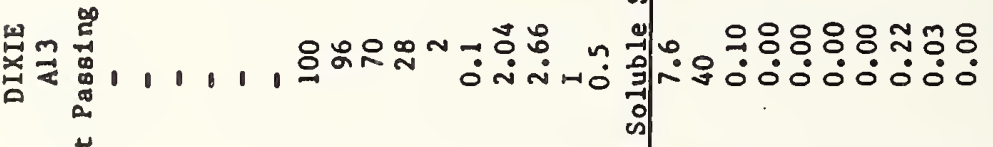

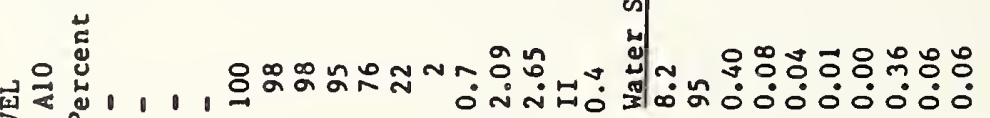

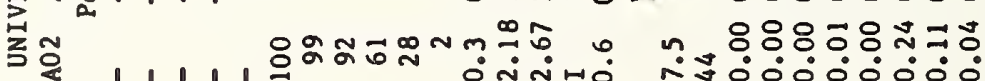

$\stackrel{8}{\stackrel{2}{0}}$



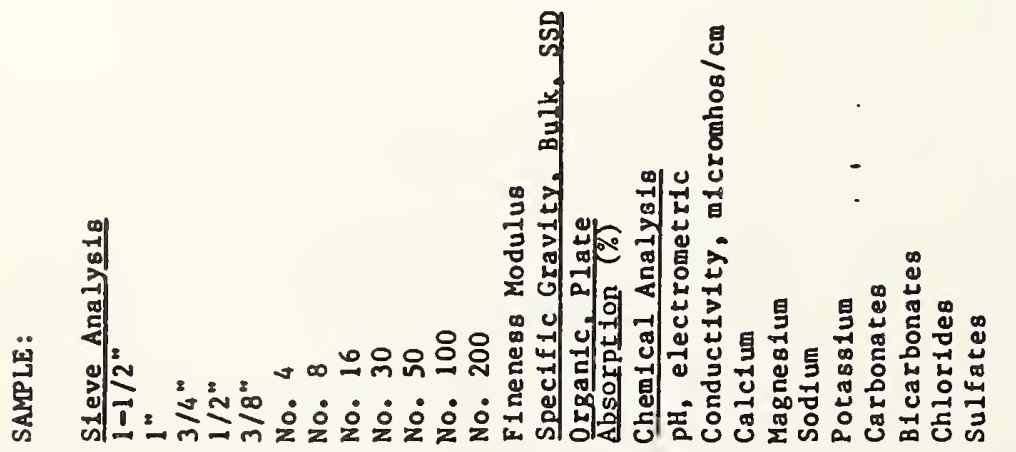


TABLE A. 2

CEMENT ANALYSIS RESULTS

SAMPLE

$\begin{array}{lll}\text { AO1 } & \text { A12 } & \text { ASTM } \\ \text { UNIVEL } & \text { DIXIE } & \text { C150, TYPE I }\end{array}$

PHYSICAL DATA:

Time of setting, Gillmore Initial, hr:min

$3: 00$

$1: 42$

Final, hr:min

$4: 46$

$2: 54$

Autoclave Expansion, 7

Fineness Blaine, $\mathrm{m} 2 / \mathrm{kg}$

Compressive Strength, psi

$+0.04$

400

$+0.06$

392 .

1490

1 day

3 days

3030

7 days

3890

28 days

5460

Alr Content, $z$ vol

7.7

1640

2810

3870

5370

6.5

1:00 min. 10:00 max 0.80 max. $280 \mathrm{~min}$.

CHEMICAL ANALYSIS:

Silicon Dioxide, $\%$

Aluminum $0 x$ ide, $\%$

Ferric 0xide, $\%$

Calcium $0 x$ ide, $\%$

Magnesium Oxide, $\%$

Sulfur Trioxide, $\%$

Alkalies, $\%$

Loss on Ignition, $\mathbf{x}$ :

Insoluble Res idue, $\%$

Tricalcium Silicate, C3S, $x$

Dicalcium Silicate, C2S, $\%$

Tricalcium Aluminate, C3A, $\%$

20.1
3.7

3.7

60.0

3.9

3.0

0.64

0.90

0.42

1800 min. 2800 min. $3500 \mathrm{~min}$. 12.0 max.

Tetracalcium Aluminoferrite, C4AF, $\%$

56

15

4.7

9

$\begin{array}{rl}19.2 & - \\ 4.5 & - \\ 3.3 & - \\ 61.3 & - \\ 0.7 & 6.0 \max . \\ 2.9 & 3.0 \max . \\ 0.42 & 0.60 \max . \\ 1.43 & 3.0 \max . \\ 0.04 & 0.75 \max .\end{array}$

* For low alkali cement 
TABLE A.3

WATER TEST RESULTS

SAMPLE

$\mathrm{pH}$, electrometric

Alkalinity as ppm $\mathrm{CaCO} 3$ Phenolphthalein Total

Total Hardness as ppm $\mathrm{CaCO} 3$

Calcium, ppm

Magnesium, ppm

Sodium, ppm

Potassium, ppm

Manganese, $\mathrm{ppm}$

Phosphorus, $\mathrm{ppm}$

Iron, Ppm

Carbonate, ppm

Bicarbonate, ppm

Chloride, ppm

Sulfate, ppm

Conductivity, micromhos per $\mathrm{cm}$

*Less than $0.05 \mathrm{ppm}$

$\begin{array}{ccl}\text { A04 } & \text { A05 } & \text { A15 } \\ & \text { UNIVEL } & \text { DIXIE } \\ \text { MIX } & \text { POND } & \text { MIX }\end{array}$

ANALYSIS

$\begin{array}{ccc}7.2 & 7.6 & 7.9 \\ 0.0 & 0.0 & 0.0 \\ 70 & 204 & 46\end{array}$

$\begin{array}{lll}60 & 612 & 74\end{array}$

$20.1 \quad 142.0 \quad 16.0$

$\begin{array}{lll}2.4 & 62.7 & 8.3\end{array}$

$\begin{array}{lll}80 & 370 & 75\end{array}$

$\begin{array}{lll}5 & 25 & 4 \\ \star & * & \text { * }\end{array}$

$0.1 \quad 0.1 \quad 0.1$

$\begin{array}{lll}4.0 & 0.4 & 0.6\end{array}$

$\begin{array}{lll}0.0 & 0.0 & 0.0\end{array}$

$\begin{array}{lll}85.4 & 248.9 & 56.1\end{array}$

$300 \quad 2080 \quad 320$

$\begin{array}{lll}60.0 & 82.8 & 58.0\end{array}$

$580 \quad 2400 \quad 520$ 
TABLE A. 4

ADMIXTURE TEST RESULTS

\begin{tabular}{|c|c|c|c|c|c|c|}
\hline \multirow[t]{3}{*}{ SAMPLE } & A06 & A07 & A08 & A09 & A16 & Al7 \\
\hline & \multicolumn{4}{|c|}{ UNIVEL } & \multicolumn{2}{|c|}{ DIXIE } \\
\hline & DAREX & 79 & 19 & TYPE 3 & DAREX & 79 \\
\hline $\begin{array}{l}\text { Specific Gravity } \\
\text { e } 75 \mathrm{C}\end{array}$ & 1.016 & 1.229 & 1.175 & 1.157 & 1.013 & 1.182 \\
\hline Total Solids, \% & 5.9 & 41.8 & 34.5 & 31.1 & 5.7 & 39.7 \\
\hline
\end{tabular}


Table A.5. Core Compressive Strength Test Results

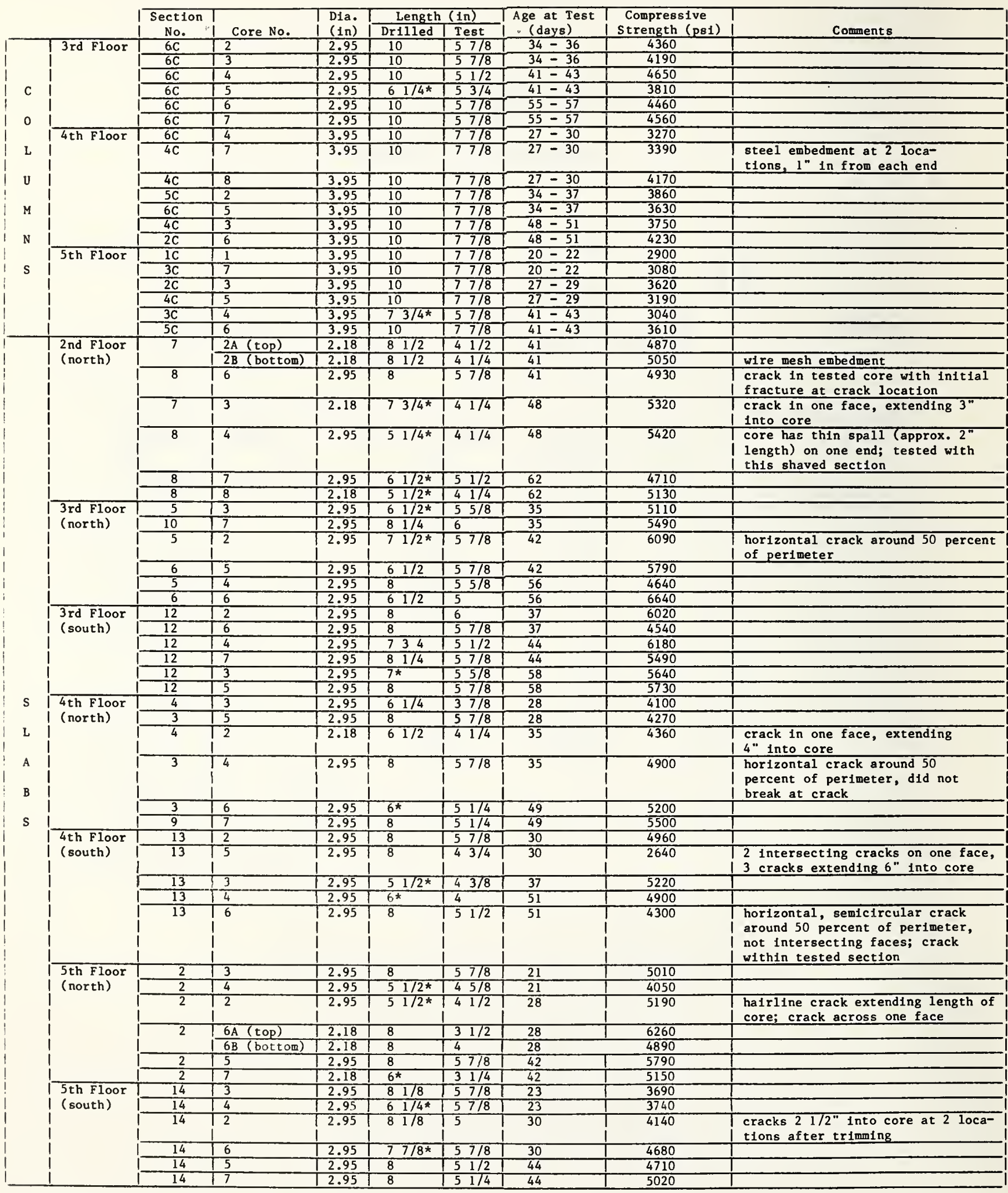

* Broken core not extending through structure.

$1 \mathrm{in}=25.4 \mathrm{~min}$

$1000 \mathrm{psi}=6.9 \mathrm{MPa}$ 
TABLE A.6

PETROGRAPHIC ANALYSIS RESULTS

Concrete: 5th Floor, Columns

SAMPLE :

P01

$\mathrm{P02}$

P03

P04

P05

TEST RESULTS

C856 (Comments)
Paste
color
texture
uniform
hydration
Voids
entrained
entrapped
water gain
Retempering
Cracks
Aggregate
fine
coarse
Other

C457 (percent by volume)

$\begin{array}{lllll}\text { gray } & \text { gray } & \text { buff } & \text { gray } & \text { gray } \\ \text { medium } & \text { medium } & \text { medium } & \text { medium } & \text { medium } \\ \text { no } & \text { ok } & \text { ok } & \text { ok } & \text { ok } \\ \text { ok } & \text { ok } & \text { ok } & \text { ok } & \text { ok }\end{array}$

slight slight slight slight slight

mostly mostly mostly mostly mostly

slight slight slight slight slight

some some none slight slight

none none none none none

Paste 26

Fine Aggregate

Coarse Aggregate

27

ok ok

ok ok

ok ok

wood

cement -

piece ball

Air Voids

44

24

29

28

29

Spacing Factor, in.

2.6

24

25

30

$2.6 \quad 2.7$

43

44

37

C642 (after immersion

$0.030 \quad 0.029$

3.5

3.8

3.5

and boiling)

Absorption, $\%$

$8.8 \quad 9.3$

0.026

0.034

0.029

Specific Gravity, dry

Spectfic Gravity, SSD

2.05

9.4

9.3

9.5

2.23

2.04

2.00

2.03

2.02

Voids, permeable, $\%$

$18.0 \quad 19.0$

2.19

2.22

2.21

C85 (modified, percent of dehydrated sample) -

18.8

$18.9 \quad 19.1$

$13.3 \quad 13.7$ 
TABLE A.6

PETROGRAPHIC ANALYSIS RESULTS

Concrete: 4th Floor, Columns

SAMPLE:

P06

P07

P08 P09

P10

\section{TEST RESULTS}

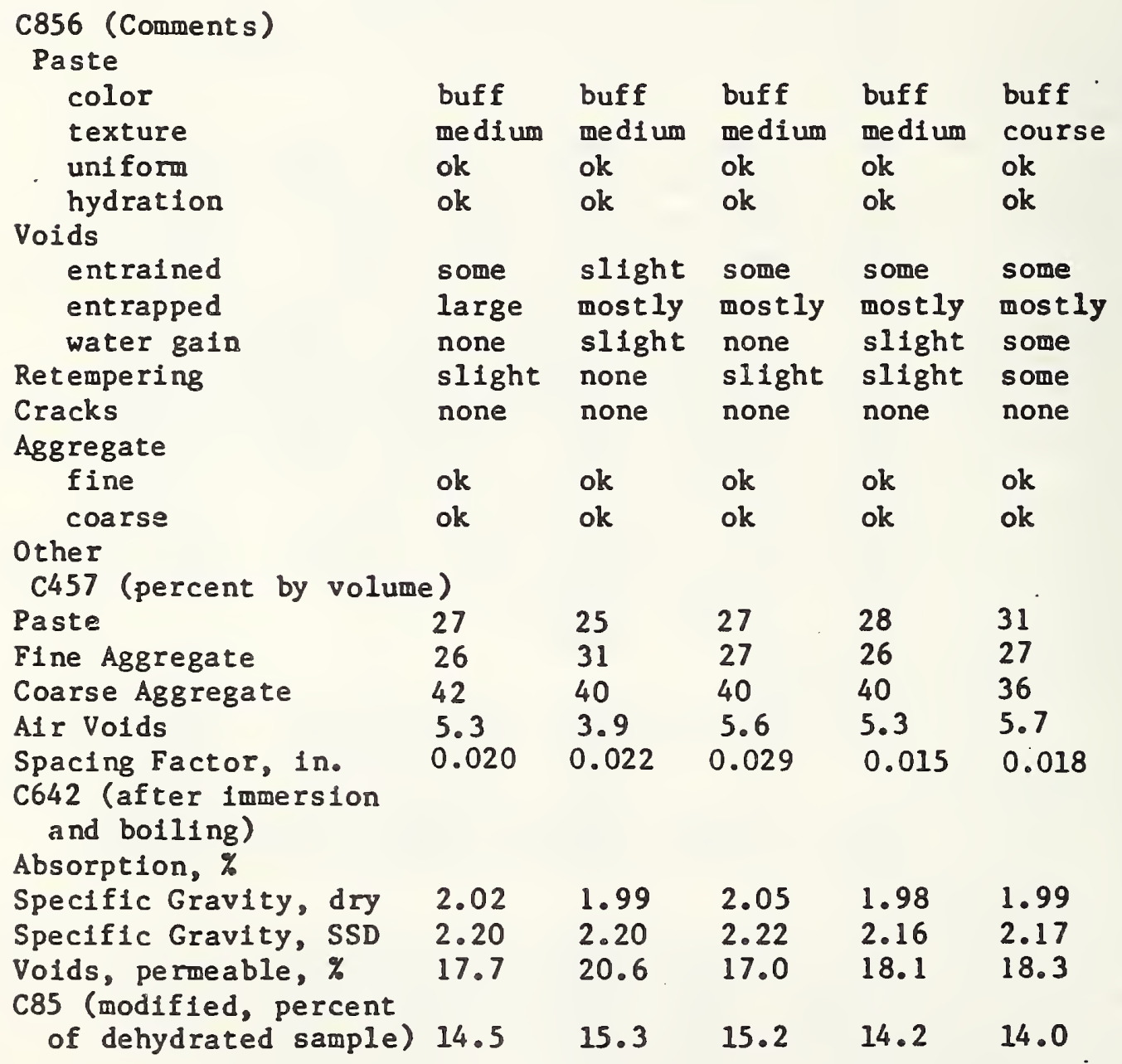


TABLE A. 6

PETROGRAPHIC ANALYSIS RESULTS

Concrete: 3rd Floor, Columns

SAMPLE :

\section{P11}

\section{TEST RESULTS}

$\begin{array}{ll}\text { C856 (Comments) } & \\ \text { Paste } & \text { buff } \\ \text { color } & \text { medium } \\ \text { texture } & \text { ok } \\ \text { uniform } & \text { ok } \\ \text { hydration } & \\ \text { Voids } & \text { some } \\ \text { entrained } & \text { mostly } \\ \text { entrapped } & \text { none } \\ \text { water gain } & \text { some } \\ \text { Retempering } & \text { none } \\ \text { Cracks } & \\ \text { Aggregate } & \text { ok } \\ \text { fine } & \text { ok } \\ \text { coarse } & - \\ \text { Other } & \\ \text { C457 (percent by volume) } \\ \text { Paste } & 27 \\ \text { Fine Aggregate } & 24 \\ \text { Coarse Aggregate } & 45 \\ \text { Air Voids } & 4.3 \\ \text { Spacing Factor, in. } & 0.019 \\ \text { C642 (after immersion } & \\ \text { and boiling) } & \\ \text { Absorption, \% } & 8.5 \\ \text { Specific Gravity, dry } & 2.03 \\ \text { Specific Gravity, ssD } & 2.20 \\ \text { Voids, permeable, } & 17.2 \\ \text { C85 (modified, percent } \\ \text { of dehydrated sample) } & - \\ & \end{array}$


TABLE A.6

PETROGRAPHIC ANALYSIS RESULTS

Concrete: Sth Floor, Slab

SAMPLE:

Volds

ralned

entrapped

water gain

Retempering

Cracks

Aggregate

fine

coarse

Other

C457 (percent by volume)

Paste

Fine Aggregate

Coarse Aggregate

Air Voids

Spacing Factor, in.

C642 (after immersion and boiling)

Absorption, $\%$

Specific Gravity, dry

Specific Gravity, SSD

Volds, permeable, \%

C85 (modified, percent

of dehydrated sample) - $\begin{array}{lll}\text { P12 } & \text { P13 } & \text { P14 }\end{array}$

TEST RESULTS

$\begin{array}{lll}\text { gray } & \text { gray } & \text { buff } \\ \text { medium } & \text { fine } & \text { coarse } \\ \text { ok } & \text { ok } & \text { ok } \\ \text { ok } & \text { ok } & \text { ok }\end{array}$

slight some slight

mostly mostly mostly

none slight none

some some some

none none none

ok ok ok

"dry" ok ok

$\begin{array}{lll}30 & 28 & 27\end{array}$

$30 \quad 30 \quad 26$

$36 \quad 39 \quad 44$

$\begin{array}{lll}4.3 & 2.6 & 3.2\end{array}$

$\begin{array}{lll}0.026 & 0.017 & 0.023\end{array}$

$\begin{array}{lll}9.7 & 9.5 & 8.7\end{array}$

$2.02 \quad 2.04 \quad 2.08$

$2.22 \quad 2.23 \quad 2.26$

$19.7 \quad 19.4 \quad 18.2$

$11.0 \quad 12.41$ 
TABLE A.6

PETROGRAPHIC ANALYSIS RESULTS

Concrete: 4th Floor, Slab

SAMPLE :

Voids

entrained entrapped water galn

Retempering

Cracks

Aggregate

fine

coarse
P15 P16

TEST RESULTS

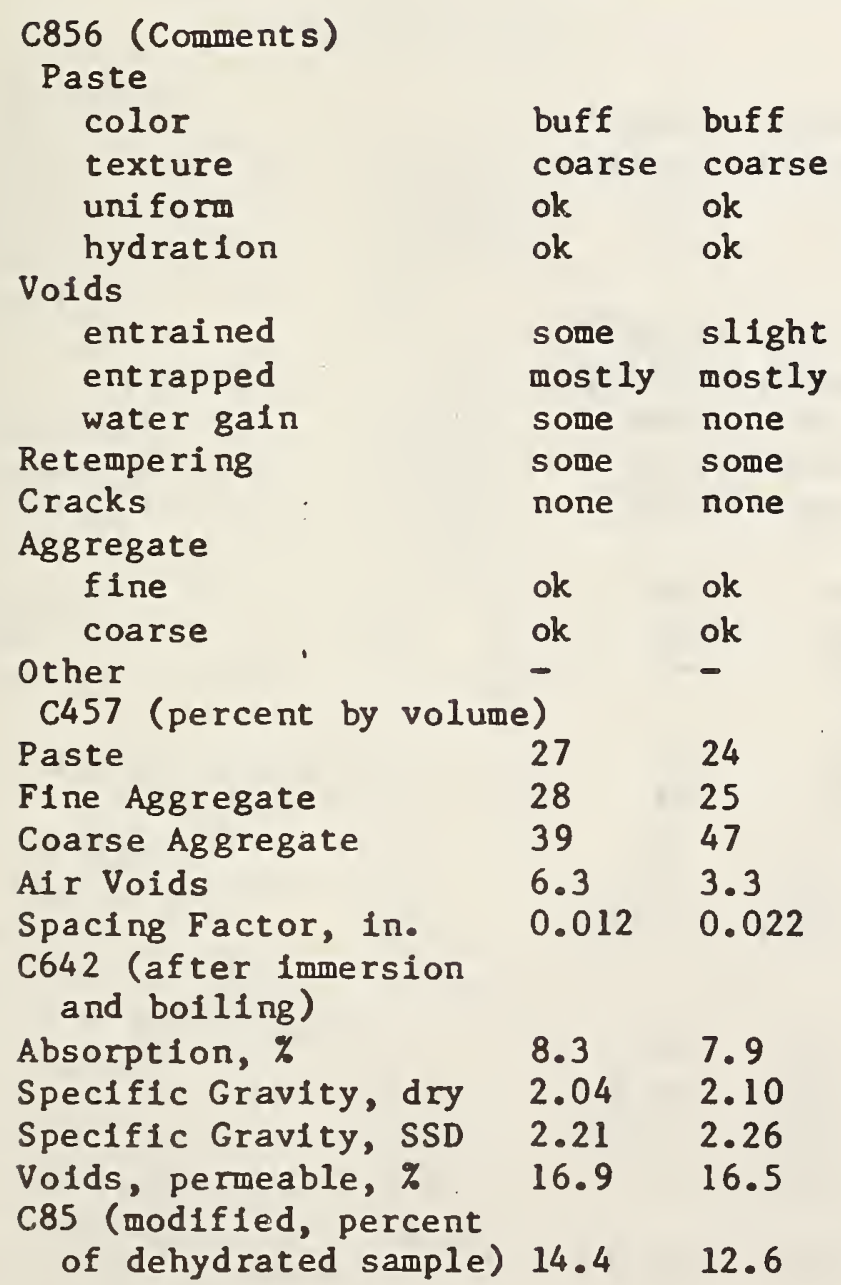


TABLE A.6

PETROGRAPHIC ANALYSIS RESULTS

Concrete: 3rd Floor, Slab

SAMPLE :

entrained

entrapped water gain

Retempering

Cracks

Aggregate

fine

coarse
P17 P18

TEST RESULTS

$\begin{array}{ll}\begin{array}{l}\text { buff } \\ \text { medium } \\ \text { no }\end{array} & \begin{array}{l}\text { buff } \\ \text { medium } \\ \text { ok }\end{array} \\ \text { ok } \\ \text { slight } & \text { slight } \\ \text { mostly } & \text { mostly } \\ \text { none } & \text { none } \\ \text { slight } & \text { some } \\ \text { none } & \text { none }\end{array}$

ok ok

ok ok

other

C457 (percent by volume)

Paste

$27 \quad 31$

Fine Aggregate

Coarse Aggregate

Air Volds

Spacing Factor, in.

C642 (after immersion

and bolling)

Absorption, $\%$

Specific Gravity, dry

Specific Gravity, SSD

Volds, permeable, $z$

$27 \quad 25$

$44 \quad 43$

$2.4 \quad 1.3$

$0.034 \quad 0.027$

$7.9 \quad 8.1$

$2.12 \quad 2.12$

$2.29 \quad 2.29$

$16.7 \quad 17.2$

C85 (modified, percent

of dehydrated sample) $\mathbf{1 3 . 3} \quad \mathbf{1 2 . 2}$ 
Concrete: 2nd Floor, Slab

SAMPLE :

P19

\section{TEST RESULTS}

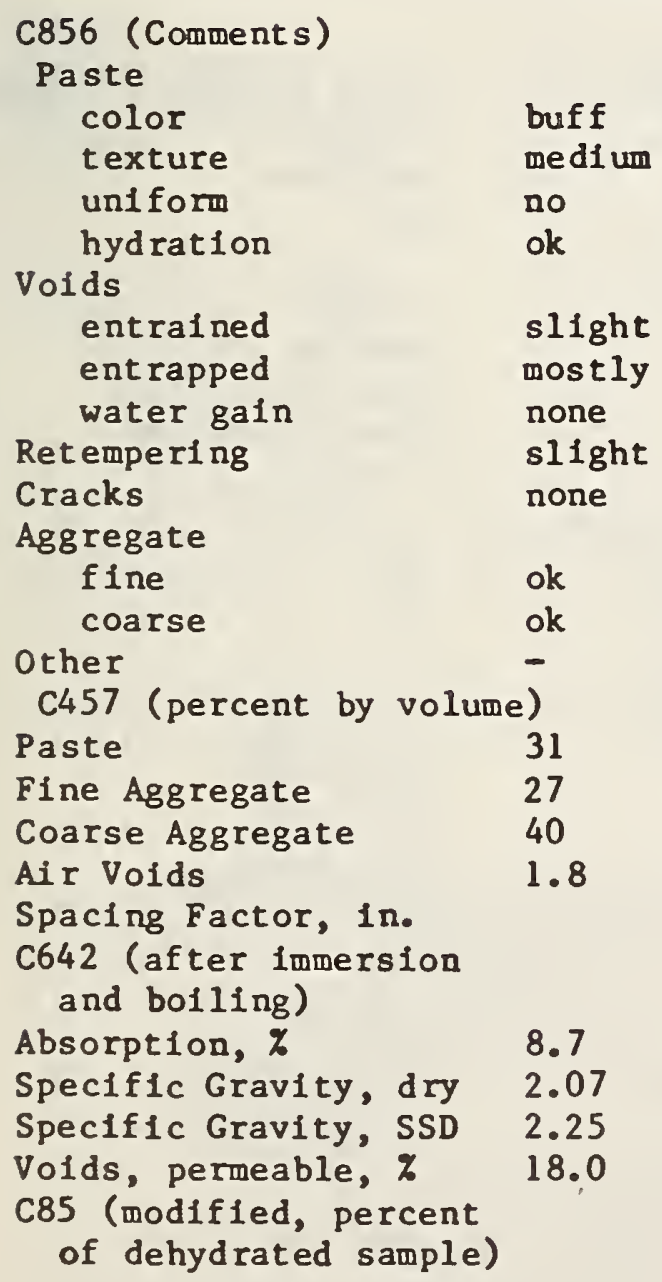


TABLE A. 6

PETROGRAPHIC ANALYSIS RESULTS

Concrete: Average Results

SAMPLE:

COLUMNS

SLABS

TEST RESULTS

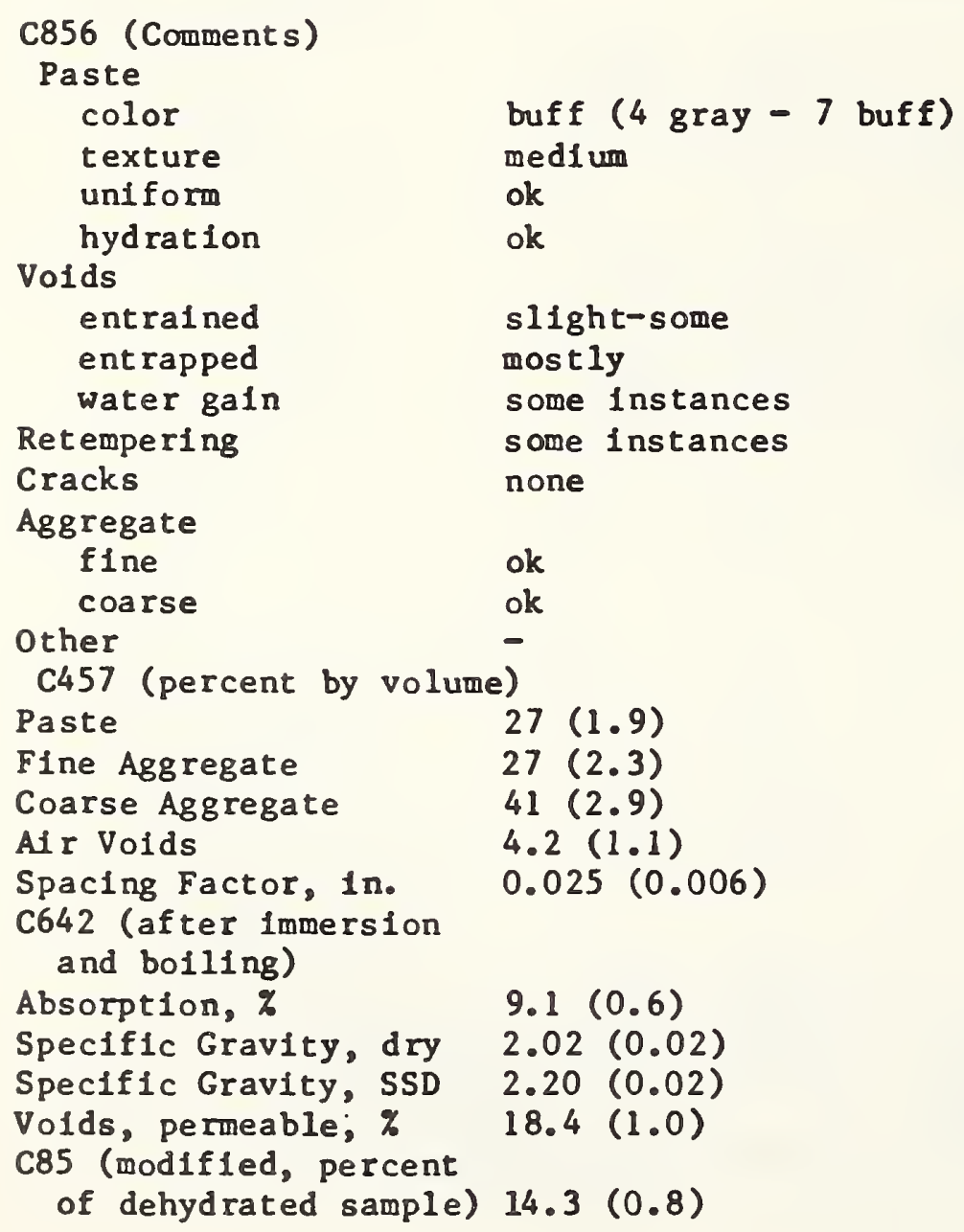

of dehydrated sample) $14.3(0.8)$

$9.1(0.6)$

$2.02(0.02)$

$2.20(0.02)$

$18.4(1.0)$

$8.6(0.7)$

$2.07(0.04)$

$2.25(0.03)$

$17.8(1.2)$

$12.7(1.2)$ 
TABLE A.7

SUMMARY OF CONCRETE TESTS

Concrete 5th Floor, Columns

SAMPLE :

P01

P02

P03

P04

P05

Material Proportions,

approximate, $1 \mathrm{bs} . / \mathrm{yd}^{3}$

\section{Cement* \\ Fine Aggregate \\ Coarse Aggregate \\ Water**}

Admixture, $\% * * *$
WRDA 79
WRDA 19
Type III

Unit Weight, SSD, 1 bs./ft. $3 * t \star \star$

Air Voids, $\%$

Spacing Factor, in.

Absorption, $\%$

Permeable Voids, $\%$

$\begin{array}{llllr}- & - & - & 454 & 451 \\ 1210 & 1299 & 1099 & 1112 & 1353 \\ 1866 & 1874 & 1814 & 1844 & 1582 \\ - & - & - & 327 & 345\end{array}$

$\begin{array}{ccccc}0.02 & 0.01 & 0.02 & 0.01 & 0.06 \\ X & X & X & - & X \\ - & - & - & X & - \\ - & - & - & X & -\end{array}$

$\begin{array}{ccccc}139.2 & 139.2 & 136.7 & 138.5 & 137.9 \\ 2.6 & 2.7 & 3.5 & 3.8 & 3.5 \\ 0.030 & 0.029 & 0.026 & 0.034 & 0.029\end{array}$

$\begin{array}{lllll}8.8 & 9.3 & 9.4 & 9.3 & 9.5\end{array}$

$\begin{array}{lllll}18.0 & 19.0 & 18.8 & 18.9 & 19.1\end{array}$

Notes:

* Cement content determined from C85, Modified C85 and dehydration to allow for calcareous coarse aggregate (1imerock) and calcareous material (shell) present in fine aggregate.

**Water estimate determined by using percentage of paste volume and calculated cement content.

***Admixtures extracted from concrete using carbonate method for sulfonates. (X) indicates presence of admixture.

****Unit weight SSD estimate by using bulk SSD specific gravity (C642) after immersion and boiling. 
TABLE A.7

SUMMARY OF CONCRETE TESTS

Concrete 4th Floor, Columns

SAMPLE:

P06

P07 P08

P09

P10

Material Proportions,

approximate, $1 \mathrm{bs} \cdot / \mathrm{yd}^{3}$

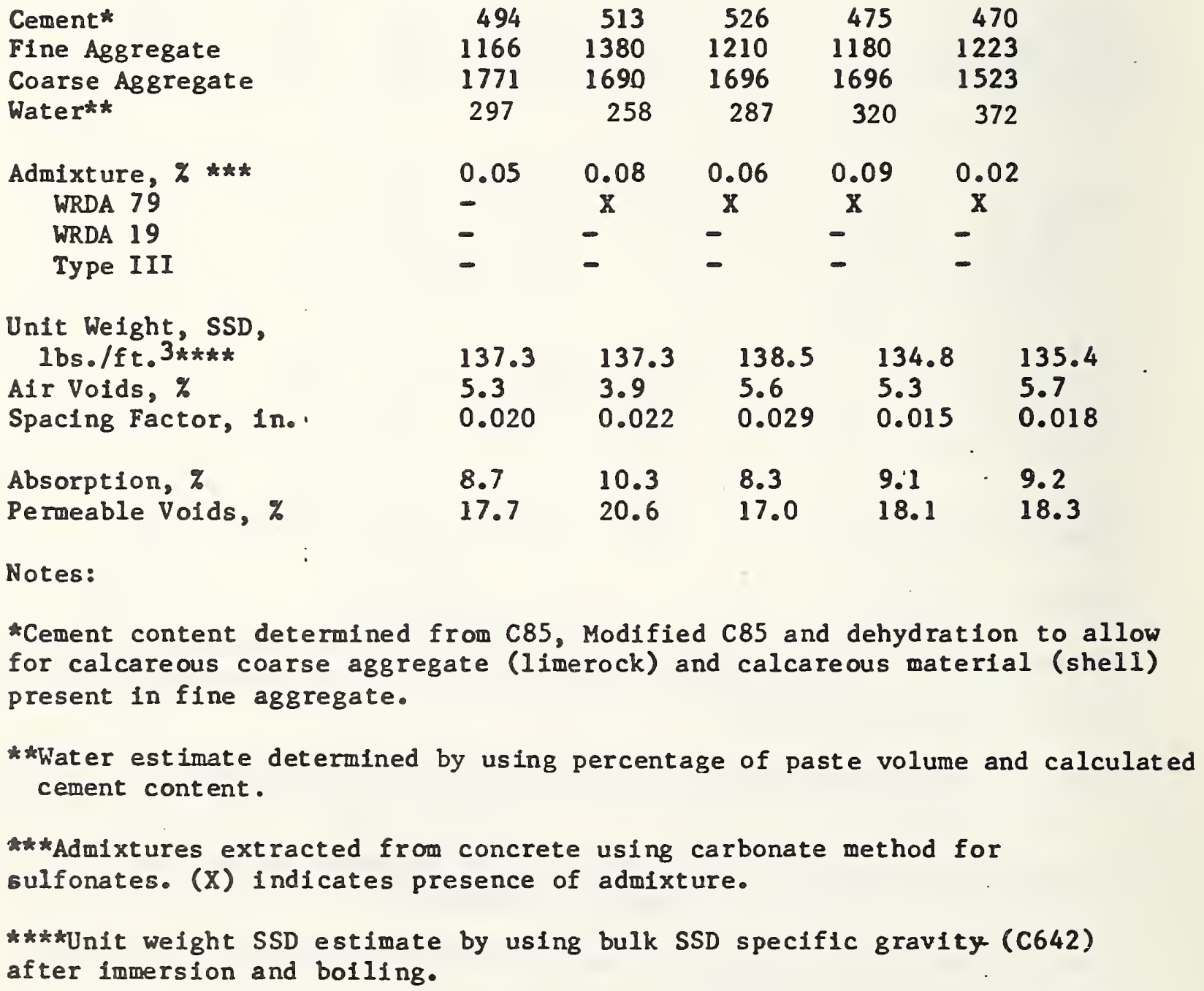


TABLE A.7

SUMMARY OF CONCRETE TESTS

Concrete

3rd floor, Columns

SAMPLE :

P11

Material Proportions, approximate, $1 \mathrm{bs} \cdot / \mathrm{yd}^{3}$

\section{Cement* \\ Fine Aggregate \\ Coarse Aggregate \\ Watert* \\ Admixture, $\% * * *$ \\ WRDA 79 \\ WRDA 19 \\ Type III}

1890

0.02
-
$x$
$x$

Unit Weight, SSD,

$1 \mathrm{bs} . / \mathrm{ft} .3 * t * *$

Alr Volds, $\%$

137.3

Spacing Factor, in..

4.3

0.019

Absorption, ' $\%$

8.5

Permeable Voids, \%

17.2

Notes:

*Cement content determined from C85, Modified C85 and dehydration to allow for calcareous coarse aggregate (11merock) and calcareous material (shell) present in $f$ ine aggregate.

** Water estimate determined by using percentage of paste volume and calculated cement content.

***Admixtures extracted from concrete using carbonate method for sulfonates. (X) Indicates presence of admixture.

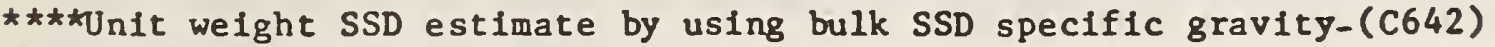
after immersion and boiling. 
TABLE A.7

SUMMARY OF CONCRETE TESTS

Concrete 5th Floor, Slab

SAMPLE :

P12

P13 , P14

Material Proportions, approximate, $1 \mathrm{bs} \cdot / \mathrm{yd}^{3}$

Cement*

Fine Aggregate

Coarse Aggregate

Wate $r^{\star *}$

Admixture, $\% \star \star \star \star$

WRDA 79

WRDA 19

Type III

Unit Weight, SSD, lbs./ft.3****

Air Voids, $z$

Spacing Factor, in.

Absorption, \%

Permeable Voids, $\%$ $\begin{array}{lll}- & 375 & 427\end{array}$

$\begin{array}{lll}1323 & 1326 & 1148\end{array}$

$\begin{array}{lll}1517 & 1660 \quad 1852\end{array}$

- $352 \quad 319$

$\begin{array}{lll}0.02 & 0.10 & 0.08\end{array}$

- $\mathrm{X}$ X

X $\quad-$

$138.5 \quad 139.2 \quad 141.0$

$\begin{array}{lll}4.3 & 2.6 & 3.2\end{array}$

$\begin{array}{lll}0.026 & 0.017 & 0.023\end{array}$

$\begin{array}{lll}9.7 & 9.6 & 8.7\end{array}$

$\begin{array}{lll}19.7 & 19.4 & 18.2\end{array}$

Notes:

* Cement content determined from C85, Modified $\mathrm{C85}$ and dehydration to allow for calcareous coarse aggregate ( 1 lmerock) and calcareous material (shell) present in fine aggregate.

**. Water estimate determined by using percentage of paste volume and calculated cement content.

***Admixtures extracted from concrete using carbonate method for sulfonates. (X) indicates presence of admixture.

****Unit weight SSD estimate by using bulk SSD specific gravity_(C642) after immersion and boiling. 
TABLE A.7

SUMMARY OF CONCRETE TESTS

Concrete 4th Floor, Slab

SAMPLE :

Material Proportions, approximate, $1 \mathrm{bs} . / \mathrm{yd}^{3}$

Cement *

Fine Aggregate

Coarse Aggregate

Water**

Admixture, $\% \star \star * *$

WRDA 79

WRDA 19

Type III

Unit Weight, SSD, lbs./ft. 3 t*t*

Air Voids, $z$

Spacing Factor, $1 \mathrm{n}$.

Absorption, \%

Permeable Voids, $\%$
P15 P16

$494 \quad 443$

$1245 \quad 1139$

$1634 \quad 1984$

$297 \quad 263$

$\begin{array}{cc}0.08 & 0.09 \\ X & - \\ - & X \\ - & X\end{array}$

$137.9 \quad 141.0$

$6.3 \quad 3.3$

$0.012 \quad 0.022$

$8.3 \quad 7.9$

$16.9 \quad 16.5$

Notes:

*Cement content determined from C85, Modified $\mathrm{C85}$ and dehydration to allow for calcareous coarse aggregate ( 1 imerock) and calcareous materlal (shell) present in fine aggregate.

** Water estimate determined by using percentage of paste volume and calculated cement content.

***Admixtures extracted from concrete using carbonate method for sulfonates. (X) Indicates presence of admixture.

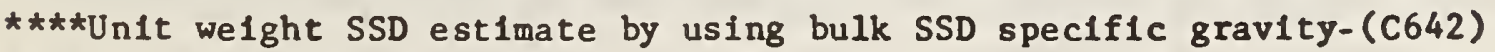
after immersion and bolling. 
TABLE A.7

SUMMARY OF CONCRETE TESTS

Concrete 3rd Floor, Slab

SAMPLE:

Material Proportions, approximate, $1 \mathrm{bs} \cdot / \mathrm{yd}^{3}$

Cement*

Fine Aggregate

Coarse Aggregate

Water**

Admixture, $\% \star \star \star \star$

WRDA 79

WRDA 19

Type III

Unit Welght, SSD,

lbs./ft.3****

Air Volds, $\%$

Spacing Factor, in.

Absorption, $\%$

Permeable Volds, $z$
P17

P1 8

$475 \quad 435$

$1196 \quad 1102$

$1833 \quad 1798$

$303 \quad 383$

$0.01 \quad 0.01$

- $\quad-$

$\mathrm{X} \quad \mathrm{X}$

$\mathrm{X} \quad \mathrm{X}$

$137.9 \quad 141.0$

$2.4 \quad 1.3$

$0.034 \quad 0.027$

$7.9 \quad 8.1$

$16.7 \quad 17.2$

Notes:

* Cement content determined from C85, Modified C85 and dehydration to allow

for calcareous coarse aggregate ( 1 lmerock) and calcareous material (shell)

present in fine aggregate.

** Water estimate determined by using percentage of paste volume and calculated cement content.

***Admixtures extracted from concrete using carbonate method for sulfonates. (X) Indicates presence of admixture.

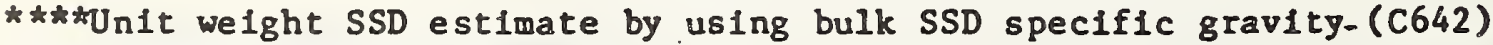
after immersion and bolling. 
TABLE A.7

SUMMARY OF CONCRETE TESTS

Concrete 2nd Floor, Slab

SAMPLE :

P19

Material Proportions, approximate, $1 \mathrm{bs} . / \mathrm{yd}^{3}$

Cement*

Fine Aggregate

Coarse Aggregate

1669

Wate $\mathrm{r}^{\star \star}$

Admixture, $z \star \star \star \star *$

WRDA 79

0.02

WRDA 19

Type III

Unit Weight, SSD,

1 bs./ft. $3 * * t *$

Air Voids, $\%$

140.4

Spacing Factor, in.

1.8

0.030

Absorption, \%

8.7

Permeable Voids, $z$

18.0

Notes:

*Cement content determined from C85, Modified C85 and dehydration to allow for calcareous coarse aggregate ( 1 imerock) and calcareous material (shell) present in fine aggregate.

** Water estimate determined by using percentage of paste volume and calculated cement content.

***Admixtures extracted from concrete using carbonate method for sulfonates. $(X)$ indicates presence of admixture.

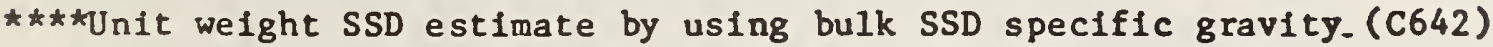

after immersion and bolling. 
NBS-114A (REV. 2-80)

U.S. DEPT. OF COMM.

BIBLIOGRAPHIC DATA

SHEET (See instructions)

1. PUBLICATION OR
REPORT NO.
$81-2374$

4. TITLE AND SUBTITLE

INVESTIGATION OF CONSTRUCTION FAILURE OF HARBOUR CAY CONDOMINIUM IN COCOA BEACH, FLORIDA

\section{5. $\operatorname{AUTHOR}(S)$}

H. S. Lew, N. J. Carino, S. G. Fattal, and M. E. Batts

6. PERFORMING ORGANIZATION (If joint or other than NBS, see instructions)

NATIONAL BUREAU OF STANDARDS

DEPARTMENT OF COMMERCE

WASHINGTON, D.C. 20234

9. SPONSORING ORGANIZATION NAME AND COMPLETE ADDRESS (Street, Chy, StOte, ZIP)

7. Contract/Grant No.

8. Type of Report \& Period Covered

Occupational Safety and Health Administration

U. S. Department of Labor

Washington, D.C. 20001

10. SUPPLEMENTARY NOTES

Document describes a computer program; SF-185, FIPS Software Summary, is attached.

11. ABSTRACT (A 200-word or less factual summary of most significant information. If document includes a significant bibliography or literature survey. mention it here)

The investigation of the collapse of a five-story reinforced concrete flat-plate structure under construction at Cocoa Beach, Florida is presented in this report. The investigation included onsite inspection, laboratory tests and analytical studies.

Based on the results of this investigation, it is concluded that the most probable cause of the failure was insufficient punching shear capacity in the fifth-floor slab to resist the applied construction loads.

Two factors contributed to the low punching shear capacity: one in the design and the other in the construction of the building. In the design, the omission of a check for punching shear resulted in a smaller slab thickness than needed to satisfy the code requirements. In construction, the use of specified chairs having insufficient height to support the top reinforcing steel resulted in more than the cover specified in the structural drawings. Both factors contributed to reducing the effective depth of the slab such that it had insufficient strength to resist the construction loads.

The analysis showed that shear stresses in the slab at many column locations on the fifth floor exceeded the nominal shear strength. Thus, punching shear failure at one of the columns precipitated a progressive failure of the slab throughout the entire fifth floor. Collapse of the fifth floor, in turn, caused the successive collapse of the lower floor slabs. The failure of the fifth floor slab most likely initiated at column G-2, an interior column which supported the last bay of freshly placed roof concrete prior to the collapse.

12. KEY WORDS (Six to twelve entries; alphabetical order; capitalize only proper names; and separate key words by semicolons) Building; collapse; concrete; concrete strength; construction; failure; flat plate; shear; strength

14. NO. OF PRINTED PAGES

15. Price 

